Portland State University

PDXScholar

$1-1-1986$

\title{
Technology impact assessment: the effectiveness of advanced instructional technology in remedying learning difficulties of disadvantaged youngsters in an urban setting
}

Wossen Encubahre

Portland State University

Follow this and additional works at: https://pdxscholar.library.pdx.edu/open_access_etds Let us know how access to this document benefits you.

\section{Recommended Citation}

Encubahre, Wossen, "Technology impact assessment: the effectiveness of advanced instructional technology in remedying learning difficulties of disadvantaged youngsters in an urban setting" (1986). Dissertations and Theses. Paper 541.

https://doi.org/10.15760/etd.541

This Dissertation is brought to you for free and open access. It has been accepted for inclusion in Dissertations and Theses by an authorized administrator of PDXScholar. Please contact us if we can make this document more accessible: pdxscholar@pdx.edu. 
TECHNCICGY IMPACT ASSESSMENT:

THE EFFECTIVENESS OF ADVANCED INSTRUCTIONAL TECHNOLOGY

IN REMEDYING LEARNING DIFFICULTIES OF

DISADVANTAGED YOUNGSTERS IN

AN URBAN SETTING

by

WOSSEN ENCUBAHRE

A dissertation submitted in partial fulfillment of requirements for the degree of

\author{
DOCTOR OF PHILOSOPHY \\ in \\ URBAN STUDIES
}

\author{
Portland State University \\ 1986
}


TO THE OFFICE OF GRADUATE STUDIES AND RESEARCH:

The members of the Committee approve the dissertation of Wossen Encubahre presented October 27, 1986
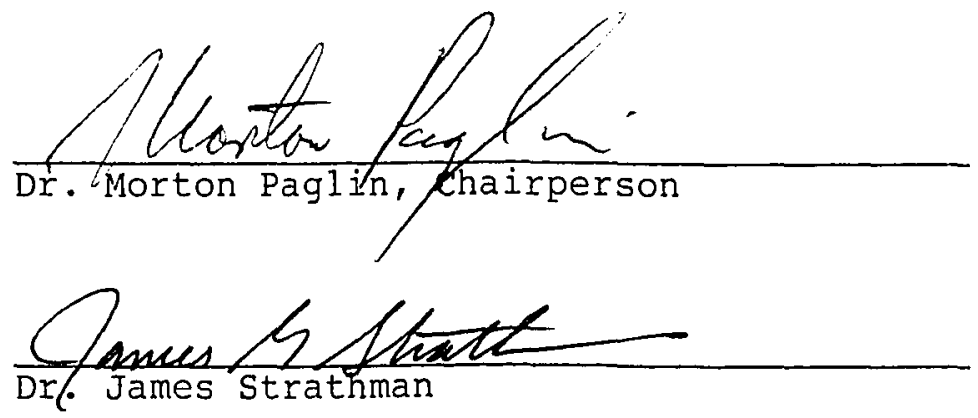

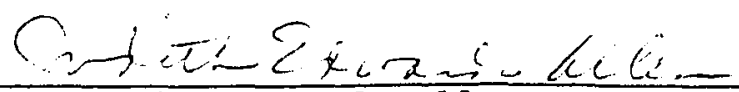

Dr. Judith Edwards-Allen
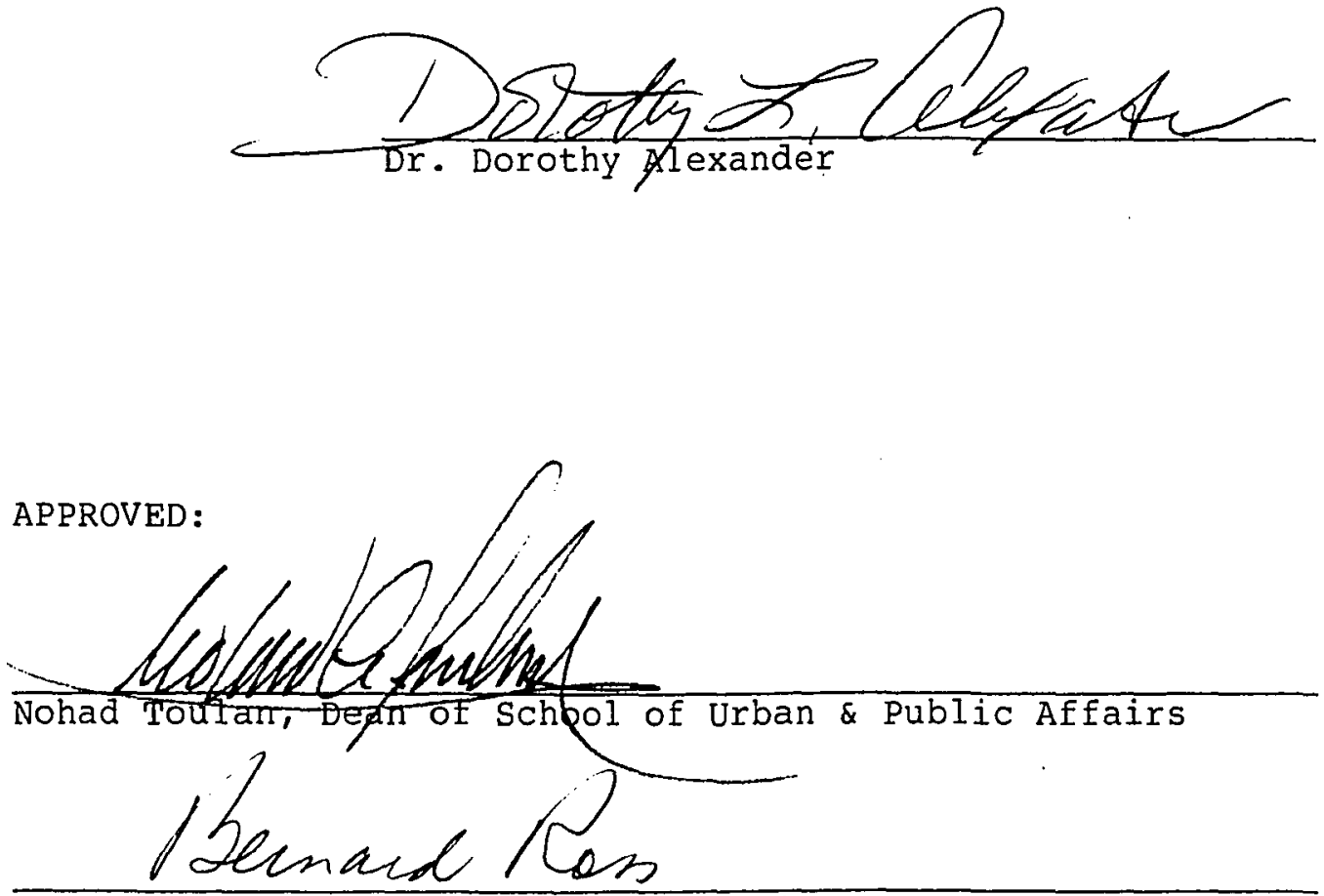

Bernard Ross, Dean of Graduate Studies and Research 
AN ABSTRACT OF THE DISSERTATION OF WOssen Encubahre for the Doctor of Philosophy in Urban Studies presented october 27 , 1986.

Title: Technology Impact Assessment: The Effectiveness of Advanced Instructional Technology in Remedying Learning Difficulties of Disadvantaged Youngsters in an Urban Setting

APPROVED BY MEMBERS OF THE DISSERTATION COMMITTEE:
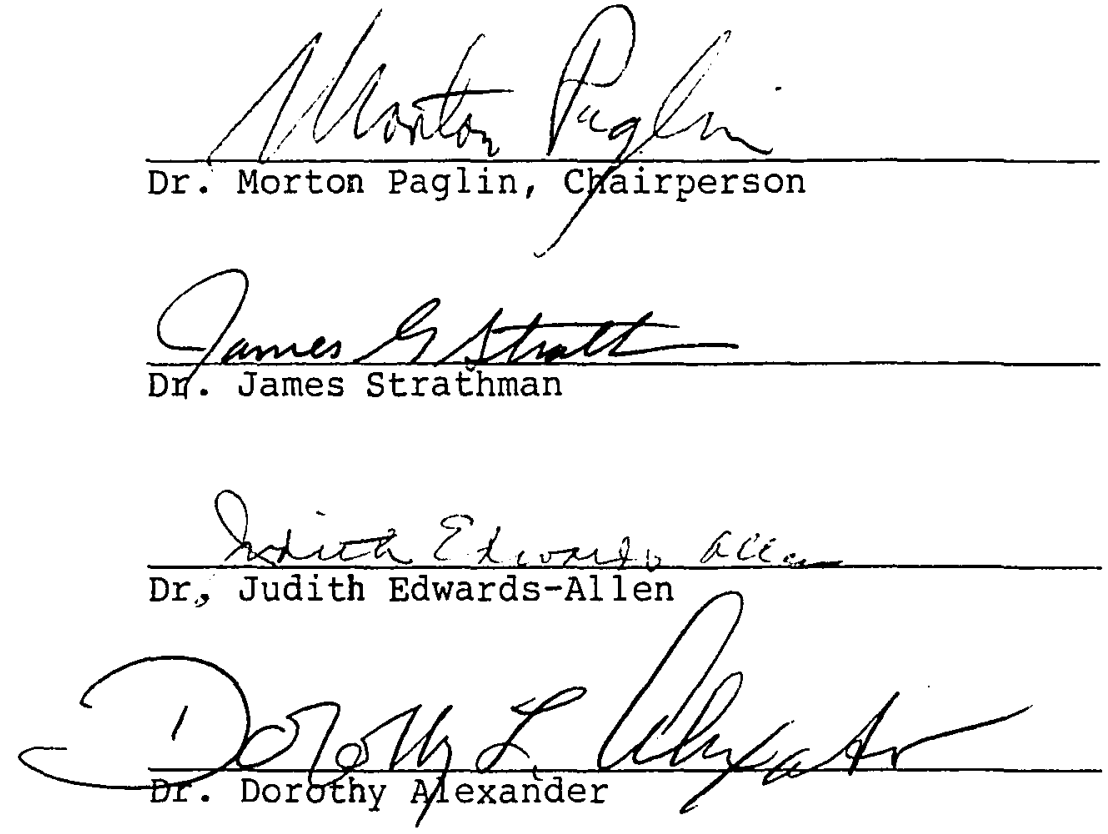

Technological advancement has allowed widespread use of computers in virtually every area of society and recently into classrooms of elementary and secondary education. 
Computer based instruction (CBI) now assists teachers in educating talented, disabled, disadvantaged and average youngsters.

Introduction of computers into primary and secondary education has been prompted by several factors: declining enrollment, which reduces school revenues and the ability to hire teachers; pressure to improve student achievement; and, in the face of increasing public rejection of operating levies, to cut costs. Claims made for and against computers on educational, economic, and political grounds have raised several important issues. Some advocate CBI enthusiastically, saying computers inprove academic achievement and cost effectiveness. Others discourage the use of CBI, fearing displacement of teachers by computers and dehuinanized education. A third group argues that computers may create a class of technologically disadvantaged students as a result of a growing gap in access to computers between rich and poor schools in terms of availability at home. Therefore, they are questioning the wisdom of its application. Since disadvantaged students tend to be deficient in basic skills, there is a tendency to confine the use of computers to improving those skills. In nondisadvantagea schools computers have a wider application, such as drill and practice, simulation, dialogue, computer science and computer programing. The objective of this research is threefola: to 
examine issues surrounding the instructional application of computers; to review relevant literature to assess the academic and economic rationales for their use in educational instruction; and, finally, to make appraisals of CBI for instructional and resource effectiveness.

Quasi-experimental research was carried out by conducting a comparative summative evaluation les post facto) between two "experimental" CBI groups and a control group of Title I (now Chapter I) schools in the Portland Public School District. The experimental groups were users of Computer Assisted Instruction (CAI) and Prescriptive Learning Lab (PLL). The control group involved recipients of "traditional" Title I instruction (TMI). A sample of 1,336 participants was selected, and multiple criteria of effectiveness with a casual-comparative approach were used.

Primary data on pre- and post-test scores and computer instructional time were collected from the school district master file. Cost figures were collected from various departments of the district and from the contracting corporations. Census data were obtained from the Population Studies Center at Portland State University, while crime figures came from the Bureau of Police, City of Portland.

The data were analyzed using two new approaches: Comparative economic analysis and "product refinement" analysis--a method of instructional and noninstructional variable impact assessment. Multiple-regression and 
regression-based covariance analysis of treatment effectiveness were also applied. Finally, a survey of instructional personnel was conducted to evaluate courseware quality.

Findings of this research highlight the following points: Title I students initial or final achievement is not homogeneous; computer based instruction fosters effective compensatory education in basic skills. CAI resulted in superior instructional achievement and cost-effectiveness. Resource variables and neighborhood factors are responsible for a significant portion of achievement variation. While instructional (computer) time is related to achievement, the impact of time is not always positive and not a linear predictor of achievement, especially in CAI. A survey of instructional personnel confirmed most of the above findings, as well as the superiority of CAI courseware quality over that of PLL.

The expansion of instructional computer use is encouraged, together with recommendations for caution in the selection of hardware and for careful examination of courseware/curriculum compatability. It is also strongly recommended that future investment in advanced technology involve teachers in the process of selection and implementation to assure that future technological expansion should provide optimal compatibility of teachers and computers. 
When Ethiopia

Stretches Her Hands Unto

Her Brave Sons and Daughters,

A Great Many Selfless

Heroes and Heroines March.

A Salute To:

Aba Tatek Kassa,

Alula Aba Nega, Belay Zeleke, Abdissa Aga, Zeri Deres,

Taranta Babu, Abakenter Shiffe, Aba Nebso Balcha.

And To:

Yelew Ayeker Encubahry, and

His Fallen Compatriots. 


\section{ACKNOWLEDGEMENTS}

This dissertation would not have been possible without the assistance, support, and encouragement of several individuals and organizations. Dr. Morton Paglin, who supervised the work, provided support, unflagging assistance and guidance. Dr. James Strathman and Dr. Abdul Qayum made valuable suggestions and offered constructive methodological criticisms. Dr. Judith Edwards-Allen gave encouragement, valuable comments and suggestions. Dr. Dorothy Alexander reviewed the evaluation methods.

Appreciation also goes to Dr. Nohad Toulan, Dr. B. J. Williams, and Drs. Matthew Prophet, Walter Hathaway, George Ingebo and Kan Yagi of the Portland Public Schools; the Multnomah County Fellowship Foundation; and Portland State University. Special appreciation also goes to Mr. Ayalew Adamu and Mr. Ibrahim A. Karim for their encouragement and comments; and to Mr. Tsegaye Asfaw, Ms. Bisrat Afework, and Mr. Richard Thombs for their clerical assistance.

I wish also to acknowledge and extend my thanks to Mr. and Mrs. Frederick I. Thombs for their professional editing and typing assistance. Their comments and encouragement were very helpful in the writing and printing process.

Finally and most importantly, my wife Laura J. Encubahre deserves special appreciation and thanks. Her 
tolerance, encouragement, support and word processing skill was a major factor in the completion of this project. Appreciation is also due to my daughters Andrea Meléta and Galila Kulentie who have helped with their patience and understanding. 
TABLE OF CONTENTS

PAGE

ACKNOWLEDGEMENTS . . . . . . . . . . . . . . . iv

IIST OF TABLES . . . . . . . . . . . . . . . . . . ix

LIST OF FIGURES • • • • • . • • • • • • • • • • • • • • xi CHAPTER

\footnotetext{
I INTRODUCTION . . . . . . . . . . . . 1

II PROBLEM APPRAISAL . . . . . . . . . . 22

Educational Services to the Needy . . . 27

Service Targeting

Family Background Problems

School Related Problems

Diagnostic and Performance Problems

Advanced Technology in Education . . . 77

III THE THEORETICAL AND EMPIRICAL BACKGROUND . . 91

Theory of Learning . . . . . . . . 91

Theory of Instructional Technology . . . 95

Empirical Background . . . . . . . 102

Relevant Issues

The State of the Art of Technology

Literature of Impact Studies . . . . . 111

Implications of the Proposed

Technology Act

Cost Impact

Attitude and Motivation

Achievement Impact Review

Time Impact

The Impact of Other Factors
} 


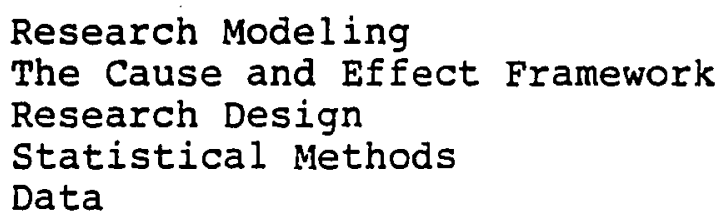

Research Question and Hypotheses . . . 151

Treatment Outcome Assessment

Outcome Refinement Methods

Descriptive Analysis . . . . . . 163

Instructional Setting

Correlational Analysis

Pre-Test Analysis

Treatment Outcome Assessment . . . . 170

Post-Test Analysis

Adjusted Post-Test

Treatment Impact Analysis

Model

Input-Output

Performance Rank Assessment

Relative Growth Assessment

VI ANALYSIS II . . . . . . . . . . 205

Outcome Refinement ......... 205

Regression Analysis

Instructional Time

Resource Effectiveness . . . . . . 222 


\section{LIST OF TABLES}

TABLE

PAGE

I Percentage of Service Distribution . . . . . 34

II Percentage of the Needy by Percentiles... . 35

II Percentage Differences of Scores between the

National Mean and Ethnic Groups by

Age and Subjects . . . . . . . . . . 49

IV Value of Computers Sold . . . . . . . . . 85

$\mathrm{V}$ Percentage Increase of Schools Using Micro-

computers by Enrollment Size and Level

1981-82 ............... 86

VI Distribution of Microcomputers in Low Income

Schools ................ . 87

VII Treatment Effect Design . . . . . . . . 141

VIII Pre-test Group Mean Differential . . . . . 169

IX Post Test Group Mean Differential . . . . . 173

X Polynominal Multiple Regression . . . . . . 182

$X I$ Instructional Input-output in Grade

Equivalents............. . 193

XII Gains in $\mathrm{NCE}$. . . . . . . . . . . 201

XIII Multiple Linear Regression of Home Background

Variables . . . . . . . . . . 214

XIV Instructional Resource Distribution Model • . 225

XV Comparative Unit Cost Analysis . . . . . . 229 
$\begin{array}{ll}\text { TABLE PAGE } & \text { PAT }\end{array}$

XVI Comparative B/C Analysis . . . . . . . . 238

XVII Instructional Personnel Ratings of CBI . . . 240 
LIST OF FIGURES

FIGURE

PAGE

1. Life Cycle of the Disadvantaged . . . . . .

2. Resource Allocation and Technology Productivity . . . . . . . . . . .

3. Conceptual Relationships of Cause and Effect . . . . . . . . . . . . 137

4. Title I Instructional Services . . . . . . 138

5. Factors of a Learner's Microcosm . . . . . . 139

6. Probability Distribution of Standardized Residuals . . . . . . . . . . 164

7. Regression of Post-test on Pre-test. . . . . 184

8. Predicted Gain Scores by Method of Instruction . . . . . . . . . . 187

9. Treatment and No-treatment Expectation Achievement Score.......... 200

10. Hypothetical Relationships of Cost to Grade Placement Scores $(q)$. . . . . . . . 234

11. Survey Comparison: CAI vs PLL

Courseware . . . . . . . . . . 241 


\section{CHAPTER I}

\section{INTRODUCTION}

It has been over a century since the predecessor of the modern compliter was introduced, and almost half a century since the earliest computers were introduced into higher education, business corporations, and the military. In the last fifteen years a technological revolution has enabled computers to touch almost every aspect of life.

The application of computers as an advanced instructional technology was achieved through the joint efforts of educators, administrators, and curriculum and computer experts. This effort has been facilitated by continuous innovations in hardware and software, as evidenced by the availability of computer based instruction for almost all academic subjects at almost every level of education. It has become common in some schools to use such instruction to satisfy the needs of regular and special educational groups at the elementary and secondary level. Using computers to assist low-ächieving students to learn the basic skills of math and reading is the main interest of this research. However, we should first examine the conditions that brought about the introduction and lises of computers in the schools.

First of all, computers as instructional tools for 
elementary and secondary education have appeared at a time when the public schools are facing criticisms regarding their mission and their performance. Elementary schools are experiencing a declining enrcllment, mainly due to a reduced school-age population. This trend, along with constraining economic conditions, has brought about difficulties in passing school levies. In some cases schools have been closed down.

Because of limited funds public schools are losing competent teachers, students from middle class families, and bright students to private schools. There is also a growing lobby that is pushing for a voucher system, and for education tax-credit legislation that may enable more families to send their children to private schools. The public is also raising issues regarding student achievement, discipline, and teachers' competence in public schools (Coleman et al., 1982). These problems have created questions about public school effectiveness.

Despite the fact that studies on achievement and resource effectiveness of computers in education are not conclusive, increasing numbers of public school administrators and educators introduce computers into their schools for instructional and management purposes, (Market Data Retrieval, 1982). Several experiments that involve computers, and various instructional arrangements and alternatives are being carried out. A case in point is in 
the Portland Public Schools, which, like many cther schools around the country, have introduced two types of computer based instruction for low-achieving disadvantaged youngsters in the Title. I (now Chapter J.) program. These two instruction programs are Computer Assisted Instruction (CAI), and Prescriptive Learning Laboratory (PLL). The former involves a micro computer used with teachers and aides, whereas PLI is a mini computer system using teachers and aides, augmented by an audio-video multi media learning laboratory.

The intrcauction of computers is motivated by various rationales, including the desire to modernize education and improve the quality of instruction. Additionally, some educators claim that they want to introduce teachers and students to advanced instructional technology. However, the underlying reason for the introduction of computer based technology originates in public pressure to increase student achievement and also cut costs. These points are, in fact, the major advantages claimed for computers by their advocates and vendors.

The application of computers in instructional service delivery is taken fnr granted by some, yet a desire to know if it is as effective as traditional methods of instruction is an important concern for many educators. Computer application to basic skill instruction for low achievers has become interesting to educators who wish to know if it works 
at all. There are reasons for skepticism. Low-achieving youngsters with learning difficulties may have trouble just learning to use computers. Any problem in the effort of learning how to use computers can frustrate understanding in the basic skills. Also, claims laid down by computer companies, such as Computer Curriculum Corporation, make computers appear attractive, ideai instructional alternatives--devices which can do away with many of the problems faced by educators and administrators--even though actual findings are still mixed (Edwards, 1975). This perceived attractiveness of computers is reinforced by some educators in general, and in Portland in particular, who are convinced that the courseware is compatable with curriculum objectives. claims regarding computer capability were reviewed, and relevant issues of cost and achievement identified. Accordingly, this research uses these selected claims as tools of inquiry to evaluate the effectiveness of computer based instruction.

The claims that are most attractive to educators--and are also most relevant to this study--are those which assert that computers can:

1. increase student learning achievement;

2. help to use learning time effectively;

3. provide individualized instruction;

4. increase cost-effectiveness. 
These claims amount to a declaration that teachers and aides, using computers, can render more effective instructional services than their counterparts in the traditional method of instruction (TMI). This implies that when TMI is supplemented by computers, students can increase their learning achievement. These attractive claims prompted a widespread introduction of computers. The other reasons are the growing pressure educators feel to improve student performance, the weakening of teachers' competence, and increasing costs in the face of changing situations. The passage of tax levies to finance school operations has become increasingly difficult. Public schools with limited funds and a negative image are losing competent teachers and students to private schools. Declining student achievement, as measured by very limited increases in test scores lexcept SAT test scores, which seem to be rising now), along with other issues, has become a serious concern to public school officials. On the other hand, both public and private schools are also facing a shortage in the supply of qualified teachers. Educators and school administrators, in a desperate search for ways to deal with problems such as funding, teacher shortage, public image, and low acnievement scores, have embarked on "experiments" with advanced instructional technology. As a result, both public and private schools are currently experiencing an invasion of the latest instructional technology, specifically computers. 
The application of computers as tools of instruction and of management is a growing national phenomenon. The debate as to the usefulness of the new technology as a tool of instruction is very lively and increasingly important, for reasons such as:

1. the availability of hardware and software alternatives, and their growing penetration in schools;

2. the desire to modernize instruction by integrating $\mathrm{CBI}$ in the curricula;

3. impressive claims made for the compatability of the needs of various groups of learners and the new technology;

4. claims made for its cost effectiveness;

5. claims made for the computer's ability to raise the achievement scores of disadvantaged youngsters;

6. claims made regarding computer based instruction's ability in facilitating learning opportunity, as well as accelerating learning by motivating students and exciting teachers.

Several schools and school districts have opened their doors to this new instructional technology. The Portland Public School District is one of thousands in the nation to join the "computer club". Since 1980 the Portland Public Schools have employed two computer based instruction programs in some elementary and middle schools under the Title I Act. Both Computer Assisted Instruction (CAI) and Prescriptive Learning Lab (PLL) use computers. The former uses a time-sharing system of micro computers, and the latter uses mini computers augmented by multi media. Both 
are advanced technological instruction methods compatible with the curriculum, and both are applied in a drill and practice mode.

This introduction of technological instruction is facilitated by hardware and software innovations. The claims and promises set forth by some educators and technologists have enhanced its attractiveness to schools across the country. Some school administrators think that reduction in teaching personnel is imminent and that technology will become even more important in the future. They feel that youngsters should learn to use advanced technology as early as possible. Others feel that the technological methods embodied in computers are ideal for drilling low achievers.

The introduction of computer based instruction is advocated for its effectiveness and is emphatically endorsed by those who believe it to be appropriate for basic skill instruction (reading, math and language arts) for disadvantaged youngsters. Hence, the need to assess the viability of computers as tools of instruction has become increasingly important.

Several factors have contributed to an interest in close scrutiny and systematic study of the claims for computer based instruction. Some studies have obtained mixed results, and those findings will be discussed in the review of the literature. Studies which reported positive 
findings show differences among curricula (software), types of test employed, testing time and conditions, as well as for non technological support inputs that were not controlled. Such differences affect the relevance and the validity of generalizations from the findings. The national and local controversy over the need for, and the effectiveness of, advanced technology in instruction is still strong among educators. Issues of accountability for public expenditure on experimental projects have come to the attention of taxpayers. Parents who closely monitor their children's education are taking part in the debate over computer based instruction. Therefore, evaluative research like this study is essential in order to shed some light on the issues.

The identification of cost-effectiveness will be of great value to decision makers in resource allocation. In other words, studies such as this one will provide information that can help to identify "experimental" programs that should be sustained or expanded on the basis of demonstrated remedial effectiveness. Therefore, the assessment of the impact of advanced instructional technology in remedial intervention is very much of local and national interest. Thus, the assessment of the two methods of technological intervention, CAI and PLL, in the Portland Public Schools is relevant with the interests of educators and decision makers at large. 
Those n.t:c are either unsure of the usefulness of the computer, or who are opponents of the instructional use of computers, call for caution. They argue that using computers causes students to feel alienated and they warn that educators may come to rely excessively on the computer. Moreover, there is concern that computers may perpetuate a trend towards displacement of traditional teacher-oriented methods. Another issue of concern is the burden of "learning to learn" to use computers, compounding the problem of the learner by generating fear, e.g., "mathphobia" and "computerphobia," which may frustrate some learners. These issues are becoming important to educators and administrators at large, as well as here in the portland Public School District.

The fundamental intent of this research, then, is to assess the comparative impact of both technological and "experimental" methods of instruction from resource and output points of view. A comparison of the remedial impact is based on a quasi-experimental design. Summative evaluation research is considered appropriate and is applied in this study. The issues mentioned above are addressed in the review of literature by examining the impact of using mini computers and micro computers, both alone and in combination with other media, as tools of instruction at elementary and middle school levels within the Title I program. This federally funded compensatory program serves 
youngsters who are identified as having learning disadvantages (disabilities) in the basic skills of reading, language arts and mathematics.

This study compares the two "experimental" methods of computer based instruction (CBI), namely CAI and PLI, both of which are currently in operation in the Portland Public School District. This study examines the effects of these two new modes of instruction in the basic skills of reading and mathematics on the achievement of disadvantaged youngsters in grades five through eight.

The first step of this study focuses on the major advantages of computer based learning as advocated by its proponents. The second step raises questions and states hypotheses as to the credibility or validity of some of these claims. The third step addresses the statistical methods and techniques to be used in testing the hypotheses. The major benefits claimed by advocates using micro computers as tools of instruction in the drill and practice mode can be divided into four areas:

1. Cognitive and affective. One of the common claims made for the computer focuses on the excitement and motivation of teachers and students. Computers are associated with diagnosis, feedback and pacing flexibility, which accomodate learning rate differences of various groups. 
2. Time on task. It is claimed that the computer can increase either the amount of learning for a given time, or reduce the amount of time needed for a given learning task. This claim is made relevant to the traditional method of instruction (TMI).

3. Opportunity of instruction or instructional resource distribution. The opportunity is measured by increased student-instructor interaction, which is one of the claims made by CBI proponents. A one-to-one studentteacher instructional setting is considered as one of the most important advantages of CBI over TMI.

4. Resource effectiveness. The cost of computers, especially for hardware, has reduced greatly compared to five or ten years ago. However, software costs are still rising. Nonetheless, advocates of CBI claim that computers are very inexpensive and more cost-effective than TMI. This claim is based on the fact that the advancement in technology is changing the size, capability, quality and price of computers; however, the question of whether CBI is more cost-effective than TMI remains an important issue, despite the fact some researchers have dealt with it.

These major claims establish the grounds on which to raise several important questions. Many of the more important ores are addressed in this study. To assess claims made about the cognitive and affective impact of CBI, methods have been devised to compare CBI with traditional methods, with the TMI recipients used as a comparison group. The findings are compared with the results of a survey of teachers and aides using a software evaluation form that measured the level of satisfaction with the educational function of CAI and PLI.

The following is a description of four major 
objectives of this research. The first is a comparative analysis of conditions and circumstances in which programs were implemented and operated. This includes the demographic characteristics of the students and a distinction between hardware and courseware of the two computer based programs. The first question is, did the three groups start with equal learning abilities; did they have equal pre-test scores? Although identified as low achievers, there could have been ability differences among them. It was postulated that these differences would be insignificant.

The second objective is to assess the treatment effect, i.e., learning achievement differences. Are the three groups different in treatment outcome? The question is whether there is any difference in the post-test achievement of the three groups. The research examines treatment effects by analyzing the impact of group membership and learning growth rates, the major hypothesis being that there would be a significant difference between the post-test achievement of the three groups.

The third objective of tinis research is a comparative economic analysis of the experimental and control treatments. As stated earlier, one of the claims made for the computer is its low cost. The criteria of comparison are (a) product assessment (input output), (b) cost analysis (unit-cost), (c) resources distribution analysis 
(student-instructional resource ratio), and (d) cost-saving assessment (cost-benefit). Questions are raised to examine whether the three groups differ on these criteria. This is discussed in detail later; however, this research postulated that the three groups would differ on the four criteria, and that these differences would favor CAI. It was also anticipated that PLL and TMI would be roughly equal to one another on these criteria.

The final objective focuses on comparison of the two experimental CBI programs. There are two parts to this objective: examination of home background variables and instructional time. The first is framed to address the impact of nontreatment variables. Instructional experiments, like any other social program experiments, are not free of interference from nontreatment factors. Accordingly, the question to be examined is whether student characteristic and home background variables can explain achievement differences, if any, when the two computer based instruction programs are compared. It was hypothesized these variables would be correlated with achievement and provide significant contributions in explaining achievement differences. It was also postulated that CAI and PLL would differ significantly on home background variables.

The second part of the final objective focuses on the effect of instructional time. After assessing whether there is any relationship between achievement and time spent on 
computers, an examination of the relationship is pursued. The question to be addressed was whether the relationship is linear or nonlinear. Based on the review of the literature, this research postulated that the relationship would be nonlinear.

The methodological approach that corresponds to each objective discussed above is given in sections below.

The first compares the three methods descriptively, in terms of their objectives, inputs, and operational processes. The basic model of evaluation followed in this study is that of Stufflebeam's CIPP model, CIPP is an acronym for context (C), input (I), process (P), and product (P) (Bloom, 1971). The model is flexible, being applied fully or partially. Thus, context, input, and process are addressed together in this section, followed by a significance test of differences in the pre-test means.

The second section of the research methods deals with assessment of outcomes, using growth models to examine achievement relative to learning potential. A covariance based multiple regression analysis is applied on the post-test to examine treatment membership effects.

The third section of the research approach assesses the resource impact for each method. Cost-effectiveness of the three methods is compared using cost-per-student-hour. The cost-saving effect is estimated using a shadow price with which to calculate outcome values in a cost-benefit 
analysis. This section also analyzes the impact of resource distribution using a measurement similar to student-instructor ratio.

The fourth section of the research approach examines the influence of instructional and noninstructional variables, such as student characteristics, home background, school resources, and instructional time in a multiple regression analysis. This is an attempt to learn whether or not these variables make significant contributions in explaining variation in post-test achievement. As stated in the second part of the fourth objective, instructional time is further examined to describe whether achievement is a linear or nonlinear function of time.

The above research objectives and methods are designed in light of an extensive review of other research and studies. Literature deemed relevant to basic skill instruction of disadvantaged urban youngsters was reviewed. Special attention was given to literature pertaining to instructional technology and its application in basic skill training. The theory of learning was also reviewed to examine the theoretical foundation of computer application in special education. Empirical studies related to this issue were carefully examined.

This study was conducted along traditional lines of research on instructional effectiveness and student achievement. It is summative evaluation (ex-post facto) 
research. The impact of instructional time (time-on-task) on achievement is also examined, as it has been by others (Gagne, 1967; Suppes, 1976). The cost-effectiveness method is also similar to other research in its cost per capita approach (Wells, 1974; Abt, 1967; Oosternoff, 1979). However, this research takes a new direction in its comparison of the resource distribution (student-instructor) ratio between CBI and traditional methods of instruction. This approach is taken to examine relative individualization of instruction. Another new step introduced in the resource-effectiveness assessment is the benefit-cost analysis.

As background information, particular attention was devoted to needs assessment of disadvantaged youth and the extent of deprivation. In addition to economic and educational disadvantage, some causes and related conditions of deprivation are examined. In light of previous research, this study has examined the influence of neighborhood variables on learning achievement (Auerch and Keisling, 1970; Eisman, et al., 1976; Jencks, 1972). Most of all, this research has augmented its principle of multiple criteria of assessment by conducting a software evaluation survey of teachers and aides directly involved in the operation of the CBI program.

The subjects considered in this study are all elementary and middle school students in the Portland Public 
School District served by Title I programs for disadvantaged youngsters. Schools having either Computer Assisted Instruction (CAI), or Prescriptive Learning Lab (PLI), were considered as treatment schools.

Three conditions were set for a school to be selected:

1. The school must have one of the two treatment programs in operation.

2. The school must have had the treatment program in full operation for at least one year. The students must have available pretest (fall) and post-test (spring) scores for the school year $1981 \cdots 82$.

3. These schools must have one of these treatment programs operating in grades five through eight.

The three groups of schools should not be "contaminated" by treatment programs other than regular Title I instruction.

The design of this study differs from other technology impact research. Other studies have used a control group of students that are non-Title $I$. This study takes this effort one step further. First, this research compares two "experimental" treatment programs using two different sets of hardware and software to another group using regular Title I instructional methods. Second, control groups and "experimental" groups are matched with regard to curriculum, neighborhood location and school size, based on relative enrollment. The three groups are also matched regarding the proportion of students that come from low-income families 
(Table XXVI-XXIX). Third, data on family and neighborhood variables is collected and applied in a casual-comparative fashion to capture the net treatment impact.

One of the contributions of this study is construction of a benefit-cost approach by linking time and cost. Both instructional input (time) and output (gains) are equated with program cost. This study provides information that contributes to methodological discipline. The findings can be expected to be helpful to decision makers, administrators, educators, researchers and taxpayers regarding CBI. The study also adds to a body of research and knowledge regarding technological remedial intervention and its impact on the instruction of disadvantaged youngsters. The research demonstrates whether the portland Public School District has had a positive experience with one or both of the methods of advanced instructional technology.

Two steps attempt to deal with resource issues. First, resource effectiveness of computer based instructional programs has not been adequately assessed in the past, despite the fact that similar programs are expanding every year in number, level, and type of applications. Second, learning outcomes for disadvantaged youngsters using computers in a drill and practice mode have not previously been defined in terms of nontreatment factors. It is hoped that findings on these two major 
points will be useful to the district and other, similar schools in making future decisions about CBI.

This research also represents an effort to contribute to advances in educational research methodology in areas of instructional distribution by developing a method of "total instructional resource unit" (TRU), which is a resource based measurement in a comparative evaluation of instructional delivery. In the area of economic analysis this research has explored the use of benefit-cost analysis by employing the shadow prices of learning outcome. This study has also built a data base of achievement scores and home environment factors for the subjects of this research.

In addition, this study focuses on comparing the achievement of disadvantaged youngsters in both experimental and nonexperimental groups. Hence, it is of significance that the control groups and experimental groups are matched in curriculum, neighborhood location and school size. The two groups are also matched in the proportion of students from low-income families. Application of multiple assessment criteria, especially the cost-effectiveness measurement, in the comparison of experimental and control groups adds to the value of the study.

This research is divided into six chapters. The first is the introduction. The second chapter addresses briefly the historical background of the Title I program. It discusses how participants are selected and how 
disadvantaged youngsters are identified. The second main point of this chapter is that it addresses the theory of deprivation by examining some circumstantial problems that contribute to a youngster's low achievement, and also points out problems and issues in the instructional service delivery.

The third chapter is an extensive discussion of the literature, and consists of two parts, theoretical and empirical. The theoretical part reviews the theory of instruction and theory of learning. The empirical part first briefly reviews computer applications in education, then presents research on the impact of computers on learning in various academic subjects.

The fourth chapter presents in detail the research questions and hypotheses, as well as research methods (i.e., models, statistical designs, and test), dependent and independent variables, and data sources.

Chapter five tests the hypotheses, anaiyzes the data, and discusses the implications of the findings.

Finally, chapter six consists of a summary of the findings, a conclusion, recommendations, and a discussion of areas for future research. This study's conclusion and recommendations are both valid and important. Their validity comes from their reliance on multiple criteria of evaluation; their importance lies in their relevance to the growing number of schools incorporating computers into 
curricula. Similarly, these conclusions and recommendations present points that have relevance to schools and school districts regarding matters of decision making, future research, and evaluation efforts. 
CHAPTER II

PROBIEM APPRAISAL

Participation by the public sector in the provision of educational services has several major implications. First of all, education is one of the most basic of human needs, long recognized as such and later so decreed by the United Nations, which called upon countries to provide free education to all citizens. This declaration is based on the fact that education is essential to the development of social, cultural, moral, and political views and values. Such developments also imply that the quality and level of national educational achievements are part of the very foundation of civilization and humanity.

Second, education is an important economic activity. Its significance is exhibited in its role in the gross national product (GNP) of nations. The statistical report of UNESCO shows that nations have continued to devote an increasing portion of their GNP to education. This is demonstrated in the comparison of the USA and other nations for the years 1970 and 1980. United States allocated 6.5 percent of its GNP in 1970 and 6.9 percent in 1980 . Similarly, the figures for other developed nations were as follows: France ( 4.9 percent, 5.3 percent); West Germany (3.5 percent, 4.7 percent); Britain (5.3 percent, 5.7 
percent; USSR ( 6.8 percent, 7.1 percent); Norway $(6.0$ percent, 7.2 percent); Japan ( 3.9 percent, 5.9 percent); and Sweden ( 7.7 percent, 9.1 percent).

Third, education is part of the service economy that directly touches the lives of over a quarter of the population of the United States. According to the Digest of Educational Statistics of the National Center for Education Statistics (NCES, 1982), there were 57.2 million students, 3.3 million teachers and 0.3 million administrative and other staff. A total of 61.4 million people, or 26.5 percent of the population of the country was involved in education. They served 90 percent of the five year-old population, 99 percent of the 6-13 year olds, 94 percent of the 14-17 year olds, and 29 percent of the 18-24 year old age group.

Fourth, education enhances the advancement of technology which, in turn, improves the quality of education and educational activities, such as scientific research and development. In recognition of this intrinsic relationship between education and technology, nations have devoted a major portion of their efforts and resources to research and development which, in itself, is a form of technology. Scientific innovation applied in education also promotes instructional technology and quality of education. In 1980, 76.9 percent of the world's educational investment in scientific research and development was distributed among 
three groups: USA ( 18.0 percent); Europe $(22.3$ percent); and USSR ( 36.6 percent). As a result of this investment, these three groups produced 86.5 percent of the world's scientists, (USA 32.1 percent, Europe 34.0 percent, and the USSR 20.4 percent (UNESCO 1984, V-21).

Fifth, "education" is a basic social institution, second only to the family, that socializes and intellectually harnesses the fertile minds of youngsters. It is an institution whose task is to provide "knowledge, skill and competence of desirable qualities of behavior or character" (Webster's Third International Dictionary). This implies that the level of education people acquire has at least two long-term effects: an effect on the market value placed on their labor skill (wages and salaries), and on the family environment they create as adults. It is a well-known fact that there is a high correlation between the level of education attained and the income level one reaches, even when some social factors such as racism and sexism are accounted for (Goel, 1975, p.7).

Sixth, government's effort to assure basic skills and education to all is a form of redistribution of resources, providing an opportunity for all to enhance their initial skill or training, entry level, and qualifications in the labor market. Those who have learning disabilities and who are slow learners have special needs that require more resources. Most of these groups come from economically 
disadvantaged families and are recognized as educationally disadvantaged. Remedial programs are devised to redress the disadvantages based on a premise of deprivation. These services, like basic services mentioned earlier, are also delivered by public schools and by some private schools. Public policy that made such services a reality is a result of society's recognition of the impact of learning disabilities and low achievements on urban youngsters, and the resultant impact on their adult life.

The parity between income and training or education is generally dictated by the labor market. Those who are not equipped or ill-trained in necessary education and skills are less Iikely to find employment, and, if they do, they are more likely to be subjected to low income. Such dire circumstances not only create poor families but also a generation of educationally, and hence economically, disadvantaged youngsters, who inevitably become a permanent underclass. Therefore, the federal government has adopted and operated a policy of equal economic and educational opportunities, demonstrated by job training in employment and remedial programs and financial aid in education.

The public school system, a mechanism by which all levels of government join in a cooperative outreach effort, makes education accessible. Local educational agencies, such as school districts, have a mandate to provide equal opportunity of education for all. One should note that it 
is almost impossible to mandate equality of results, as there will always be differences of ability, background, and social environment. The public schools, as part of the public sector, are the educational service providers, whose scale of operation and successes at meeting demands depends on federal, state, and local revenues. Be that as it may, what is of particular interest to this research is the outreach effort and its effect.

The appropriate methods of assessing educational services in a developed country like the USA should involve determining the opportunity for and access to education, as well as its quality. The level of achievement or improvements realized by special segments of the population can also be a measure of national efforts and effectiveness in the area of diagnosis and treatment of learning disabilities.

The Elementary and Secondary Education Act of 1965 (Title I) was passed to address the learning difficulties of the disadvantaged. However, given the fact that there is a relationship between family poverty and youngsters' low learning achievements, many legislators and educators felt that an increase in spending might help the youngsters without solving any underlying causes. Most eaucationally disadvantaged youngsters come from families who are economically disadvantaged. The purpose of this law is intended to demonstrate the public concern and commitment 
for equality of opportunity to all citizens; however, it is not designed to address all problems associated with learning difficulties.

Since the late $1970^{\circ}$ s several concerns, issues and criticisms have been raised about public education in general, and compensatory education in particular. Issues such as the quality of education and qualification of teachers in public schools have been raised, and public schools have been compared with private schools in the areas of resource costs, program effectiveness, student discipline, and levels of achievements. These comparisons continue to exert pressure on public school educators (Coleman et al., 1982).

Reluctance of the public to pass tax levies for school funding, and reduction in state and federal assistance for supplementary educational services have also led to drastic changes and new alternatives, such as advanced instructional technology. The remainder of this chapter will give an appraisal of problems associated with a youngsters' social environment. After assessing the perspectives of deprivation, the trend of educational technology is examined.

EDUCATIONAL SERVICES TO THE NEEDY

A legislative provision of 1965 created a series of compensatory programs which officially declared the presence 
of a linkage between being economically and educationally disadvantaged. This legislation is known as "The Elementary and Secondary Education Act of 1965 (ESEA) Title I." It is the cornerstone of all "compensatory education" programs. Compensatory Education is a general Title I program operated by local educational agencies (LEAS) for educationally deprived children. "Educationally deprived (disadvantaged) children" means children with educational attainment below a level appropriate for their age (34 CFR 201.2 [b] of July 1, 1982 p. 431). The ESEA of 1965, sec. 101, states the policy as follows:

In recognition of the special educational needs of children of low-income families and the impact that concentrations of low-income families have on the ability of local educational agencies to support adequate educational programs, the congress hereby declares it to be the policy of the United States to provide financial assistance to local educational agencies serving areas with concentrations of children from low-income families to expand and improve their educational programs by various means which contributes particularly to meeting the special educational needs of educationally deprived children ( 20 USC 241 a, PL-89-10, enacted in 1965 and amended $1966,1968,1970$ and 1982).

Title I general programs are not the only compensatory education efforts of the federal government. Educationally disadvantaged students are also aided under a series of programs such as Head Start, Follow Through, Post Secondary (Title IV), ESEA Title III, ESEA Title VII, Migrant Children (i.e. children of inter-, intrastate and migratory students). The Indian Education Act, The Right to Read, 
Health Start and Home Start. There are also various extended services under each of these programs. Some of them are similar to Upward Bound, Talent Search, and Special Services for the Disadvantaged in Post Secondary Education. The Indian Education Act addresses three different areas of bilingual and bicultural problems and needs. There are also local programs, such as Parent-child Centers, home-based centers and Child Development Associates.

According to the National Schools Public Relations Association's study of compensatory programs of 1972, an estimated 10 million children attended public and nonpublic schools in urban, rural and suburban areas across the country. These were not all cultural, ethnic or racial minorities, as 60 percent of these disadvantaged youngsters were white. The children from migrant families were also estimated to number half a million, coming from families with a median education of 6.2 years and a 17 percent illiteracy rate. Twenty-five percent of these families had either not attended school at all, or had no education beyond the fourth grade.

In 1972 there were 400,000 children from migrant families, of which 85 percent were elementary students who received educational and supplementary services (Ibid, p.23). The Right to Read research also reported that there were seven million elementary and secondary students who were considered to be educationally disadvantaged, and 19 
million adults who were "totally or functionally illiterate" (Ibid p. 29). Follow Through served 90,000 youngsters of which 80 percent were from low-income families li.e earning less than $\$ 4,320$ yearly).

There are several outreach programs to assist youngsters. Upward Bound served 25,000 youngsters who were "turned off by traditional values of schooling." Another program, Talent Search, served 125,000 of "those who were overlooked" in the traditional settings by providing placement and training information. Similarly, Title III reached out to 900,000 compensatory education students by finding "creative solutions" to various problems in the private and public schools. The Bilingual Education program (Title VII) served a high concentration of children from low-income families, mainly Mexican-Americans, Puerto Ricans and Cubans. Such services were extended to, and accessed by, 22 other non-English speaking minority groups (Ibid p.21)

According to both a National Advisory Council on the Educationally Disadvantaged Children Report to the President, and a U.S. Congressional study of 1971, there were more than 7.4 million children identified as needy (NACEDC, 1974). Out of these, less than 6.3 million were assisted. Of these, 5.9 million were in public and 0.3 million in private schools (Ibid, p.74). In 1972, a little over $\$ 5.6$ billion was allocated for 8.1 million 
educationally disadvantaged children. These youngsters were located in 2,876 counties and 15,785 cities. These cities and the counties were quite different in appropriation of their Title I funds. The cities spent 56 percent of the allocation on operation and management and 44 percent on capital, while the counties allocated 44 percent for operation and management and 56 percent for capital development (Ibid p.16).

In 1972, Pacific $T \& T$ Corp. researched the Head start program, one of the compensatory education programs (NACEDC, 1974, p.12). The research discovered that compensatory programs like Head Start are sensitive to location, duration of service and economies of scale. There is a cost difference between those served in urban as opposed to rural areas. There is also a cost per child per day difference between urban and rural schools, as well as between partand full-day attendance. The rural service cost is $\$ 6.52$ for part-time and $\$ 7.30$ for full-time. The equivalent figures for urban services was $\$ 6.18$ and $\$ 6.63$, respectively. It is clear that with the addition of eleven cents over rural part-time daily cost, a child in an urban area can be served for a full day. This cost differential is mainly due to economies of scale. The research points out that "programs serving 200 to 800 children cost less than those serving less than 200." 
Service Targeting

According to service targeting procedures of Title I, the Local Educational Agency (LEA) identifies the project area "a school attendance area in which a high concentration of children from low-income families reside." That is the area from which schools are selected to participate in a ESEA Title I project (ESEA, 1982). The determination, as specified under sec. 201.11, should be based on satisfactory census data on a school district basis, one which is served by the LEA and has at least ten children (sec. 111 c).

An eligible school is one selected by the LEA, in which children are to be selected to participate in Titie I projects and to receive services supported by Title I funds. The Title I funds are allocated among project areas and schools by the LEA according to the number and needs of the children to be served (sec. 201.15). Special educational need groups are educationally deprived children in areas with high concentrations of low-income families, or children in local institutions, or those either delinquent or neglected.

Once the area and, subsequently, schools with a high concentration of children from low-income families have been identified, a student selection process begins. Since fund allocation criteria call for the qualification of the schoolm-not necessarily the student--all students qualify for Title I assistance, regardless of whether or not they 
are from low-income families, since eligibility is determined only on the basis of their educational needs.

All students within the selected school and grade levels will participate in a selection test. Some schools do their selection on the basis of a pre-test, which has a technical shortcoming to be discussed later. Normally, once a selection test is administered, scores are used to determine how many and which students need Title I assistance. The selection test is sometimes checked against the teacher's judgement of the individual student's general performance. This method helps to serve the needy who may score highly on the selection test, but whose record or teacher's observation indicates otherwise.

Title I students, hence, are those students in a school selected for Title I funding who scored low on the selection test or who are deemed needy by their teachers. The needs assessment, a process of identifying the basic skills in which a student is deficient, proceeds by comparing test scores. Basically, those students below grade level (50th percentile) are considered disadvantaged. However, the typical Title $I$ student is at the 20 th percentile. The selection of students who are eligible and are to be served depends on funds available and the number of students who need services. If funds are not sufficient, which is almost always the case, the decision as to which grades will be served is heavily inluenced by the philosophy 
of each school and its district officials. Usually, the issue is whether most of the project funds should be allocated to lower grades (early interventionist) or upper grades (career-oriented), and also whether priority or emphasis of services should be given to mathematics, reading or language arts. According to Hinckley (Hinckley, 1978), there are poor and non-poor, low achievers and non-low achievers who are served by Title I and other compensatory programs.

Table I, below, shows that local agencies were not able to serve all who were educationally and/or economically disadvantaged. The table shows that 61 percent of the economically and educationally disadvantaged who needed reading assistance, and 71 percent of those who needed math assistance, did not get any compensatory education.

TABLE I

PERCENTAGE OF SERVICE

DISTRIBUTION

Compensatory

Educational Services

1- Title I (CES)

1- Title I

2- Other CES

3- NO CES

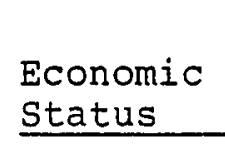

Poor

Non-Poor

Poor

Non-Poor

Poor

Non-Poor
Educationaliy Disadvantaged Rd. * Mth. * 25

9

16

5

13

14

10

9

$61 \quad 71$

$81 \quad 87$

* Rd.= Reading Mth.= Mathematics 
Those who were educationally but not economically disadvantaged and who needed similar assistance numbered 81 percent and 87 percent, respectively. A further breakdown of the economically disadvantaged into four levels of educational disadvantage (a quartile grouping of percentiles) shows that the higher a student is in the quartile system the less likely he or she will be to receive assistance. This is given in Table II.

TABLE II

PERCENTAGE OF THE NEEDY BY PERCENTILES

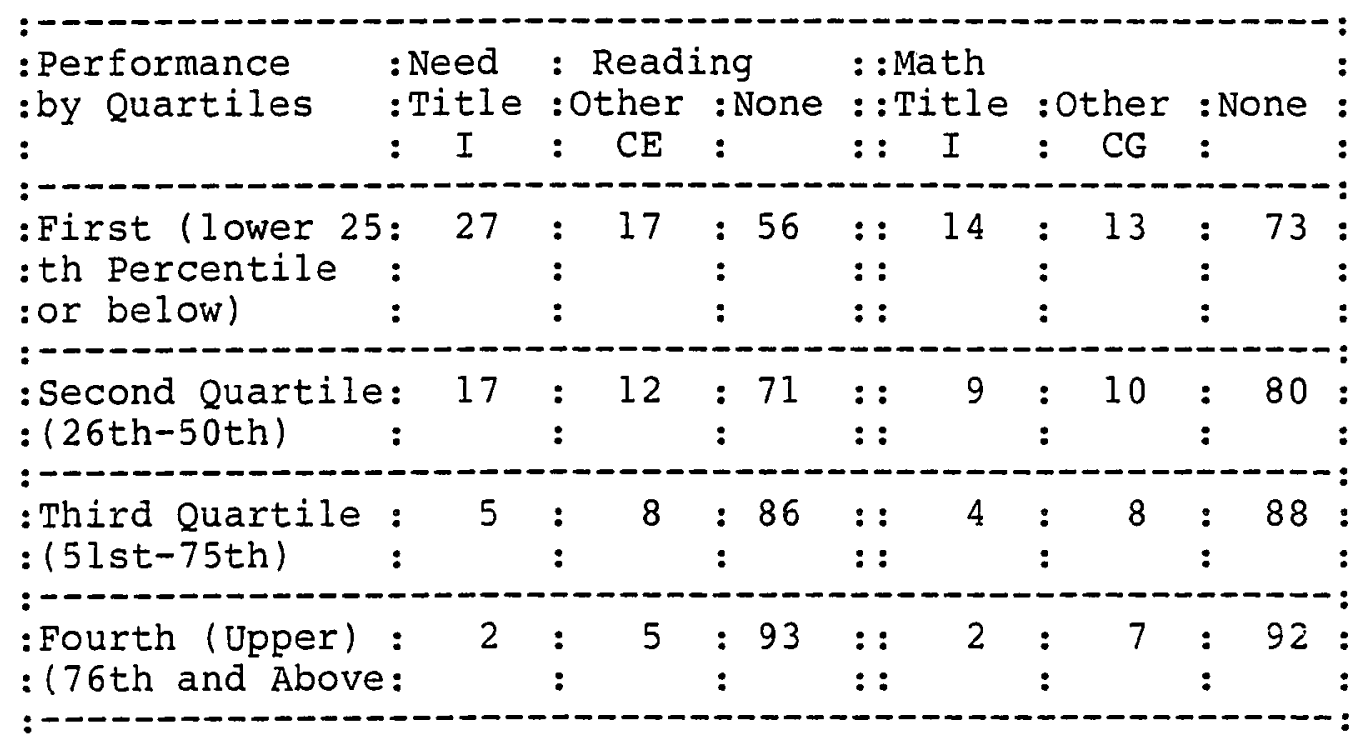

This table illustrates that a student qualifies for services in relation to his/her performance. Those youngsters who are in lower quartiles, i.e. below grade levels, have a better chance of receiving compensatory education than those in the upper two. Unfortunately, due to an insufficient appropriation of funds, less than half of 
all youngsters in either of the bottom two quartiles receive compensatory assistance. More than half of those who were identified as economically and educationally disadvantaged, and who were also below their respective grade levels, were not served. Of those who needed help in reading and mathematics, 56 percent and 73 percent respectively, were in the bottom quartile, and 71 percent and 80 percent were in the second quartile. The Hinckley report also shows that a significant relationship exists between a student's economic status and his educational achievement (Ibid, p.10).

Contrasting the achievements of the poor and non-poor illustrates differences between the "haves" and the "have nots," as discussed earlier. However, a correlation between ability and income sheds some light on the differences between two classes. Some of the differences are inbedded within the wealth and intelligence inherited. In addition, conditions that make one better or worse off have to do with the individual's effort and social environment. If one assumes that educational performance is a unique function of environment alone, it would be difficult to explain why 26 to 30 percent of the poor perform above the national median and about 44 percent of the non-poor perform below the national median achievement.

Those students who were poor and also below the national median achievement in reading and mathematics numbered 74 percent and 70 percent respectively, while those 
who were non-poor numbered 44 percent and 43 percent. Similarly, those whose performance was above the national median numbered 57 percent and 56 percent for the non-poor, and 26 percent and 30 percent for the poor in reading and mathematics, respectively.

A comparison of actual numbers of low achievers, who are poor and non-poor and receiving services, provides a glimpse of the extent to which needs have been met. of an estimated 10.007 million low-achieving poor and non-poor youngsters, only 3.657 million were served by compensatory programs in reading. Among these youngsters, the non-poor constituted two out of every three that were served. Similarly, out of 9.698 million poor and non-poor low achievers who were considered needy in math, only 2.283 million were served, and 1.918 million of the low-achieving and poor did not receive compensatory assistance; however, for every five youngsters who received help, two were poor and low-achievers.

Family Background Problems

As already presented in Table I, Title I served 25 percent of the poor and 9 percent of the non- poor in reading, and 16 percent of the poor and 5 percent of the non-poor in mathematics, (Hinckley, 1978). Although the rest of the low-achieving poor and non-poor were not served, it should be noted that, without all the educational resources provided by local and federal agencies, the 
youngsters served would not have been able to get help. Moreover, given individual differences in ability and other socioeconomic characteristics, 50 percent of young people always perform below the median grade. Therefore the basic mission of compensatory education is not to radically alter normal distribution, but reverse a further decline of performance and alleviate the impact of deprivation in basic skills. As stated before, these data are sited to demonstrate the relationship between educational achievement and income level.

Recent studies also show that, on the basis of 1980 family income statistics, upper-class youngsters from families making $\$ 25,000$ and over were mostly in private schools, with only a quarter of this group in public schools, (Coleman, et al, 1982, p. 32). Similarly, 8.9 percent of low-income students $(\$ 11,900$ or less annual family income) were able to attend private schools, accounting for only one-fifth of those schools' total enrollment. Low-income low achievers-Title I students-were mostly served in public schools.

While educational background is important to a youngster's learning rate, the aspiration and background of other students in the school is additionally important (Coleman, 1966, p.22). It has also been discovered that a child's family background interacts with the social composition of the school, influencing his or her 
performance.

Initial grade placement of a student is not solely determined by the teaching process. The student is subjected directly and indirectly to various forces and factors (Smith and London, 1981; Griffith and Lonōon, 1981; McAdoo, 1981) that can be generalized as an ecosystem divided into two components, microcosm and macrocosm. The microcosms are the domestic and educational institutions--the family and the school. These two basic social units impress their norms, values, doctrines and philosophy of life upon a youngster. The macrocosm is the system of neighborhoods and communities that encompass the microcosm of family and school.

The quality of the environment within the basic microcosm--the family--depends primarily on culture and level of family income. The lower the level of cultural development and income of the family and community, the lower the quality of basic necessities. Therefore, when families are less and less able to afford basic needs (i.e., sncial and educational assistance, food, housing, health or security), then quantity rather than quality becomes a primary concern. The impact of these social conditions exhibits itself in urban areas of many cities and countries throughout the world. In other words, these conditions are a worldwide social phenomenon. Progress made in combating these conditions should not overshadow the magnitude of the 
remaining problems.

over the years American society in general, and the family in particular, have experienced several positive developments. National median education has grown from 10.6 years in 1960 , to 12.2 years in 1970 , and 12.5 years in 1980. The mean nutritional intake value has continuously improved, i.e., food energy (calories) increased by 6.2 percent between 1960 and 1970 and 5.8 percent between 1970 and 1980. Protein intake also increased by 4.1 percent and 3.0 percent respectively. Longevity has increased and death rate and infant mortality have declined. In the last decade (1970-1980), the proportion of whites and blacks living in central cities has also declined. Those residing outside central cities rose by 13.1 percent for whites and 42.7 percent for blacks.

There are also social changes that affect families. A comparison of the last two decades shows that traditional two-parent families decreased from 4.4 percent in 1970 to 74 percent in 1980. On the other hand, female-headed households grew from 24.1 percent to 52.7 percent for the same period of time. The number of teenage mothers (fifteen years and younger) has decreased for both blacks and whites. There are also changes in the number of children per family for both ethnic groups. Black families made drastic changes in this area. In 1960 black families who had no children numbered 43.8 percent, and those with four children or more, 
27.9 percent. In 1980 the corresponding figures were 38.2 percent and 8.1 percent respectively. Those families who received Aid for Families with Dependent Children (AFDC) were 22 percent of the black and 3 percent of the white families; however, the recipient population was 43.9 percent black and 51.7 percent white (Statistical Abstract of the United States, 1981, p.16, 46, 71, 127, 142, and 346).

Changes in family structure is another factor that contributes to variations in ability, motivation, and performance, as well as in parental support and involvement in the student's learning. According to the 1980 U.S. Census, there were 1.4 million mothers who had never married, of which eight percent were awarded child support, and five percent were able to collect payment. The proportion of single mothers still increases. The proportion for the age group 24-44 years old was 12 percent white and 39 percent black. As pointed out earlier, the number of single mothers or female-headed families has constantly increased over the last few decades. The number of mothers in early and late age brackets is increasing and these women are frequently single. This social and historical trend has become a difficult problem in social service policy. The solution lies in both the man and woman accepting responsibility for their children and in a public policy to induce cooperative spirit.

A review of studies done by McAdoo such as 
Blatchelez's and Furstenberg's shows that, contrary to common allegations, young women are neither encouraged by their parents nor plan on their own to have babies as means of receiving or increasing public assistance, (McAdoo, 1982, p. 226). The findings also show that unwanted pregnancy is a result of knowlege about their body's reproductive processes and lack of effective birth control. Public assistance has become an easy alternative means of support. This undermines responsibility and self-sufficiency regarding child support and life style. In some cases, AFDC has become counterproductive by encouraging having children in order to receive public assistance. There is also a high rate of teenage separation from Eamilies and movement to states where benefits are higher. A restriction on assistance to two-parent families is a policy that has driven men from many households. This policy is now changing in many states, but it may be a case of too little too late in some instances.

An increase in the number of single mothers is reflected in problems faced by growing numbers of young mothers and by their children as learners. Nationally, nearly 20 percent of school age children live in a home having only one parent. The figure for black children of the same age group is nearly 50 percent (Smith, 1981, p.249). Most of these children suffer from poverty and low academic achievement. A contrast of high and low achievers 
by type of family shows that 17 percent of high and 40 percent of low achievers come from single parent families. Corresponding figures for children from two-parent families is 30 percent for high and 24 percent for low achievers (Smith and London, 1981, p.249). In other words, 36 percent of the low achievers and 53 percent of the high achievers are from households and other living arrangements.

The emotional impact of parental separation or absence of one parent on a youngster's learning ability cannot be overstated. The income level of single- or two-parent families also has an impact on both children and parents. In 1980, the median income of a white family was $\$ 18,370$; the figures for hispanic and black families was $\$ 12,570$ and $\$ 10,880$, respectively (ACYF, 1980). Sixteen percent of the children were from families below the poverty level; of these, 11 percent were white and 42 percent black. The income of an average single mother was less than half that of a two-parent family median income, regardless of ethnic category. The income of a white single mother was 38 percent of that for a two-parent white family's median income. Corresponding figures for black and hispanic single mothers were 40 percent and 39 percent of their respective ethnic group's median income. The actual figures were $\$ 8,799, \$ 5,598$ and $\$ 5,247$ for white, black and hispanic single mothers.

The distribution of single and multiple earners of 
black and white families over the 1970-80 decade reflected certain employment trends. The proportion of white families with a single wage earner declined as mothers went to work to add to their families incomes, leading to an increase in multiple-earner families. Though this condition separated mothers from their children, added income lead to an affordable day care or pre-school education for the child. On the other hand, the number of black multiple-earner families declined because of an increasing number of unemployed black men. As more housewives joined the black women whose husbands were unemployed, the proportion of single-earner black families increased. Although this might lead to less child care cost, the impact of this reversal of the traditional roles of husband and wife (on their relationship and on the child) is not known, (McAdoo, 1981, p. 263).

The distribution of income earners has generally improved as can be seen from changes occurring between 1964 and 1977. The level of employment and real income increased, but as welfare policies improved and age distribution shifted, the number of public assistance dependents and families without earners increased slightly. over the thirteen year period, families in this category increased for all ethnic groups by 50 percent for black, 29 percent for hispanic, and 34 percent for white families. Positive changes can be seen in the increase of median 
family income (1981 constant dollar) from $\$ 20,054$ in 1965 to $\$ 22,388$ in 1981 (American Council on Education, 1982).

One of the factors that influence student achievement of family income. An understanding of the general changes in income can explain some of the changes in achievement. The proportion of families making $\$ 5,000$ or less was 7.2 percent in 1965 and 5.8 percent in 1981. Similarly, those families making $\$ 25,000$ or more were 34.1 percent in 1965 and 44 percent in 1981. It should be pointed out that in 1970 and 1981 the percent of families making $\$ 5,000$ or less increased from 4.3 percent to 4.5 percent for whites and from 12.5 percent to 14.8 percent for blacks. This could be as a result of: (a) a shift of those who made a little above $\$ 5,000$ to this margin; (b) those families who had never worked now made some income within this bracket; and (c) change in the population structure, i.e., very young and very old famiiies tend to niake less. The income brackets between $\$ 5,000$ and $\$ 25,000$ shows significant positive changes. Therefore, on the average, the proportion of those who were worse off was very small compared to those who were better off, but since Title I serves youngsters who are disadvantaged, the improved income may not exert a profound effect on achievement.

Research shows that educationally disadvantaged students exhibit the negative impact of their microcosmic effect. These youngsters show a significantly low level of 
achievement, a high dropout rate and, subsequently, a high unemployment rate compared to youngsters who are not from economically disadvantaged families. This relationship should not be mistaken for causality. There are cases where some high achievers come from poor families, while some low achievers come from middle- and upper-income families. It would be a simplistic and erroneous conception of the problem if one assumed that raising the income of the poor would eliminate an educational performance gap. Nevertheless, it should be noted that there is a relationship among income, ability, gender, race and age. A case in point is the 1981 income of full-time, year-round workers. The median income for those who had four years of college was $\$ 26,864$ for white male workers and $\$ 16,463$ for white female workers. The corresponding figures for black males and females were $\$ 17,523$ and $\$ 14,955$, respectively, (American Council on Education, 1984).

Patricia sexton (1967) studied the income-achievement relationships in youngsters of the fourth, sixth and eighth grades. She divided median income into four groups: (I) $\$ 3,500$, (II) $\$ 5,000$, (III) $\$ 7,000$, and (IV) $\$ 9,000$, and used Iowa Achievement Test composite scores to measure achievement. In all three grades there was a higher level of achievement consistently associated with higher levels of income. If we call Group I poor and Group IV rich, the average achievement for the 4 th, 6 th and 8 th grade poor was 
$3.48,5.23$ and 6.77 , while the corresponding achievement for the rich was $4.82,7.05$ and 8.67 on the Iowa Achievement Test (Saxton, 1967, p.529).

The percentage of educationally disadvantaged youngsters by level of income for groups (I-IV) was 96 percent, 82 percent, five percent and zero percent, respectively. This distribution of gifted and "problem" children per 10,000 students confirms the same sad story. The rate of gifted and talented per 10,000 youngsters for income groups I-IV were zero percent, 7.2 percent, 56.1 percent and 78.8 percent. The youngsters who were identified as displaying "problem behavior" for the same ratio and groups of income in the same order were 37.7 percent, 14.8 percent, 4.2 percent and zero percent. The data collected on big city schools on the number of youngsters in detention for the same income groups was 85.7 percent in Group I, 40.2 percent in II, 6.9 percent in III, and 2.7 percent in Group IV for every 10,000 youngsters. The negative effect of some of the factors discussed above could be minimized or averted altogether by parental counseling, and moral and intellectual support, along with the opportunity for parents to improve their income and level of education. The subsequent positive effects of such policies could enhance a youngster's socialization process, self-concept, motivation, and learning ability. The public effort to eliminate illiteracy has paid off by reducing the 
number of parents with five years or less of education from 10.8 percent in 1950 to 3.3 percent in 1981 . In 1950 illiteracy rate by ethnic groups was 2.8 percent for white and 8.1 percent for minority families. In 1981 the median school years had risen to 12.6 percent for whites and 12.2 percent for minorities. Efforts to improve the spread and quality of education has also increased over the years. In 1972-73 federal and nonfederal financial aid enabled 24.9 percent of the poor to continue their education as fulltime freshmen students, (American Council on Education, 1984). Also 8.1 percent of the rich, 8.2 percent of low-ability, and 21.7 percent of the high-ability youngsters benifited in like manner. This encouraged high school students, and their dropout rate slowed between 1971 and 1981 from 15.1 percent to 12.1 percent for whites and from 25.9 percent to 19.9 percent for blacks, (NCES, 1984).

The enrollment rate of ethnic groups in institutions of higher education from 1978 to 1980 increased by five percent for blacks, 13 percent for hispanics and 7 percent for white students.

The adult pop lation, when broken down by level of education and ethnic groups, shows that a great majority pursue education beyond the elementary level. In 1981 only 1.7 percent of white adults had only eight years of elementary education, 11.5 percent had four years of high school, and 26.9 percent completed four years of college. 
The rest of this group consisted of those with some high school, some college and beyond four years of college. Of the black population the figures were 1.9 percent, 7.6 percent, and 20.0 percent. And for hispanic adults they were 3.5 percent, 10.9 percent, and 19.1 percent (NCES, 1981, p.17, 102, 126; 1983, p.160; American Council on Education, 1984, p.71, 94, 100, and 148).

A comparison of variations in educational performance among youngsters of three ethnic groups (blacks, hispanic and whites) is reflected in a 1975-1980 study. Table II below shows variations in performance. Blacks and hispanics are below national mean, and whites are above it.

TABLE III

PERCENTAGE DIFFERENCES OF SCORES BETWEEN THE NATIONAL MEAN AND ETHNIC GROUPS BY AGE AND SUBJECTS

$\begin{array}{ll}: & :\end{array}$

* $\mathrm{Bl}=\mathrm{Black}, \mathrm{Hi}=\mathrm{Hi}$ spanic, Wh=White

This table shows that, among three age groups in three skill areas, the scores for blacks consistently fell below the mean. Youngsters from big cities whose parents were not 
high school graduates also showed negative changes in mathematics and science, where differences in achievement levels is more pronounced with the student's age. Black children from central cities and ghetto areas had a similar pattern of achievement in both mathematics and science (NCES, 1982, p.25).

The traditional method of compensatory instructiona? service delivery involves practices that may bring about a stigma. First of all, educationally disadvantaged youngsters from low-income families, especially those from minority groups, perform unsatisfactorily on most measures public school officials deem important. Hence, when the disadvantaged child starts school, he or she is placed one or more grades below the age-grade parity, or grade level. Second, traditional remedial practice involves "pull-out" (isolation) instruction in basic skill areas. These practices result in a form of racial segregation or academic isolation, which automatically brings about the stigma of inadequacy. This situation directly affects the attitude of the student. It has been pointed out that a pupil's attitude has a stronger relationship to achievement than any other school factor (Coleman, 1966). Coleman found that minority pupils, except orientals, have far less conviction than whites do that they can affect their own environment and future, probably for reasons discussed earlier in this chapter. However, he also found that changes in this 
attitude has helped blacks to outperform whites who lack that conviction.

By constructing indices of "counter culture" and "anomie," Sethard Fisher (Fisher, 1981) conducted a study of class, race and achievement in grades two through nine in the Berkeley Public Schools. Fisher discovered that students from a working class background had a lower achievement rate than those from upper classes. In the third grade and above, however, youngsters from the black upper classes scored lower than all other working class students. The Oriental upper class scored above all other ethnic classes up to seventh grade. After the seventh grade, Oriental and white upper classes do not show significant differences.

While compiling his anomie index, Fisher found that blacks ( 78.9 percent) were high up on the index compared to whites $(27.0$ percent). The anomie score for the lower classes of both groups was higher than their respective upper classes, the disparity being greater for blacks than for whites. Fisher also concluded that a high anomie score is associated with low academic achievement. When the grade point average (GPA) of one who is nonanomie is compared with those having anomie, and then are compared by ethnic group, the GPA of whites was 3.026 vs. 2.820 and that of blacks was 2.578 vs. 2.231

Another index of counter culture, a reponse to 
questions about work ethics, was also constructed and tested by Fisher. He found that a higher proportion of blacks (52.9 percent) were counter-culture than whites (31.9 percent). Lower and upper classes of both black and white ethnic groups maintained a relatively similar trend. The two groups also had a smaller counter-culture upper vlass compared to their respective lower classes. In terms of their aspirations, as measured by responses of youngsters in Grades 10 to 12 to questions concerning the importance of college, a larger proportion of the lower classes 181.5 percent) showed higher levels of aspiration than the upper classes (73.6 percent). Similarly, both classes of blacks showed higher levels of aspiration than did whites (Fisher, 1981).

The findings discussed above need a clear examination, especially the study of class, aspirations and national origin (ethnic groups) on the anomie scale. A great majority of low achievers are white youngsters. However, while both black and white lower classes showed very high aspirations toward upward mobility, it is only the black lower class that scored high on the anomie scale. Fisher's explanation is that "blocked opportunity (i.e. discrimination) and insufficient preparation (i.e. lack of pre school education) generates anomie and is sufficient to account for high aspiration of lower class black students" (Ibid, p.164). The author seems to imply that enforcement 
of affirmative action laws and expansion of compensatory programs can alleviate both problems. If so, one should not discount the psycho-cultural role on aspiration and effort which may not be assessed by the impact of such programs.

White lower class youngsters appear to be free of ancmie for two reasons. First, white working class students, contrary to their black counterparts, identify with high achieving middle class whites. Second, it appears that the class awareness (consciousness) of whites is overshadowed by ethnic identity. Students from white working class families fail to grasp the commonality of experience and interest among classes, especially within the lower class. Thus, they are hostile toward other lower class ethnic groups. Their failure in achievement is seen as a matter of personal inadequacy instead of a malfunction of social conditions.

The performance (achievement) of upper class blacks is low for two reasons. First, there is a lack of socialization of the black upper class with the white upper class, because the white upper class, like the white lower class, has emotional values along racial (ethnic) lines rather than class lines. Therefore, class solidarity or affinity among black and white upper classes is weak. Secondly, black upper-class people, who are few in number, frequently lack acceptance by white coworkers, and they tend to build friendships with the counter-culture white middle 
class. These friendships are fragile because of the latter's failure to recognize the pride in ethnic origin and cultural heritage of the former (Fisher, 1981). Third, in a school environment friendships formed by upper-class blacks are with lower-class blacks, whose achieveme-t is by and large low. As a result, upper-class blacks have lower achievement rates than the white upper class, and in some cases lower than that of the white middle class, since a pupil's achievement is strongly related to the educational backgrounds and aspirations of other students in the school (Coleman, 1966, p.22). This school-based socialization of youngsters along ethnic and class lines follows a pattern of its own. In a neighborhood setting class (income) seems to dictate choice of residence rather than ethnic identities. In almost all U.S. metropolitan areas, middle- and upper-class whites reside in the suburbs and blacks in central cities, especially in the ghetto areas. As education and income changes, this pattern of settlement also experiences some changes. In 1970 the white population was 27.8 percent in the central city and 40 percent in suburban areas. Similarly, 58.2 percent of blacks were in the central city and 16.1 percent in the suburbs. In 1980 the white population was 25 percent in the suburban area and blacks were 23.3 percent. (Statistical Abstracts of the United States, 1981, p.16). 
School Related Problems

In the previous few pages we have seen that some achievement problems are related to a learner's microcosm, i.e, family structure, income, class and ethnic origin. Although none of the literature cited above proves causaity between a student's achievement and the effect of his/her microcosm, the relationship is nevertheless clear. The second part of a student's microcosm, the school, and his macrocosm, the neighborhood or community, also have varying impact on the ability of the learner.

The school environment is a component of the learner's ecosystem and brings to bear various forces that interact with the instructional setting. Two very important factors need to be addressed: school quality and teacher effect. As there is an explicit correlation between a student's ability to achieve, and the socioeconomic status of the student's family (Wells, 1974, p.16; McAdoo, 1981, p.261; Coleman, 1966, p.21), there exists a relationship between a student's achievement and the type or quality of school the student attends .

The educational achievement of youngsters is an outcome of the impact of several factors, such as participant effort, instructional staff and institutional facilities. Consequently, the school is a force that brings several factors into operation to educate the learner. "Effective" schools have ordered environments and present 
strong academic demands. Furthermore, factors such as instructional and administrative leadership influence goals, tasks, expectations, instructional effort and time, as well as performance standards for both teachers and students--all of which make crucial differences in schools (Smith 1981). Educators and administrators in public schools are criticized for students' poor attitude towards school and learning; for their low motivation effort, and academic achievement; and for their undisciplined behavior. They also come under fire for inadequate teacher accountability and for runaway operational costs.

Research shows that schools differ according to levels of racial integration and levels of operational spending. Racially balanced primary schools show higher achievement levels than those that are not. There is also evidence that to the extent that the student body is not dominated by a single ethnic minority, student achievement is not adversely affected (Fisher, 1981, p.151; Coleman, 1966, p.22). Further, schools differ regarding their impact on various racial and ethnic groups. On the other hand, they are similar in their efforts on student achievement when the socioeconomic background of students is taken into account (Coleman et al, 1966).

Many largely white schools have high achievement levels. Given the proportion and distribution of white and black people in the population, many smaller cities have 
educational institutions that are largely white. Most institutions of higher education in 1974 had largely white enrollment--89.4 percent in two-year colleges, 87 percent in four-year colleges and 94.9 percent in universities. In most predominantly black colleges, 96.4 percent of the students were blacks. The American Council on Education and UCLA conducted a study of college freshmen achievement in 1974. The study showed that 16.3 percent of freshmen averaged "B" or better in two-year colleges, and 48.7 percent did so in universities. The respective proportion in predominantly black colleges was 12.4 percent. On the other hand, those whose grade average was "C" or below were 12.2 percent in two-year colleges, 8.3 percent in universities, and 26.4 percent in black colleges. In 1976 those who scored "B" or better were; 19.1 percent in two-year colleges, 54.1 percent in universities, and 13.5 percent in black colleges. This is an improvement for all groups compared to 1974. However, those who averaged a "C" or lower in two-year colleges increased from 12.2 percent in 1974 to 16.3 percent in 1976, unlike universities and black colleges which showed improvements (American Council on Education, 1982).

One of the factors considered a source of differences among schools in learning outcomes is the instructional facility and allocated resources. Although Coleman's findings later showed otherwise, Kenneth Richmond compared 
schools that were considered "good" and "poor" in terms of their levels of outcome and found that school expenditure was an important factor (Richmond, 1968). He compared the achievement of schools in New York state to the national average. "Good" and "poor" schools differed in their enrollment size, staff selection and "quality" of the teaching staff (education and experience) and annual expenditure per student. Unlike Coleman's findings, in Richmonds examination the "good" schools" median expenditure grew from $\$ 331$ per student in 1956 to $\$ 673$ in 1961 . The poor schools' spending rose from $\$ 362$ to $\$ 489$ for the same years. In contrast, Coleman found that school expenditure is not a major factor, although he did note that "negro" schools have fewer facilites than predominantly white schools (Coleman, 1966, pp.9, 22, 183, 201, and 290).

Although taxpayers complain about the constant increase in operational costs for schools, in 1982 only a small group of the complainants agreed to cut back the number of teachers (24 percent), teachers' salaries (24 percent), the number of special services (17 percent), and basic services 7 percent (NCES, 1982, p.50). The report also presented a survey that assessed the public perception of public schools. The survey asked respondents to rate public schools. The study included samples of parents and nonparents, and those whose children were in public and private schools. Thirty-seven percent gave a grade of "B" 
or better to the public schools in their locale and 22 percent gave this grade to public schools nationally. Those who had children in public schools and felt the local schools deserved "B" or better were 32 percent, which was lower than those whose children were in private schools (38 percent), or those who had no children ( 49 percent). The dissatisfaction of parents of public school children was probably based on their personal assessment of their children's performance.

A special report by Education USA (undated) evaluated several compensatory education programs for disadvantaged students. The schools were selected on the criteria of achievement, attendance, positive self-concept and physical needs. The students who were considered were those who achieved the 50th percentile or above and whose gain was at least one month for each month of instruction. The study found eight common characteristics among those successful schools:

1. systematic planning

2. clear objectives

3. intensity of treatment

4. attention to individual needs

5. flexibility in grouping

6. personnel management

7. Structured program approach

8. parental involvement

The attitude, aspiration, satisfaction and expectations of teachers are among the major factors having a direct impact upon learners. First of all, the 
interaction of teachers and students in the classroom is a major factor in accounting for sudents' confidence in their capacity to learn, their interest in school subjects, and their cognitive growth (Smith and London, 1981, p.254). Attitude and motivation of the student is closely related to cognitive characteristics.

Second, research shows there is a positive correlation between student expectations and achievement gains (Smith and London, 1981, p.255). Although the students ' basic personalities are important factors in the student-teacher interaction, the attitudes of their role models are important as wel1. This is underscored by Smith and London, who wrote, "Students incorporate the attitudes of significant others (i.e., parents and peer grc ps) toward them into their own personality structures." (Ibid). Peer group leaders or gang leaders in neighborhoods frequently threaten and ridicule children who show interest in school work and achievement-oriented motivation.

Third, direct instruction is also important to student achievement. On the average, students actually receives instruction of only 28 percent of the time they are in class. This means that, of five and a half hours of instruction, the net instructional time a student receives in both individual and class-wide instruction is quite low (Conant, 1973, pp.33-39).

According to Conant, there are four main class 
activities, three of which use up to 72 percent of instructional time. They are routine work, nonlearning dead time, and other activities. Research also indicates that, in low-income urban schools, a greater proportion of time is spent on maintainance of order (Griffith and London,1981, p.436).

Although students come into the classrooms with their individual and social problems, there are latent problems that teachers bring in as well. In some cases public school performance is severely affected by problems that are related to teachers. First, schools attended by the urban poor are frequently staffed by teachers having less experience and lower qualifications than those attended by students of middle class families.

Second, teachers assigned to large urban schools are often not prepared to teach in such an environment. It should be noted that the effort here is not to put a blame on teachers or students, but to understand the problem. It appears that the problem is a product of class-based subculture (as Edward Banfield would say), encounter, and lack of understanding of the problem at hand and the mission at stake. A large part of the problem is a complete breakdown of family and community attitudes supportive of education and school work. Some teachers come from middle and upper class suburban families with racial biases that may influence their social relations in ghetto classrooms. 
Consequently, they develop negative attitudes toward inner-city neighborhoods and children. Some inner-city chilaren perceive their teachers' negative attitude and lose interest in learning, which causes student and teacher to become a problem to one another. Such a critical situation inevitably causes 75 percent of class time to be used in trying to maintain order (Griffith and London, 1981, p.436). Third, as most teachers in the nation's schools are white and middle class, a problem arises in contact between members of a different "subculture." Such background differences between a child and a teacher in ghetto areas may also contribute to a negative reaction toward one another. The success of a teacher to bring up achievement scores in a ghetto area depends on the skill and experience of the teacher, a change in socioeconomic factors that bear a strong relation to academic effort of parents, and on the community, (Coleman, 1966).

Fourth, at times teachers feel threatened with the loss of their jobs as issues and pressures grow in the area of tenure and competency (Smith and London, 1981, p.248). Since teachers are preoccupied with personal problems such as these, they may develop low expectations and negative attitudes toward asking or accepting a parent's help regarding the child's behavior and education. In some cases teachers resist any help from parents (Smith and London, 1981). Thus, teachers alienate parents and shun the 
responsibility of solving the child's problem.

Fifth, demand for and supply of teachers changes from time to time. When demand is high, those who score low in their Graduate Record Examination (GRE) major in education, resulting in numerous new and inexperienced teachers. When demand is low, there are more teachers looking for teaching positions than there are job openings. On the other hand, the National Center for Education Statistics survey shows that, of B.A. recipients qualified to teach, 10 percent wanted to be teachers and 90 percent did not. There were also those who made teaching a career, whereas 57 percent did not (NCES, 1982, p.50). Fortunately the pattern of teacher supply and demand seems to be headed for an even ratio of new teacher to new teaching job opening. This is reflected in the s/d ratio projected by the National Center for Education Statistics. Past trends show that in the years $1971-75$ the ratio was 163.1 , in $1976-80$ it was 120.7 , in 1981-85 it was 103.1, and between the years 1986-90 it will be 100.3 .

The factors discussed above arising from the students' two microcosms--family and school--greatly influence the youngster's learning difficulties. The opportunities which encourage a student to move on to higher education become less and less, and this leads to frustration and pessimism, even among youngsters who perform well. As a result, disadvantaged children study subjects that can help them fit 
into traditional lower class careers. Subsequently, after high school the positions they look for are what they feel are appropriate for their traditional "caste," their socioeconomic role (McAdoo, 1981). Low-income groups are enrolled in health education and liberal arts, while upper income groups are heavily represented in academic subjects that lead to technical and professional careers (sexton, 1967, p. 537).

The educational level exhibits differences in class and ethnic representation. Distribution of all degree recipients by ethnic groups shows that the higher the level of the degree, the lower the number of ethnic minority graduates. In 1981, of bachelor's, master's, and Ph.D degrees awarded, 86,83 , and 80 percent were received by whites; blacks received 6.6 and 4 percent; and $2.3,2.2$ and 1.2 percent of the recipients were hispanics. The remaining percentage represents other minorities and aliens. It should be noted that some of this low representation is due to the fact that there are fewer of these groups in the general population. In 1980, of the low-ability youngsters that were able to go to college right after high school 13.6 percent were from low socioeconomic groups and 31.1 percent were from high socioeconomic groups. Similarly, of those with medium ability, 31.2 percent of the low- and 67.7 percent of the high socioeconomic groups were able to go to college (American Council on Education, 1983). 
Schools have differing student mobility and teacher turnover rates. Retention of students can be considered as a measurement of stability and quality of education that may indicate changes in social environment, attitudes of teachers and student towards each other, and learning rates and motivation of the learner. Whatever the individual cases may be, students who drop out of school seem to have some reasons in common. In 1978, of all dropouts from two-year colleges, 37 percent of the white, 47 percent of the hispanic and 54 percent of the black dropouts cited "general" acadenic reasons for doing so. Withdrawal for nonacademic reasons were cited by 32 percent of white, 34 percent of hispanic and 47 peicent of black dropouts, (McAdoo, 1981, p.272). Dropout rates to the age of 18-19 increased for both black and white, and after the age of 20-21 through 34, the dropout rate for whites ranges from 14.6 percent to 13 percent and for blacks 23.3 percent to 21.2 percent, (NCES, 1983-84).

Some big cities such as New York had very high dropout rates--as high as 45 percent (LeRoy, 1983, p.122). In other words, it is highly likely that only one in three youths from poor families in large central cities will complete high school, which may ultimately have a negative impact on the family they raise.

The probability of any youngster reaching a higher level of education decreases for several reasons as he/she 
goes through the hierarchy of the education system. In 1981, of all youngsters in elementary schools, 75 percent finished high school, and of these graduates, 46 percent entered various degree programs. Half of these, or 23 percent, pursued graduate studies, (NCES, 1982).

Since fewer and fewer lower-class youngsters manage to get into a professional field, and because more and more remain at a lower level, both dropouts and some graduates do not have the necessary basic training enabling them to advance into higher training or be prepared for skilled positions (McAdoo, 1981). The unemployment rate for youngsters who finish high school was 14.9 percent of whites and 51.4 percent of blacks (NCES, 1982, p.183). Yet, an increasing number of youngsters without basic skills necessary for the labor market are leaving schools. In other words, a vicious circle of a lower-class life cycle is passed on and sustained through generations by those who are frequently members of ethnic minorities. Some ethnic groups have been quite upwardly mobile. Breaking the negative cycle requires individual motivation, basic education and training programs, and a policy of training the trainers.

Whenever the economic situation (including the job market) is tight, disadvantaged youngsters--frequently minority youths--feel the effect immediately. In 1982, approximately half of all disadvantaged youths in the United States experienced chronic unemployment. In some cities 
unemployment rates for such youths ranged between 40 and 60 percent (LeRoy, 1983, p.120). The economic and psychological cost to young families and the nation is significant and may even worsen as the labor market for unskilled workers shrinks. The national economy is growing, but it is also shifting to emphasize service and information industries which require high skills, (LeRoy, 1983, p.123, Coleman, et al, 1981). This implies that demand for highly skilled labor will increase. In the face of this trend, teenage dropouts in general, and the disadvantaged in particular, may increasingly give up hopes of employment, and enter the "permanent under-class" (McAdoo, 1981, p.268). On the other hand, there are food chains that are hiring more older workers. Illegal aliens do not seem to have difficulty getting jobs. This raises some questions as to whether unemployment figures exclude those who are not actively seeking employment. Some unemployed persons may belong to the underground economy (hidden income) which may pay more than minimum wage, yet they may be considered unemployed. So, one has to keep in mind how unemployment figures are derived.

The breadth and depth of the problems for a disadvantaged youngster in an urban setting has been discussed above. Griffith and London provide a precise definition of the problem: "Urban educational problems are very complex problems associated with students, teachers, 
the environment or community from which they come and the schools they attend" (Griffith and London, 1981, p.435). It is apparent that any solution to these problems requires innovative ways of understanding the problem by educators and other experts who are directly involved in education. Without family and community revitalization, any effort to improve student achievement would be seeking to remedy a symptom instead of curing the problem. When remedies to the symptoms becomes the goal (e.g., more welfare and more welfare dependency, female headed households etc.), then the victims increasingly become under-class economic casualties who inevitably contribute to an increase in the number of educationally disadvantaged. Children may set goals that follow their parents' footsteps, creating a "caste system" of lower status for life (McAdoo, 1981, p.270).

A solution to the problem of educational disadvantage depends on a comprehensive analysis of a learner's environment, home and school. The youngster's social environment influences his/her social characteristics, individual values and abilities. This condition is recognized by many educators and psychologists. Gordon and Griffith succinctly described how these different systems of social environment, interact, and exert their influences on the learner.

The ring relationships which encircle teachers, students and parents within a school and its community, is an essential one that affects 
learning. A break anywhere in this circle results in a breakdown in student performance (Griffith and Iondon, 1981, p.438).

Relationships and conditions that may weaken or strengthen have been discussed above. The influence or impact of these sets of social environment factors may exhibit itself in the attitude, motivation and performance of a learner when innate or inherited biological factors are accounted for. Therefore, the following pages will discuss how learning disabilities are diagnosed, and the rate and level of performance assessed.

\section{Diagnostic and Performance Problems}

A common method of remedial instruction in reading and mathematics is drill and practice. After identifying a youngster's strengths and weaknesses, lessons are prepared and presented in a way to accomodate them. Although the old cliche", "practice makes perfect" has promoted the drill and practice mode of remedial treatment, application of any method should be based on a correct diagnosis of a given student's problem. Then one must identify teaching methods suitable to that student's special needs. Most learning tasks involve the "memory" process; coincidentally, most youngsters with learning difficulties also have memory problems.

The process of memory involves a variety of subordinate issues; for example, attention, remembering, 
perception, and matters of cognition (Gottlieb and Strichart, 1981). These three issues may be elaborated upon:

1. One may have problems of being attention selective or deficient in attention span, which may be improved through reinforcement.

2. Memory involves a bundle of tasks; for example storage and retrieving information.

3. Perception or cognition difficulties involve problems of employing mastered phonetic strategies and organizing activities. The effort to pinpoint problems related to memory processes can be frustrated by the relationship of subtask operations, and conflicting views there of (Gottlieb and Strichart, 1981, p.191).

There are factors, other than memory processes, which contribute to learning disabilities. For example, youngsters with learnin difficulties are known to have differences of perception, orientation and learning mechanisms. Some youngsters may be auditory or visual learners. A learner may also be deficient in learning strategies. One may be good at incidental learning, yet not good at central learning. One may also pay attention to learning tasks either "selectively" or "equally." However, learning disorders may also result from mismatches between learning and attention. This happens when "equal attention" is paid to "incidental learning," and "central learning," or when "selective attention" is paid to "central learning." Motivation, optimum growth and development of the 
individual to his/her greatest potential are influenced by the type of security and stimulation the social environment provides (Gottlieb and Strichart, 1981). Similarly, basic needs such as food can also affect development of normal mental functioning. Experiments show that malnutrition has adverse effects on intelligence and can also impair learning ability and basic acadenic skills.

Research also shows that even deletion of meals affects the behavior and scholastic achievement of youngsters. In fact, there is a relative proportionality between elementary students who do not eat breakfast ( 25 percent) and those that have learning disabilities (25 percent) (Gottlieb and Strichart, 1981, p.14). In other words, nutrition is not only a source of energy to the physique, but also nourishment to the psychological and biological functions of the learner.

A mismatch between instructional and learning strategies may also misguide the researcher in the interpretation of learning outcomes. The right hemisphere of the brain, is dominent in some youngsters and the left in others. Thus there are two types of learners in terms of their learning strategies and subject interest differentials.

Based on a review of the literature on individualized instructions, it shows that there is no single method of instruction signifying the need of all groups of learners. 
As some studies pointed out, there was a difference in achievement related to lesson format and presentation (Jetter, 1982). When a lesson is presented in a challenging and demanding format, learners from highsocioeconomic-status families tend to achieve better than those from low-socioeconomic-status families. Contrarily, when lessons are presented in a drilling format with multiple choices, cues and questions, low achievers from low-socioeconomic-status families show higher gains. It is also pointed out that workbook-based student-teacher interaction benefit low achievers, whereas oral instructions, such as lectures and discussions, favor students from high socioeconomic backgrounds (Jetter, 1982, p. 19).

There are various theories that attempt to explain the causes of the difficulty disadvantaged youngsters have in learning and achievement performance. One of these theories relies on socioeconomic factors and is known as the theory of deprivation. As the following diagram shows, there is a vicious circle of economic and educational disadvantages. Two of the most important factors in social-class differences are level of education and income. 


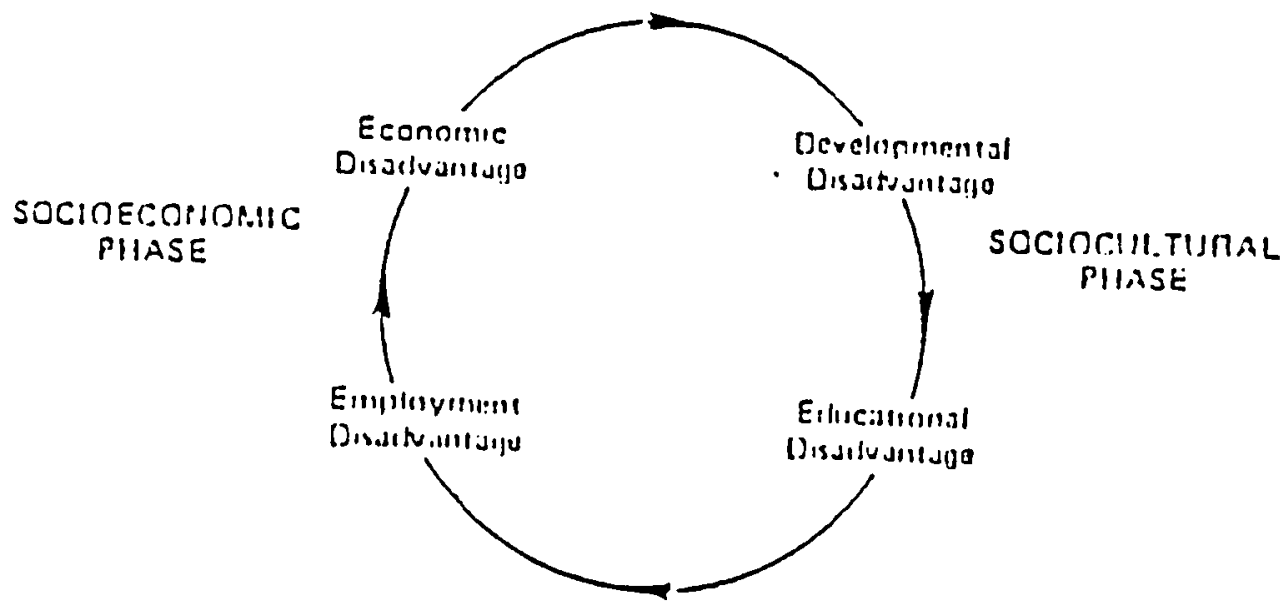

Figure 1. Life cycle of the disadvantaged.

An inquiry into the solutions to socioeconomic inequalities is beyond the scope of educational policy. In some societies, where inequality is the rule rather than the exception, there appears to be a universal axiom. For every person born with a silver spoon in his mouth, there are thousands who may never see one. This is not due to divine pronouncement but a result of misplaced opportunities.

The lower learning ability often found among disadvantaged youngsters may also be related to nutritional balance, which relates, in turn, to socioeconomic background. As noted earlier, nutritional balance of meals in general, and having breakfast in particular, are related to daily activities: attention, attitude, scholastic achievement, concentration and sociability. A youngsters normal mental function will be impaired if he/she has suffered from malnutrition at an early age, as well as if 
he/she is subjected to a deprived psychological environment (Gottlieb and Strichart, 1981, p.15). Conditions of the social environment and degree of security also influence a learner's stimulation. These factors should be included in any diagnosis of basic skill treatments. Just as a good gardener does not water his plants and then ignore the importance of temperature, light and other nourishments, the researcher must consider all the variables. If adequate resources are not available to a learner, then analysis of the problen will be limited, and treatment outcome may be minimal and diffiult to sustain. Even when resources are not a problem, there are other problems which have to be faced. Research efforts and public policies have focused on issues, alternatives and solutions.

First of all, solutions to a child's learning difficulties can best be explored by the theory of deprivation that allows a complete analysis of economic, social, biological, and political factors. Desegregation of schools was a step taken toward integrating society and creating opportunities for the learner to improve his/her achievements through better education and greater interaction with groups of various abilities (Coleman, 1966). Court Cases such as Brown vs. the Board of Education, made it clear that segregation negatively affects the equity of education.

Second, various methods of instruction and 
instructional environments have been advocated as a solution for learning problems of the educationally disadvantaged. As discussed above, there have been research efforts to analyze the problems and synthesize solutions to improve student achievement. A search for a solution has led some educationists, psychologists and other experts of various disciplines to find theoretical and practical reasons behind low achievement. Educational technology appears to be a result of these efforts which is conceived to change instruction and learning.

Third, there are educators who perceive the problem from a social structure and systems analysis point of view. These educators focus on philosophy, practice and administration of public schools. In the search for a solution, these educators embarked on the idea of changing public policy. They call for a broader revision of public school policies and practices. They also call for changes in educational philosophies and practices in classsroom instruction, teacher training, and school-community relations. Some place the burden of change on the school, echoing James Coleman's words: "It is one of the functions of the schools to make academic achievement independent of the social background of the pupils" (Filling, 1980 p. 260). However, it is questionable whether an adequate school experience, by itself, could help a youngster overcome his/her problems, most of which are rooted in the social 
environment.

As discussed above, of those who are concerned about the problem, some explore its cause and others proceed further and propose solutions. There are two propositions, one of which addresses the basic interest of this study. Some concerned educators argue that private schools are much better for low achievers than public schools because of teacher quality, discipline, level of motivation, and differences in school environment (Coleman et al., 1982). These educators propose a policy of education "tax-credits," or "voucher systems," to enable minorities and low achievers to attend private schools.

The second proposed solution and the one of interest to this research is the application of advanced instructional technology--computer based learning. The computer, earlier limited to government, business and universities, is now appearing even at the kindergarten level in some areas. Advocates of the computer and other educational technology claim several advantages in the use of instructional computers for basic skills (reading, mathematics and language arts), especially for the educationally disadvantaged. Claims regarding pacing, individualization, qualitative and effective instruction, low cost, etc., are made for computer based instruction. Therefore, it is the basic interest of this research to examine this new method's impact on schools, resources and 
learning achievement of youngsters.

ADVANCED TECHNOLOGY IN EDUCATION

The application of computers in the education system is becoming increasingly popular. The grade levels and subject areas affected by application are also expanding with time. This study will first examine what led to the increasing influence of computers in the educational community. Second, it will examine the instructional and learning theories upon which $\mathrm{CBI}$ is based. Third, it will examine available empirical findings regarding mathematics and reading in elementary and secondary schools which encourage use of computers for disadvantaged youngsters. And fourth, it will assess the impact of computer based learning on the achievement of disadvantaged youngsters in the Portland Public Schools.

Increasing interest in computers among educators of private and public schools is born out of necessity and availability. From an historical perspective, application of instructional technology in education is not new. It has always been in use in one form or another. Technology, in this research, is defined as the unity of matter and mind that produces a better way or technique of doing things. Such a unity is exemplified in computer courseware and hardware, which also demonstrates the evolution instructional technology has experienced to date. 
The historical roots of computers can be traced to the first artificial intelligence introduced into the classroom: the "difference engine" of 1849. Almost one hundred years later, International Business Machines (IBM) introduced the first computer-type calculator, called Mark I, in 1947. In 1954 IBM succeeded in introducing its first large-quantity commercial compu $r$, the IBM-65D. These computers were very expensive and their use was limited to research and development, training in big business, in the military and institutions of higher education.

In less than five years, between 1960 and 1964, there were nearly 34,000 computers--16,000 in commercial and 18,000 in scientific use-with a total value of nearly $\$ 265.7$ billion (Sharpe, 1969). As the technology of computers improved, passing through various "generations" that utilized such innovations as vacuum tubes, transistors, integrated circuits, and large-scale integration, demand for computers and diversity of their application grew quickly. Reduction in size and cost, plus increased memory capacity and broader range of flexibilty, has made computers very attractive to a broad range of users.

A contrast between thirty years ago and now shows how accessible computers have become to educators and others. Thirty years ago one of the first commercial computers, the IBM-65D, occupied 1500 square feet of space, weighed thirty tons, had 18,000 vacuum tubes worth over one million 
dollars, and processed information in about three milliseconds (3/1000 of a second). Today a product smaller than one-nineteenth of an inch thick and one-fourth of an inch square, with a cost of less than one thousand dollars, can process information in a pico-second lone trillionth of a second) (Bylinsky, 1981). Such improvement in computer technology has made it possible to extend applications of computers into the educational service of elementary and secondary schools in administration, management and instruction. This application has made computers the latest advanced instructional technology in education.

Introduction of computers into the education sector of the economy was heralded as a major breakthrough. Some were concerned about its effectiveness and about the skills and training necessary for computer operation. These matters will be discussed later. However, there are some who praise the computer and call for its support. Stolurow, of Harvard University, compared computers to the past innovations of Gutenberg, the Wright Brothers and Ford's first Model-T car, citing its future potentials and long-term positive consequences. By implying a lag in fruition, he also points out the unfairness of assessing the viability of the new technology by using such criteria as cost effectiveness. Addressing both immediate and long-term benefits, he advocates public subsidies (Stolurow, 1968).

Some educators have argued that individualized 
instruction marks an inevitable transition away from mass education technology such as radio, or group learning technology such as television and other audio and video systems, toward a technology of individualized instruction--computers.

A growing trend in individualized instruction, growth of information to be acquired, and shortage of qualified teachers were primary reasons for such a movement (Hickey, 1968). The expected benefits to teachers, students and administrators were also presented as another plus for computers.

Although the new technology has been around for decades now, its diversity and rate of application has touched upon all spectra of life and has inevitably engulfed school and classrooms across the country. It has also come at a time when a growing number of educators have become disciples of the philosophy of "individualized instruction." Efforts made in this direction have brought computers in to supplement some teachers and teacher aides, leading to a lower student-instructor ratio, advancing toward the philosophy's ideal of one-to-one instruction.

The goal of a one-to-one teacher-student ratio is idealistic. To hire as many teachers and aides as there are students to be served is beyond the realm of financial possibility. Contrary to the one-to-one ideal, public school educators now find themselves in a state of shrinking 
resources and increasing criticisms corresponding to the current economic and political climate.

It is clear that the new technology feeds upon itself, producing new computing machines, calculators and computers, and robots and machines with "artificial intelligence." It is fueling its own growth by penetrating almost all areas of human activity. It is true that "the new industrial revolution has begun" (Bylinsky, 1981). The function, capacity, capability and cost of computers have changed radically in a short period of time. It has become attractive to individuals and institutions of both the private and public sectors. Educators have not been indifferent to the opportunity to get on the bandwagon as the computer market has expanded into their profession. Technologists have been working with educators and have thereby opened new doors. There is a new market for computer corporations and technologists (hardware and courseware developers) and for new methods of instruction for educators, all of which has provided opportunity for individualization of instedion, programming instruction, and classroom management. Thus, the instructional application of computers computer based instruction (CBI), has been adapted to various subjects, grade levels, and special need groups.

The earliest users of CBI were members of the computer industry in the late 1950s, employing computers for the 
purpose of training their own personnel. As federal funding for education increased during the 1960s, it stimulated the application of computers in education (Atkinson and Wilson, $1969)$.

Coincidertally, as educators were looking into
programmed instruction as a means of individualizing instruction, $C B I$ became a natural combination of emerging computer technology and programmed instruction. Following IBM's lead in the 1960s, CBI attracted corporations such as Digital Equipment, Control Data and Hewlett-Packard. The availability of funds from the federal government and the National Institute of Education (NIE) attracted the combined corporate interest and the technical expertise of individuals in projects such as the stanford project of CBI. The Institute of Mathematical studies in the Social Sciences at Stanford University first began the Stanford CBI project in 1963 with a tutorial based on applications in mathematics and language arts. In the second phase of the project, programs in mathematics and reading were developed for culturally disadvantaged youngsters, and served over 400 students daily during its initial period of operation. The third phase of this project developed and demonstrated the utility of the drill and practice mode of instruction in math, reading and spelling. This phase also tested for the first time the practice of remote CBI by instructing students at remote locations. 
The use of computer based instruction became increasingly common. In 1967, there came another CBI system of Individual Communication (INDICOMM), that was claimed to be the first public school CBI in the Midwest. The University of Illinois initiated a computer based teaching system in 1960, which was later known as PLATO (Programmed Logic for Automatic Teaching Operation). Similarly, the University of Pittsburg, active in CBI in the 1960s, also produced a system known as "Project solo" and a facility known as "Soloworks Lab Project." This project focused on skill development and proficiency in problem solving--for example, programming, modeling and simulation--and applying mathematical concepts in various areas.

In 1970, the Massachusetts Institute of Technology, under the direction of seymore Pappert, developed the "TURTLE" CBI project, characterized by a philosophy which stressed "creative function as opposed to the role aspect of subject matters." Turtle was centered on a belief that there is a need to provide learning environments that allow students to experience and deal with models of mental functions in mathematical and mechanical perspectives. Pappert's system also took the initiative in showing the weakness of the traditional curriculum in the areas of delaying techniques and the logic of problem solving, predisposing the learner to excessive dependence (Pappert, $1980)$. 
As various projects were started, a need for common direction and curriculum increased. The stanford CBI project again took the lead in developing courseware for educational computers. As the project expanded, the curriculum for $\mathrm{CBI}$ drill and practice became attractive to corporations who wished to enter the hardware and courseware business. The Computer Curriculum Cc oration (CCC), set up in 1967, was one of the earliest corporations to develop curriculum currently being used on a nationwide basis in mathematics, reading and language arts in elementary and secondary schools incorporating instructional assistance programs, such as in Title I.

Hardware and software development has also facilitated the use of computers in basic skills training and beyond. Programs are available for math, reading, language arts and other subjects. These programs are now available in various modes, for example, problem solving, simulation and gaming, tutorial, inquiry, and drill and practice. Thus, schools have become a new market for computers.

There is a fair amount of competition among the hardware and courseware producers. Increase in the number of manufacturers, producers and publishers has led to an increase in the number of vendors. In 1982 computers costing less than $\$ 10,000$ had invaded homes, schools, small businesses, offices and scientific research centers, as shown in Table IV. 
TABLE IV

VALUE OF COMPUTERS SOLD

Customers

Homes

Schools

Small Businesses

Offices

Scientific Research Centers

\begin{tabular}{cc}
1980 & $\begin{array}{c}1985 \text { (projected) } \\
\text { Dollars in Milizions }\end{array}$ \\
\hline 20.0 & 475.0 \\
35.0 & 145.0 \\
590.0 & $2,700.0$ \\
90.0 & $1,450.0$ \\
220.0 & $1,020.0$
\end{tabular}

These computers' total worth was over one billion dollars, and this figure is projected to increase by nearly 449 percent in 1985, which would lead to a total sales of six billion dollars at 1982 prices (MDR, 1982).

According to the Market Data Retrieval Co. (MDR), in 1982 there were more than 49,000 computers in the nation's school districts: 16,000 schools had microcomputers, while another 33,000 schools were in districts that either had computers or intended to buy them. Market Data Retrieval made a nationwide survey of schools by level in 1982, the results of which are'given in the following table. In Oregon alone 14.6 percent of the school districts and 31 percent of the public schools have computers. 
TABLE V

$$
\begin{gathered}
\text { PERCENTAGE INCREASE OF } \\
\text { SCHOOLS USING MICRO-COMPUTERS } \\
\text { BY ENROLLMENT SIZE AND LEVEL 1981-82 }
\end{gathered}
$$

School Levels

Elenentary

Junior High

Senior High
Percentage Increase By School Size*

$\begin{array}{llllll}1 & 2 & 3 & 4 & 5 & \text { Average }\end{array}$

$$
\begin{array}{rr}
7.9 & 12 \\
12.9 & 19 \\
23.9 & 31
\end{array}
$$$$
19 .
$$$$
13.0 \quad 13.0 \quad 12.4
$$$$
11.8
$$

* Size code: $1=$ under 200

$2=200-299$

$3=300-499$

$4=500-999$

$5=1000+$

Schools with a significant poverty-level population are also part of the computer market. Due to insufficient tax revenues these schools receive federal funds under Title I to enable them to accomodate the needs of disadvantaged students. Those schools whose incomes were below the poverty line (BPL) by 5 percent, 11 percent, and 25 percent were using computers. The proportion of users in each of these groups were 30 percent, 21 percent and 12 percent, respectively. (See Table VI.) 
TABLE VI

DISTRIBUTION OF MICROCOMPUTERS

IN LOW INCOME SCHCOLS

Poverty level, as measured by $\%$ of Students

\begin{tabular}{ccc}
\multicolumn{3}{c}{ Number of Schools. } \\
Total & With computers & \& \\
\hline 12,112 & 3,613 & 29.8 \\
26,220 & 5,605 & 21.4 \\
28,377 & 4,764 & 16.8 \\
14,072 & 1,685 & 12.0
\end{tabular}

This reflects how computer use is directly tied to a school's finances, since most well-off schools had more computers compared to those less wealthy. Yet it is obvious computers have penetrated almost all schools having high or low income, public or private, and institutions with higher or lower levels of education. In two years time, 1980-82, the number of computers in public schools tripled. Similarly, the proportion of high schools that had microcomputers jumped from 42 percent in 1981 to 60 percent in 1982. The number of school districts and schools having microcomputers also increased by 43.5 percent and 61.2 percent.

The Digest for Educational Statistics (NCES, 1983) presents additional information acout the type of computer systems in use at various school levels in the 1981-1982 school year. There were three types of computer systems in the nation's elementary and secondary schools. These 
systems were computers, microcomputers and mainframes. of all schools that had "computing" education, that is, programming, management, instruction, computer science and literacy, 35 percent had "computers" (minicomputers) for instructional purposes. Twenty-two percent of these were elementary schools, 52 percent junior high, and 74 percent senior high schools. Thirty-four percent of all schools had the second class of computer, "microcomputers." The breakdown of this group of schools was 22 percent elementary, 52 percent junior high, and 67 percent senior high schools. The third type of computing machine, called the "mainframe," was in use in 7 percent of all schools. The breakdown by level was two percent elementary, 9 percent junior high, and 26 percent senior high schools. Of the microcomputers used in elementary and junior high schools, 14 percent were used in compensatory education and 19 percent in basic skills (NCES, 1983). Instructional use of computing machines in elementary and secondary education between 1981-82 and 1982-83 jumped by 40 percent.

This phenomenal surge of interest in computing education has prompted an alliance of individual engineers and social scientists to form private companies that have joined the education market. In addition to dealing with traditional subject matter, computers have created new subjects altogether, such as computer programming and computer science. The increased popularity of computers led 
11 percent of the elementary schools and 42 percent of the school districts of the nation to introduce CBI. The corresponding figure in the state of Oregon was 30.8 percent and 46 percent (MDR, 1982).

The Portland Public School District is the leader in the state of oregon in the application of computers. The major application of computers in the District's schools is for disadvantaged youngsters from fourth through twelfth graajes, mainly in the basic skills of language arts, reading and mathematics. As a result, computers in classrooms are becoming common. There are over 100 student stations connected to large mainframe computers and over 170 stand-alone microcomputers. The total number of computers of various sizes and brands was over 280 located in 21 elementary and middle schools and 11 high schools.

The introduction and expansion of instructional technology, particularly computer based instruction (CBI), is not without empirical or theoretical grounds. Those who decide whether or not to purchase computers for schools are conscious of accountability. Research findings about which hardware and software are easy to operate and effective are highly sought for justification of action. The dilemma education decision makers face arises from difficulties in identifying quality systems and gathering reliable information about their performance. The following chapter examines the theoretical foundations for introductional 
technology and empirical findings of various research efforts on performance. 
CHAPTER III

THE THEORETICAL AND EMPIRICAL BACKGROUND

THEORY OF LEARNING

The application of computers to education is based on traditional learning and instructional theories. Most of these theories are generally drawn from the fields of education and social psychology. However, specialized areas of psychology, such as experimental psychology, psychoanalysis, psychodynamics, cognitive psychology and stimulus response psychology have also made contributions. Following is a discussion of the contributions of these theories as examined from the point of view of learning and instruction.

There is no comprehensive definition of direct and indirect learning that fully captures learning and related activities (Hilgard and Bower, 1966, p.2). However, given the definition provided by Hilgard and Bower, this study defines "learning" as the process of synthesizing and imprinting structures and conceptions that originate in factors that are internal and external to the organism called a learner. This effect is manifested in events of relevant incidence that call upon the behavioral and physical being to perform a task. As this definition 
implies, the theory of human development and motivation will also be included where it is relevant to the theory of learning and instruction.

The literature on the theory of learning and instruction, as presented by Hilgard and Bower, was reviewed for this research. Among the theories of learning, two contending schools of thought, cognitive and stimulus-response, are characterized by several differences in their views of the process of learning. Both agree on the logic of experimentation and accept demonstrated relationships and facts. However, their strong differences lie in their interpretation of facts and the inferences based on their observations.

Some of the major differences between the two theories of learning that need to be examined are the issues of thinking, learning, and problem solving. The cognitive theorists claim that "thinking" is a central brain process -- "central intermediaries." The stimulus-response theorists believe that "thinking" is a movement-produced response -- "peripheral intermediaries." Regarding the question of learning, the cognitive theorists believe it is the acquisition of cognitive structures, while the stimulus-response theorists believe learning is the acquisition of habits. Regarding the issues of how a learner arrives at solutions, cognitive theorists claim that it is the method of presentation that permits "perceptual 
structuring" leading to "insight" and problem restructuring. On the other hand, the stimulus response theorists claim that problem solving and learning are arrived at by prior experience and that trial and error is used where this is not applicable.

There are also difference among members of the same schools of thought. Hilgard and Bower identified four areas of disagreement:

1. Whether learning takes place by reinforcement (Guthrie), or by association and contiguity (Tolman), or by both contiguity and

." rêiñorcemènt (Thorndike and skinner)

2. Whether the process of learning takes place step-wise (Hull), or leap- or jump-wise (Guthrie). (This issue seems to divide stimulus-response theorists only)

3. Whether learning is a unified "single factor theory," or a many-faceted "multi-factor theory"

4. Whether intermediaries need to have properties of "intervening variables," or if they can only be demonstrated and explained -"hypothetical constructs"

Hilgard and Bower also raise six issues of importance to both learning and instruction. A comparison of the views of theorists and schools of thought in the discussion is concisely presented in the following tables. The six issues are used as criteria to compare the theoretician's views and thoughts of functionalists and Gestal psychologists:

1. capacity--the limits of learning

2. practice--the role of practice, exercise and 
repetition in learning

3. motivation--the importance of derived

incentives and reinforcements in learning

4. understanding--the role of understanding and insight

5. transfer--the application of learning one thing to the learning of another

6. forgetting--the process of remembering and forgetting

The theories and schools of thought can be divided into four groups (Ibid p.297):

1. stimulus-response and other behavioral theories (that of Pavlov, Guthrie, Skinner and Hull)

2. cognitive theory and Gestalt theory

3. psychodynamic theory, mainly that of Freud

4. dynamic psychology--functionalism as advocated by Woodworth, Robinson and others, such as Thorndike and Dewey, who are considered

"antedate behaviorists."

The theories relevant to the problem of educationally disadvantaged youngsters are those dealing with drill and practice, experience and insight. If prior experience is important to problem solving, as is claimed by Trace psychologists such as Kaffka, then a disadvantaged child who is subjected to an "experience deficient" environment is obviously unequipped with an important tool of learning and problem solving. Although Gestalt psychologists, such as Wheeler, claim that the role of experience is not as 
important as "insight," they do not deny that thinking process and mental ability of analysis have their roots in past experiences. Associative psychologists add the role and significance of memory to the two issues above. The basic theory of learning is summarized on six criteria as given in Table XVIII-XXIII. The summary tables are derived from Hilgard and Bower's discussions (Hjlgard a Bower, 1966 pp. 44-350).

\section{THE THEORY OF INSTRUCTIONAL TECHNOLOGY}

Owing to the lack of a solid base in a theory of instructional technology, educators and technologists have been influenced by disciplines, most of them grounded in the theory of learning. Most of the work done in this area has been instigated by Skinner and Gagne.

The Theory of Instructional Technology is still in its infancy. It is clear, however, that this process introduces a new element, technology, into the theory of learning and instruction. Academicians and theorists from disciplines other than psychology and education bave collaborated on the development of a meaningful theory. In order to account for the effect of the environment onfeedback, reinforcement, and control, it has been argued that systems theory and the cybernetic approach are compatable with instructional technology. The cybernetic model of learning is especially advocated as being consistent with stimulus-response 
principles and individualized instruction.

other disciplines can also contribute to concepts and theories of instructional technology. To demonstrate the learning and irstructional potential of communication media,

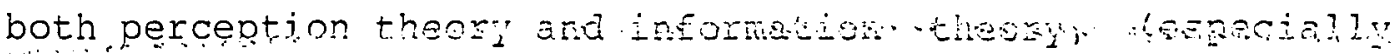
visual/pictoral communication, have been considered compatible with stimulus-response principles of learning.

Along with the building of a theory of instructional technology, the taxonomy of computers as an advanced instructional technology and as classification of their application have also been developing. From a pedagogical point of view, Patrick suppes points out that the ideal mode of application of CBI is drill and practice, tutoral, and dialogue. Rogers takes suppes's classification further and adas two more applications, the simulation of environment and decisions.

Instruction in the basic skills of reading, arithmetic and other school subjects by mechanical means was first proposed by skinner in 1954, although, like most psychology theories, it is based on laboratory experiments on animals. Skinner anticipated that his inventions would increase the efficiency of teaching over traditional methods. He also declared that "operant conditioning" was the principle behind his invention (Hilgard and Bower, 1966, pp.131-132).

The difficulty of applying psychological research methods to the real world of training has been with military 
institutions for a long time. However, expanding that experience into the educational system posed two major problems. First, most technology based military training is designed to achieve uniform-objectives, usually involving weapons and targeting, by a single group. This approach is not compatible with the objectives of education, which are targeted for broader objectives and where subject matter is basic and abstract.

Second, some of the psychological research findings that served as bases for training were either theoretical inferences or conclusions based on laboratory animals. Hilgard and Bower made this explicit when they said, "It has been found enormously difficult to apply laboratory-derived principles of learning to the improvement of efficiency in tasks with clear and relatively simple objectives" (Hilgard and Bower, 1966, p.542). Similarly, it has also been recognized that widely used principles of learning, such as response practicing and reinforcement, are also inadequate in designing effective training (Gagne, 1967).

In the past two decades effort by various researchers and technologists has resulted in a successful instruction by applying the classical theory of learning to advanced instructional technology. The strategy of identifying relationships between level of ability, practice, and rate of performance in basic skill learning, as well as the practice of breaking down learning tasks into hierarchal and 
distinctive sequence of units, helped to improve its application. The effort to make learning easier and more successful was a challenge to some educators. On the basis of research and experience, educators have identified that successful learning is a function of both the learner's ability (aptitude, intelligence and perserverence), and the instructional process that provides a learning opportunity. Through research findings, along with Pressey's self-scoring machine (1926-27), skinner pursued the idea of using machines as teaching aides, and the possibility of introducing teaching machines and programmed learning became a common educational issue. In 1958 Skinner kept this issue alive by equating and comparing a tutor with programmed instructions in terms of pacing, gradual and incremental progress, response practicing, cueing, and sequencing lessons.

The case for teaching machines was also made based on their ability to accomodate individual differences in rates of learning, and also on their flexibility, that is, in allowing the learner to go backward or forward on a given task. This was obviously attractive to innovators and educators. Schramm's review of over one hundred papers pointed out that students learn from programmed instruction if these programs have features such as the following (Hilgard and Bower 1966, p.558):

1. An ordered sequence of frames with gradual, step-by-step progress. 
2. Learner-constructed responses with reinforcement and immediate feedback.

3. A self-pacing lesson for heterogeneous groups.

The application of learning theories and principles discussed above have gradually been incorporated into instructional technology. Computer based instruction has drawn its principles and concepts from both stimuli-response and cognitive theory, using both as a foundation for its instructional applications. The stimulus-response theory has contributed to the following concepts:

1. Active learner ("learning by doing") approach.

2. Syncronized frequency, repetition and duration as retention.

3. Using positive rather than negative reinforcement.

4. Application of generalization and discrimination.

5. Enhancing novelty through cueing.

6. The importance of drive for motivation and conditioning.

The cognitive theory has also contributed to the design and operation of programs for instructional technology. The following are viewed as important conditions of learning.

1. Improving the way a problem is displayed (a perceptual feature).

2. Organizing problems from simple to complex 
tasks.

3. Utilizing a learning process involving understanding and feedback.

4. Setting goals based on success or failure with solving a problem at hand, and inducing the motivation to discover solutions to problems by developing "divergent" thinking to arrive at logical and correct answers.

Instructional technology has also drawn some of its principles from motivation and personality theory. Such as:

1. Diagnosing and recognizing a learner's abilities and accommodating slow, rapid and specialized abilities (capacity).

2. Understanding the influences that have shaped the learner's development, such as the diagnosis of "postnatal developments".

3. Understanding the learner's cultural background and how the learning process is assimilated.

4. Recognizing the anxiety level of the learner.

5. Recognizing the differences among learners according to their motives, as some are motivated by affiliation and others by achievement.

6. Recognizing that learning products and satisfaction are affected by "organization of motives" (the relationship between long- and short-range goals), and "group atmosphere" exhibited in participation and affiliation.

The principles applied to instructional technology come mainly from Guthrie, Skinner, Hull, and Gestalt psychology. Lack of experimentally tested principles, on the one hand, and pressure from advocates, on the other, had their effect on developing and introducing instructional 
technology into the school system. Nevertheless, the application of some of the theorists' contributions to advanced technology is discussed by Hilgard and Bower (1966, p.565). Some significant contributions and applications are as follows:

1. The concept of cueing of responses is from Guthrie's "Contiguous Conditioning," which is combined with a modified version of stimulus-response.

2. The concepts of learning by small steps, timed reinforcement, reward and self-pacing are derived from Skinner's Operant conditioning.

3. The idea of cue-response, sequencing, reward, and drive-reinforcement are from the theories advocated by Miller, Dollard, Hull (Ibid p. 569).

4. Hierarchical learning techniques, ranging from simple to complex exercises, and the mastery of these learning tasks from lower to higher levels of difficulty, are attributes of Gagne's hierarchical model. This model, based on the principle of mastery of learning, is also based on hierarchical "chaining" of various types of learning, such as signal, stimulus-response, association, discrimination, and problem solving.

A combination of the theories of instruction, learning, and technology is considered to form a link between research and development in basic science and technology. This has opened new directions in education by creating a theoretical and empirical foundation for instructional technology.

The process of combining the two areas of research into one as a pedagogic innovation is presented in the 
appendix, which is a modified version of one used by Hilgard. As shown in the chart, a general point of school interest is identified first. After examining the relevant studies, a scientific inquiry about animals is carried out. Then, by focusing on similarities observed between human and animal behavior, their relevance to human mastery of certain learning tasks is determined.

In a technology-based experimental approach, a laboratory is set up, and resources are allocated. The experiment is then carried out in classes. Positive findings and their conclusions, are put together for manual and textbook developments. The product of this process creates advocates for the adoption and expansion of the new experimental method. This process shows that development and application of educational innovations, such as computer based instruction, are based on scientific procedures.

\section{EMPIRICAL BACKGROUND}

\section{$\underline{\text { Relevant Issues }}$}

The three leading authorities on the theory and application of instructional technology are Pressey, skinner and Pappert. The latter two have conducted several studies in the area of applying technology (computers) to learning tasks. Skinner (1968), who emphasized the role of the environment in acquiring knowledge and learning, presented three theories to form the basis for an application of 
instructional technology in learning. They were: (1) the theory of frequency (arilling); (2) the theory of recency (experiencing); and (3) the theory of trial and error. Skinner further argued that by arranging appropriate contingencies of reinforcement, a desired form of behavior can be brought about using selected stimuli.

Pappert also advocated instructional technology (i.e. computers) as an effective educational method, an important cultural "germ" or "seed" (Pappert, 1980, p.9). He also claimed that computers help learners master a given task, to be creative and "active builders" of their own intellectual capacity (Ibid, p.19). He further argued that computers reduce alienation between the learner and knowledge (Ibid, p.177).

The views of these two experts on instructional technology, along with others, initiated a national trend toward computer based education. The Portland Public School District (PPSD) is no exception to this trend. Three PPSD internal memos obtained by this researcher demonstrate the magnitude of this trend in the school district. However, those who are excited about the introduction of computer based instruction in the district are not without opposition. An inquiry by Thomas Clint, Deputy Superintendent of the district, concerning the instructional applications of high technology generated heated responses and a variety of opinions. These opinions were documented 
in the Dec. 10, 1981 memo of the principal of Lincoln High School, Collin Karr-Morse, who, in his memo to Thomas Clint (December 10, 1981), said:

In America today the schooling system at many levels has become almost disengaged from the "power" of communication technologies which are having a profound impact on other sectors of society.

Dr. Karr-Morse argues that the fundamental purpose of education is to select and pass on accumulated beneficial knowledge of a given culture and that the process of doing so should reflect the most advanced communication and information processing capabilities available. This proposition did not go unchallenged. Dr. Edward Schneider presented a stern opposition. In a memo of December 29, 1981, he said:

In the haste to become current with the fast pace of growth in computer education, or to be on the cutting edge of new innovations, it appears that some proponents are becoming over zealous in promotion of this instrument (computer), laying claims to possibilities which are at best premature and in some cases probably unattainable.

Dr. Schneider, calling for caution, added,

The decision to expend funds for speculative uses of computers in schools uses up scarce resources and is not supported by research or sound educational theory.

In an address to school board members, Dr. James Fenwick, after examining arguments for and against computer applications in instruction, presented his views. He 
advocated the introduction and expansion of computers in the district in a memo dated December 31, 1981;

I am absolutely convinced that high technology has enormous contributions to make to instructional theory and practice in the 1980 s and 1990 s.

He recommended to the board that significant effort and money be invested to keep pace with developments in computers and other high technology. These memoranda reflect not only the fact that computers are coming into the schools, but also the rising of two significant groups of educators: advocates and opponents of instructional technology.

Despite the fact that increasing research has made more information available, the inconclusive nature of these studies has kept the viability issue alive. However, computer based instruction is advocated as a solution to learning rate and mastery. Such ideas have become popular, and the issue seems to be tilting in favor of the proponents. Problems such as the concepts of drill and practice, learning rate and mastery have become popular topics closely identified with computers. Most of these concepts, and their identification with computers have been popularized by educators like Block, Carrol, Bloom and Gagne. This condition has added a favorable environment for CBI. Moreover, studies of the computer's effectiveness, such as those of Jamison, Atkinson, and Suppes, began 
shedding additional light on the new technology. Regarding economics, Sharpe and Levin listed additional information, making computers even more attractive and viable.

As a result of a variety of concerns, closer scrutiny of computer-based learning is increasingly important:

1. In the face of limited resources, increased attention is being given to computers as economical tools of instruction, and effective users of resources.

2. There is increasing criticism of traditional teaching methods.

3. There are educators who question the cost-effectiveness of the new technology and its viability as a tool of instruction.

Educators in public schools are facing challenges regarding the quality of instruction. Some studies (Coleman, et al., 1982) have claimed that private schools offer a quality of education which public schools lack. In defense of the integrity and viability of public schools, some educators have felt it necessary to modernize instruction so that they don't fall behind private schools. since criticism on the part of technologists is specifically directed against traditional methods of instruction (TMI), public school officials have begun to pay attention to pro-technologists who point out that learning achievement problems in TMI schools can be remedied with CBI.

Some critics of TMI claim that teachers fail to outline learning tasks, motivate the student, accommodate 
learning capacity differences, diagnose problems, monitor progress, provide feedback or conduct follow-up activities (Block, 1971, p.30). TMI is also alleged to be artificial, inefficient and may possibly alienate the student from knowledge (Pappert, 1980, p.8, p.170). TMI is often criticized for being incapable of absorbing complex responses of the learner, as well as its inability to generate quick and frequent reinforcements needed in learning. Moreover, lack of proper diagnosis, prescription and sequencing of learning tasks is pointed out as another weakness of TMI (Skinner, 1968). Skinner, an advocate of high technology, also points out that more schools and more teachers do not provide a solution to the problem of an increasing demand for education in a growing population.

The views and thoughts espoused by skinner, Pappert, and Block on CBI are commonly expressed in Portland, Oregon, just as they are across the country. Advocates who point out the difficulty of providing quality education are in fact criticizing TMI for creating a "blockage between explosion of information and human potential for learning" (Karr-Morse, Ibid). It is also alleged that TMI is preventing quality education by "diverting resources into a far less productive practice" (Ibid). Hence, such issues deserve a direct assessment for the purpose of future decisions regarding implementation and expansion of CBI.

Demands for an evaluation of computers in education is 
based on the concerns of those who are not convinced of their alleged benefits or future prospects in instruction. However, it should be pointed out that computers have positive instructional impact for some students. Some positive aspects of computer based learning are diagnosing, sequencing, cue reinforcement, stimulating, inducement to recall, and providing immediate feedback (Skinner, 1968; Pappert, 1980; Suppes et al, 1975; Block, 1971). Still, side effects from technological instruction are of concern to educators as well as to those who are "computer-phobic."

A combination of the role of and the ability to acquire computers, may play a part in sustaining an "economic class." If so, this may eventually lead to a "permanent underclass" (Hollmark, 1982). The computer's major role, drill and practice, is aiso a concern, since the learner is conditioned to a method of learning that does not require the ability to integrate knowledge or to generalize concepts and principles. The development of creative thinking may also be damaged (Schneider, memo, 1981). The view that machines (computers) dehumanize the education process is also a concern of some parents and teachers.

\section{The State of the Art of Technology}

A quick review of the state of the art of technology makes it clear that this new mode of instruction, the computer, needs to be thoroughly understood, especially 
since recent developments (NWREL, 1981) show that the computer's role and its areas of application are growing as advances are made in the development of courseware.

Courseware is now available for mathematics; the Add Program, The Sharpe Program for geometry, and the word Problem Program for nonremedial instruction. Courseware also exists for special instruction groups, such as the disadvantaged, learning disabled, physically handicapped, mentally retarded, and hearing and visually impaired. In reading, software is also available that can break lessons into smaller steps, teach word attack skills and phonetics, aninate words, teach reading and vocabulary, teach syllable sounds and spelling, show sentence structure and object drawing, teach linguistics and language constructions, show writing and syntax, and teach English as a second language.

Given proper software, computers can also train soldiers, workers and teachers in specific skills. Software for teachers is also available, with programs such as Mr. Computer for learning programming, the Pilot for CBI courses and the development of models and the Assist for designing, developing and evaluating CBI lessons for handicapped children.

The future of computer technology is of concern to some educators, especially teachers who are concerned it may be used as a displacement tool. Others are concerned that it might influence the future labor market. However, some 
very attractive improvements are taking place in computers. Their cost and the space they require are both decreasing rapidly. On the other hand, its information processing power, speed, and capacity for memory are dramatically increasing. Both hardware and software are increasing in quality and quantity.

If the projections of educators and technologists like Melmed, Bork, Pappert, J. Arter, Edwards, Carpenter and Koehn are feasible, then one should not hesitate to acknowledge the beginnings of a new industrial revolution (Bylinsky, 1981). What is needed is only the imagination to perceive the computer's potential (Dexter, 1984, No. 19 p. 148). Computers are "learning to learn," exhibiting powers of reasoning and judgement, and to condu-t "discursive" dialogue.

By the end of this century more than 65 percent of the labor force will be in the communication and information industry. Schools with classrooms will no longer exist, and "resource centers" and "technological libraries" will have taken over (Pappert, 1980). It is also predicted that in the future many more parents will buy computers for their children (NWREL, 1981). If so, it may be the "haves" and not the "have nots" who will ultimately suffer from further technology-based disadvantages.

The last decade of this century will see not only an era of a new educational system, but also a new culture--a 
computer culture (Pappert, 1980). It will be a culture not of classrooms, walls and teachers, but of classrooms anywhere, anytime; then the marriage of push-button telephones and computers will become a reality. Systems are also in the making whereby the computer will call the student, day or night, and assign homework (NWREL, 1981, p.207). Needless to say, audiovisual aids which supplement instruction may even supplant lectures and demonstrations.

The last reason for the necessity of evaluating computer based education is based on concern by those who question its efficiency and viability as an instructor. There is a great deal of interest among instructors and administrators in acquiring computers (Bozeman and Burns, 1981). However, they need more information on the effectiveness and efficiency of $\mathrm{CBI}$. There are several conflicting claims, as discussed earlier, and questions arise regarding claims and promises made for the technology. There is also a concern as to whether technology can contribute to gains in education in the same way it has increased the efficiency of agriculture and manufacturing (Clark, 1963, p.27).

\section{LITERATURE OF IMPACT STUDIES}

The impact of computer based instruction is not limited solely to its effects on learners. In the following section, literature that deals with various kinds of $\mathrm{CBI}$ impact is 
discussed in the following order: cost, attitude/motivation, achievement, influence of learning time on CBI achievement, and the influence of noninstructional factors. To begin with, information is supplied on the multifaceted impact of instructional technology on education as it was presented in the debates for and against the passage of the proposed Technology Education Act of 1982 (H.R. 5573). The debate is interesting, because it was discussed in detail (Misrocomputer in Education, 1982), and is summarized below. The issues center around the expectation that this legislation would encourage companies to donate computers to schools.

Implications of the Proposed Technology Act BENEFITS CONCERNS

Impact on students and teachers:

Interested teachers who have no equipment will get help to get something started. Opportunity will be provided for many more teachers to become familiar with computers.

Teachers will be provided with more experience on which to base decisions about equipment selection, software applications, and curriculum.

Students will get an early start on computer literacy and skills essential to many careers. All students will be encouraged to consider technical and scientific areas of study and
One machine may not be enough to be useful.

Frustration may result from shortage of machines and lack of quality applications.

Without training and support materials, teachers may not see the contribution of computers to learning and teaching.

Disillusionment results if machines stand unused or are used only for games. It is difficult for teachers to use machines without full support (administrative, technical, inservice training, etc.). 
employment.

Families will receive help

in selecting a computer and

efficiently using it for

home education.

\section{Impact on manufacturers:}

Three or more times as much equipment can be donated for educational purposes by companies.

Increasing the consumer market base will attract investment and publication of new materials.
Is it realistic to expect any more educational equipment than at present?

It is too costly to support only one machine in each school (documentation, training service, etc.), with many of them far removed from stores and service centers.

\section{Impact on publishers}

There will be a broader base for marketing computerrelated aids to education.
Quality software can be prepared quickly enough.

\section{Cost Impact}

There are claims that computers can cut the cost of education and reduce the thirteen year school cycle. It is also hoped that computers will provide the child with new possibilities to harness learning, contribute towards emotional and cognitive growth (Pappert, 1980, p.17). Pappert claims that the cost of a thirteen-year education $(\mathrm{K}-12)$ of a child between $1987-2000$ will be $\$ 130,000$. Given that the cost of a computer has decreased from $\$ 70,000$ in 1968 to $\$ 800$ in 1982, Pappert claims that, using less than 5 percent of this thirteen-year cost, every child can have a computer. The payoff will be in reduced education cost as a 
result of accelerated learning growth and higher learning achievement. There are, however, some shortcomings in this grand ambition for example, it is unclear where the finances will come from in the initial year. Pappert also fails to address the cost of maintenance or replacement within the thirteen year cycle. Therefore, the cost of computers, based on actual expenditures, should be addressed.

The cost of a computer depends on its capability for memory, speed, frequency of use, number of users, and operational and maintenance cost. The NWREL Administrators Handbook divided computers into three catagories: stand-alone, cluster, and time-sharing. By assuming 15 minutes per day of instruction in mathematics and reading, with a drill and practice mode for 100 students, cost per-student-hour for 1000 hours was estimated to be $\$ 1.40$ for stand-alone microcomputers, $\$ 0.36$ for cluster microcomputers, and $\$ 1.47$ for time-share minicomputers, (NWREL, 1981, p.62). The former two figures were computed for math only, and the latter for math, reading and language arts. These figures are equivalent to $\$ 135.00, \$ 27.75$ and $\$ 110.25$ per 15 minutes of instruction for 100 students per year respectively. If the three systems were to perform 15 minutes of instruction in two areas of basic skills, the cost would be $\$ 270, \$ 55.50$ and $\$ 220.50$.

Some of the commonly used units of cost-effectiveness are cost-per-student, or student-hour, and cost-per-standard 
score-gains. Computer cost analyses differ mainly in their method of cost accounting. Common measures include any one or a combination of the following: administrative cost, operational and maintenance cost, cost of plant and equipment, supply cost, and instructional technology's hardware and software costs.

The literature on computer cost analysis in education is very Iimited, unlike that for corporate research and business applications (Sharpe, 1969). David Thomas (Thomas 1979) reviewed several cost studies in the area of CBI. The review included studies by Fricke, Toggenburger and MCDanial. Fricke's study was based on CBI application for ninth-grade involving twenty terminals using the CCC system in the drill-and-practice mode for reading, language arts, and math. The results, in terms of cost-per-student contact hours were $\$ 3.80$ (which was higher than that of Atkinson, 1969), \$0.55 per-day-per-student, or $\$ 97.00$ per-studentper-year for the same material and mode.

In the Toggenburger and McDanial study, Thomas (Ibid) pointed out that remedial programs, including Title I, with a CBI program using a Hewlett-Packard 2000 and CCC software, had similar results. Annual cost-per-student favored CBI $(\$ 146.00)$ over TMI $(\$ 275.00)$. This cost can even be reduced by using the system frequently. Cost-per-hour of operation in the first year (1969-1970) was $\$ 163.16$, and in the following year, as the system was used more often, it went 
down to $\$ 74.98$ per hour. Both authors concluded that maximum use of the system could further cut the cost to $\$ 3.17$ per hour.

Other studies focused on other instructional technology, such as microcomputer applications in higher levels of education or in the training of workers and soldiers. These studies are excluded from this review, because they are considered not relevant to this research. Nevertheless, Gene L. Wilkinson's systems based cost analysis (Wilkinson, 1972) needs to be exainined. This research discusses the type of information needed in order to conduct cost analysis in education. The author discusses further the type of information needed to conduct studies on the productivity and efficiency of instructional technology. However care must be taken when tryiig to understand the essential operational factors, because the kind of information collected about the instructional production or conditions of the learning process will determine its outcome. This is important. because research outcomes can have profound implications for educational policies (Business Week, May, 1971, p. 72; Phi Delta Kappa Feb. 1971 p. 386$)$.

Some educators perceive education as an industry in which the more experienced are less productive and more costly. Education as a system is also believed by some to require "an ever increasing portion of the nation's wealth 
without producing a proportional increase in learning outcomes" (Wilkinson, Ibid, p.33). Such views, and the so-called "Baumol crunch" (which states that no one part of a system can indefinitely increase its consumption of resources at a greater rate than the rate of increase in the return of the total system), encourage evaluation and research on varius methods of instruction.

In light of the arguments presented above, there are three points that need to be made about learning outcomes and achievement as criteria for assessing teacher productivity. First, measuring teacher productivity by assessing the learners' achievement is unsound, since there are several intervening factors and activities, such as planning, curriculum, and other support systems. Further, learning acheivement depends on the student's background, initial ability, interest, attendance, and parental cooperation.

Second, a teacher's task includes activities other than instruction. Hence an attempt to assess a multifaceted activity (instruction) with a single measurement (learner's achievement) is simplistic and misleading. Similarly, the "Baumol crunch" assumes that educational products (ali instructional and noninstructional activities) are monetized like other consumer goods. In fact, to date there is not a single measurement that can monetize the "affective" and "cognitive" changes, and the social values of outcomes of 
educational investments.

The third point concerns the purpose and goals of education. Education is an activity that has abstract and concrete social gains; hence, any attempt to assess its full impact will be only partially captured. However, the resources needed to carry out such an assessment can be justified by the pareto principle. The teaching of disadvantaged youngsters and the obligation to carry out compensatory education is a form of resource redistribution. It should also be pointed out that frustrations associated with an effort to measure the value of instructional productivity may involve conceptual compromise and misleading corlclusions. This may be parts of the explanation for statements which declare education an activity wherein the cost is constantly increasing while productivity is not. Another concern is that misleading conclusions may also arise from the confusion of hypothetical and empirical cases. An example of such cases is implicitly presented in Wilkinson's educational resource analysis regarding educational technology. Wilkinson's cost analysis (Ibid), portrays a hypothetical cost relationship between labor (teachers) and capital (software and hardware). The diagran below portrays a smooth s-curve that shows a direct relationship between percent of budget allocated and capital. It also shows an inversely proportional relationship of budget to labor. 


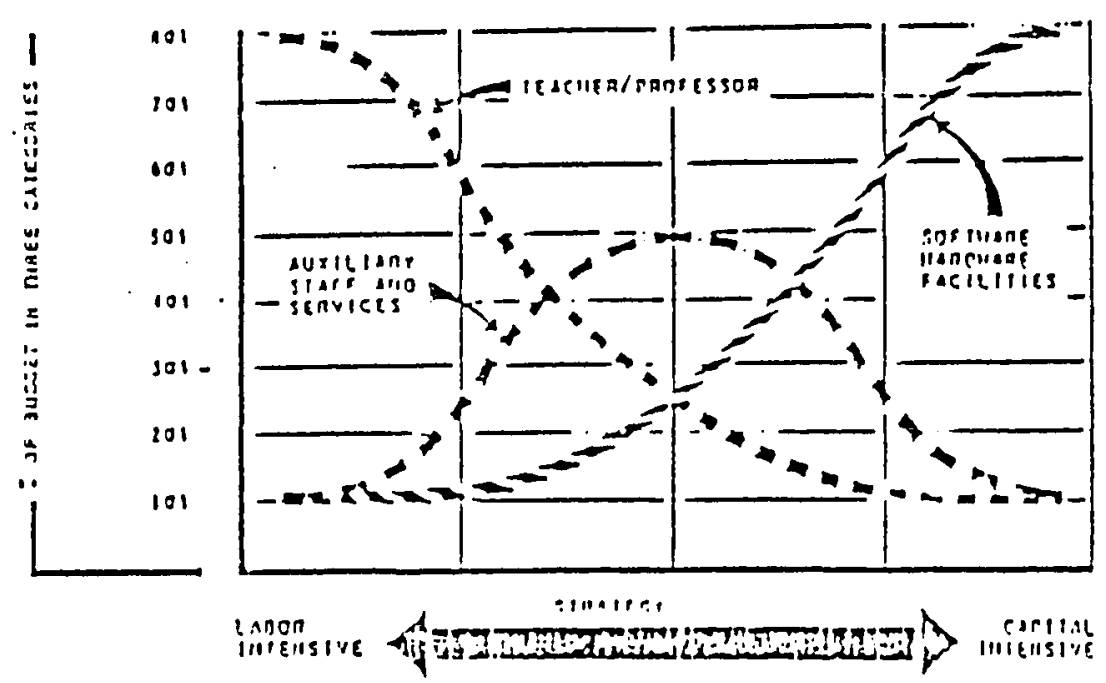

Figure 2. Resource allocation and technology productivity.

Three observations should be made with reference to this diagram. First, by reducing the proportion of the budget allocated to labor, and by increasing that to capital, output per dollar tends to increase. Second, when an equal proportion of the budget is allocated to labor and capital, the corresponding proportion of the budget spent on support "auxiliary" staff and services rises. Third, when nearly 80 percent of the budget is allocated to capital, output per dollar will increase, with labor and service costs falling to a minimum, i.e. 10 percent of the budget. It is not clear to what extent productivity varies in response to a shift in the budget allocation. Even though this approach exemplifies the intrinsic relationship between labor and capital involved in instructional technology, it 
fails to show variations associated with rearrangement of resources.

Another problem in understanding educational activities is the dual nature of its product (consumer good and investment good) and its market (political and economic market). Clark C. Abt's analysis shows that governments operate in a political market, and businesses operate in an economic market. However, both are subject to changes that depend on their consumers. Education, as a business and government activity, of necessity must deal with diverse consumers (students, parents, teachers, administrators, employers and educational technologists) who have various desires and preferences.

According to Abt, to successfully operate educational activities in the political and economic markets, three conditions must be fullfillea:

1. availability and accessibility of economic and political alternatives

2. consumer dessimination of information

3. the degree consumers' exercise control over their choices and some form of participation in decision making.

These conditions are indirectly followed by technologists in CBI. In Texas and Florida, for instance, parents are very informed and involved in the financing and operation of computer classes. Hence, the economic and political markets seem to be working harmoniously in that 
particular case.

Attitude and Motivation

Some educators point out how their students become excited about using computers in the drill- and-practice mode of basic skill instruction. Although this in itself was encouraging to some staff members, the effect of such excitement on the learner's achievement was of concern to other educators, as it may artificially--and therefore only temporarily--boost achievement (Hawthorne Effect), with gains declining as the novelty starts to wear off. Such an effect was actually found to be insignificant (Bozeman and Burns, 1981, p.39). It explained less than one percent of the changes in math achievement in drill and practice. Similarly, in the tutorial mode such effect made an insignificant contribution to achievement (i.e., $\left(R^{2}=.00 i 2\right)$ ( Ibid).

The idea of using computers as teaching tools may be exciting to some, but it is intimidating to others. Seymour Pappert, after discussing the problem of "math-phobia," claimed that computers would act as liberators from such fears. Two teachers at the University of Texas studied low-achieving math students feelings about using computers for learning. They found that those who avoided computers were "afraid of being judged" as to how they approach problems and whether they would be labeled as "trial and error" or "analytic" solvers of problems. After sufficient 
orientation, those who had some fear ("computer phobia") decreased from 22 percent to 12 percent.

A review of some of the attitude related literature, (i.e., attitudes towards $\mathrm{CBI}$ ), was conducted by David $B$. Thomas (1979). Thomas pointed out (citing King's study of 1975 ) that students exposed to CBI have "high" motivation for the subject compared to those who are not exposed. He also discussed Johnson's 1974 finaings regarding CBI tutorial for mathematics, which reported that participating students showed a more positive attitude towards instruction than students exposed to other programmed methods.

Thomas discussed other studies which found a high interest in learning among CBI students as compared to those who were in other programs. In 1973-74 Frederick reported similar findings in London where, among CBI biology students, 75 percent of the girls and 63 percent of the boys showed a positive attitude. Another study discussed by Thomas was one carried out by Bukoski and Korotkin. This study observed students of two different school districts in two different states, and found similar positive attitudes among $C B I$ math students.

Another review of literature on attitude and motivation regarding $\mathrm{CBI}$ was conducted by the Northwest Regional Educational Laboratory (NWREL, 1981, p.40). This review shows that several studies found positive changes, 
while a few did not find any difference between the attitudes of CBI and TMI students. Among the studies reviewed, those of Ragosta, Beck, Maser and Deblassio showed highly positive changes. Thomas found that CBI students had at least the same, and in some cases more positive, attitudes towards learning in general compared to other control groups. Thomas also showed that studies such as the one conducted by Cranford and Harris found no differences in attitude towards mathematics among $C B I$ and non-CBI learners. However, the NWREL review (1981, p.44) pointed out that studies conducted by Mravetz, Casner, Smith and Wess showed positive findings.

It should be pointed out that comparison of changes in attitude and motivation are of two types. In the first type a student is asked, before having actual CBI experience, how he/she feels about using computers or learning skills with CBI. Then he/she is asked again after the experience. Studies conducted in this manner need to be interpreted with care, as they are based on subjective judgements rather than standardized survey tools. The second type of assessment is based on some scale. The responses of TMI and CBI learners to standardized instruments about attitude and motivation are evaluated. The results are either compared with standardized scores or percentages of those who showed positive changes are presented. 
Achievement Impact Review

For the present research a review of literature on computer based instruction in basic skills of mathematics, reading and language arts was conducted both manually and, of course, by computer. Sources used were professional journals, magazines, books, references, dissertation abstracts, international social sciences journals, and other relevant research reports. A computer search using ERIC (Educational Resource Information Center) was also carried out for this research. Other relevant sources were also consulted.

A review of the ERIC literature on effectiveness of CBI shows that most schools find computers very helpful. Rappaport and Savard (NWREL, 1981) reveiwed studies on CAI. The report cited authors and studies and summarized their conlusions. The conclusions of these studies are based on findings in five broad areas of inquiries:

1. Whether CBI, as a supplementary tool to the traditional method of instruction (TMI), can increase student achievement. This was confirmed by more than 71 studies, refuted by three, and shown to be inconclusive by six.

2. Whether CBI can be used as a substitute for TMI, was mildly confirmed by nine studies, and found to be inconclusive by eleven.

3. Whether CBI leads to a "better" attitude towards learning than does TMI. This inquiry considered 60 studies, of which 31 showed findings that "tend" to support the efficiency of CBI, one refuted it and 28 were inconclusive. 
4. Whether CBI has an advantage over TMI in saving learning time or completing more material in the same amount of time. This was mildiy confirmed by twenty-one studies.

5. Whether retaining or sustaining material learned can be improved using CBI, which 11 studies tend to support, two deny, with 21 being inconclusive.

The review of literature on the effectiveness of CBI was as specific as possible. It was geared towaràs basic skills of mathematics and reading, and excluded language arts. The reason for the exclusion of language arts from the research was that some elementary and middle schools who use CBI did not clearly differentiate between reading and language arts. Although overlap of tasks was not a major concern, language arts was not a common subject among the experimental and comparison groups.

The grade levels that were of major interest in the study were elementary and middle school grades, excluding high schools, for two reasons. Most of the CBI programs for disadvantaged youngsters were in operation in the lower grades. The application of computers in high schools was mostly for computer literacy, computer science, computer programming, and some basic skill instruction for disadvantaged youths. Therefore, the literature reviewed was selected on the criteria discussed above, and only those studies relevant to disadvantaged youngsters using computers in basic skills were considered.

One of the relevant reviews of CBI literature was that 
of Edwards (1974). Edwards reported that CBI was found to be equally effective when compared with language labs and individual tutoring (especially as supplementary instruction), and more effective than TMI. On the other hand, when CBI was used alone and then compared to TMI, studies were divided, and it is inconclusive whether or not CBI is more effective. This was more or less confirmed by Thomas (1979).

The studies of Edward and Thomas were summarized in the NWREL report (1981). The following studies were also cited in the ERIC search done for this study. The drill-and-practice mode of CAI as a supplementary instruction tool for reading was found to be effective by Jamison, Litman, Anneli, Evans, Maser, Wilkinson, and Ragosta. In 1974 Jamison found that both boys and girls exposed to tutorial CBI had scores comparable to those exposed to TMI. In 1978 Anelli reported that girls scored higher than boys, and in Litman's 1977 studies showed that CBI boys scored higher than boys using TMI. The 1977 study done by Maser found that CBI was effective; however, he emphasized the importance of "good teaching" as a factor.

Application of the drill-and-practice mode of CBI, as a supplement showed a relatively positive impact on student achievement. Positive and significant gains by CBI users over control groups was reported by wells, Ramero, and Ragosta (NWREL, 1981 ). 
Lysiak, et al (1976) found mixed results on CBI's effectiveness for high school students, whereas students in midale schools showed a math achievement significantly higher than the control groups. Nevertheless, when the mathematics achievement of those who participated in CBI reading and language arts programs were compared with those who had CBI mathematics only, the former performed higher than the latter.

The comparison of achievement levels of various schools using computers may be misleading unless some of the underlying factors are considered. The achievement of students from different schools may depend on the manner under which the CBI programs were implemented, i.e, whether sufficient staff training was given and computer companies' recommendations were followed. The operation of the program, especially extra help and out-of-class access to computers, is not taken into account. Moreover, there is a diversity in hardware and software capabilities. In other words, without standardized text books and tests, results may not be comparable.

Most Iiterature reviewed on the effectiveness of CBI has been concerned with the use of CCC, and had normal measurements of standard scores, such as Rit scores, percentiles or normal curve equivalences (NCES). Some studies used grade equivalents as a measure of effectiveness; however, this method of measurement could be 
misleading, unless a special care is taken.

Time Impact

One of the major claims for computer based learning is related to the value of learning time. Drill and practice requires learning task repetition. Repetition requires time. The credit claimed for CBI is due to its proponent's claims that it individualizes instruction, facilitates learning at the individual's own speed, reduces the time required, and can also produce more learning for a given amount of time.

In the NWREL review, Edwards reported findings from her studies of eight elementary and one junior high school that had used CBI. The summary of these studies showed that the necessary time for a given task was reduced for CBI students. A review by Thomas confirmed this same trend.

In 1974, in a study of CBI math programs, wells examined the contribution of time to marginal productivity of learning gains, using a Cobb-Douglas production function that employed time as an independent variable. The importance of Wells' study is his test of various logarithmic relationships in an attempt to derive an optimal coefficient. However, the study was weak, being based on the assumption of an arbitrary equivalence between hours of computer instruction and years of an instructor's teaching experience. Even so, the study was 1mportant in using the Cobbs-Douglas approach. It reported a diminishing rate of 
return to instructional time. This finding confirmed prior studies, such as those of Karweit, walberg, wiley, and Harnischfeger. Frederick and walberg also discovered that time predicts outcome at a significant level.

Evaluations of CBI elementary (of CCC) curriculum between 1975 and 1977 was compiled and analyzed by Gloria Poulsen and Elizabeth Macken (Poulsen and Macken, 1978). The study covered thirteen schools in eight states. It specifically addressed the effect of CAI on time and task. The main focus of this study was whether 10 minute-per-day instruction, or 25 hours a year (the recommended time) has an effect on an expected achievement of a one month gain for each month of instruction.

Most of the studies showed high correlations between time spent in CBI and gains in CBI grade placement levels when students were grouped by individual learning rates. By comparing the actual against the recommended time, the researchers found that most groups did not receive more than 75 percent of the normal dose of CBI instruction. They concluded that, had the students received the recommended dose of time, the gains would have been much higher than those reported. The ten-minutes-per-day or 1500-minutesper-year instruction is based on the assumption that there are thirty weeks or 150 days of instruction. Since the test norm dates are set from October to April, the actual treatment period is less than 150 days. Therefore, a 
ten-minute instruction per day for 150 days is an unrealistic expectation.

\section{The Impact of Other Factors}

As discussed earlier, the student is constantly exposed to his/her microcosm and macrocosm, which might influence achievement positively or negatively as they interact with the instructional processes. When the student is in the classroom, the characteristics of the teachers and classmates are subordinate factors having impact on the learner. Out of the classroom there are school factors which also need to be taken into consideration, i.e., resources, activities, facilities, and school environment.

similarly, the student in his microcosm (i.e. the family), is exposed to factors which have an impact on his learning ability. As has been discussed earlier in this study, nutrition, the level of the parents' education, and family income are some of the significant factors in the child's cognitive skill development. The student's macrocosm includes the social environment that exists around his/her school and family. There are factors of the social environment such as recreational facilities, crime rate, and residential mobility that have impact on the student's attitude and motivation.

Several studies have attempted to examine the actual impact of such factors on the student and related learning activities. Walberg and Frederick (1980) reviewed studies 
that focused on learning time. One of these studies used a regression analysis on variables of home environment (i.e, social and economic characteristics of the home), school, teachers, students and community, along with time in predicting achievement. The result showed that these variables explained 74 percent, 85 percent and 58 percent of the achievement differences of grades six, eight and twelve. A close relationship between community measures and attendance as well as mild relationships between achievement and home background variables was confirmed.

The classical studies that specifically addressed the effects of community or neighborhood qualities on student achievement were done by Coleman, Jencks, Blum and Davis. Family mobility in rental residence is higher than among owner-occupied residences. The higher the family mobility, the more frequently peer groups and reference groups will have a short-lived relationship. This may affect the emotions of the youngsters who are moving or staying. Crime rates in the neighborhood and their effect on achievement have not been closely examined in terms of their implications to the student's affective behavior.

The proportion of white residents and their influence on the achievement (of white or nonwhite students) is examined in a few studies (Coleman, et al, 1966; Jencks, 1972). The impact of residential density or school crowding on learning outcome for lower achievers is also examined. 
Needless to say, student characteristics such as age, sex and ethnic identity have been examined by several studies. Those variables that have not been examined thoroughly need to be investigated. Several of these are examined in the product refining approach of this research. This approach, along with statistical models, is discussed in detail in the following chapter on the research methodology. 
CHAPTER IV

METHODOLOGY

\section{RESEARCH APPROACH}

Any research attempting to assess the impact of a previously implemented program, (whether public or private) must resort to summative evaluation. In an evaluation of this kind, one must identify both the conditions of implementation and the intended objectives. In addition, it is necessary to identify the statistical techniques of assessment. It is in this tradition of scholastic inquiry that this study has selected an evaluation research method in examining the impact of advanced instructional technology.

In some social service programs, such as manpower training and compensatory education, tests are given in order to determine entry-level performance (pre-tests). Following the prescribed trainings or "treatments," tests are conducted (post-tests) to assess the change in performance or program effectivness. An analysis is accomplished using descriptive or quantitative statistical methods. In compensatory education programs, such as Title I, norm referenced or criterion referenced tests are used for comparative assessment. When applied in a learning 
situation, summative evaluation is practical, because it provides information or how much students have changed with respect to course goals and learning objectives. Thus, this research uses a norm referenced test with an equal interval standard score (i.e., Rit scores) in a summative approach to obtain a reliable and valuable assessment of change, (Block, $1971)$.

Research on traditional Title I program is quasi-experimental, rather than true scientific experiments. First of all, neither the subjects (students) nor the "treatments" were selected randomly, nor were they assigned randomly. The participants are selected on the basis of prescribed economic and performance criteria. Second, the subjects selected are not randomly assigned to "treatment" groups. Third, all Title I programs focus on targeted services, as is the case in the Portland Public Schools, and do not involve "control" groups. Fourth, this research, like other social science research, has little or no control over independent variables that might have influence on the outcome of the "experiment."

As mentioned above, if intervening independent variables are not controlled, they cannot be manipulated. However, such research can still reflect the basic scientific methods by using a quasi-experimental approach, which requires a logical and valid measurement cf dependent and independent variables. It also hypothesizes a 
relationship between dependent and independent variables and makes assertions, albeit without the confidence ensured by a true experiment. Hence, the research design appropriate to a summative evaluation in a quasi-experimental situation is ex post facto research as defined below by kerlinger:

Ex post facto research is a systematic inquiry in which the scientist does not have direct ccntrol of independent variables because their manifestations have already occurred or because they are inherently not manifulable. Inferences about relations among variables are made, without direct intervention, from concomitant variation of independent and dependent variables (Kerlinger,1973, p. 379).

In addition, Sax, by discussing various applications of ex post facto research, points out that it is a cross between descriptive and experimental investigation, (Sax, 1968). Hence, one of the methodological steps of this research includes a description of instructional setting, i.e., the program implementation process. This chapter discusses research design, statistical techniques, and models deemed appropriate to the research. The next step of the research method raises research questions and hypotheses considered relevant to the evaluation objectives. 
RESEARCH TECHNIQUE

Research Modeling

Before we talk of evaluation, technical details of the research methods employed in this study need to be clarified. This study is based on evaluation research methods, and is a summative rather than a formative type of evaluation research. The appropriate classical model for such a research is stufflebeam's CIPP model (CIPP being an acronym for Context, Input, Process, and Product evaluation). This research follows the framework of the summative approach with the CIPP model that emphasizes outcome evaluation (Dyer, 1966; Stufflebeam, 1974).

This model is unique in structure and flexibility. Four major parts of the model can be applied either independently or in conjunction with one another. Therefore, the first three steps (CIP) will assess the instructional setting in order to provide a background for product evaluation. In addition, the model will be extended to accomodate this research. Stufflebeam's model concludes with an evaluation of the product and stops short of explaining or accounting for effects or exogenous variables. The model in this study, however, will have an addendum which addresses variables external to the treatment in order to refine the outcome--hence product refinement (CIPPR).

As discussed above, the underlying concept of the research is casual-comparative based on ex post facto 
information. Therefore, this research is a quasiexperimental research designed with a comparative or "control" group.

\section{The Cause and Effect Framework}

Evaluation from a cause and effect perspective should be comprehensive, as input represents actions, "causes," and subsequent results represent "effects." when both causes and effects are put together in an evaluation model, they become an integral part of the conceptual framework. The following figure illustrates some of these inter-relationships.

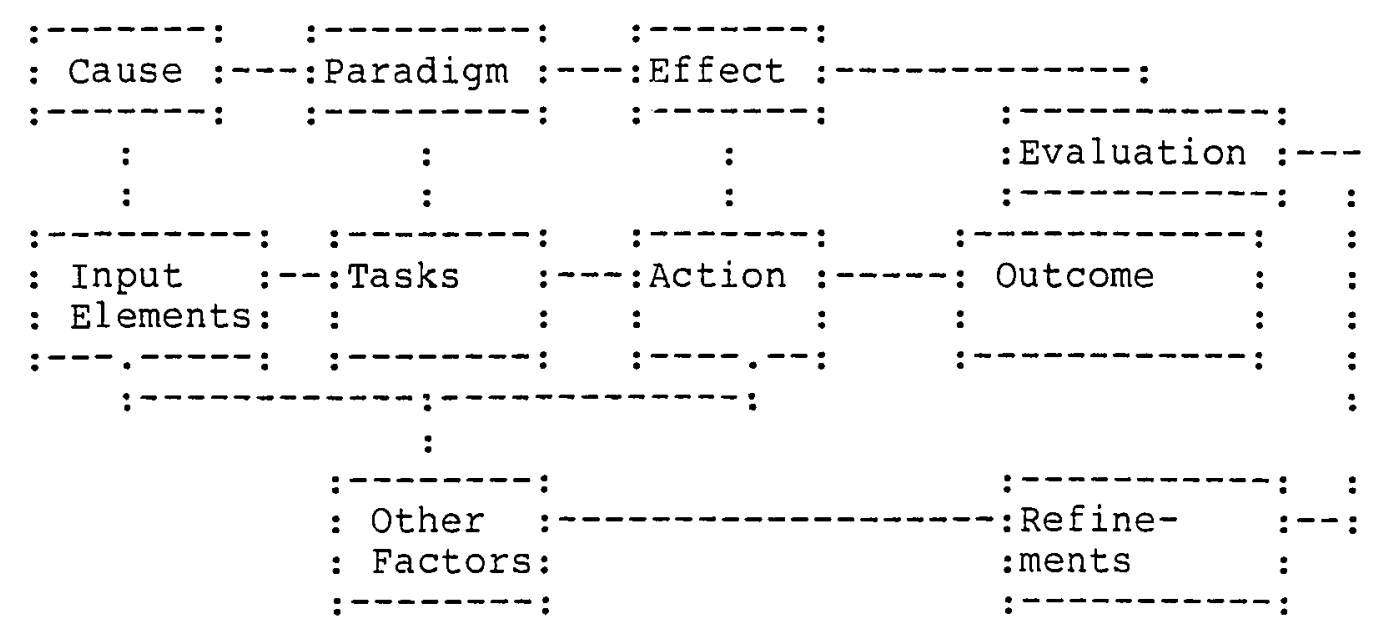

Figure 3. Conceptual relationships of cause and effect.

The challenge of cause-effect research involves not only how much of the result is the effect of the quantified input elements, but also how exhaustively to account for external factors that may be part of the "real" effect. An 
assessment of a learning outcome that does not account for the environmental effects on achievement would leave some important questions unanswered. The final product becomes an overstated treatment effect.

The cause-effect evaluation can also be simplistically framed to reflect both traditional and nontraditional methods of assisting disadvantaged urban youngsters. As stated in detail in Tables XXIII and XXIV, the following chart summarizes current Title I practices in all districts. Figure 4 illustrates the relationship of the resource allocation decision processes.

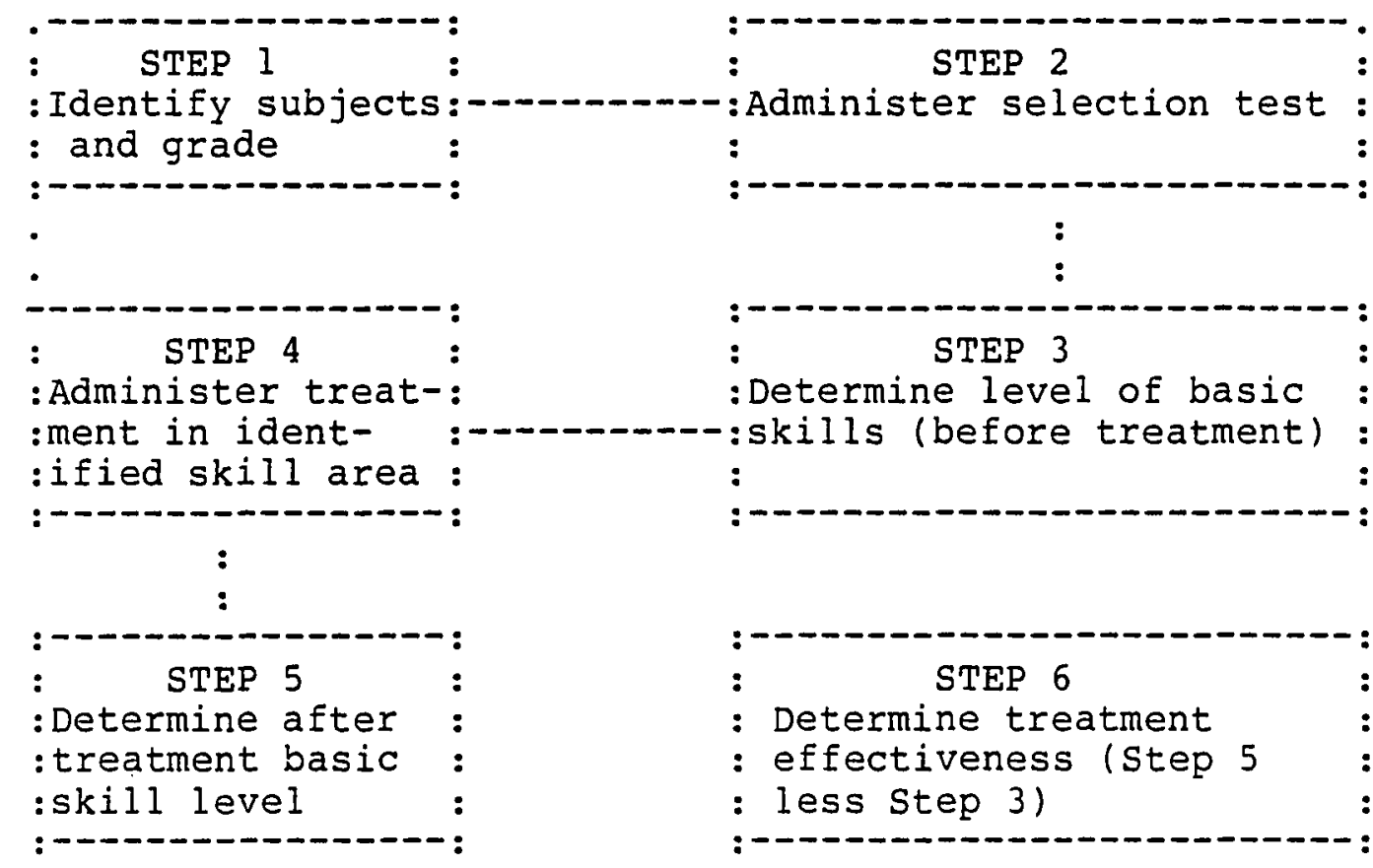

Figure 4. Title I instructional services. 
The central question in both the traditional and nontraditional treatment comparisons focuses on the pre-treatment and post-treatment measurements. In this research the target schools are middle schools or other schools that serve grades four through eight.

\section{Research Design}

Before turning to samples, variables and statistical methods of manipulation, it is important to identify factors that impact, under various conditions, the two "experimental" treatment groups and the control. As pointed out in the literature review, there are factors in a learner's microcosm that have a positive or negative effect on learning outcome. The following schematic figure illustrates their impact on the learner in either a formal or an informal way.

Family or Household

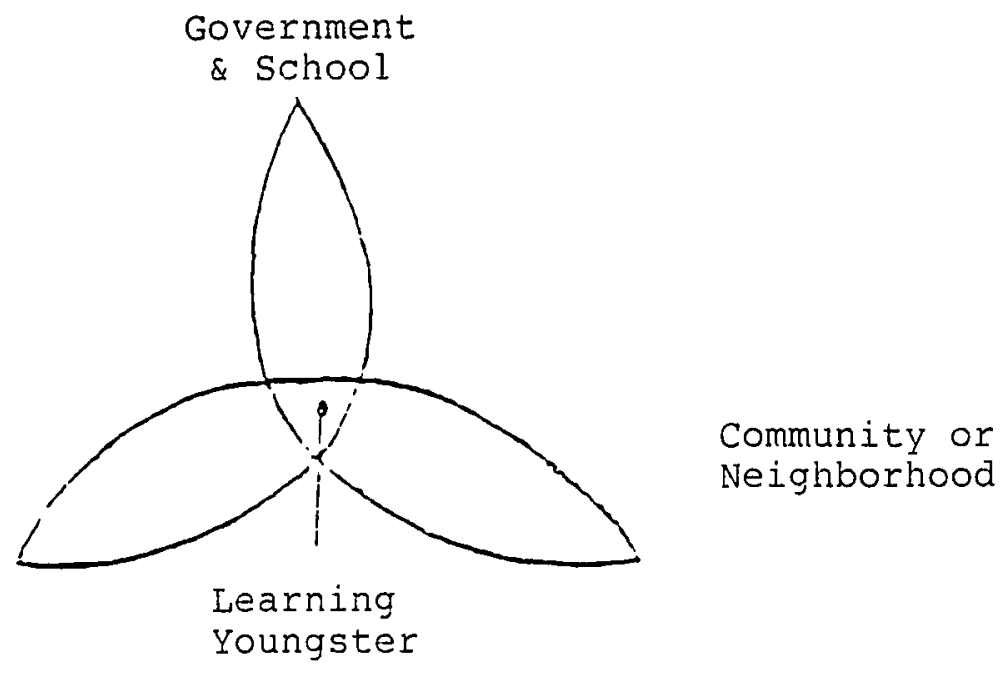

Figure 5. Factors of a learner's Microcosm. 
This schematic diagram demonstrates how cognitive growth in general, or treatment outcome in particular, may not be a result exclusively of the treatment. There are factors that influence, interact with or have a definite effect on a learner by virt!e of being in the learner's social milieu.

Recognizing these environmental factors and
identifying those that are treatment inputs enables us to
Iist those factors that should be taken into consideration. As the scheme shows, there are four major ones:

1. student family learning factors

2. community or neighborhood factors

3. school factors

4. learning or treatment factors.

This research attempts to capture the first three and put them in conjurction with the fourth. Therefore, the treatment effect being the hinge of the research, the following design is set forth. 
TABLE VII

\section{TREATMENT EFFECT DESIGN}

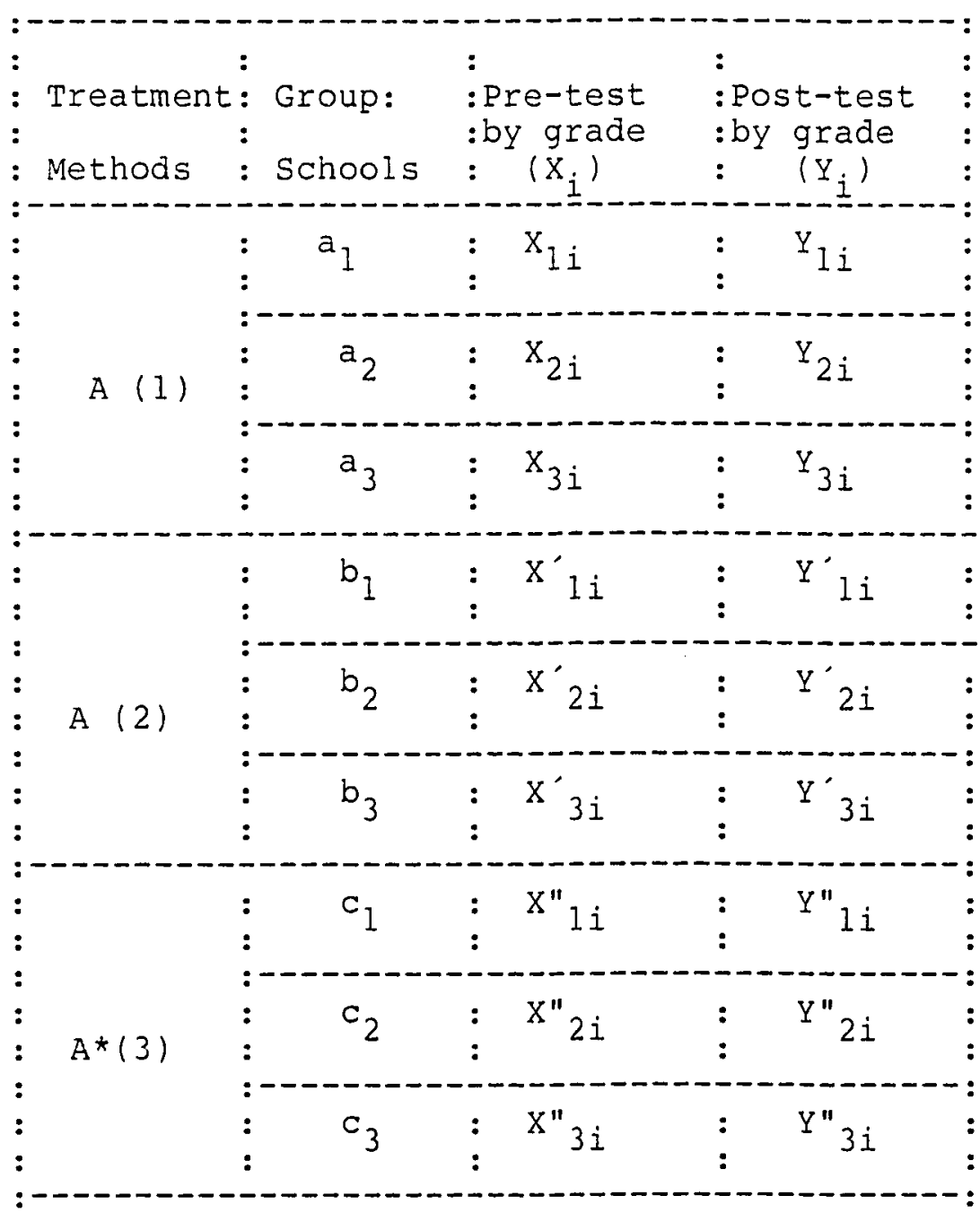

* This treatment method is used as a control group.

where:

$x_{i}=$ pre-test of grade $i$,

$Y_{i}=$ post-test of grade $i$

grades $(i)=5,6,7,8$

Methods: $A(1)=$ CAI, $A_{2}=$ PLI, $A_{3}=$ TMI

$a_{1}, a_{2}, a_{3}=$ CAI Schools; 
$b_{1}, b_{2}, b_{3}=$ PLI Schools and

$c_{1}, c_{2}, c_{3}=$ TMI Schools.

Statistical Methods

This research has used descriptive statistics such as frequency distribution to assess the normality of the sample distribution. The achievement group means by grade, sex, race, schools and method of treatment was derived using Rit standard scores. Additional statistical information such as variance, standard deviation, and group size, etc. was obtained using sPSS cross-tabulation, breakdown and both descriptive as well as nondescriptive statistical methods (Nie, et al, 1975).

Relevant statistical approaches were selected to test the hypotheses that were entertained in response to research questions. Common primary tests used for most of the hypotheses were

1. the test of "significance" $(t, f)$;

2. the test of the trend of relationship among variables ( $R$ );

3. the test of the strength of the relationship between dependent and independent variables $\left(R^{2}\right)$.

The trend of the relationship was tested by calculating multiple correlations among all variables. The following formula is applied using computers and information on the sample mean, variance, and standard deviation. (Nie, 
et al. p.2801

$$
R=\frac{\sum_{i=1}^{N}\left(x_{i}-\bar{X}\right)\left(Y_{i}-\bar{Y}\right)}{\sum_{i=1}^{N}\left(x_{i}-\bar{X}\right)^{2} \sum_{i=1}^{N}\left(Y_{1}-\bar{Y}\right)^{2}}
$$

Where $x_{1}=$ independent variable $x$ and $\bar{x}$ is its mean, $N$ $Y_{1}=$ dependent variable $Y$ and $\bar{Y}$ is its mean.

The result of this formula (R) tells us more about $R^{2}$, which also provides a measure of the strength of that relationship. It is a coefficient of determination, or proportion of change or variance in the dependent variable, that is explained by the independent variables. It is also a measure of the accuracy of the regression equation in predicting the dependent variable.

The contribution of each independent variable to an explanation of changes in the dependent variable is measured by a coefficient called the "regression coefficient" or "B." This is a measure of the total influence of each explanatory variable on the criterion variable. The formula, which is also calculated by computer, is as follows.

$$
B=\frac{\sum_{i=1}^{N}\left(X_{i}-\bar{X}\right)\left(Y_{i}-Y \bar{T}\right.}{\sum_{i=1}^{N}\left(X_{i}-\bar{X}\right)^{2}}
$$


The test of the significance of "B" is a measure of its contribution in explaining $Y$. The explanatory contribution of the independent variable is tested by using the t-test. The formula, again calculated by computer, is as follows.

$$
t_{b}=-\frac{B}{s_{b_{j}^{2}}^{2}}
$$

Where $B_{j}$ is the regression coefficient and $s^{2} b_{j}$ is its covariance.

A test of the strength of the relationship between criterion and explanatory variables can be made by the coefficient of determination, $\mathrm{R}^{2}$, which is the square of their relationship, $R$. The significance of this strength can also be tested by the F-ratio (Blalock, 1960, p.304).

$$
F_{1}=\frac{R^{2} /(N-2)}{\left(1-R^{2}\right) /(N-K)} \quad(\text { EQ } 4.4)
$$

In the above formula, the F-ratio is the proportion of the total sum of squares of the criterion variable ( $Y$ ) explained by a given number of explanatory variables (X), which is $\mathrm{R}^{2}$ divided by the unexplained sum of squares $\left(1-R^{2}\right)$, then multiplied by $(N-2)$, the degrees of freedom. $\mathrm{N}-\mathrm{K}$ is also degrees of freedom, that is, the sample size (N) ana the $K$ terms in the regression equation (Borich, 1974 , p. 3921 . 
The significance of the attributes of one or more variables that may be either nominal (dummy coded) or interval, and also the explanation of the variance in the criterion variable, can be tested using the F-ratio. In this research, attention is particularly given to group membership and treatment effect in order to assess their influence on the variance in post-test achievement. The F-test formula is given below, (Borich, 1974, p. 392).

$$
F=\frac{\left(R_{y x d}^{2}-R_{y x}^{2}\right) / d y x}{\left(1-R^{2}\right) /(N-K)}
$$

New terms in this formula $(4.5)$ are $D, N-K$ and $d$. The others remain the same, as in the earlier definition. $D$ is a binary code for the nonmetric variable, $N$ is the sample size, and $k$ is the number of terms in the regression equation. Hence, $\mathrm{N}-\mathrm{K}$ is the degree of freedom and $\mathrm{d}$ is the number of treatment groups. This formula is also used in controlling the influence of ability differences that existed prior to treatment. If it is merely to account for the explanatory contribution of a variable, a squared partial-correlation coefficient can be utilized (Nie, et al, 1974, p.334).

The last formula used in this research is the significance of the difference between the sample means of the treatment groups with a universe whose standard deviation is unknown. The estimate of the sample variance 
is:

$$
\overline{\mathrm{x}}_{1}-\bar{x}_{2}=\quad \begin{gathered}
\mathrm{n}_{1} \mathrm{~s}_{1}^{2}+\mathrm{n}_{2} \mathrm{~s}_{2}^{2} \\
\mathrm{n}_{1}+\mathrm{n}_{2}-2
\end{gathered} \mathrm{n}_{1}^{+\mathrm{n}_{2}}
$$

A test of significance of differences between the group means is examined by using the following formula. It is used for testing the pre-test and post-test differences among the treatment and control groups. The task of comparing the computed t-value with the $t$-value from the table (corresponding to the level of probability selected and the degree of freedom) is used to determine whether the postulate is acceptable or not.

$$
{ }^{T} \sigma_{i}-\bar{x}_{j}=-\frac{\left(\bar{x}_{i}-\bar{x}_{j}\right)}{s^{2} / n_{i}+s^{2} / n_{j}} \quad \text { (EQ 4.7) }
$$

$\underline{\text { Data }}$

The data used in this research are obtained from primary sources. All schools and the communities in which the schools are located were visited and some of the classes were also observed during the treatment period. A survey of teachers and aides involved in the operation of CAI and PLI was conducted for exploratory purposes, and the findings will be considered tentative. A copy of the survey may be found in the appendix.

Primary data were obtained from various sources. Individual student achievement data were obtained from the 
district's master file. Data used to assess teachers' and aides' levels of satisfaction with CBI were collected by conducting a survey at each school. Cost information was collected from each school, from the district's Budget and Contract office and from the local and national headquarters of the CAI and PLI corporations. Lease terms and contracts were reviewed and double checked with documents located at the school district's legal office.

Data on neighborhood characteristics were obtained from the Population Study Center of P.S.U. Data on each variable was by census block where each participating student resides. Student address information by I.D. was obtained from the district's Data Processing Center. The crime rate for 1981 (total reported offenses per 1000 residents) was obtained from Portland Police Bureau reports. In this way, precinct boundaries were reconciled with block group boundaries where the students resided. Data concerning school characteristics, such as crowding and operational costs-per-student, were calculated from the district's plant and equipment annual inventory report.

\section{VARIABLES}

Dependent Variable

The dependent variable in this research is the post-test score, ( $Y$ or POT), representing after-treatment outcome. This is the Rit score, which is a standard score with its own norm table. As mentioned earlier the Rit score 
is based on the Rasch model, which is adjusted to test item difficulty and individual ability levels.

Independent Variables

Almost all variables were selected on the basis of the literature. In this study various models are used to answer the research questions or test the corresponding hypothesis. In other words, the independent variables are used in various models. The research uses eighteen independent variables. A list of all independent variables and their operational definitions is given below.

Pre-test: measure of a basic skill at entry stage of the treatment. This is a test score different from a selection test score. It is measured in Rits score units ( $\mathrm{X}$ or PRE).

Time: the amount of exposure of a youngster to a treatment measured in aggregate minutes. The time for CAI is actual engaged time $\left(t_{1}\right)$ while the other two methods represent allocated or scheduled time, as in PLL $\left(t_{2}\right)$.

School resources: variables used to measure school resources or costs devoted to the treatment projects. These include operational costs per student $\left(S R_{l}\right)$, and classroom capacity or crowding index $\left(\mathrm{SR}_{2}\right)$.

Operational cost per student: the total cost of instruction in the Title I program, measured in constant dollars divided by the number of participants $\left(S R_{1}\right)$.

Capacity index: measure of planned classroom space 
for students. It is the ratio of students to planned classroom space. If the numerical value of the index is greater than one, then there is crowding; if it is less than one, then there is no crowding; when equal to one, the number of students and the classroom spaces are equal $\left(\mathrm{SR}_{2}\right)$. Home environment variables: characteristics of the neighborhood in which the youngsters participating in the treatment program Iive. The data were obtained from the 1980 census report by block, which is a sub-tract. The data are for the block area around a student's home.

Income: the median income of the block area of the student's residence (MEDY).

Education: measured by noting the number of block residents who complete twelve or more years of school as a fraction of the total number of residents in the block (PRED) .

Ethnic diversity: measured by the proportion of whites to the total number of block residents (PWP).

Home-ownership: the proportion of owner-occupied homes among all housing units in the block (PHO).

Home-value: the median value of owner occupied homes in the block (MHV).

Rental value: the median rental value of all rental units in the block (MRV).

Vacancy rate: the proportion of vacant housing units among the total number of residential units in the block, 
based on an adjusted annual figure (VAC).

Crime rate: the estimated total offenses by block per one thousand residents, as derived from the 1980-81 police report ( $C P C)$.

Density index: the number of people per acre of land. The ratio of all residents to the area of the neighborhood measured in acres (PPA).

Nonmetric or Dummy Varjables

The following variables are coded corresponding to each participating student.

Method of treatment: the two experimental groups, CAI and PLL, and the control group, TMI. They are represented by $D_{1}, D_{2}$ and $D_{3}$, in binary dummy code where $D_{1}=1, D_{2}=1$, and $\mathrm{D}_{3}=0$.

Skill area: the academic subjects of math $\left(P_{1}\right)$ and reading $\left(\mathrm{P}_{2}\right)$. Where $\mathrm{P}_{1}=1$ and $\mathrm{P}_{2}=0$.

Grade-level: Eifth, sixth, seventh and eighth grades. They are represented by $G_{1}, G_{2}, G_{3}$, and $G_{4}$, respectively.

Sex: a dummy variable representing the student's gender, male $\left(S_{1}\right)$ and female $\left(S_{2}\right)$, where $S_{1}=1$ and $S_{2}=0$ as dummy variables.

Ethnic: the participant's ethnic background. In this study, ethnics groups represented are Indian $\left(E_{1}\right)$, white $\left(E_{2}\right)$, black $\left(E_{3}\right)$, hispanic $\left(E_{4}\right)$, oriental $\left(E_{5}\right)$, and others $\left(E_{6}\right)$, however, in a dummy coding, white is $E_{1}=0$ the aggregate $\left(E_{1}, E_{3}-E_{6}\right)$ representing nonwhite is $E_{2}=1$. The 
Oriental performance was not statistically different from other minorities, so they are included in the aggregate, $E_{2}$.

\section{Interaction Variables}

This is an exploratory measure to examine whether interaction exists between pre-treatment ability level and method of instruction. It is a cross-product between the metric variable pre-test $(X)$ and dummy variable method of treatment (D), where 1 inear cross-product is $I_{1}=X * D_{1}$; $I_{2}=X^{*} D_{2} ; \quad I_{3}=X^{*} D_{3} ;$ and the quadratic cross-product is $C_{1}=x^{2} * D_{1} ; C_{2}=x^{2} * D_{2} ;$ and $C_{3}=x^{2} * D_{3}$ corresponding to $C A I$, $P L L$, and TMI.

\section{RESEARCH QUESTION AND HYPOTHESES}

In order to set criteria of evaluation by which to assess the claims discussed above, a step-by-step identification of the method is necessary. Cognitive gains can be assessed directly and affective gains indirectly by measuring pre- and post-treatment achievement. Significance of time on task is evaluated using an input-output model, using the expected growth of one month grade-equivalent per one month of instruction. Claims related to individualization of instruction and resource use are examined by means of a comparative economic analysis.

From a statistical and modeling point of view, the above issues can be examined under four major parts. The first part deals with whether or not the experimental 
treatment is influenced by initial levels of achievement. The technical issues are (a) whether the initial achievement levels are significantly different from each other, and (b) whether the final achievement is related to the initial level of achievement.

The second part is an analysis of treatment effectiveness add: ssing the issues of (a) whether the three groups differ on final levels of achievement, (b) whether final achievement is still different when initial differences are adjusted for, and (c) whether group membership explains achievement differences.

The third part, outcome refinement, deals with the influence of treatment and nontreatment variables on achievement. The issues ar whether post-treatment achievement variations can be explained by nontreatment factors. These are factors of student characteristics, variables of school resources, treatment placement and student home environment. One of the variables examined in detail is instructional time. It is one of the benefits claimed for computers. The concern is (a) whether time to learn is related to post-treatment results, and if so, (b) whether that relationship is linear or nonlinear. The third concern is whether the treatment project improves the youngster's grade-level outcome.

The fourth part is an assessment of learning growth rate. The main issues are (a) whether CBI fulfills a target 
cutcome of one month grade equivalent for every month of instruction, (b) whether the initial performance rank is improved by the treatment, and (c) whether CBI has a higher growth rate compared to TMI.

The fifth and last part deals with resource effectiveness assessment. The major issues of this part are (a) whether resources are distributed more effectively in CBI than in TMI, (b) whether the technology based treatment is more cost-effective (net cost) in terms of cost per-student-hour of instruction compared to traditional treatment methods, and (c) whether more benefit is realized from CBI than from TMI. This research uses a new approach instead of student-instructor-ratio assessment, which is a student resource unit ratio. This approach is deemed to be adequate to address distribution of resources, i.e., individualization of instruction.

It should be clear that the evaluation objectives of this research are to determine whether CBI is a more effective instructional method than TMI. This objective has two dimensions of effectiveness, the learning and the resource dimensions.

In order to answer questions related to these two dimensions of effectiveness, one can simply compare pre-treatment and post-treatment differences (gain) for the former, and cost-per-unit-of-output as a measure of costeffectiveness for the latter. However, use of a single 
measurement of effectiveness has inherent weaknesses that could possibly lead to erroneous conclusions. The use of gain scores has a built-in bias that favors those who have low pre-test scores by creating a higher growth chance as opposed to those with high pre-test scores. On the other hand, it has the advantage of being clear and straightforward. This research has elected to use it as much as the post-treatment achievement scores in conjunction with other multiple indicators of effectiveness (Tuckman, 1979). Hence, the above five major parts, issues, and measurements, correspond to claims made by pro-computer educators and technologists. In the following pages each of these issues is discussed with the relevant research questions, hypothesis and statistical tests.

\section{Treatment Outcome Assessment}

The research questions in this section are directed at outcome and its components, that is to say, the relationship between pre-test and post-test and the differences between pre-test and post-test. The relevant questions are:

1. Is there a significant correlation between pre-test and post-test?

2. Are there significant differences among the pre-tests of the three groups?

3. Are there significant differences among the post-tests of the three groups?

4. If the pre-test differences are significant, do the three groups differ in their post-tests after the pre-test differences have been 
controlled or accounted for?

5. Are group membership and pre-test significant predictors of post-treatment achievement levels?

The first point here is whether the best model of prediction is linear or nonlinear. The second point is whether pre-test and group membership are significant explanatory variables, i.e., an explanation of changes in post-treatment achievement. The relevant research question is as follows: What is the best achievement predicting model, linear or nonlinear?

The hypotheses below are predicated values for the research questions raised above. They are presented in the same order as are the research questions. The first hypothesis anticipates a significant correlation between the average pre-test and the post-treatment achievement of each group.

(i) Hypothesis: Correlation

$$
\begin{aligned}
& \mathrm{H}_{0}: \mathrm{R}_{\mathrm{y}} \cdot \mathrm{x}>0 \text { where } \mathrm{Y}=\text { post-test and } \mathrm{X}=\mathrm{pre} \text {-test } \\
& \mathrm{H}_{\mathrm{a}}: \mathrm{R}_{\mathrm{y}} \cdot \mathrm{x}
\end{aligned}
$$

In educational research evaluation, it is customary to examine pre-treatment ability in order to ascertain whether achievement differences are a result of treatment effectiveness or growth chance associated with the levels of the pre-test. Likewise, this research puts forward hypotheses to examine the level of the pre-test scores. This approach also serves as a pre-test to percentage gains, 
which will be discussed under part four.

The second hypothesis predicts that there wili not be differences among the pre-tests of the three groups; if there is any difference, it will not be significant. This is given in (d) below. The $(a-c)$ are alternatives to protect the hypothesis from adverse findings.

(ii) Hypothesis: Pre-tes:. Deferentials

(a) $\mathrm{H}_{0}: \mathrm{x}_{1}>\mathrm{x}_{3} \quad \mathrm{H}_{\mathrm{a}}: \mathrm{x}_{1} \& \mathrm{x}_{3}$

$$
x_{1}<x_{3} \quad x_{1} k x_{3}
$$

(b) $\mathrm{H}_{0}: \mathrm{X}_{1}>\mathrm{x}_{2} \quad \mathrm{H}_{\mathrm{a}}: \mathrm{x}_{1} \& \mathrm{x}_{2}$

$$
x_{1}<x_{2} \quad x_{1} \neq x_{2}
$$

(c) $\mathrm{H}_{\mathrm{o}}: \mathrm{x}_{2}>\mathrm{x}_{3} \quad \mathrm{H}_{\mathrm{a}}: \mathrm{x}_{2} \ngtr \mathrm{x}_{3}$

$$
x_{2}<x_{3} \quad x_{2} \nless x_{3}
$$

(d) $\mathrm{H}_{\mathrm{O}}: \mathrm{X}_{1}=\mathrm{X}_{2}=\mathrm{X}_{3} \quad \mathrm{H}_{\mathrm{a}}: \mathrm{X}_{1} \neq \mathrm{X}_{2} \neq \mathrm{X}_{3}$

where $X=$ mean pre-test and $1,2,3=$ CAI, PLL and TMI.

Test: t-test of the mean difference will be used to accept or reject the hypotheses.

The third hypothesis pertains to post-test comparisons in the same manner the pre-tests were examined. It is predicted that average post-test achievement for each of the three groups would be significantly different.

(iii) Hypothesis: Post-test differential
(a) $\mathrm{H}_{0}: Y_{1}>Y_{3} \quad \mathrm{H}_{\mathrm{a}}: \mathrm{Y}_{1} \not Y_{3}$
$Y_{1}<Y_{3} \quad Y_{1} k Y_{3}$
(b) $\mathrm{H}_{\mathrm{O}}: \mathrm{Y}_{1}>\mathrm{Y}_{2} \quad \mathrm{H}_{\mathrm{a}}: \mathrm{Y}_{1} \neq \mathrm{Y}_{2}$

$$
Y_{1}<Y_{2} \quad Y_{1} \nless Y_{2}
$$


(c) $\mathrm{H}_{\mathrm{O}}: \mathrm{Y}_{2}>\mathrm{Y}_{3} \quad \mathrm{H}_{\mathrm{a}}: \mathrm{Y}_{2} \not \mathrm{Y}_{3}$

$$
\mathrm{Y}_{2}<\mathrm{Y}_{3} \quad \mathrm{Y}_{2} K \mathrm{Y}_{3}
$$

Test: t-test of significance of the differences post-test mean will be applied.

The fourth hypothesis has to do with adjusted post-test achievement. It is hypothesized that when pre-test differences are controlled or adjusted for, significant differences would remain between the post-test achievement of CAI, PLI and TMI. However, differences between PLI and TMI would not be significant. (iv) Hypothesis: Adjusted post-test differentials

(a) $H_{0}: Y_{1}$ adj. $>Y_{3}$ adj. $H_{a}: Y_{1}$ adj.by $y_{3}$ adj.

$$
Y_{1} \text { adj.> } Y_{3} \text { adj. } \quad Y_{1} \text { adj. } P Y_{3} \text { adj. }
$$

(b) $H_{0}: Y_{1}$ adj.>Y $Y_{2}$ adj. $H_{a}: Y_{1}$ adj. $\nmid Y_{2}$ adj. $Y_{1}$ adj. $\left\langle Y_{2}\right.$ adj. $\quad Y_{1}$ adj.kY $Y_{2}$ adj.

(c) $H_{0}: Y_{2}$ adj.>Y $Y_{3}$ adj. $H_{a}: Y_{2}$ adj. $\gg Y_{3}$ adj. $y_{2}$ adj. $\left\langle Y_{3}\right.$ adj. $\quad y_{2}$ adj.k $k y_{3}$ adj.

The fifth hypothesis concerns the specifications of an optimal model for explaining treatment effect. An additive linear model and polynomial model will be built and the two will be compared. It is postulated that a quadratic model would be the best predictive model of post-test achievements. In other words, there would be a significant difference between the coefficient of determination $\left(R^{2}\right)$ 
derived from linear and quadratic models of the same groups of variables, i.e, pre-test, group membership, and a product of both pre-test and group membership (interaction factor). It is also anticipated that any difference would be in favor of the quadratic model.

A corollary to the hypothesis above is the postulate that a product-term or interaction factor between pre-test and group nembership would be significart in an explanation of changes in the outcome among groups. It is also postulated that a model consisting of pre-test, group-membership and interaction factors would account for most variations in post-test differences in a nonlinear relationship. In other words, the difference between the linear, $\mathrm{R}_{1}^{2}$, and the quadratic, $\mathrm{R}_{2}^{2}$, would be statistically significant.

Models:

Polynominal: (EQ 4.8)

$$
Y=a+b_{0} X+b_{1} D_{1}+b_{2} D_{2}+b_{3} X^{2}+b_{4} I_{1}+b_{5} I_{2}+b_{6} C_{1}+b_{7} C_{2}+E
$$

Linear: (EQ 4.9)

$$
\mathrm{Y}=\mathrm{a}+\mathrm{b}_{0} \mathrm{X}+\mathrm{b}_{1} \mathrm{D}_{1}+\mathrm{b}_{2} \mathrm{D}_{2}+\mathrm{b}_{4} \mathrm{I}_{1}+\mathrm{b}_{5} \mathrm{I}_{2}+\mathrm{E}
$$

Quadratic: (EQ 4.10)

$$
Y=a+b_{1} D_{1}+b_{2} D_{2}+b_{3} X^{2}+b_{6} C_{1}+b_{7} C_{2}+E
$$

where the terms are as defined earlier under interaction variables.

This approach first calls for a quadratic trend test and then for a test of interaction. Both tests will be 
discussed in detail in the next chapter. However, the hypothesis will be accepted if the F-ratio is significant at $p=0.01$ level in both cases; otherwise it will be rejected, and the F-test given in EQ 4.5 will be applied.

Outcome Refinement Methods

As there are intended and unintended, direct and indirect, tangible and intangible effects of outcomes, there are input factors with similar effects. Outcome research evaluations of this kind should attempt to account for the influence of most of the input factors. The effort can lead to achieving the net outcome, or net effect, of the treatment.

The question here is whether variables related to student identity, school and home environment make significant contributions in determining variations in post-treatment achievement.

It is anticipated that:

1. student identity (gender and ethnic) will not make a significant contribution;

2. school resources $\left(S R_{1}, S R_{2}\right)$ will make a significant contribution;

3. home environment variables (listed earlier) will also make a significant contribution in explaining changes in the dependent variable.

The statistical test here is the test of significance of the regression coefficients ( $B$ ) of the variables in 1 and 2 and a test of the significanse of $\mathrm{R}^{2}$ in 3 . 
The second part of this research is a further step in outcome assessment. This step involves the effects or contribution (which may be positive or negative) of variables endogenous or exogenous to the treatment process. The methodological purpose of this process is to "completely" account for "all" attributing variables by using a multiple regression analysis in a causal comparative form. The variables to be examined are those related to student characteristics, school resources, and home environment. Surrogate variables for these factors will be built into both a general and a sub-model of regression analysis to assess their impact on variations in post-test achievement.

Post-test achievement $=f$ (pre-test, method, time, student characteristics, school resources, home environment or characteristics).

Full Model: (EQ 4.11)

$y=a_{1}+b_{1} x_{1}+b_{2} X_{2}+b_{3} X_{3}+B_{4} x_{4}+B_{5} X_{5}+B_{6} X_{6}+B_{7} X_{7}+b_{8} x_{8}+b_{9} X_{9}+$

$b_{10} x_{10}+b_{11} x_{11}+b_{12} x_{12}+b_{13} x_{13}+b_{14} x_{14}+b_{15} x_{15}+$

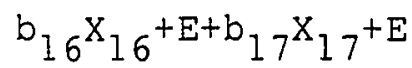

Where $Y=p o s t-t r e a t m e n t$ achievements in Rits score

$$
\begin{aligned}
& x_{17}=\text { pre-test score } \\
& x_{1}=\text { method of treatment (CAI) } \\
& x_{2}=\text { method of treatment (PLI) } \\
& x_{3}=\text { student's sex (male or female) coded as } \\
& \quad s=1 \text { male } s=0 \text { female }
\end{aligned}
$$




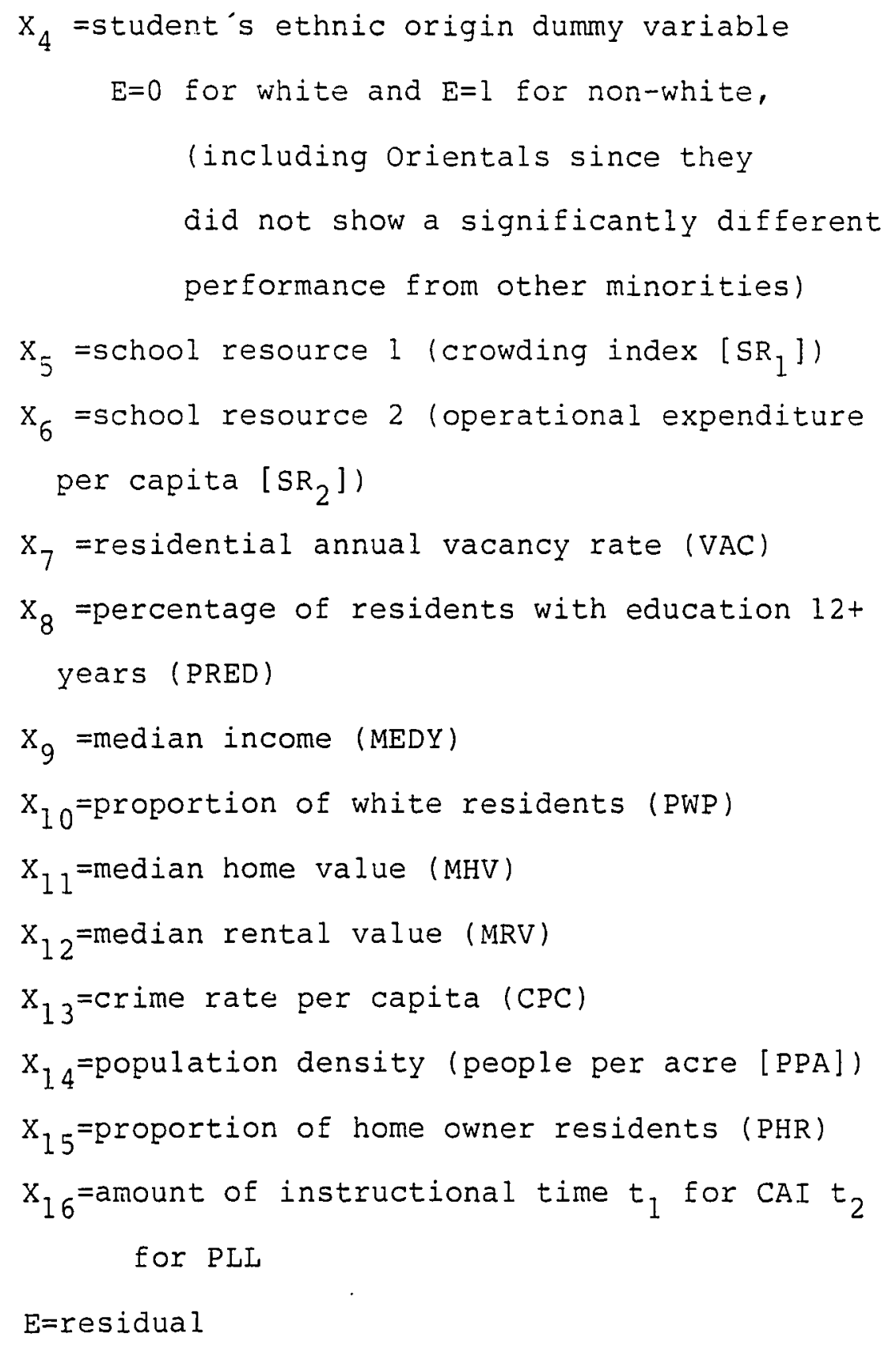

The regression results of this model are presented and discussed in the next chapter on data analysis. Because of a high colrelation between the pre-test and post-test, three separate regressions were performed. Two runs were made 
with post-test as a dependent variable with and without the pre-test. The third run used gain scores as a dependent variable and pre-test included with the rest of the independent variables of the model. 
CHAPTER V

ANALYSTS I

\section{DESCRIPTIVE ANALYSIS}

Research questions and subsequent hypotheses in this study have been focused toward a comprehensive determination of the effects of three approaches of treatment of learning disabilities in our school systems. The main thrust, of course, is the question: can technology-based treatment--computers in the classroom--exceed or at least equal results obtained from traditional methods of instruction (TMI) used in conventional instructional settings?

Three study groups were employed. Group one utilized computers alone (CAI). Group Two used an audio-video media assist to the computer (PLL), while Group Three relied solely on TMI. A total of 1336 "subjects" in mathematics and/or reading were covered, and a selected sample tested for normalcy in distribution.

Figure 6 shows a probability scatter plot of standardized residuals. The forty-five degree line represents a normal distribution by way of relationships of expected and observed values. 


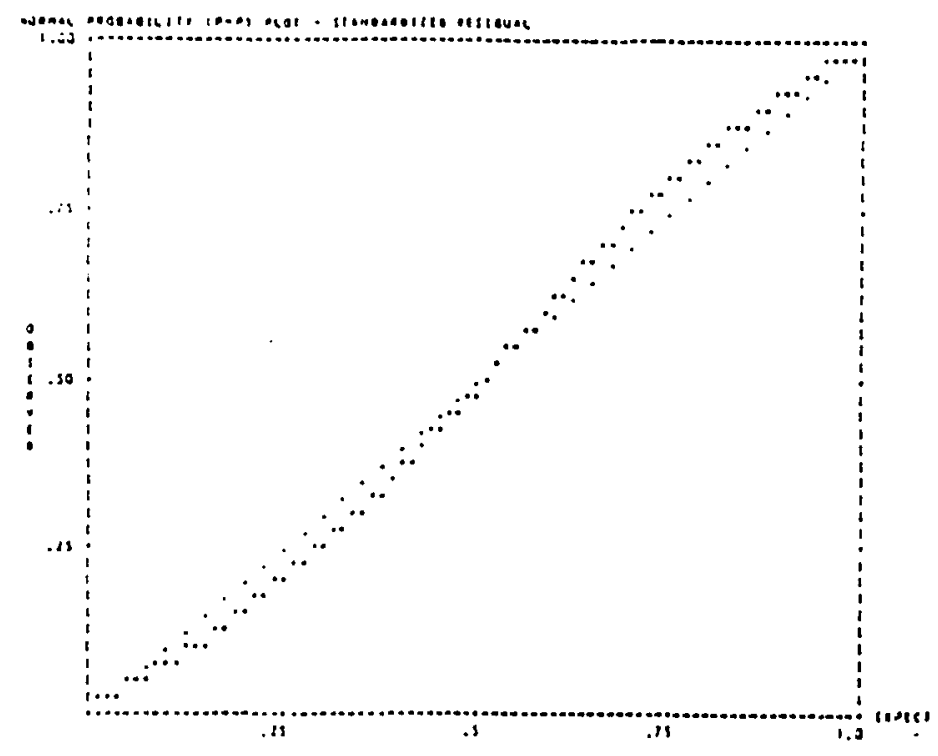

Figure 6. Probability distribution of standardized residuals.

\section{Instructional setting}

The initial step in this analysis is description of the three programs, their inputs and their implementation processes, which is the context for the evaluation research. The social environment of the three groups appears to differ slightly. CAI schools served at least 532 youngsters each. The percentage of youngsters from low-income families ranged from 45.3 percent to 61.9 percent. PLL schools served between 531 and 722 youngsters each. The proportion of youngsters from poor families ranged from 26 percent to 35 percent. TMI schools served 366 to 786 youngsters each, and 28 percent to 56 percent from poor families. The demographic characteristics of the three groups in the sample (CAI, PLL, and TMI) are discussed in previous chapters and in the Appendix B. Grade levels of primary 
interest to this research were five to eight. Distribution of the sample by grade and school is given in Table XXVI-XXIX. The data on Table XXVI show that representation ranged from 25.2 percent (fifth grade) to 31.1 percent (sixth grade). The range of ethnic representation in the sample was 3.4 percent for orientals and 49.9 percent for whites, while the second largest group represented was blacks. Gender distribution was 57.4 percent male and 42.6 percent female (Table XXVIII). The sample consisted of "clear and intact" groups having pre-test and selection test scores recorded separately, with post-test scores available. Mathematics program participants included 89.1 percent of the youngsters. Similarly, 88.7 percent were in the reading program. More than 88 percent of the subjects participated in both mathematics and reading.

\section{Correlational Analysis}

The next step examines the question of whether there is any relationship between the covariate (pre-test) and the criterion (post-test), which is a question of correlation. Using the sPSS scatter plot, the pre-tests and the post-tests were plotted by skill areas. A correlation between pre-test and post-test scores in math for the two experimental groups was $R=0.87754$, with a significant $F$ at. $\mathrm{p}=0.0000$. The overall correlation for the three groups in both skill areas was $R=0.87997$, with the same level of significance as above. 
The simple correlation analysis of the pre-test and post-test of each group (CAI, PLI, and TMI) was made for both mathematics and reading. The findings confirm the nul hypothesis that che correlation between the pre-test and post-test is significantly greater than zero for all groups and all skill areas.

Correlation analysis of achievement scores used by other studies showed similar results. The finding is that the pre-test and post-test correlation is higher in mathematics than in reading, as shown in previous findings. That means that the influence of pre-test on post-test is strong, and any further analysis needs to take this into consideration (Borich, 1974; Williams, et al., 1979; Kerlinger, 1973; Walberg and Frederick, 1980; and Horst et al., 1975).

Pre-test Analysis

The second methodological step calls for an examination of the mean pre-tests $(X)$ of the groups. A graphic comparison of the pre-test of the three groups with that of the districts is given below. An inspection of both skill areas, mathematics and reading, shows that there is a difference between the pre-tests. A test of the mean pre-test differences is important in the assessment of treatment impact (wells et al., 1974; Gay, 1976, p. 253; Tuckman, 1979, p.171; Fitz-Gibbon and Morris, 1978, p.66). Therefore, there should be tests of significance of such 
differences (Feldman and Sears, 1970, p.13; Bozeman and Burns, 1981, p.37; Tuckman, 1979, p.190). If the pre-test is significantly different, then it should be purged off the post-test or the post-test has to be adjusted (Kerlinger, 1973, p.337; Borich, 1974, p.389; Blalock, 1960, p.377). The pre-test also needs to be tested fur whether there is interaction (linear or quadratic) with the treatment method (Borich, 1974, p.389; Williams, et al., 1979, p.109; Gay, 1976, p.256; Tallmadge, 1976). Therefore, below the pre-test of the three groups, CAI, PLL, and TMI, are compared below for tests of significance of differences.

The pre-test of the two experimental groups, CAI $\left(x_{1}\right)$ and PLL $\left(\mathrm{X}_{2}\right)$, are compared with that of the control group, TMI $\left(\mathrm{x}_{3}\right)$. As stated earlier, it is hypothesized that each of the pre-tests would be different but the differences would not be statistically significant. Statistically speaking, the probability of such a difference occurring by chance is one in one-hundred, i.e., $p=0.01$.

The findings show that:

$$
\begin{aligned}
& x_{1}=203.473 \\
& x_{2}=195.797 \\
& x_{3}=200.044
\end{aligned}
$$

Therefore, the following hypotheses are accepted:

$$
\begin{aligned}
& \text { (a) } x_{1}>x_{3} \\
& \text { (b) } x_{1}>x_{2} \\
& \text { (c) } x_{3}>x_{2}
\end{aligned}
$$


The following tests of the significance of the differences between the group means is applied:

(a) CAI VS. TMI

$$
t_{\mathrm{d} 2}=\frac{\left(\bar{x}_{1}-\bar{x}_{3}\right)}{\sqrt{s_{1}^{2} / n_{1}+s_{3}^{2} / n_{3}}}
$$

(b) CAI VS. PLL

$$
t_{\mathrm{d} 2}=\frac{\left(\overline{\mathrm{x}}_{1}-\overline{\mathrm{x}}_{2}\right)}{\sqrt{\mathrm{s}_{1}^{2} / \mathrm{n}_{1}+\mathrm{s}_{2}^{2} / \mathrm{n}_{2}}}
$$

(c) PLL VS. TMI

$$
t_{\mathrm{d} 2}=\frac{\left(\overline{\mathrm{x}}_{2}-\overline{\mathrm{x}}_{3}\right.}{\sqrt{\mathrm{s}_{2}^{2} / \mathrm{n}_{2}+\mathrm{s}_{3}^{2} / \mathrm{n}_{3}}}
$$

Where $\bar{X} 1,2,3=$ CAI, PLL, and TMI; $S^{2}, 1,2,3=$ variance of the respective groups; and where $\mathrm{N} 1,2,3=$ sample size of each group in the same order.

These comparisons and tests of the significance of differences were calculated on a Honeywell 66 computer, and the results are given below. Such an approach has also been suggested in other studies (Borich, 1974; Gay, 1976; Feldman and Sears, 1970; Bozeman and Burns, 1981; Tuckman, 1979). 


\title{
TAELE VIII
}

\author{
PRE-TEST \\ GROUP MEAN DIFEERENTIAL
}

\begin{tabular}{|c|c|c|c|c|c|c|}
\hline & $\begin{array}{l}\text { Number } \\
\text { of Cases }\end{array}$ & Mean & $\begin{array}{l}\text { Standard } \\
\text { Deviation }\end{array}$ & $\begin{array}{l}\text { Standard } \\
\text { Error }\end{array}$ & $\begin{array}{c}F \\
\text { Value }\end{array}$ & $\begin{array}{l}2 \text {-Tail } \\
\text { Prob. }\end{array}$ \\
\hline Group 1 & 674 & 203.4733 & 19.317 & 0.744 & \multirow[b]{2}{*}{1.10} & \multirow[b]{2}{*}{0.286} \\
\hline Group 3 & 364 & 200.0440 & 18.379 & 0.963 & & \\
\hline Group 2 & 394 & 195.7970 & 13.498 & 0.680 & \multirow{2}{*}{1.85} & \multirow{2}{*}{0.000} \\
\hline Group 3 & 364 & 200.0440 & 18.379 & 0.963 & & \\
\hline Group 1 & 674 & 203.4733 & 19.317 & 0.744 & \multirow{2}{*}{2.05} & \multirow{2}{*}{0.000} \\
\hline Group 2 & 394 & 195.7970 & 13.498 & 0.680 & & \\
\hline
\end{tabular}

Separate Variance Estimate

\begin{tabular}{|c|c|c|c|c|c|c|}
\hline & $\begin{array}{l}\text { Number } \\
\text { of Cases }\end{array}$ & Mean & $\begin{array}{l}\text { Standard } \\
\text { Deviation }\end{array}$ & $\stackrel{T}{\text { Value }}$ & $\begin{array}{l}\text { Degree } \\
\text { of } \\
\text { Freedom }\end{array}$ & $\begin{array}{c}\text { 2-Tail } \\
\text { Prob. }\end{array}$ \\
\hline Group 1 & 674 & 203.4733 & 19.317 & \multirow[b]{2}{*}{2.82} & \multirow[b]{2}{*}{776.31} & \multirow[b]{2}{*}{0.005} \\
\hline Group 2 & 364 & 200.0440 & 18.379 & & & \\
\hline Group 2 & 394 & 195.7970 & 13.498 & \multirow{2}{*}{-3.60} & \multirow{2}{*}{662.88} & \multirow[t]{2}{*}{0.000} \\
\hline Group 3 & 364 & 200.0440 & 18.379 & & & \\
\hline Group I & 674 & 203.4733 & 19.317 & \multirow{2}{*}{7.62} & \multirow{2}{*}{1032.84} & \multirow{2}{*}{0.000} \\
\hline Group 2 & 394 & 195.7970 & 13.498 & & & \\
\hline
\end{tabular}

The comparison of (a) and (b) in the t-test above confirmed the hypotheses that the pre-tests of CAI would be slightly greater than those of PLL and TMI. The t-ratio for (a) is 2.82 , significant at .005; the t-ratio is 7.62 for (b), significant at 0.0001 , and the t-ratio for (c) is -3.60 also significant at 0.0001 . Therefore, the null hypotheses 
in both cases is supported. The third comparison (c) is between PLL and TMI. The hypothesis that the pre-test of PLI would be smaller than TMI is supported. The difference showed a T-ratio of -3.64 , which is significant at 0.0001 .

The findings of significant differences between group pre-tests calls for precaution when comparing and interpreting the group differences of post-test achievements. Differences between post-test achievements in the three grcups may be due to initial differences. Since we know that the pre-tests are correlated with the post-test, it is possible that the outcome may be dependent on the initial level of achievement. The next logical step, then, is to test for differences among the post-test scores.

\section{TREATMENT OUTCOME ASSESSMENT}

\section{Post-test Analysis}

The second important part of the research is the comparison of the post-treatment outcomes. Post-treatment achievement is at the heart of this research. As stated in the previous chapter, the hypothesis is that post-test achievement would show significant differences among the three groups. The calculated results below show differences of post-test achievement among the three groups. 
The post-test achievements of the groups are:

$$
\begin{aligned}
& Y_{1}=209.095 \\
& Y_{2}=200.492 \\
& Y_{3}=203.852
\end{aligned}
$$

In light of this finding, the following hypotheses are confirmed:

$$
\begin{aligned}
& \text { (a) } Y_{1}>Y_{2} \\
& \text { (b) } Y_{1}>Y_{3} \\
& \text { (c) } Y_{3}>Y_{2}
\end{aligned}
$$

The t-test formula is modified for testing the difference in the means of the post-test, as given below:

(a) CAI vs. TMI

$$
t_{d 1}=\frac{\left(\bar{Y}_{1}-\bar{Y}_{3}\right)}{\sqrt{s_{1}^{2} / n_{1}+s_{3}^{2} / n_{3}}}
$$

(b) CAI vs. PLL

$$
t_{\mathrm{d} 2}=\frac{\left(\bar{y}_{1}-\bar{y}_{2}\right)}{\sqrt{s_{1}^{2} / n_{1}+s_{2}^{2} / n_{2}}}
$$

(c) PLL vs. TMI

$$
t_{d 3}=\frac{\left(\bar{y}_{2}-\bar{y}_{3}\right)}{\sqrt{s_{2}^{2} / n_{2}+s_{3}^{2} / n_{3}}}
$$

The t-ratios derived from these equations are 5.03, 
8.91 and -3.29 respectively. So, the hypotheses predicting that post-test achievement of the CAI participants would be greater than PLL and TMI is accepted. The probablity of this finding occurring by chance is less than one in ten-thousand $(.0001)$ in both cases. The hypothesis that the achievement of the comparison group, TMI, would be greater than that of the PLL group is also confirmed and accepted. The probability of this happening by chance is one in one thousand $(0.001)$.

The finding of differences in pre-test and post-test achievement may lead to paradoxical conclusions regarding treatment effects. It is obvious that treatments make differences; however, how much gain learners make depends on where each group started. Accordingly, the next section addresses the question of the differences in treatment outcome when all participants start on an equal footing. 
TABLE IX

POST-TEST
GROUP MEAN DIFEERENTIAL

\begin{tabular}{|c|c|c|c|c|c|c|}
\hline & $\begin{array}{l}\text { Number } \\
\text { of Cases }\end{array}$ & Mean & $\begin{array}{l}\text { Standard } \\
\text { Deviation }\end{array}$ & $\begin{array}{l}\text { Standard } \\
\text { Error }\end{array}$ & $\begin{array}{c}\text { F } \\
\text { value }\end{array}$ & $\begin{array}{c}\text { 2-Tail } \\
\text { Prob. }\end{array}$ \\
\hline Group 1 & 674 & 209.0950 & 18.114 & 0.698 & \multirow[b]{2}{*}{1.50} & \multirow[b]{2}{*}{0.000} \\
\hline Grolip 3 & 364 & 203.8516 & 14.772 & 0.774 & & \\
\hline Group 2 & 394 & 200.4924 & 13.234 & 0.667 & \multirow{2}{*}{1.25} & \multirow{2}{*}{0.033} \\
\hline Group 3 & 364 & 203.8516 & 14.772 & 0.774 & & \\
\hline Group 1 & 674 & 209.0950 & 18.114 & 0.698 & \multirow{2}{*}{1.87} & \multirow{2}{*}{0.000} \\
\hline Group 2 & 394 & 200.4924 & 13.234 & 0.667 & & \\
\hline & $\begin{array}{l}\text { Number } \\
\text { of Cases }\end{array}$ & Mean & $\begin{array}{l}\text { Standard } \\
\text { Deviation }\end{array}$ & $\begin{array}{c}\text { eparate } v \\
T \\
\text { value }\end{array}$ & $\begin{array}{l}\text { Jariance } \\
\text { Degree } \\
\text { of } \\
\text { Freedom }\end{array}$ & $\begin{array}{c}\text { 2-Tail } \\
\text { Prob. }\end{array}$ \\
\hline $\begin{array}{l}\text { Group } 1 \\
\text { Group } 2\end{array}$ & 364 & $\begin{array}{l}209.0950 \\
203.8516\end{array}$ & $\begin{array}{l}18.114 \\
14.772\end{array}$ & 5.03 & 879.23 & 0.000 \\
\hline $\begin{array}{l}\text { Group } 2 \\
\text { Group } 3\end{array}$ & 394 & $\begin{array}{l}200.4924 \\
203.8516\end{array}$ & $\begin{array}{l}13.234 \\
14.772\end{array}$ & -3.29 & 730.12 & 0.001 \\
\hline Group 1 & 674 & 209.0950 & 18.114 & \multirow{2}{*}{8.91} & \multirow{2}{*}{1014.59} & \multirow{2}{*}{0.000} \\
\hline Group 2 & 394 & 200.4924 & 13.234 & & & \\
\hline
\end{tabular}

\section{Adjusted Post-Test}

Findings of differences between the pre-tests calls for adjustment of initial differences (i.e, pre-test). However, it is necessary to raise the question, would there be significant differences in adjusted post-treatment achievement? As stated in the hypothesis, the answer to 
this question is anticipated to be in the affirmative.

An adjustment of the criterion variable for covariate differences is appropriate for a technically sound comparison of the post-test differences, as these are influenced by the level of the covariate (Kerlinger, 1973). The process of controlling pre-test differences and their effects on post-tests results require the following statistical approach for the three groups, CAI, PLL and TMI, respectively:

$$
\begin{aligned}
& \text { (1) } \bar{Y}_{1} \text { adje }=\bar{Y}_{1}-b\left(\bar{X}_{1}-\bar{X}\right) \\
& \text { (2) } \bar{Y}_{2} \text { adj. }=\bar{Y}_{2}-b\left(\bar{X}_{2}-\bar{X}\right) \\
& \text { (3) } \bar{Y}_{3} \text { adj. }=\bar{Y}_{3}-b\left(\bar{X}_{3}-\bar{X}\right)
\end{aligned}
$$

Where $\bar{Y}_{1}, \bar{X}_{1}$ are mean post- and-pre-tests, respectively; $i=$ $1,2,3$ group membership of CAI, PLL, and TMI in the same order; $\mathrm{X}$ is the grand mean of $\mathrm{all}$ pre-tests; and $\mathrm{b}$ is the common regression weight.

The grand mean of the pre-test is $x=200.49$, Rit score, and the common regression weight is $b=0.83457$. The post-tests are $Y_{1}=209.095, Y_{2}=200.492$, and $Y_{3}=203.852$. The mean pre-tests are $\mathrm{x}_{1}=203.473, \mathrm{x}_{2}=195.797$ and $\mathrm{x}_{3}=200.044$. The application of the three formulas above is as follows:

$$
\begin{aligned}
& \bar{Y}_{1} \text { adj }=206.605 \\
& \bar{Y}_{2} \text { adj }=204.408
\end{aligned}
$$




$$
\overline{\mathrm{Y}}_{3} \text { adj. }=203.523
$$

Therefore, the three hypothes are accepted as shown below:

(a) $\bar{Y}_{1}$ adj. $>Y_{3}$ adj. is accepted since $(206.605)>(203.523)$

(b) $\bar{Y}_{1}$ adj. $>Y_{2}$ adj. is accepted since $(206.605)>(204.408)$

(c) $\bar{Y}_{2}$ adj. $>Y_{3}$ adj. is accepted since $(204.408)>(203.523)$

The last statistical test to be carried out is to determine whether the differences between the adjusted mean post-tests are significant. The following formula is applied for this purpose:

$$
t_{i j}=\frac{\bar{y}_{i} \text { adj. }-\bar{y}_{j} \text { adj. }}{\sqrt{M S R(1 / n i}+1 / n j)+1+(\text { ss resc/Kss Resc })}
$$

where $i, j=$ represent membership; $M S R=$ residual mean square; $\mathrm{n}_{i}, \mathrm{n}_{j}$ = number of subjects in groups $i$ and $j ;$ ss Reg $C=$ regression sum of the squares of the residuals; $K=$ number of coded vectors or degrees of freedom for treatments.

A comparison of adjusted post-test achievement differences between CAI and TMI has a t-ratio $\left(t_{1}, 3\right)$ of 3.6416, which is significant at $p=0.01$. A similar comparison of the significance between CAI and PLL is $t_{1}{ }^{\prime}=2.6621$, which is also significant at 0.01 . A test of the significance between PLL and TMI is $t_{2 \cdot 3}=0.9881$, which is insignificant at 0.5 level. 


$$
\begin{aligned}
& \text { (a) } t_{1,3}=3.5416 \text {, significant at } .01 \\
& \text { (b) } t_{1,2}=2.6621 \text {, significant at .01 } \\
& \text { (c) } t_{2,3}=0.9881 \text {. not significant }
\end{aligned}
$$

The values applied in the above formula are as follows:

$$
\begin{aligned}
& \mathrm{Y}_{1} \text { adj. }=206.61 \\
& Y_{2} \text { adj. }=204.4 \\
& Y_{3} \operatorname{adj} \cdot=203.52 \\
& \text { MSR }=66.64356 \\
& \text { SS reg } c=293265.29 \\
& \text { ss res } c=95167.00 \\
& \mathrm{~N}_{1}=674 \\
& \mathrm{~N}_{2}=394 \\
& \mathrm{~N}_{3}=364
\end{aligned}
$$

\section{Treatment Impact Analysis}

A significant difference between adjusted group means in post-treatment results is a logical base from which to explore treatment impact, or group membership effect. As mentioned earlier, this is a major research question.

The issue is whether achievement differences can be explained by treatment group membership. The sub-parts to this issue are, 1 . whether group membership is related to achievement; and if so, 2. whether the two experimental groups CAI and PLL have equal effect on achievement; and 3 . whether the relationship can best be explained in a linear or nonlinear model. An optimal regression model should 
examine the combined effects of pre-test group membership and the interaction between pre-test and group membership (Horst et al., 1975; Jamison et al., 1974; Kerlinger, 1973; Borich, 1978; and Gay, 1976). Hence, it is also postulated that group membership, a dummy variable, would significantly contribute to the explanation of changes in post-test ashievement. It is alsc postulated that a polynominal model would be the best to account for changes in achievement. The models below are developed and tested:

$$
\begin{aligned}
& \text { 1. Iinear: } \mathrm{Y}=\mathrm{f}\left(\mathrm{X}, \mathrm{D}_{1}, \mathrm{D}_{2}, \mathrm{I}_{1}, \mathrm{I}_{2}\right) \\
& \text { 2. quadratic: } \mathrm{Y}=\mathrm{f}\left(\mathrm{x}^{2}, \mathrm{D}_{1}, \mathrm{D}_{2}, \mathrm{C}_{1}, \mathrm{C}_{2}\right) \\
& \text { 3. polynominal: } \mathrm{Y}=\mathrm{f}\left(\mathrm{X}, \mathrm{X}^{2}, \mathrm{D}_{1}, \mathrm{D}_{2}, \mathrm{I}_{1}, \mathrm{I}_{2},\right. \\
& \left.\mathrm{C}_{1}, \mathrm{C}_{2}\right)
\end{aligned}
$$

Where: $Y=d e p e n d e n t$ variable, post-test

$$
\begin{aligned}
& \mathrm{X}=\text { pre-test } \\
& \mathrm{D}_{1}=\text { dummy variable for } \mathrm{CAI}=1 \\
& \mathrm{D}_{2}=\text { dummy variable for } \mathrm{PLI}=1 \text { and } \mathrm{D}_{3}=0 \\
& \mathrm{x}^{2}=\text { quadratic function of the pre-test } \mathrm{X} \\
& \mathrm{I}_{1}=\text { linear interaction between } \mathrm{X} \text { and } \mathrm{D}_{1} \\
& \mathrm{I}_{2}=\text { linear interaction between } \mathrm{X} \text { and } \mathrm{D}_{2} \\
& \mathrm{C}_{1}=\text { quadratic interaction between } \mathrm{X}^{2} \text { and } \mathrm{D}^{2} \\
& \mathrm{C}_{2}=\text { quadratic interaction between } \mathrm{x}^{2} \text { and } \mathrm{D}^{2}
\end{aligned}
$$

The additive models are given in the previous chapter (EQ. 4.8-4.10). They are as follows.

1. Linear model:

$$
Y=a_{0}+a_{1} X+a_{2} D_{1}+a_{3} D_{2}+a_{4} I_{1}+a_{5} I_{1}+E_{1}
$$


2. Quadratic model:

$$
Y=r_{0}+r_{1} X^{2}+r_{2} D_{1}+r_{3} D_{2}+r_{4} C_{1}+r_{5} C_{2}+E_{2}
$$

3. Polynominal model:

$$
Y=a_{0}+b_{0} X+b_{1} D_{1}+b_{2} D_{2}+b_{3} x^{2}+b_{4} I_{1}+b_{5} I_{2}+b_{6} c_{1}+b_{7} C_{2}+E_{0}
$$

The hypothesis of group membership influence of the polynominal model follows mathematically:

$$
\begin{aligned}
\mathrm{H}_{0}: & \mathrm{H}_{\mathrm{a}}: \\
\mathrm{H}_{1}: \mathrm{b}_{1}>\mathrm{b}_{2} & \mathrm{~b}_{1} \ngtr \mathrm{b}_{2} \\
\mathrm{H}_{2}: \mathrm{b}_{1}<\mathrm{b}_{2} & \mathrm{~b}_{1} \neq \mathrm{b}_{2} \\
\mathrm{H}_{\mathrm{a}}: \mathrm{b}_{1}=\mathrm{b}_{2} & \mathrm{~b}_{1} \neq \mathrm{b}_{2}
\end{aligned}
$$

The regression result of the linear model is in Table XXXIV.

$$
\begin{aligned}
& \mathrm{Y}=47.026+0.784 \mathrm{X}+2.555 \mathrm{D}_{1}-0.030 \mathrm{D}_{2}+1.080 \mathrm{I}_{1}-0.130 \mathrm{I}_{2} \\
& \text { t-ratio }=(18.93)(64.09)(4.80) \quad(-0.05) \quad(7.16) \quad(-0.73) \\
& \text { t-sig. }=\begin{array}{llllll}
.0000 & .0000 & .0000 & .9601 & .0000 & .4637
\end{array}
\end{aligned}
$$

Hypothesis $b_{1}>b_{2}$ is accepted and the hypothesis of significant contributions to the explanation of achievement variation is true for $\operatorname{CAI}\left(D_{1}\right)$ and not for $\operatorname{PLL}\left(D_{2}\right)$. The effectiveness of CAI over TMI and PLL is proven with confidence. However, the effectiveness of PLL over TMI is questionable as the effectiveness coefficient slightly declines for every unit of increase in achievement. In every occasion of marginal change in achievement, $D_{1}$ changes by 2.55 and $D_{2}$ changes by -0.03 .

The second hypothesis is whether it is the linear $\left(R_{1}^{2}\right)$, the quadriatic $\left(R_{2}^{2}\right.$ or the polynominal $\left(R_{3}^{2}\right)$ model 
that is optimal in the explanation of changes in achievement.

$$
H_{\circ}: R_{1}^{2}<R_{2}^{2}<R_{3}^{2} \quad H_{a}: R_{1}^{2} R_{2}^{2} \nmid R_{3}^{2}
$$

When the full model was regressed, a problem of multi-collinearity was encountered (Table XXX). To solve collinearity problems, one classic solutions--the application of deviation scores--was considered relevant and was applied. A full model was then rewritten as follows, using deviation scores.

$$
\left.Y=B_{0}+B_{j}\left(X_{j}-\bar{x}\right)+B_{2}\left(X_{j}-\bar{x}\right)^{2}+B_{3} D_{1}+B_{4} D_{2}+B_{g}\left(X_{j}-\bar{x}\right) \cdot D_{1}+B_{6}\left(X_{j}-\bar{x}\right) \cdot O_{2}+B_{7}\left(X_{j}-\bar{X}\right)\right)^{2} \cdot D_{1}-B_{3}\left(X_{j}-\bar{x}\right)^{2} \cdot D_{2}+E
$$

This approach successfully corrected the collinearity problem (Table XXXIII and XXXIV). Then, the first step was to conduct a regression analysis to discover whether the linear model was better than the quadratic model in identifying both the impact of group membership and pre-test scores on post-test achievement. The second step was to. determine whether the three groups can be represented in a single polynomial equation. In other words, the task was to ascertain whether the three groups had either a common slope or parallel regression lines (Borich, 1974; Kerlinger, $1973)$.

The following formula was used to test the significance of interactions, common regression weights, or slope differences and intercepts as well. 


$$
F=\frac{R_{F}^{2}-R_{R}^{2} / d-2}{\left(1-R_{F}^{2}\right) /(N-K-1)}
$$

A multiple regression analysis was performed and from it were derived the coefficients of determination $R^{2}$ on the linear $\left(R_{1}^{2}\right)$, the quadratic $\left(R_{2}^{2}\right)$, and the polynomial or full $\left(R_{3}^{2}\right)$ models. The result is given below:

$$
\begin{aligned}
& \text { 1. } \mathrm{R}_{1}^{2}=\mathrm{R}_{\mathrm{Y}}^{2} \mathrm{XD}_{1} \mathrm{D}_{2} \mathrm{I}_{1} \mathrm{I}_{2}=.75500 \\
& \text { 2. } \mathrm{R}_{2}^{2}=\mathrm{R}_{\mathrm{Y}}^{2} \mathrm{X}^{2} \mathrm{D}_{1} \mathrm{D}_{2} \mathrm{C}_{1} \mathrm{C}_{2}=.76897 \\
& \text { 3. } \mathrm{R}_{3}^{2}=\mathrm{R}_{\mathrm{Y}}^{2} \mathrm{XX}^{2} \mathrm{D}_{1} \mathrm{D}_{2} \mathrm{I}_{1} \mathrm{I}_{2} \mathrm{C}_{1} \mathrm{C}_{2}=.77282
\end{aligned}
$$

This finding confirmed the hypothesis that the polynominal coefficient of determination, explains a greater portion of the variation in achievement.

From the above we see the significance of a linear interaction $F=31.1361$, significant at .01 level. Quadratic interaction is $\mathrm{F}=11.3252$, significantly above the .01 level. The intercept or treatment effect test is $F=13.9549$, which is also very significant. It is obvious that a significant difference of intercepts among the groups is indicative of a lack of a common slope. This means that regression lines of the three groups are not parallel. Hence, the three groups 
should not be represented with one equation, but should instead be represented by separate equations. The three equations for the three groups were derived from the general or full model (3), cited above. This model is selected because, as shown, it is optimal in explaining variation in the dependent variable. The regression output is based on CAI $\left(D_{1}\right)$ as a control group and it is given in the following table.

A regression of post-test on pre-test, group membership and the interaction factor accounted for 77.3 percent of the variation of the estimated changes. Similar studies were able to account for 58 percent to 85 percent of the post-test variation (walberg and Frederick, 1980), and 4 percent to 16 percent in Hinckley, 1978 . 
TABLE $X$

POLYNOMINAL MULTIPLE REGRESSION

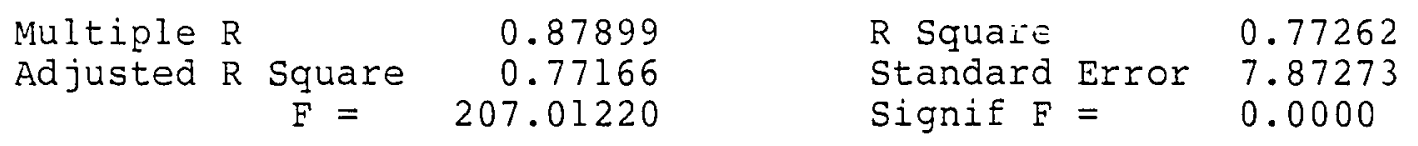

ANALYSIS OF VARIANCE

DF SUM OF SQUARES MEAN SQUARE

$\begin{array}{lrrr}\text { Regression } & 6 & 300111.00173 & 50018.50029\end{array}$

$\begin{array}{llll}\text { Residual } & 1425 & 83321.23593 & 61.97985\end{array}$

DEPENDENT

VARIABLES IN THE EQUATION--

\begin{tabular}{lrlrr} 
Variable & \multicolumn{1}{c}{$\mathrm{B}$} & \multicolumn{1}{c}{ SE B } & \multicolumn{1}{c}{$\mathrm{T}$} & SIG T \\
X11 & & & & \\
W22 & 0.82754 & 0.01395 & 59.338 & 0.0000 \\
C3 & 0.00359 & $0.5210 \mathrm{E}-03$ & 6.892 & 0.0000 \\
C33 & -0.00287 & $0.5869 \mathrm{E}-03$ & -4.892 & 0.0000 \\
D2 & -0.15219 & 0.02948 & -5.163 & 0.0000 \\
D3 & -1.61186 & 0.51680 & -3.119 & 0.0019 \\
C2 & -1.34495 & 0.55586 & -2.420 & 0.0157 \\
C22 & -0.01571 & 0.04318 & -0.988 & 0.3638 \\
(CONSTANT) & -0.00345 & 0.16270 & -0.212 & 0.3319 \\
& 205.25628 & 0.36240 & 563.377 & 0.0000
\end{tabular}

$$
\text { Where } \begin{aligned}
x_{11} & =\left(x_{j}-\bar{x}\right) \\
w_{22} & =\left(x_{j}-\bar{x}\right)^{2} \\
C_{3} & =x_{11} * D_{3} \text { linear interaction of } D_{3} \\
C_{33} & =w_{22} * D_{3} \text { quadratic interaction of } D_{3} \\
C_{2} & =x_{11} * D_{2} \text { linear interaction of } D_{2} \\
C_{22} & =w_{22} * D_{2} \text { quadratic interaction of } D_{2}
\end{aligned}
$$

The three equations that were derived from the regression output table above are given below: 
1. CAI: $Y_{1}=a_{1}+b_{1}\left(X_{j}-\bar{X}\right)+c_{1} D_{1}+d_{1}\left(X_{j}-\bar{X}\right)^{2}+g_{1}\left(X_{j}-\bar{X}\right) D^{2}$ $h_{1}\left(x_{j}-\bar{x}\right) D^{2}$

2. PLL: $Y_{2}=a_{2}+b_{2}\left(X_{j}-\bar{x}\right)+c_{2} D_{2}+d_{2}\left(X_{j}-\bar{X}\right)^{2}+g_{2}\left(X_{j}-\bar{x}\right)^{2} d_{2}$ $+h_{2}\left(x_{j}-\bar{x}\right) D_{2}$

3. TMI : $Y_{3}=a_{3}+b_{3}\left(X_{j}-\bar{X}\right)+c_{3} D_{3}+a_{3}\left(x_{j}-\bar{x}\right)^{2}+g_{3}\left(x_{j}-\bar{x}\right)^{2} D_{3}$ $+h_{3}\left(x_{j}=-D_{3}\right.$

Each of these three equations can be reduced to the following form.

(i) $\quad Y_{1}=a_{1}+b_{1}\left(X_{j}-X\right)+d_{1}\left(X_{j}-X\right)^{2}+E \quad$ (EQ 5.6)

(ii) $Y_{2}=a_{2}+b_{2}\left(x_{j}-X\right)+a_{2}\left(x_{j}-X\right)^{2}+E \quad$ (EQ 5.7)

(iii) $Y_{3}=a_{3}+b_{3}\left(X_{j}-X\right)+d_{3}\left(X_{J}-X\right)^{2}+E$ (EQ 5.8)

When the deviation scores are substituted in the equations, the final simplified separate equations are as follows.

CAI: $Y_{1}=202.30+0.9832 \mathrm{X}_{1}+0.2217 \mathrm{X}_{1}^{2}+\mathrm{E}$

PLL: $Y_{2}=203.84+0.8241 x_{2}-0.01212 x_{2}^{2}+E$

TMI : $Y_{3}=203.91+0.6754 \mathrm{X}_{3}+0.00072 \mathrm{X}_{3}^{2}+\mathrm{E}$

The three equations above have differences that should be pointed out. The pre-test, $x_{1}, x_{2}$, and $x_{3}$ have significant regression coefficients, i.e. $b_{1}=.98, b_{2}=.82$, and $b_{3}=.67$ which is the change in each independent variable associated with a marginal change in the dependant variable, $Y_{1}, Y_{2}$, and $Y_{3}$ respectively. The elasticity of the pre-tests, $\mathrm{d}_{1}, \mathrm{~d}_{2}$, and $\mathrm{d}_{3}$ is very strong in CAI and very weak in TMI. That means the elasticity of the pre-test in CAI and TMI is positive, while negative in PLL, for every unit of change in the post-test. 
When predicted values of $Y$ (post-test) are plotted against $X$ (pre-test) in a graph, the relative positions of the groups' performance can be reproduced visually. As the following graph shows, the three groups are different both in their quadratic trends and to the extent to which each method of treatment makes a difference at a given level of pre-test.

The following graph shows that the youngsters of the three groups whose achievement was less than 190 Rit Group I, Group II and Group III displayed distinctive hierarchical differences.

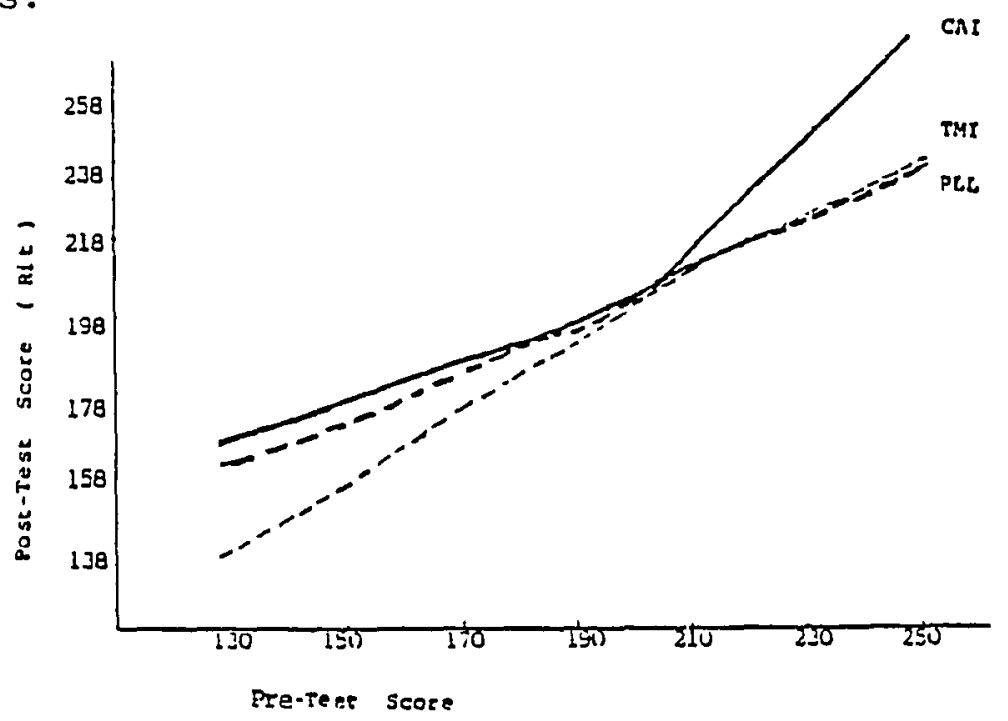

Figure 7. Regression of post-test on pre-test. With a pre-test achievement of 210 Rit, CAI consistently outperformed both PLL and TMI. Beyond this point, PLL and TMI do not differ in their effectiveness. As the graph shows, both groups can be represented by a single equation for those whose achievement is between 190 and 150 Rit scores. Both groups appear to have equal outcome values 
for the range of pre-test scores cited above. However, it is not logical, and hence inconclusive, to project treatment effects beyond the range of the observations represented by the data. Therefore, the analysis on the graph should be limited to 250 Rit of $x$-value. It is clear that, according to the findings of the regression and other tests of differences of the means discussed above, CAI is highly effective in helping youngsters with learning disadvantages.

A micro-analysis of the above regression findings shows differences in an explicit manner. Although use of gain scores has been criticized for its short-comings, its application here is not used as a single criterion of assessment, but as a supplementary one. Moreover, the computation of gain scores here is based on a predicted value of the regression model, as discussed above. When such gains are plotted against observed pre-test achievement, as shown below, it produces a graph of the most probable trend of treatment effectiveness. Moreover, the graph is a form of marginal productivity assessment that magnifies the treatment effect for each group. The graph demonstrates three distinct trends that deserve a closer examination

First of all, the three methods of treatment do help disadvantaged youngsters. Youngsters participating in one of the three treatments are, on the average, better off when compared to their pre-treatment performance rank, especially 
those whose pre-test is less than 213 Rit. Second, in the range between 130 and 213 Rit, there are clear performance differences. The gain scores of each group declines as the pre-test increases. This is a manifestation of the classical case where the increase in pre-test scores has a pull-effect on the level of the post-test score, thereby reducing the growth chance. Third, beyond the point of 205, there appears to be a trend toward divergence. Two groups, PLL and TMI, show negative score differences (i.e., the post-treatment outcome was lower than pre-treatment achievement) for youngsters with pre-test scores higher than 195 Rit. Unlike these two groups, the thira group, CAI, experienced a drastic increase in gain scores as the level of pre-test scores increased. Therefore, the outcome refinement technique, an examination of achievement differences that may be due tc noninstructional factors is necessary. It is expected to contribute to a better understanding of the circumstances that influence outcome. Hence, it is a clear extension of the inquiry of performance differences. 


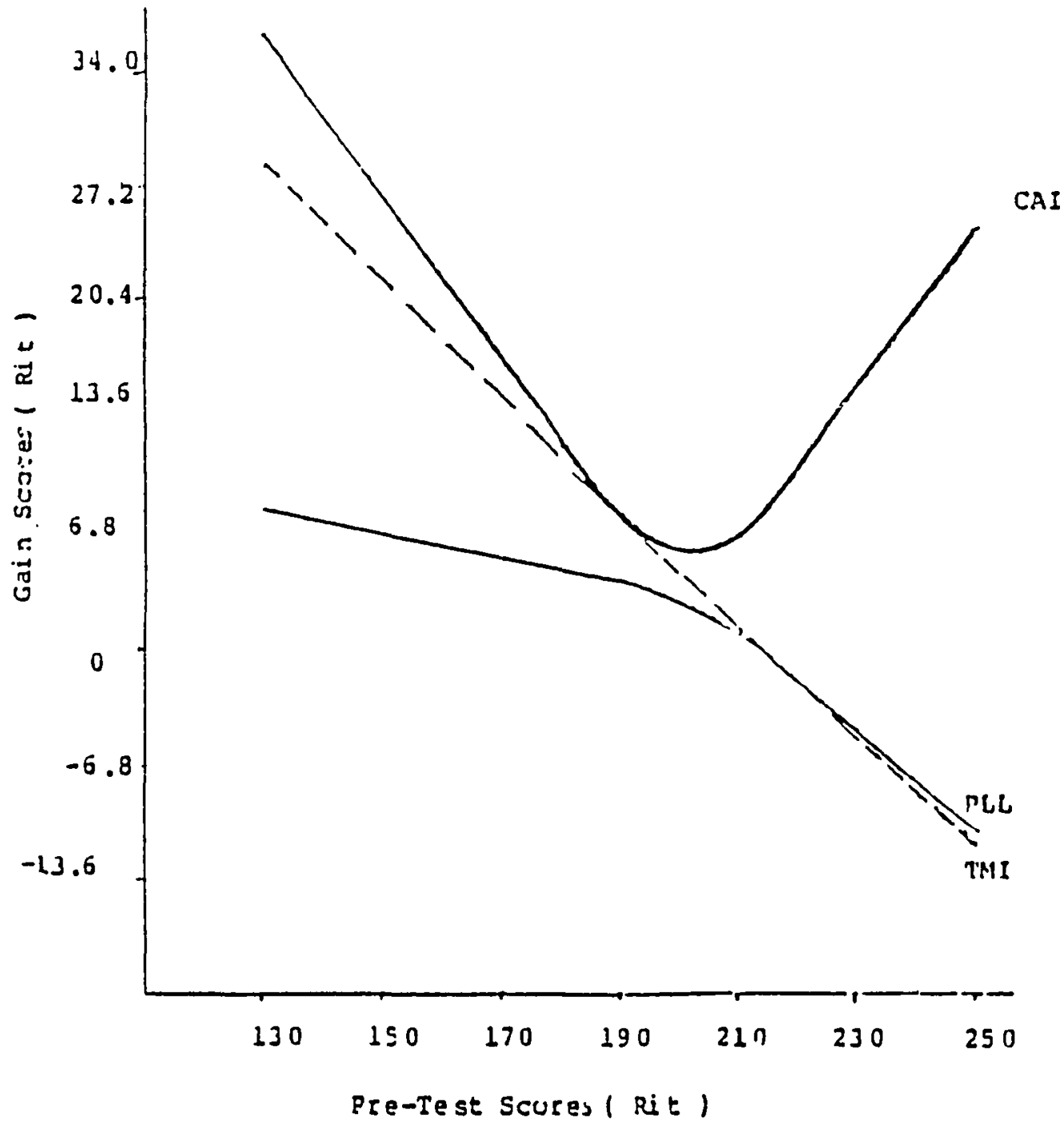

Figure 8. Predicted Gain Scores by Method of Instruction.

The second observation to be made from the graph is that there appear to be two different categories each within the PLL and the TMI treatment groups. Those who had very low pre-test scores achieved high gains, mainly due to growth chance and treatment effect. Unlike the high achievers, the low achievers are those who had high pre-test scores and then a slightly higher post-treatment achievement, which resulted in an overall lower gain. In 
the CAI treatment group, there appears to be three sub-groups: 1. those who had very low pre-tests and who achieved very high gains; 2 . those who had moderate pre-test scores and who achieved moderate gains; and 3 . those who had very high pre-test scores and who achieved very high gains. It is obvious that CAI helps low and high achievers with little ur no effect on average achievers. These differences are closely examined below using various additional criteria in order to see, first, whether the hierarchal effectiveness discussed above can be confirmed, and secondly, whether nontreatment factors contributed to the differences noted.

\section{Input-Output}

The assessment of time value is extended a step further in the comparison of the three programs, CAI, PLI and TMI. Time in this case is "months," unlike the above approach that used minutes as a measure of time. Time and other resources used in the experimental programs are converted into achievement scores. Such scores create the opportunity to compare the input time period with the time equivalent of the output. This process is captured in what is henceforth referred to as the input-output ratio (I/O).

Arriving at the $\mathrm{I} / O$ ratio assessment is a complex process. First, the Rit score of the pre-test and the post-test are converted into a normal curve equivalence (NCE) by using the 1978 Californian Achievement Test (CAT), employing a norm table especially developed for Rit score 
conversion. The NCE is then converted into percentile figures. The percentiles in turn, are converted into standard scores, which are equated with grade-equivalents (GE). This approach has been used in various studies, because of the simplicity of the idea in understanding progress (Suppes et al., 1970, Tallmadge, 1976).

Grade equivalent is a unit of progress measurement which may be misleading unless treated with caution.

Donald Horst and Tallmadge have discussed the hazards associated with the use of grade equivalent as a unit of cognitive growth measurement. Despite hazards, research findings on learning achievement are reported in grade equivalents because they are easy to understand (Corley and Lewis, 1975; Parkus, 1970; Wells et al., 1974; Edwards, 1974; Sumner, 1979; and NWREL, 1981). The public Iaw regarding Title I also recognizes grade equivalents as measurement of progress. Thus, this research has used grade equivalent as one of the learning growth measurements, in addition to others.

One of the drawbacks of the grade equivalent approach is the assumption that learning is a linear growth. Contrary to this assumption, research findings show that learning, i.e., cognitive growth, is not linear. For instance, a child at the 50th percentile is not always at grade level (Tallmadge, 1976, p. 79-84). Grade equivalent is a ten-unit measurement, representing nine units for the 
nine-month academic year and one-unit for the three-month summer. In real terms, there is onl $y$ a seven-month treatment period, not a nine-month one. Between the norm period, October (pre-test) and April (post-test), there are only seven months. However, 1.0 grade-equivalent (GE) represents a one-year achievement, and $1.3 \mathrm{GE}$. represents a one-year-and-three-month achievement. A comparison of . achievements (i.e pre-test, post-test and then gain scores) was done in terms of grade-equivalents. The simplicity of the approach and ease of understanding, has made grade-equivalent prefereble at the cost of a systematic distortion of the relationship between empirically determined cognitive growth and test scores (Tallmadge, 1976, pp. 88-92).

The grade equivalent criteria of treatment-effect assessment is, in a way, the time value of achievement. Various studies have used various measurements of time, e.g., years, weeks, days, hours, or minutes (walberg and Frederick, 1980). As mentioned in Chapter IV, this research uses minutes, months, and years as needed. To assess the full impact of time, this research used an input-output approach. The first step is to investigate the relationship between treatment time and the output value of time spent on learning tasks in terms of grade equivalent months.

Contribution of time as an input factor in the treatment process can be evaluated using the computer 
Curriculum Corporation (CCC) method and no-treatment expectation criteria. Under the CCC criteria, a one-month treatment input should produce one month grade equivalent of achievement. Hence, the question is whether CBI output is greater than the input; it is predicted that the outcome will be greater in CBI than in TMI.

Model

Let $t_{1}$ be the length of treatment time in a month and let it be the sum of the treatment effect in month grade equivalent (GE). An input-output (value added) model is as follows:

Input time value $=\sum_{i=0}^{n} t_{i k} \quad(E Q 5.9)$

Output time value $=\sum_{j=0}^{n} t_{j k}$

Where:

$\mathrm{k}=$ skill area

$t=$ aggregate time in months

$i=$ input month

$j=$ output month

Output-input or value-added Ratio $=O T V / I T V=(V A R)$

$$
\operatorname{VAR}=\frac{\sum_{i=0}^{n} t_{j k}}{\sum_{j=0}^{n} t_{i k}}
$$


Let $\mathrm{VAR}_{1}=\mathrm{CAI}$ and $\mathrm{VAR}_{2}=\mathrm{PLL}$ and $\mathrm{VAR}_{3}=\mathrm{TMI}$

According to the above postulate VAR should be equal or greater than one. That means the number of months of outcome divided by the number of grade equivalent input months.

$$
\begin{aligned}
& \text { (a) } \mathrm{H}_{0}: \operatorname{VAR}_{1} \geq 1 \quad \mathrm{H}_{\mathrm{a}}: \operatorname{VAR}_{1} \unrhd 1 \\
& \mathrm{VAR}_{1}>\mathrm{VAR}_{3} \quad \mathrm{VAR}_{1} \mathrm{VVAR}_{3} \\
& \text { (b) } \mathrm{H}_{0}: \operatorname{VAR}_{2} \geq 1 \quad \mathrm{H}_{\mathrm{a}}: \operatorname{VAR}_{2} \perp 1 \\
& \mathrm{VAR}_{2}>\mathrm{VAR}_{3} \quad \mathrm{VAR}_{2} \mathrm{PVAR}_{3}
\end{aligned}
$$

For every month of participation in the treatment program, a youngster in the CAI group acquires on the average, a little more than two months of progress, while a youngster in the PLL group gains only one and one half months. Those in TMI barely met the criteria of effectiveness, i.e., one month of return for every month of treatment. It is important to note that the participants in the three groups were exposed to treatment packages with comparable instruction in content and curriculum plans. If the recommended amount of instruction is delivered, this criterion amounts to an implicit rate of return. The grade equivalent gain scores are given in the following table by treatment groups and skill areas. 
TABLE XI

\section{INSTRUCTIONAL INTPUT-OUTPUT \\ IN GRADE EQUIVALENTS}

$\begin{array}{lllr}\text { Group } & \text { Mth. } & \text { Rd. } & \text { Average } \\ \text { 1. CAI } & 2.3 & 1.8 & 2.05 \\ \text { 2. PLL } & 1.6 & 1.5 & 1.55 \\ \text { 3. TMI } & 0.8 & 1.0 & 0.92\end{array}$

According to the above table, the three groups have met the minimum conditions of a successful treatment in reading, where $V A R \geq 1.0$. This means that every month of instruction produced a return of one or more months. However, TMI failed to meet this criterion of success in mathematics by posting 0.8 year, resujting in $V A R \leq 1.0$, a rate less than one year on the average. Therefore, the grade equivalent criterion confirms the superiority of CAI, followed by PLL. The overall I/O rate for TMI is below the minimum requirement, but it is very close, at VAR=.92. Therefore, the hypothesis that predicted that the experimental treatment would meet the minimum conditions and show a better performance than TMI is correct and it is accepted. The comparison of the above findings to other studies shows that only in a few cases was such high achievement reported. Some of the studies that had similarities of approaches to this research reported grade equivalent years .14 to .85 in Corley and Lewis (1975), .44 to 1.11 and .36 to 2.03 in Parkus $(1970), .33$ in wells et 
al. $(1974), .76$ to 1.7 in Edwards $(1974), 1.9$ to 2.3 in Fletcher and Suppes (1972), and .03 to .77 in Vinsonhaler and Bass (1972). In light of this contrast, other alternative approaches, such as percentile rank improvement, rate of learning and relative growth, should be applied to reaffirm tshe findings discussed above. The application of alternative methods that were considered are discussed below.

\section{Performance Rank Assessment}

In the educational experimental method, there is a popular assumption that if students do not appear to be learning new tasks, it is almost certain that they will not unlearn what they have learned already. In short, a student will improve his percentile rank if he/she learns new tasks. Otherwise they will maintain their rank in an after-treatment testing. Any Title I youngster performing at 22 percentile, would be expected to perform at a grade equivalent of one month gain for each month of instruction without any special efforts (Tallmadge, 1976, p.87). This is called an "expected achievement" level without treatment. Although the "no-learning" circumstances are beyond the scope of this research, we can assume that "no-treatment" expectations are greater than "no-learning" expectations. Similarly, the "treatment expectation," or expected achievement from a treatment, is greater than a "no-treatment" expectation, which is given in Figure 7 and 
discussed in detail later.

In this treatment situation, as indicated earlier, it is assumed that students will at least maintain their pre-test percentile rank during the post-test period. This is because it is a "no-treatment expectation", i.e., natural growth without treatment. It should be pointed out that a student at the 20 th percentile in the pre-test with a 170 Rit-score needs to perform higher than 170 Rit to be at the 20 th percentile rank during post-testing. The score needed to keep the student at the pre-test percentile rank in a post-test is called the "expected score" and the difference between the pre-test score and the expected score is the "expectea gain." This means that when a student is pre-tested and goes through a treatment program, the post-test result is an "observed score" or an empirical result. Treatment effectiveness can be assessed by comparing the obtained results with that of expected results (Parkus, 1970; Corley and Lewis, 1975; Fletcher and Suppes, 1972; and Horst et al., 1975).

Change in performance, or percentile rank, is an alternative way of assessing treatment effects. It is of interest to discover the pre-treatment percentile rank of the youngsters in each group by subject and grade-level. A closer analysis of the percentile rank order reveals that there is a pre-test influence, as discussed earlier, on the post-test score. A youngster with a lower percentile rank 
is likely to have a lower expected post-test rank standing. But if the treatment is effective, the obtained post-test score will enable the youngster to move to a higher-rank percentile. This treatment assessment method is applied here and the changes in percenntile derived as shown in Table XXXVI.

The findings show that CAI fifth graders participating in mathematics and reading and seventh and eighth graders participating in reading had the lowest pre-test percentile rank. The treatment effectiveness helped all CAI youngsters except eighth grade reading participants improve their post-test percentile rank. 'A comparison of the pre-test percentile rank of the three groups shows that a consistent pattern in the order of TMI, PLL, and CAI, except that sixth graders in TMI were lower than PLL in both reading and mathematics. The post-test standing more or less remained in the same order except in terms of gain scores, where groups with low pre-test achievement had advantages over others. The participants in the fifth and eighth grade mathematics in TMI suffered a setback in improving their rank, i.e., their post-test percentile was lower than their pre-test percentile--24.1 to 23.8 for fifth and 44.7 to 38.1 for eighth graders. Such negative outcomes are generally due to conditions related to testing--easy pre-test and hard post-test or other testing conditions. On the other hand, 
both CAI and PLL students had a consistently low pre-test and a very high post-test rank. This is true for almost all grade levels and subjects, except eighth grade in CAI and sixth grade reading in TMI and PLL. Therefore, the overall treatment effectiveness assessment rank standing shows that, despite major improvements, CAI and PLL did not match the post-eest standing of TMI. This finding confirms the postulate that disadvantaged groups are not homogeneous in ability and achievement, although all are below grade levels.

\section{Relative Growtin Assessment}

In the first step of reiative growth assessment, the issue to be addressed is achievement using the treatment expectation approach. To assess whether the treatment outcome is above or below expectation, a relative growth assessment model was developed. It is based on observed and expected achievement values and the change from the pre-treatment performance level. Approaches that compare obtained outcome to expectations have been commonly used in educational research, (Corley and Lewis, 1975; Fletcher and Suppes, 1972).

The common question in the comparison of obtained and expected scores is whether there is a difference between observed and expected achievement levels of both CBI and TMI, and if so, then whether that difference is in favor of CBI or TMI. Anticipated findings are that the observed 
growth will be greater than expected and more so for CBI than for TMI.

Model:

$$
r_{i}=-\frac{\left(Y_{0}-X_{i}\right)-\left(Y_{e}-X_{i}\right)}{\left(Y_{e}-X_{i}\right)} \quad \text { (EQ 5.11) }
$$

This equation can be reduced as follows:

$$
r_{i}=-\left(Y_{0}-Y_{e}\right) \quad \text { (EQ 5.12) }
$$

where $Y_{0}=$ emperical. $Y_{e}=$ expected post-test, $X_{i}=$ pre-test achievements in NCE (normal curve equivalence) $r_{l}=$ relative growth index, and $i=1,2,3$ representing the three groups. It is postulated that the relative growth index will show that CAI will be greater than the other two groups.

Sub-Hypotheses:
(a) $\mathrm{H}_{\mathrm{O}}: \mathrm{r}_{1}>\mathrm{r}_{2}>\mathrm{r}_{3}>0 \quad \mathrm{H}_{\mathrm{a}}: \mathrm{r}_{1} \not r_{2} \ngtr \mathrm{r}_{3} \ngtr 0$
(b) $\mathrm{H}_{0}: \quad r_{1}>r_{3}>r_{2}>0 \quad \mathrm{H}_{a}: r_{1} p r_{3}+r_{2}>0$

A second alternative assessment tool is the treatment-expectation criterion, which is a continuation of the re-examination of the findings with other methods discussed earlier. The treatment-expectation approach is based on three scores that are manipulated at average. The first score is the pre-test score, and the second is the expected learning progress without treatment that would enable the youngster to maintain his/her pre-test percentile during the post-test. The third score is the post-treatment 
score or the observed post-test score. The conceptual view of the difference between pre-test and expected post-test achievement, and also between pre-test and observed post-test achievement, is demonstrated in the following Eigure. The figure shows the gains difference between the two post-test achievements: as represented by the distance between the lines representing achievement with and without treatment. 


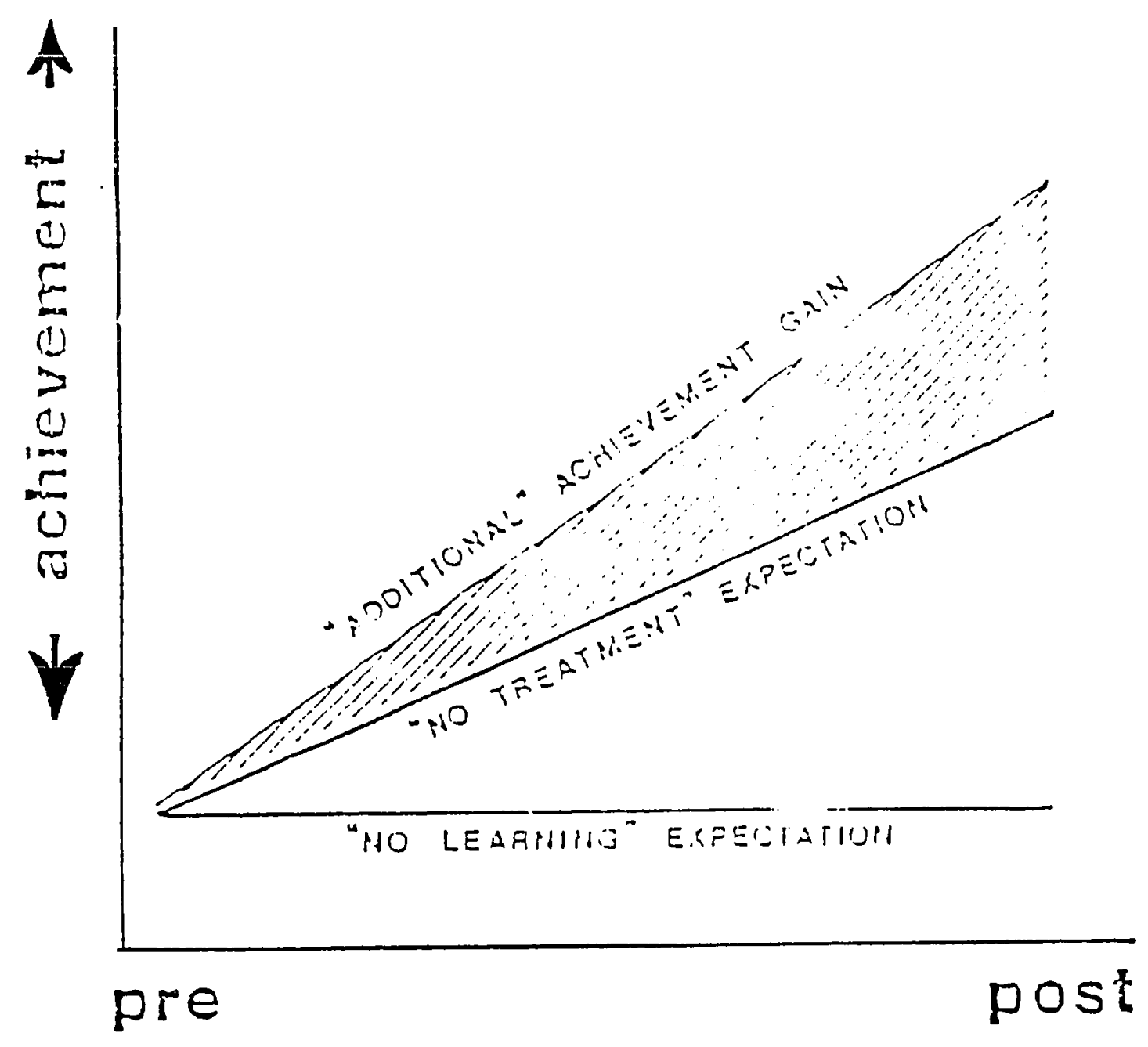

Figure 9. Treatment and no-treatment expectation achievements.

Expected scores were calculated for the three groups to find out whether observed post-treatment achievement would be greater than the expected achievement in the absence of treatment. The treatment effect, then, is assessed in relative terms of a "normal" pre-test and the expected values according to the test publisher's norm tables. The following table, derived from the actual test results, compares the two types of gain scores: 
no-treatment expectation (col. 3) and obtained treatment gains (col. 5).

TABLE XII

GAINS IN NCE

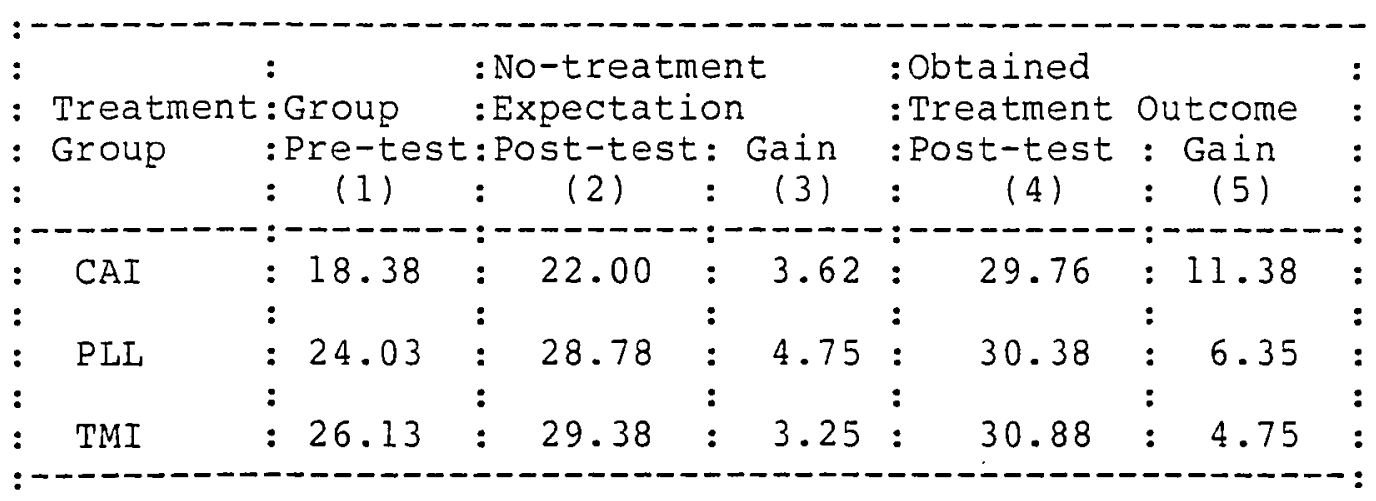

As the table shows, all three groups have surpassed their respective level of expected gains. That means column 5 is greater than column 3. A contrast among the three groups regarding the differences in the levels of obtained gain scores shows that CAI students achieved higher than the other two groups. The general finding here confirms the hierarchy of effectiveness in the order of CAI first and PLI second.

In order to test the above hypothesis, EQ 5.11 was applied to compare the obtained learning growth (gain) with the anticipated learning growth without treatment, i.e., $r_{i}$. Because of the dependence of the expected post-test score on the level of the pre-test, any difference between PLI and TMI was expected to be low, as demonstrated in previous approaches; but this approach has the advantage of adjusting 
the difference of each group's expected level:

$$
\begin{gathered}
r_{i}=-\frac{\left(Y_{0}-X_{i}\right)-\left(Y_{e}-X_{i}\right)}{\left(Y_{e}-X_{i}\right)} \\
\operatorname{CAI~}\left(r_{1}\right)=\frac{(11.38)-(3.62)=2.1436}{(3.62)} \\
\operatorname{PLL}\left(r_{2}\right)=\frac{(6.35)-(4.75)=0.3363}{(4.75)} \\
\operatorname{TMI~}\left(r_{3}\right)=\frac{(4.75)-(3.25)=0.4615}{(3.25)}
\end{gathered}
$$

Surplus growth or relative learning growth index ( $r_{i}$ ) of the three groups confirmed the postulated treatment effect. According to the above results, the hypothesis $r_{1}>r_{3}>r_{2}$ is accepted. The three groups performed better than their respective expectations. Those who participated in the CAI program, however, achieved more than twice what was expected under the "no-treatment" conditions. Similarly, those youngsters using TMI increased their expected gains scores by about fifty-percent, (.46). The second experimental program, PLI, was lower than the other two groups because of the initial high pre-test scores, which ultimately lowered the growth potential through inflated expectations relative to the pre-test scores. Consequently, the difference between the obtained and the expected post-test scores were very close. Nonetheless, the youngsters in this group were able to surpass their expected 
gain scores by over one-third (34 percent) as a result of the treatment effectiveness.

The second question raised earlier was whether the rate of learning achievement for the three groups was equal if expectation was not considered. This calls for an assessment of a simple percentage learning growth rate. It was hypothesized that the growth rate, the difference between the pre-test and the post-test scores, would not be equal and that the rate for CAI would be greater than TMI or PLL.

$$
R_{i}=\frac{\left(\mathrm{P}_{0}-\mathrm{x}_{i}\right)}{\mathrm{x}_{i}}
$$

where $\mathrm{R}=$ growth rate, $\mathrm{P}_{0}=$ Post-test score, $\mathrm{x}_{1}=$ pre-test score and $i=1,2,3$ representing the three groups.

Sub-Hypotheses:
(a) $\mathrm{H}_{0}: \mathrm{R}_{1}>\mathrm{R}_{2}>\mathrm{R}_{3}$
$\mathrm{H}_{\mathrm{a}}: \mathrm{r}_{1} \not \mathrm{r}_{2} \not \mathrm{r}_{3}$
(b) $\mathrm{H}_{0}: \mathrm{R}_{1}>\mathrm{R}_{3}>\mathrm{R}_{2}$
$\mathrm{H}_{\mathrm{a}}: \mathrm{r}_{1} \not \mathrm{r}_{3} \not \mathrm{r}_{2}$

The growth rate $\left(R_{i}\right)$ is the growth percentage a youngster achieved over his/her pre-test level. The above model EQ 5.13 was applied to figure out $R_{i}$ :

$$
\begin{aligned}
& \mathrm{R}_{1}=\frac{\mathrm{P}_{01}-\mathrm{X}_{1}}{-\mathrm{X}_{1}}=\frac{11.38}{18.3}=0.6192 \\
& \mathrm{R}_{2}=\frac{\mathrm{P}_{0} 2_{-\mathrm{X}_{2}}}{-\frac{\mathrm{N}}{\mathrm{X}_{2}}}=\frac{6.35}{24.03}=0.2643
\end{aligned}
$$


(iii)

$$
\mathrm{R}_{3}=\frac{\mathrm{P}_{\mathrm{o}}-\mathrm{X}_{3}}{\mathrm{X}_{3}}=\frac{4.75}{25.13}=0.1818
$$

According to the above findings, increases in pre-treatment level of achievement was 61.9 percent, 26.4 percent, and 18.2 percent for CAI, PLL, and TMI, respectively. This finding confirms the hypothesis $R_{1}>R_{2}>$ $R_{3}$. The youngsters using CAI experienced a very high rate of growth showing a commanding lead over those in the other two groups. 
CHAETER VI

ANALYSIS II

OUTCOME REFINEMENT

The previous chapter not only showed that there is little difference beetween PLL and TMI when the pre-test is controlled but also that there is a significant difference between these two and CAI, even when the pre-test effect is adjusted. Therefore, the "product-refinement" process is an effort to exhaust all possible sources of influence on the treatment effect that could have contributed to these differences.

An exploration of influences on post-test achievement differences is a matter of comparing relationships between some treatment and non-treatment variables with CAI and PLL post-test achievements. Prescriptive Learning Lab (PLL) is an experimental program, as is CAI. Although PLL'S effectiveness is not statistically different from TMI, the fact that it is an experimental program makes comparison with CAI interesting. Moreover, some non-treatment variables may have had a positive or negative influence on learning outcome.

The treatment variables selected for an examination of such influences are basic factors, such as (pre-test or 
trait-ability, and the students' characteristic variables, i.e. gender, ethnic background, and grade level, the latter being a surrogate variable for age. These variables may have influences on the psycho-motor and cognitive skill development as much as do forces of the social environment. The second group of variables are those that describe characteristics of home background. These are surrogates variables representing neighorhood stability (vacancy rise, proportion of owner occupied homes, median rental value, crime per capita, crowding), and also social status (median home value, median income, percentage of residents whose education is at high school level or better).

It was predicted that these variables would have a significant relationship with post-test achievement and wculd also account for a great percentage of the variation in post-test achievement. Accordingly, the following pages discuss relationships between these four groups of variables and post-test achievement. Regression findings, i.e. coefficients and particularly the coefficients of determination of the variables given in the above model are also discussed.

The first major step in this comparison is to conduct a multiple correlation analysis of home-background variables (Table XLII) as well as other variables examined earlier. Coefficients of a selected group of variables are given primary attention on the basis of expected influence on 
learning achievement. These variables are pre-test (PRE), vacancy rate (VAC), crime per capita (CPC), population per acre of land (PPA), proportion of "educated" residents (PRED) and median income (MEDY) (Table XLIII-XLVI). The second step focuses on the following group of variables: grade (GR), gender (SEX) and ethnic characteristics of the youngsters (ETH), (Table XLVII). The third step focuses on resource variables, i.e. the quadratic relationship of amount of instructional time $\left(V_{1}\right.$ and $V_{2}$ of CAI and PLI respectively), classroom congestion index $\left(\mathrm{SR}_{1}\right)$, i.e. number of youngsters in proportion to the number of spaces in the classrocm, and operational expenditure per student in $\left(\mathrm{SR}_{2}\right)$, (Table XLVIII).

The first correlational observation is home-ground variables, (Table XLII), especially those listed above. The dependent variable is gain, the additional learning achieved, or post-test minus pre-test achievement. The independent variables are vacancy rate, proportion of residents who have completed the twelfth grade or better, median income of residents, people per acre of residential area, proportion of home-owners, and crime per capita. The multiple correlation coefficient is $(R=.40171)$; the expected pattern of the relationships of some of the variables is confirmed. The relationship between pre-test and gain scores is negative, this is in line with the expected relationship $(R=-.355)$. As pre-test increases, the chance 
of learning growth, or the distance between pre-test and post-test decreases, resulting in low gains. So, lower gain scores are related to higher pre-test as well as to lower post-test, while and high gain scores are related to lower pre-test scores. This means gain and pre-test scores are inversely related.

As vacancy rate increases, especially in multiple-family residential areas, a split of peer groups takes place, generating a negative impact on the emotions of the youngsters, which subsequently affects their school performance. This expectation is confirmed by gains having a low but negative relationship with the vacancy rate $(R=-.025)$. The same logic applies to the relationship between gains and proportion of homeowners. This expectation of a negative relationship is based on an assumption that homeowners move less often than do renters, which may lead to a high pre-test, hence low gains.

The neighborhood status variables, median income and level of resident's education, correlate negatively with gains, and one of the possible explanations for this phenomenon is similar to those above. As income increases, social status is likely to be higher. Such is also the case for level of education. As income and level of education increases, it is found that the youngster is from a well-off neighborhood. Chances of a narrower gap between pre-test and post-test are high. This observation leads researchers 
to expect gains to be negatively correlated with these two variables. Hence, it is logical to say that the two experimental programs, CAI and PLL, enable youngsters to increase their gains, especially those youngsters who come from neighborhoods with families having a low income and a low-level of education.

The last of these groups of variables is PPA and CPA, which are also negatively related to gains. This simply may mean that an increase in crowding ( $P P A)$ and crime rate ( $C P C$ ) may have negative influences on the possible effect (gain) of the two treatment programs.

The second observation focuses on correlations of student characteristics variables i.e. sex, ethnic origin, and grade level (Table XIVII). The two treatment programs have positive influence on gains irrespective of sex or ethnic identity. However, gain scores and grade levels are negatively correlated $(R=-.174)$. A further analysis of the variable grade levels reflects that the correlation is actually an indirect measure of age. It is also synchronized with the level of pre-test because a youngster's grade level is dependent on where and when the youngster starts schooling. This is exhibited by a moderate correlation coefficient $(R=.48)$ between grade and pre-test. The relationship is also tied to a technical structure of the Rit measurement, which is sychronized with grade-level. Hence, as grade level increases gain scores decrease on 
average. Therefore, there is an inherent negative relationship between gain scores and grade-level.

The third observation involves correlation of resource variables with gain scores. These variables are SRl, $\mathrm{SR}_{2}$ ' $\mathrm{V}_{1}$, and $\mathrm{V}_{2}$, $\mathrm{SR}_{1}$, the index of classroom crowding, is negatively correlated with gain scores $(R=-.128)$. This is a rational trend where an increase in the number of youngsters i.e. congestion in the classroom, leads to a reduction in the student-instructor ratio as well as in the quality of the learning environment.

Operational expenditure per capita is also negatively related to gain. This indicates that education has a production function different from that of other commodity producers in terms of production costs and economies of scale. However, while these rules have relevance for production in education, there are other non-pecuniary factors that have major influences. The negative relationship implies that, to a certain extent, increased spending may increase learning gains; however, an increase beyond a certain point may not lead to a continued increase in learning gains.

It should also be pointed out that the relationship of expenditure and crowding with the pre-test score is positive. This may indicate that the influence of these two variables $\left(S R_{1}\right.$ and $\left.S R_{2}\right)$ on gains is also influenced by the pre-treatment ability or (pre-test). The relationship of 
CAI-instructional time or degree of learning $\left(t^{2}\right)$ and PLL-time $\left(t^{2}\right.$ ) (referred to here as $v_{1}$ and $v_{2}$ ) with the gains score is also negative. Time is another measure of resource. Time, like expenditure, influences gains to a certain extent. However, a great amount of instructional time may become counter-productive by way of transforming productive-time to non-learning or "dead" time when the capability of learning or making use of time goes beyond the individual's threshold.

\section{Regression Analysis}

The second major step in this "product-refinement" process is to discover whether there is a significant difference between the two experimental programs...given that they differ in their treatment outcomes. First, since we know there is a significant correlation between gains score and some of the variables discussed above, it is valid to compare the two projects, CAI vs. PLL, by means of these variables and examine the extent of the differences. A simple t-test was applied to each variable by group, CAI (1) and PLL (2) as presented in Table XLI. This approach revealed that the two experimental groups were located in neighborhoods that are significantly different from each other. The only variable to which both groups are similar is in the level of crime rate, which was not appreciably different, despite the fact neighborhoods in PLL schools had a slightly higher crime rate. 
Schools were selected to participate in the Title I project on the basis of economic disadvantage, though there were several differences between the two groups in their neighborhood environment. CAI was located in schools that were less crowded and which spent more per student on operations than did PLI. The neighborhoods of CAI participants had low levels of education, median income, proportion of white ethnic residents, proportion of home owners, median home value and low median rental value obviously a poor neighborhood. On the other hand, CAI had a low (but not significantly different) rate of crime, and high residential density. It was clear that CAI had been implemented in schools of neighborhoods that were, on average economically and educationally disadvantaged relative to PLL. Whether this was the result of an awareness of such differences in not known. The PLL program is located in schools in neighborhoods havirg either low or high scores on the variables being compared.

The second point to consider in the comparison of variable relationships is the differences in post-test achievement that can be accounted for by these variables. A multiple regression analysis was applied after identifying youngsters by treatment groups and the variables were analyzed by treatment groups. This created an opportunity to analyze the influence of the independent variables on post-test achievement in a full model for both groups 
213

together and separately. Due to the strong influence of pre-test scores on post-test results, the model for each group examined such effect through regression analysis by including in and excluding pre-test.

The full model, where $\mathrm{Y}=\mathrm{f}\left(\mathrm{X}_{1}+----+\mathrm{X}_{16}\right)$, was analysed in a multiple linear regression, after examining various approaches such as $\log$ and quadratic equations, to test for optimal coefficients on those variables that could maximize the explanation of changes in post-test achievement. The linear approach is a straight forward method to achieve a maximum coefficient of determination $\left(R_{2}\right)$. The regression result is given in Table XIII. The pre-test is excluded for two reasons: 1) it can best be examined in a sub-model representing each treatment group and 2) the purpose of the full model without pre-test allows to examine the maximum impact of neighborhood variables on achievement differences. 
TABLE XIII

MULTIPLE LINEAR REGRESSION

OF HCME BACKGROUND VARIABLES

DEPENDENT VARIABLE:POT

-95\% CONFIDENCE INTERVAL B

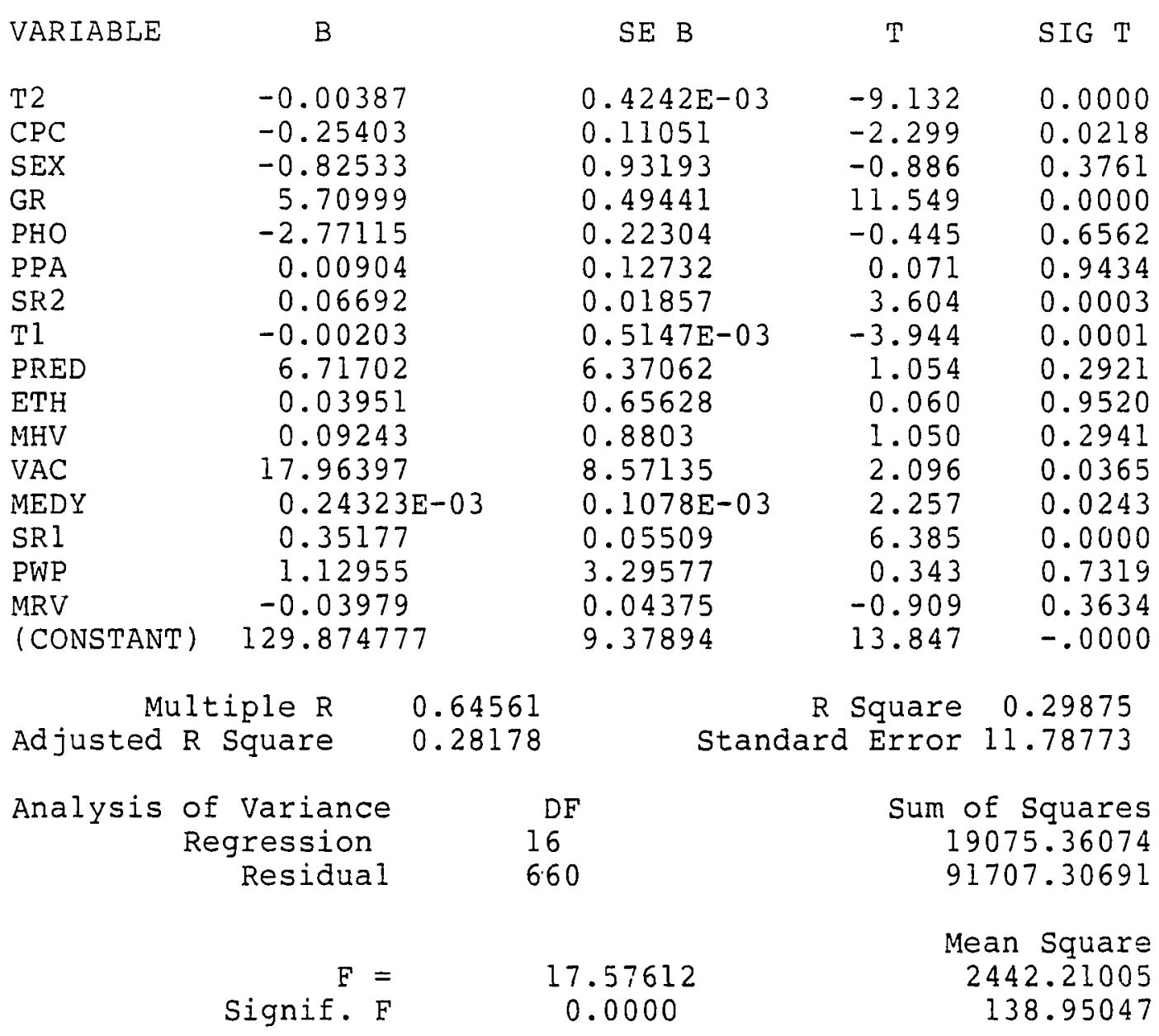

The regression result of the full model given above accounts for nearly $30 \%\left(R^{2}=.29878\right)$ of the explanation of the estimated changes in achievement differences. The following variables are significant in their contributions to the overall changes accounted for, $\mathrm{T}_{1}, \mathrm{~T}_{2}$ (degree of learning-actual learning time as a percentage of scheduled 
or recommended time), $\mathrm{CPC}, \mathrm{GR}, \mathrm{SR}, \mathrm{SR}_{2}, \mathrm{VAC}$, and MEDY.

Learning time or degree of learning and achievement have a negative but not a surprising relationship. As discussed in the correlation analysis, increased learning time leads to increased learning outcome for all youngsters only to a certain extent, beyond which time reaches a saturation point and the rate of return declines, as demonstrated by Carroll, Bloom, Harnishfeger, and wiley in Walberg and Frederick (1980, p. 183 and p. 187). Time's deminishing rate of return in the production of learning outcomes suggests the log approach to be best (Wells, 1974, Walberg and Frederick, 1980). This will be discussed in detail later. In Table XIII, however, for a marginal change in post-test scores, $\mathrm{T}_{1}$, CAI time, decreases by .002 $(p=.001)$ and $T_{2}$-PLL time also decreases by .004 ( $\left.p=.0000\right)$.

There are three very significant neighborhood variables that should be pointed out. Crime rate, CPC, housing vacancy rate, VAC, and median income, MEDY are all important $(p=.05)$. Marginal changes in post-test achievement are influenced by a reduction in crime $(-.25403)$, an increase in housing vacancy (17.9640), and Median income (.000243). Other variables that made a highly significant contribution to the explanation of changes in post-test scores are grade levels (GR), classroom crowding index $\left(\mathrm{SR}_{1}\right)$, and student cost per capita $\left(\mathrm{SR}_{2}\right)$. The latter two variables (resource variables) positively influence 
changes in post-test achievement, however, neither an indefinite increase in expenditure nor congested classrooms beyond capacity can be expected to be positive factors on achievement (Coleman, 1966; Hinckley, 1978; Suppes, 1979). In the first group, CAI, the neighborhood variables along with the pre-test account for more than $77 \%$ of changes in post-test achievement $\mathrm{R}^{2}=.77247$ (Table XLIII).

In a sub-model where the pre-test was excluded, post-test changes that can be explained by neighborhood variables was a little over $24 \%, R^{2}=.2408$ (See Table XLIV). The exclusion of the pre-test allowed other variables to be meaningful contributors to the explanation of estimated post-test changes. The regression coefficients of the following variables became significant in this sub-model, CPC at $(p=.05)$, and SR1, SR2, and PWP $(p=.0000)$. The variable PRED is also significant $(p=.01)$.

When the same conditions are applied to the second group, PLL, the impact of the variables in determining the variation of post-test achievement was less than with CAI. The coefficient of determination of the same variables is $\mathrm{R}^{2}=.64045$, (Table XLV). When pre-test was controlled they accounted for only 7.1 percent of the variation in PLL, as opposed to 24.1 percent in CAI (Table XLVI). Median income and pre-test were the only significant variables that contributed to an explanation of a unit of change in the post-test at $p=.01$ and $p=.000$, respectively. 
The third step in refining the outcome was the process of testing the hypothesis that these variables, as a group, would account for a significant portion of changes in gain scores. Findings from a multiple regression sub-model confirmed the hypothesis. It was predicted that the coefficient of determination of the sub-model and full model would be greater than zero. The "treatment" variable sub-model showed $\mathrm{R}^{2}=.12887$ (Table XIVIII), which accounted for a strong portion of the post-test achievement $(p=.0000)$. In this sub-model the pre-test and method of instruction were significant explanatory variables, whereas the kind of program or skill area was not.

The student characteristics sub-model had a coefficient of determination of $\mathrm{R}^{2}=.16297$ (see Table XLVII). Similarly, gains score is regressed on "neighborhood" variables and pre-test in a sub-model and had a coefficient of determination, $\mathrm{R}^{2}=.13377$ (Table $\mathrm{L}$ ). In other words this sub-model was able to account for 13.4 percent of the variation in the estimated changes of the gains score when pre-test is excluded from the sub-model. Only 6.3 percent of the total change can be explained by neighborhood variables (Table II). As shown above, all the sub-models have coefficients of determination that were appreciably different from zero. Most of all, it is clear that the coefficient of determination of the full model was greater that the $\mathrm{R}^{2}$ of any of the sub-models. The "resource" 
sub-model also had a similar coefficient of determination, $\mathrm{R}^{2}=.15494$.

\section{Instructional Time}

Among "resource" variables, time is of special interest to this research. Since increased instructional time is a highly claimed benefit of computer based instruction, it is important to examine this variable closely. The examination includes a linear and nonlinear regression of time and an inspection of this pattern of learning time and achievement. The issue of time is based on an assumption that an increased amount of instructional time leads to increased learning by allowing one to complete more learning tasks or to accomplish a given task in less time.

After examining linear, quadratic, cubic and logarithmic models of "time", post-test achievement as a dependent variable, the quadratic model (Table XLIX) explains changes in the dependent variable (Suppes, 1976) better than a linear model (Table LII). The two quadratic forms of time, $v_{1}$ and $v_{2}$, when regressed without pre-test, still play a prominent explanatory role in the explanation of marginal changes in post-test achievement $(Y)$. The same condition of change in post-test achievement of PLL students requires a decline of 1.5 minutes of instructional time, which is also significant $(p=.0000)$. Coefficients are extremely low, which is typical of quadratic relationships. 
CAI's time $\left(V_{1}\right)$ is positive and significant $(p=.002)$ whereas PLL's time $\left(V_{2}\right)$ is negative but significant $(p=.0000)$. Both variables account for 4.3 percent of the total change. This nonlinear relationship of time to post-test score (Y) reflects that for every unit of increase in post-test achievement, CAI learning time $\left(V_{1}\right)$ increased by 1.13 minutes, which again is significant $(p=.002)$.

A further regression analysis of the quadratic form of time, with pre-test against post-test as a dependant variable, explains a little over 75.3 percent of the variation in the post-test, with a very high level of significance. PLI's instructional time is not a significant variable in explaining changes in achievement in a nonlinear model. However, CAI's instructional time is a positive and a highly significant explanatory variable $(p=.0005)$. The level of significance of these two variables changes when a linear form of time is applied in the analysis; time in PLL becomes significant and that of CAI insignificant. However, when the pre-test is excluded, both $v_{1}$ and $v_{2}$ account for 4.3 percent of the changes in achievement, and both variables are also very significant. This finding confirms Suppes' and Wells' nonlinear models of time, especially as regards that of CAI. (Suppes et al., 1976; Wells et al., 1974; Suppes et al., 1970; and Walberg and Frederick, 1980) The relationship of instructional time to post-test achievement was examined further for this pattern (Table 
LIV-LVII). Post-test achievement in mathematics and reading for youngsters in four grades $(5-8)$ across three schools in each group were observed over time. The outcome of 186 CAI youngsters in mathematics and 201 in reading was noted. Mathematics results showed that, as the amount of instructional time increased up to 900 minutes a year, the post-test achievement increased. The achievement between 900 and 1800 minutes of instruction in associated with a decline in achievement. However, when instructional time increased beyond 1800 minutes, achievement increased again. This finding confirmed the predicted achievement pattern discussed in the treatment group effect earlier. This finding demonstrates that learners do not have equal need or use of learning time. It is also obvious that the lower and upper ends of the achievement spectrum make use of additional time compared to the average achievers.

The trend of relationships between time and reading achievement demonstrates a different phenomenon. As the amount of instructional time increased, the level of achievement decreased. This means that there is an inverse relationship between instructional time and post-test achievement in the CAI reading program. As discussed earlier, a one-minute change in CAI instructional time leads to a change of .66 Rit in post-test achievement (Table LIII). Increasing the amount of time spent on reading seems to lead to a decrease in achievement. 
Instructional time of PLI has an effect different from that of CAI. Increasing the instructional time in reading is associated with increased achievement (Table LIV-LV). However, increased time appears to have no influence on mathematics achievement (Table LVI-LVII). Generally, the findings in this research confirmed studies such as that of Walberg and Frederick, especially where time was a moderate predictor of achievement and also had low correlation with program scores (walberg and Frederick, 1980; Edwards, 1975). The general finding here was that the amount of instructional time has an effect on achievement, which depends on four factors: (1) the method of instruction (treatment), (2) basic skill area, (3) the level of trait ability (pre-test), and (4) the individual's learning rate or use of time. In the case of CAI, mathematics instructional time had a positive effect on relatively low achievers, on the one hand, and on those who are relatively high achievers, on the other. These two groups benefit much more from an increased learning time than the medium achievers. However, when it comes to reading, increased instructional time is associated with decreasing achievement. PLL scores show that increasing instructional time is associated with a slight positive change in achievement, but almost no significant association is found in mathematics achievement. on the average, both experimental treatment programs demonstrate that increased 
achievement is partly due to increased instructional time. It should be recognized that CAI helps to increase achievement through effective use of time. Youngsters in both reading and mathematics who are high achievers and low achievers have demonstrated the positive effect of CAI time more than in PLL.

\section{RESOURCE EFFECTIVENESS}

Resource Distribution

This part of the data analysis discusses the findings of a resource effectiveness approach stated in the previous chapter. There are three subordinate assessment criteria in this part that are considered necessary to evaluate the three groups in terms of their resource uses. These criteria are: distribution of resources, using student-instructor ratio; unit cost analyses, using cost per-student-instructional-hour; and the cost saving or benefit-cost ratio, comparing implied costs and benefits by relating cost with observed and expected gain scores.

Student-instructor ratio is a popular concept in the economics of education, often used to assess the distribution of youngsters in an instructional setting. Assessment of such a distribution is traditionally done by using student-instructor ratio. In this study distribution is measured by combining cost with the student-instructor ratio concept. Although it is not clear what an optimal 
size for an instructional group should be, there is a conventional assumption that a one-to-one situation is ideal. Such a belief fails to appreciate the benefit and the psychological developments that could be achieved through the competition and cooperation that are part of group learning and in which the inquiries and mistakes of one become lessons for another.

Advocates of computer based instruction claim that computers provide the instructional ideal of a one-to-one student-teacher ratio (SIR). This claim presumes that equivalence exists between a teacher and a single terminal that could be a mini-or microcomputer. It is compelling that this is another case of a rule of thumb which is not based on a technically sound comparison of single and multiple-learner situations, in other words, a comparison between a labor intensive and a capital intensive operation without a common unit of measurement. Attempts to establish such a common unit of measurement were based on a rule of thumb that equated computer sessions with years of teaching experience (Wells et al., 1974, p.22). Wells and Jamison used one year of teaching experience as the equivalent of two and a quarter CAI sessions.

Approaching the issue from a resource efficiency point of view, it is necessary first to assume that decision makers have an opportunity to choose whether their funds could be spent on teachers, on computers, or on both. 
Second, adding the average salary of an entry-level teacher and an aide is taken to represent the value of one unit of instructional resource (TRU). Such a common denominator makes resource measurement a relatively objective criteria. The approach consolodates all types of fund allocations of schools to one common standard unit, irrespective of the type of input factors used in the program, as long as they have the dollar value figures, i.e., teachers, aides, computers, and audio-video equipment. By dividing total program cost by the value of one resource unit (TRU), it can be determined how many such units are allocated in a given program for a given treatment group.

The question here is which of the three groups delivers instruction in a one-to-one or a relatively similar setting of student-"instructor" ratio? After all costs are aggregated, it is anticipated that CAI would show a comparative advantage over the other two groups. It is also postulated that claims made for CAI as one-to-one individualized instruction would not be true.

Hypothesis:

It is hypothesized that resource distribution measured in terms of aggregate resource units (TRU), hence student instructional resource ratio, (SIRR) would show CAI as beneficial over the other two. 
Ho:
a) $\mathrm{SIRR}_{1}<\mathrm{SIRR}_{2}<\mathrm{SIRR}_{3}$
$\mathrm{SIRR}_{1} \Varangle \mathrm{SIRR}_{2} \Varangle \mathrm{SIRR}_{3}$
b) $\operatorname{SIRR}_{1}<\mathrm{SIRR}_{3}<\mathrm{SIRR}_{2}$

In order to arrive at the "resource unit" distribution per student, the assessed total cost should be converted to TRU units. The following table contains figures necessary to do a computation of student-"instructional resource" unit.

TABLE XIV

INSTRUCTIONAL RESOURCE DISTRIBUTION MODEL

\begin{tabular}{|c|c|c|c|c|c|}
\hline & Average & Average & Total & $\begin{array}{l}\text { Student } \\
\text { Resource }\end{array}$ & \\
\hline $\begin{array}{l}\text { Treatment } \\
\text { Groups } \\
\text { (1) }\end{array}$ & $\begin{array}{l}\text { Treatment } \\
\text { Group Budget } \\
\text { (2) }\end{array}$ & $\begin{array}{l}\text { Group } \\
\text { Size } \\
\quad(3)\end{array}$ & $\begin{array}{l}\text { Units } \\
\text { (TRU) } \\
\text { (4) }\end{array}$ & $\begin{array}{l}\text { Ratio } \\
\text { (SIRR) } \\
\text { (5) }\end{array}$ & $\begin{array}{l}\text { Correct } \\
\text { SIRR } \\
\text { (6) }\end{array}$ \\
\hline CAI & 66.957 .33 & 242 & 4.2 & 58 & 24 \\
\hline PLL & $55,688.33$ & 158 & 3.5 & 45 & 29 \\
\hline TMI & $62,458.00$ & 100 & 3.9 & 26 & 27 \\
\hline
\end{tabular}

The average salary of an aide and a teacher at entry-level in 1981 was $\$ 16,000$. By dividing column 2 by this figure, the number of resource units (TRU on column 4) is derived. Similarly, by dividing column 3, which is the total number of participants, by column 4, teaching resource units (TRU), we get the data in column 5 , the equivalent of student-instructor ratio (SIRR). The adjusted SIRR is simply the result of dividing one hundred, which assumes 
equal number of participants given in column four. This will correct the group size biases as shown in column six. According to this criterion of allocated resource unit assessment, it is obvious that $\mathrm{TRU}_{1}>\mathrm{TRU}_{3}>\mathrm{TRU}_{2}$, which implies that resources committed for each group was not equal.

The process of testing the hypothesis involved equalizing the group size, as shown in column six. On the basis of the findings in column six, the hypothesis $\operatorname{SIRR}_{1}<\operatorname{SIRR}_{3}<\operatorname{SIRR}_{2}$ is accepted, since $(24: 1)<(27: 1)<(29: 1)$ is true. The SIRR approach assumes an equal number of youngsters to be served by each member of treatment. It is clear that the proclaimed individualized instruction under CAI cannot be supported; however, it is apparent that the smaller the group size, the closer it is to individualized instruction. Hence, CAI is preferable because it comes closer to providing individualized treatment. According to the SIRR criteria, the claim that computers provide a one-to-one-instructional service cannot be supported in the absolute sense. Nonetheless, CAI provides more instruction in relatively small groups than PLL or TMI. Likewise, TMI provides instruction in smaller groups compared to PLL. The difficulty experienced in measurement of resources and effectiveness is a recognized problem in educational evaluation (Carpenter and Haggart, 1970). This approach is exploratory and could not be compared with other studies, as almost none exist. It is worthy, because it combines 
assessment of cost and outcome, which makes it possible to determine whether resources used do render worthwhile results.

Unit Cost Analysis

The question here is whether CAI is more cost-effective than TMI. It is hypothesized that CAI will be the most cost-effective, followed by PLI and then TMI. Two important factors are cost and time. Cost is the aggregate expenditure on hardware (HC), courseware (CC), supply cost (SC), instructional personnel cost (PC), and other consumables and supplementary service costs (OC). The total cost (TC) is hence the sum of these four. The cost-per-student method of cost-benefit analysis is influenced by the number of students participating in each group. Similarly, the number of students attending a given school is dependent upon several socioeconomic and administrative factors.

This means that, if complete cost information could be collected, the cost-per-student as a method of cost effectiveness assessment would be biased. Therefore, cost-per-student hour is preferred as the appropriate method of cost-benefit analysis. 
Average hour of instruction per subject

$$
\mathrm{T}_{t}=\ldots \sum_{i=0}^{n} t_{i}+\sum_{j=0}^{n} t_{j}
$$

Average operational cost $\left(\mathrm{T}_{\mathrm{C}}\right)$ :

$$
\begin{aligned}
& \sum_{i=0}^{n} c_{i}+\sum_{j=0}^{n} c_{j} \\
& \mathrm{~T}_{\mathrm{C}}=-\ldots
\end{aligned}
$$

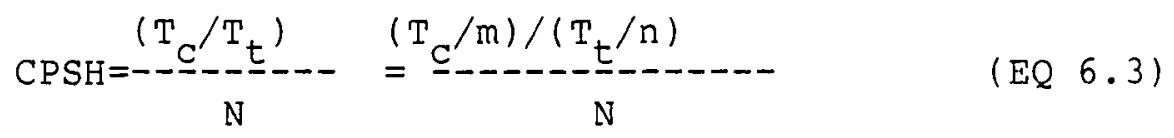

Cost-per-student-hour ( $\mathrm{CPSH}$ ) is calculated as follows:

where $i=$ math, $j=$ reading, $t=$ hours, $N=$ participants and $k=$ number of subjects.

As shown above, equation (6.3) is derived by dividing equation $(6.2)$ by $(6.1)$.

The amount of instruction generated can be thought of as the sum of the time produced by instructional personnel $\left(P_{t}\right)$ and the computer system $\left(S_{t}\right)$. The total instructional time $\left(T_{t}\right)$ can be compared to the total cost $\left(T_{C}\right)$.

Cost per month $(\mathrm{CPM})=\mathrm{T}_{\mathrm{C}} / \mathrm{m}$

Where $\mathrm{m}=$ months in academic year ( 9 months)

Instructional hours per month $(\mathrm{hpm})=\mathrm{T}_{t} / \mathrm{n}$ where $\mathrm{n}=$ months of instruction (7).

The relevant question at this point is whether computer based instruction (CAI and PLL) have any comparative cost advantage over TMI. It is hypothesized 
that CAI and PLL would show a cost advantage over TMI. If we assume that CPSH of $C A I=C_{1}, C P S H$ of $P L L=C_{2}$ and $C P S H$ of TMI $=\mathrm{C}_{3}$, the comparison is postulated in the following hypothesis:

Cost per instructional hour per student is lower in CAI than the other two methods. It is also postulated that PLL would show a comparative cost advantage over TMI.

Hypothesis:

$$
\mathrm{H}_{\mathrm{O}}: \quad \mathrm{C}_{3}>\mathrm{C}_{2}>\mathrm{C}_{1} \quad \mathrm{H}_{\mathrm{a}}: \quad \mathrm{C}_{3} \ngtr \mathrm{C}_{2} \ngtr \mathrm{C}_{1}
$$

The testing of this hypothesis applies an economic analysis technique using a unit-cost criteria, which allows the comparison of cost and outcome, i.e. cost-effectiveness. The following table presents the computerized results of cost data collected from various departments of the Portland Public School District.

\section{TABLE XV}

COMPARATIVE UNIT COST ANALYSIS

\begin{tabular}{|c|c|c|c|c|c|}
\hline $\begin{array}{l}\text { Treatment } \\
\text { Groups }\end{array}$ & $\begin{array}{l}\text { Tota } 1 \\
\text { Cost } \\
\text { (1) }\end{array}$ & $\begin{array}{l}\text { Group } \\
\text { Size } \\
(2)\end{array}$ & $\begin{array}{l}\text { Annual Total } \\
\text { Inst. Hr. } \\
(3)\end{array}$ & $\begin{array}{l}\text { Cost } \\
\text { Per Hr. } \\
(4)\end{array}$ & $\begin{array}{l}\text { Ratio } \\
\text { Per Stu. Hr } \\
\quad(5)\end{array}$ \\
\hline CAI & $66,957.33$ & 242 & 293 & 225.91 & 0.94 \\
\hline PLL & $55,688.33$ & 158 & 128 & 442.72 & 2.75 \\
\hline TMI & $62,458.00$ & 100 & 117 & 533.83 & 5.34 \\
\hline
\end{tabular}

As the figures in the above table show, CAI's high cost was distributed over the largest number of participants and generated the highest number of instructional hours. It 
appears that TMI did not serve as many participants, nor did it generate as much instructional time as PLL or CAI.

The distribution of the annual program cost over the number of participants, i.e., cost per student (CPS), in CAI, PLL, and TMI is $\$ 276.68, \$ 352.46$, and $\$ 624.58$, respectively. However, the weakness of such a method of assessment is its dependence on the number of participants. Several studies have used various approaches in assessing the cost-effectiveness of computers. Because of differences in the type and quantity of input factors in computer based instruction, similar unit cost approaches have produced different results. Other factors, such as rate of computer usage, the number of months it is used, the number of users, and the estimated useful life of hardware, are also responsible for cost differences. The unit applied in assessing cost distribution also varies. Some of these are cost per session (Levin and woo, 1981); cost per student hours (Thomas, 1979, NWREL, 1981, p.63; Wells et al., 1974); and cost per gain (Sumner, 1979, p.14).

The cost per student hour, which is considered to be more reasonable, is calculated by estimating cost overhead and dividing that by the average annual instructional hour per student. The result, in cost-per-student-hour, shows a cost of $\$ 0.94, \$ 2.75$, and $\$ 5.34$ for CAI, PLL and TMI, respectively. This finding indicates that the hypothesis $C_{3}>C_{2}>C_{1}$ should be accepted, since $(5.34)>(2.75)>(0.94)>$ is 
true. The claim that CAI costs less than the other two methods is true and justified according to these findings. Therefore, the cost of CAI is less than PLI, and that of PLI is less than TMI. It is apparent that the cost per student-hour approach, as a criterion of resource assessment, does support the claim that CAI is most cost-effective.

Comparison of this finding with other studies was also carried out. Although this is discussed in detail in the review of the literature, some of those studies should be mentioned here again. A comparison of average estimated cost per student hour of a computer in a stand-alone, cluster, or time-shared operation is $\$ 3.60,0.76$ and 2.76 , respectively (NWREL, 1981, p.63). The findings of this research shows that CAI, a time-shared system, is highly cost-effective, since the expected average cost is $\$ 2.76$, while the finding above is only $\$ 0.94$. PLL, which is comparable to a cluster system that costs 0.76 , appears to be costly. However, this is not so when the comparison group is TMI whose cost is $\$ 5.34$. Both CAI and PLL appear reasonably low cost compared to equivalent cost figures derived from wells and others (1974), which had a range of $\$ 1.50$ to $\$ 4.50$ per student hour. 
Cost Saving (C/B) Analysis

This approach compares the actual monthly cost of the project and the foregone or opportunity cost of the output in terms of grade equivalent months.

The model of input-output ratio, or the value added ratio, is given below. It is the output month value for each month of input for the project. Let $B=$ senefit, and $\mathrm{C}=\cos \mathrm{t}$.

$$
\text { OVM }=\text { }
$$

where $n=7, j=$ (output units months), $i=$ (input units) and k=skill area.

The relevant research question is whether the three groups generate benefits by way of foregone cost. In other words, is the cost per observed gain lower than the cost per expected gain? If the expected cost per gain is higher than the observed cost per gain, then the expected cost per gain becomes a foregone cost which is a form of benefit saving. Hence, if we assume that expected cost and actual cost represent cost and benefit, the benefit-cost ratio for each group can be calculated. The next question is whether the three groups produced a benefit that is worth the cost. In other words, the benefit-cost ratio should be at least equal 
to one. Therefore, it is anticipated that cost per observed gain would be lower than cost per expected gain. It is also postulated that the three groups, led by CAI, would produce benefits greater than the cost.

The necessary approach taken here is centered around differences between expected and observed gain scores, and the cost calculation is extended to cover cost differences between them. The relationship between cost and gain from observed and expected points of view is depicted in the figure below.

First, the necessary equations developed and used to arrive at both observed and expected cost and gain are as follows:

Assume that some benefit is realized when actual cost is lower than expected. Also assume the distribution of and average cost over expected gain is equivalent to expected cost, observed gain is also equivalent to observed cost, as shown in the following figure. 


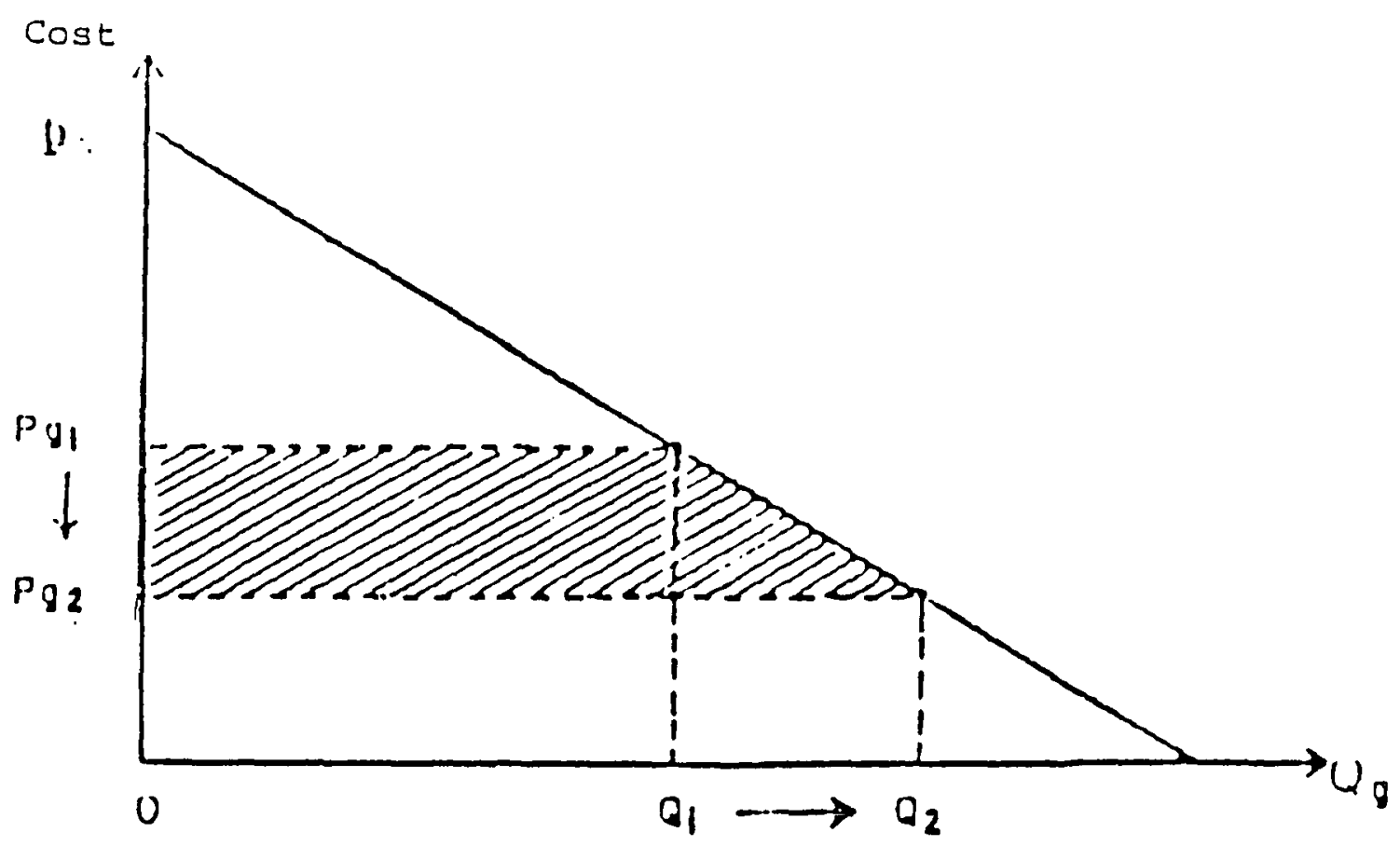

Figure 10. Hypothetical relationship of cost to grade placement scores $(q)$.

As stated in EQ $6.3 \quad C_{s}=\left({ }^{c} / t_{t}\right) / N$

$$
\begin{array}{ll}
G_{e}=Y_{e}-X_{i} & (E Q 6.5) \\
G_{0}=Y_{0}-X_{i} & (E Q 6.6) \\
C e_{i}=C_{s} / G_{e} & (E Q 6.7) \\
C O_{i}=C_{s} / G_{O} & (E Q 6.8)
\end{array}
$$

Where:

$$
\begin{aligned}
& \mathrm{N}=\text { number of participants } \\
& \mathrm{C}=\text { total cost } \\
& \mathrm{T}=\text { total time in HRS. } \\
& \mathrm{C}_{\mathrm{S}}=\text { cost per student HR (CPSH or CS) } \\
& \mathrm{G}_{\mathrm{e}}=\text { expected gain }
\end{aligned}
$$


$G_{0}=$ (observed gain)

$Y_{e}=$ the expected post-test achievement

$x_{i}=$ pre-test,

$Y_{0}=$ observed post-test achievement

$C_{e i}=$ Cost-per expected gain of group $i$ and

$C_{o i}=$ Cost-per observed gain of group $i$

Let's assume that the foregone cost is represented by

$\mathrm{C}_{e i}$, which is equivalent to some benefit, $B_{i}$, then $C_{e i}=B_{i}$ and $c_{0}=C_{i}$.

The cost-saving criteria are based on the foregone or opportunity costs. The fundamental principle is the linkage of cost to empirical and expected gain. An alternative way to assess the effectiveness of the treatment is the "no-treatment" situation, a compared outcome after the "treatment." By linking this concept with costs, the next step is the configuration of the cost distribution over expected and empirical gain scores. This approach generates the data to enable this research to carry out a cost and benefit comparison.

The distribution of cost per student over average expected and observed gains creates a formidable criterion of cost-effectiveness. Hence the cost distribution of each treatment group produces "cost per expected gain" $\left(C_{e}\right)$ and "cost per observed gain" $\left(C_{0}\right)$. It is hypothesized that the observed cost per gain of each group would be less than the expected cost per gain in the three groups. 
Ho: $\mathrm{C}_{\mathrm{Oi}}<\mathrm{C}_{\mathrm{ei}} \mathrm{Ha}: \mathrm{C}_{\mathrm{Oi}} \mathrm{dC}_{\mathrm{ei}}$

In circumstances where treatment is effective, as in this case, the cost of expected gain will be higher than the cost of observed gain. In other words, $\mathrm{Ce} i>\mathrm{Co}_{i}$ can be tested by calculating $\mathrm{C}_{e}$ and $\mathrm{C}_{0}$ for CAI, PLL and TMI. The result is $\mathrm{Ce}_{1}=76.06, \mathrm{Co}_{1}=24.31$ for $\mathrm{CAI} ; \mathrm{Ce}_{2}=74.20, \mathrm{Co}_{2}=55.51$ for PLL; and $\mathrm{Ce}_{3}=192.24, \mathrm{Co}_{3}=131.49$ for TMI. This finding confirms the hypothesis $\mathrm{Ce}_{i}>\mathrm{CO}_{i}$ in the three groups. The cost-per-gain approach should be used with caution, as increased cost does not necessarily lead to increased gain, nor the other way around. Some studies tend to imply this relationship in the application of the concept (sumner, 1979; and wilkinson, 1972). The concept should be used merely for resource effectiveness measurement.

The benefit-cost ratio is a part of the cost-saving method discussed above. The concept of observed and expected gains has already been discussed. However, the introduction of cost requires further discussion. The "cost per expected gain" and the "cost per observed gain" makes up the foundation of the cost and saving analysis.

The finding shows that there is cost difference as a result of differences between the two types of gains. That means there is a foregone cost, which implies an indirect saving, because the cost of the expected gains is the sum of the cost of the observed gains plus some extra savings. The expected cost as stated above, is equivalent to the value of 
the benefit that decision makers are willing to pay, and the cost of the observed gain is the actual cost that the decision makers paid. Hence, $C_{e}$ is benefit (B), and $C_{0}$ is actual cost (C).

The benefit-cost ratio $\left(B_{i} / C_{i}\right)$ of each group is:

$\mathrm{CAI}$ is $\mathrm{Ce}_{1} / \mathrm{CO}_{1}=\mathrm{B}_{1} / \mathrm{C}_{1}$

PLI is $\mathrm{Ce}_{2} / \mathrm{CO}_{2}=\mathrm{B}_{2} / \mathrm{C}_{2}$

TMI Ce $3 / \mathrm{Co}_{3}=\mathrm{B}_{3} / \mathrm{C}_{3}$

The above benefit cost ratio can be used to compare the three groups. On the basis of the findings of other criteria, it is hypothesized that CAI would have a benefit-cost ratio greater than PLL and TMI.

Hypothesis:

Ho:

a) $\mathrm{H}_{1}: \mathrm{B}_{1} / \mathrm{C}_{1}>\mathrm{B}_{2} / \mathrm{C}_{2}$

b) $\mathrm{H}_{2}: \mathrm{B}_{1} / \mathrm{C}_{1}>\mathrm{B}_{3} / \mathrm{C}_{3}$

c) $\mathrm{H}_{0}: \mathrm{B}_{1} / \mathrm{C}_{1}=\mathrm{B}_{2} / \mathrm{C}_{2}=\mathrm{B}_{3} / \mathrm{C}_{3}$
Ha:

$\mathrm{B}_{1} / \mathrm{C}_{1} \& \mathrm{~B}_{2} / \mathrm{C}_{2}$

$\mathrm{B}_{1} / \mathrm{C}_{1} \ngtr \mathrm{B}_{3} / \mathrm{C}_{3}$

$\mathrm{B}_{1} / \mathrm{C}_{1} \neq \mathrm{B}_{2} / \mathrm{C} 2 \neq \mathrm{B}_{3} / \mathrm{C}_{3}$

The findings regarding the research questions and these hypotheses will enable this study to provide information that may strengthen the claims of advocates of technology based instructions. In addition, it will shed light on the viability of either one or both competing methods of assisting disadvantaged youngsters.

In order for a program to be considered viable, this ratio has to be greater than one, because any operation that 
costs more that what it actually can pay back as a benefit is uneconomical (Mishan, 1972). Hence, for any project to be considered viable there should be some benefit that is greater than its cost. The calculated $B / C$ for the three groups is given below.

TABLE XVI

COMPARATIVE B/C

ANALYSIS

Treatment Group (1)

CAI

PLI

TMI
Cost/Gain method (2)
Benefit/Cost Computed method (3)

\section{Result (4)}<smiles>[14CH]=C[Te][GeH2]</smiles>

$$
\mathrm{B}_{1} / \mathrm{C}_{1}
$$

3.14

$$
\mathrm{Ce}_{2} / \mathrm{CO}_{2}
$$$$
\mathrm{B}_{2} / \mathrm{C}_{2}
$$

1.34

$$
\mathrm{Ce}_{3} / \mathrm{CO}_{3}
$$

$\mathrm{B}_{3} / \mathrm{C}_{3}$

1.46

The result in column four demonstrates that $B_{1} / C_{1}>1$ is true for the three groups, because each ratio is greater than one. The hypothesis that the benefit-cost ratio of CAI is greater than the ratio of the other two groups (i.e., $\mathrm{B}_{1} / \mathrm{C}_{1}>\mathrm{B}_{2} / \mathrm{C}_{2}$ or $\left.\mathrm{B}_{1} / \mathrm{C}_{1}>\mathrm{B}_{3} / \mathrm{C}_{3}\right)$ is true, and the hypothesis is confirmed and accepted.

The benefit-cost approach as an alternative resource-effectiveness critericn demonstrably confirms the claim made that computer assisted instruction is cost-effective in its application to disadvantaged youngsters. In other words, the benefit-cost analysis confirmed the findings of the cost-per-student-hour and other approaches used to test CAI's effectiveness over the 
other two methods in general and TMI in particular.

\section{SURVEY OF INSTRUCTIONAL PERSONNEL}

This section of the assessment is an exploratory step intended to compare the two computer based instructional treatment methods, CAI and PLL, by using a software evaluation form. The form was first developed by the Computer Technology Center of the Northwest Regional Educational Laboratory (NWREL). However, it was thoroughly revised and modified for this research based on input from evaluation personnel at Portland Public Schools. The evaluation form was used as an exploratory tool to help assess the views of the instructional personnel--teachers and aides who were involved in the two experimental programs. It was also a part of the cause-effect inquiry into whether there was a perceived difference in software quality between the two computers used in CAI and PLL.

The evaluation form (Table LVIII) was distributed to teachers and aides directly involved in both CBI programs. These personnel had received training to run the programs and to be able to assist enrolled youngsters. The purpose of this form is to see:

1. whether the instructional personnel differ in their assessment of the quality of the CBI softwares they used;

2. whether their rating, on a scale of four to one, measuring "very high" to "very low" quality, would concur with the findings of the various other criteria discussed earlier. 
Therefore, ten instructional personnel who used PLL and 12 who used CAI were asked to rate the quality of the software for the computers they used. These 22 instructors were given 40 instruments to assess four aspects of the software quality, i.e., content, instruction, technique, and performance, with ten instruments for each.

A graphic display of the findings, Figure 8, show's the relative differences of CAI and PLL in program effectiveness. The graph is based on the data in the following table.

TABLE XVII

\section{INSTRUCTIONAL PERSONNEL} RATINGS OF CBI

Quality

Assessement

1. content of task

2. instructional delivery

3. accomodation techniques

4. operational control
Avg. CBI Treatment Rating* CAI PLL

$\begin{array}{ll}3.51 & 3.40 \\ 3.53 & 2.94 \\ 3.32 & 3.28 \\ 3.27 & 2.80\end{array}$

Mean quality Rate $(q) q_{1}=3.41, s d=.11, q_{2}=3.11, S D=.24$

* SCALE: On a scale of four to one measuring a subjective judgement of "very high" to "very low".

On the average, both CBI treatment instructors rated their respective software much higher than the average, 2.50. However, a comparison of the ratings shows that PLL 
personnel were not as satisfied as CAI personnel, especially on the criteria of instructional delivery and operational control.

In regards to the other two criteria, "content" and "accomodation," there was a very similar level of satisfaction, even though CAI still had an edge. In general, the software quality rating for CAI was higher than that for PLI by almost 10 percent.

The following graph shows how far apart the two computer based instructional approaches are in terms of software quality differences (quality index II followed by index I). The remaining indices show small differences. This exnibits that CAI is superior to PLI.

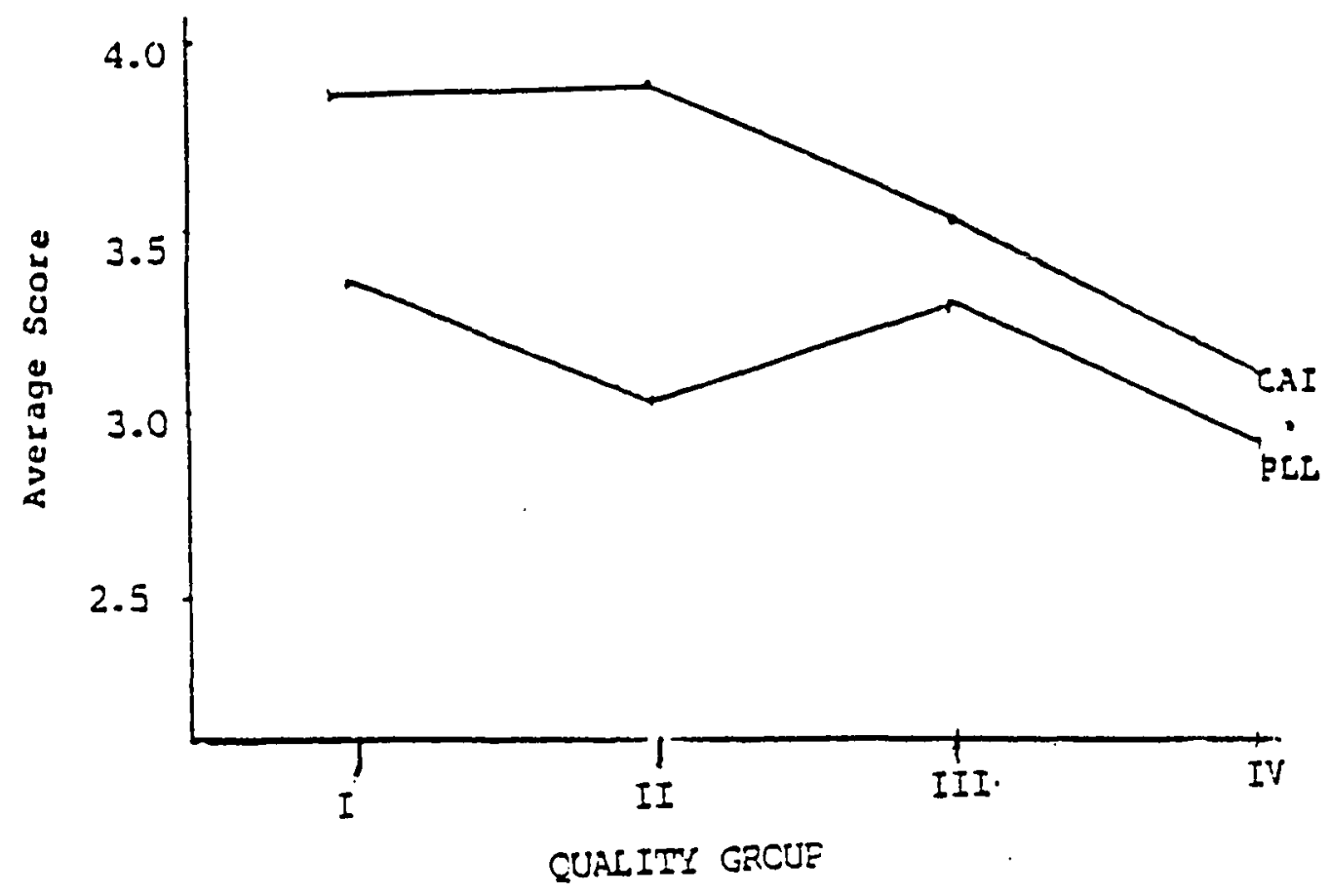

Figure 11. Survey comparison: CAI vs PLL courseware. 
The above result confirms findings of the approaches used earlier in this chapter. Therefore, using multiple criteria of evaluation, this research has demonstrated the superiority of CAI over the other two alternative methods of assisting disadvantaged youngsters in the instruction of basic skilis. 
This chapter is the concluding part of the research. It has four major components. They are the summary, conclusion, recommendations, and implications. The summary has two sections, the overview and the findings of the research. The conclusion consists of an overall assessment and inferences based on the findings. Recommendations are based on the research findings, the survey conducted, and the author's on-site observation of computer labs. The last component of the chapter is a glimpse at the future of technology and indications of research that needs to be carried out.

\section{SUMMARY}

\section{Introduction}

This research was initiated as a result of a direct observation of and experience with the issue of computer based instruction in elementary and secondary education. Application of computers to assist disadvantaged youngsters in the central city middle and elementary schools of Portland, oregon was selected as a specific instance of an emerging phenomenon: the innovative use of computers in the 
classroom.

The major focus of the research was to find out how disadvantaged youngsters respond to this encounter with advanced instructional technology, given the fact they are experiencing learning difficulties in the tirst place. These youngster: were one year or more behind their age/grade level at or below the twenty-sixth percentile in their class standing. They were selected for instructional "experiments" to test the validity of impressive claims made by some technologists and educators that instructional technology is truly helping disadvantaged youngsters to increase their learning achievement.

Questions whether the hardware and courseware are compatable with the district's curriculum arose. Each vendor made claims that their own package was ideal. Also, the validity of in-house advocacy for various packages needed study. After careful consideration of these matters, Portland Public School District officials acquired Computer Curriculum Corporation's (CCC) Computer Assisted Instruction (CAI) as well as prescriptive Learning, Incorporated's Prescriptive Learning Laboratory (PLL) packages. The district contracted for these two computer based instructional packages for a period of three years, the contractors agreeing to provide hardware, courseware, personnel training and services in selected elementary and middle schools in the basic skills of language arts, 
reading, and mathematics.

The objective of this research was to provide answers to questions common among teachers, administrators, curriculum specialists, school board members and parents. These questions involved the validity of claims regarding flexibility, pacing, individualized instruction, feedback, motivation, etc. Most important of all, this research pursued a criterion of achievement and cost. Does computer based (CBI) instruction help disadvantaged youngsters? Can these youngsters increase their achievement by using computers? Is this advanced technology cost-effective? These questions are at the heart of this research.

Schools providing Title I assistance for disadvantaged youngsters were selected for study. Only those schools having one of the two previously mentioned CBI systems were selected for assessment of the technology based "experiment." A number of comparably sized schools were selected as a "control" group. These "control" schools are Title I schools that provide educational assistance the traditional way, i.e., via teacher, aide, books, etc. On-site visits to all of the schools were conducted, and achievement data for participating youngsters collected. Data on home background variables were also collected. An exploratory assessment of the instructional quality of computers was carried out through a software evaluation survey completed by teachers and aides. Findings are 
summarized below.

Overview

Access to resources, or the acquisition of wealth, has been a fundamental criterion of social division into rich and pocr. This division has also been a compelling reason for gcvernment to act in the public irterest, to assure citizens' well being and equal access to opportunities. Education is one of the important activities influencing success and opportunity. In a market economy education is provided by both private and public sectors; however, given the reality of service by ability to pay, social division can only be aggravated. So it is the public sector that is the major provider of equal opportunity in education.

The dominant role of the public sector in educational services in what is mainly a market economy was born out of circumstance and necessity. The role of the U.S. Government in education was basically intended to promote American rather than European education, eliminate sectional and local prejudice, and prcmote political intelligence. In 1954 a White House conference called for an increasing government role in education, and this was later enacted under the National Defence Education Act (NDEA), prompted largely by the Soviet Union's launching of Sputnik in 1957.

In the $1960^{\circ}$ s expenditures for education were recognized as an investment, and the rationale for much of federal education policy was educational opportunity as a 
means of fighting poverty. The Elementary and Secondary Education Act of 1965 was specifically enacted to provide special instructional programs for economically and educationally disadvantaged youngsters. Efforts in the following years focused on promotion of equal opportunity, stimulating innovation and reform, as well as promoting research and work-related training.

$$
\text { Government efforts for distribution of equal }
$$
educational opportunities for disadvantaged youngsters has not achieved the anticipated level of success. "Nonschool" factors that put the youth at a disadvantage have not been overcome by schools, and little opportunity is being provided for schools to do so (Coleman, 1966). A growing concern about the effectiveness of compensatory programs in general, and Title I programs in particular, coincided with an increasing popularity of a new information technology: computers.

In the 1970 's increasing concern about program effectiveness, on the one hand, and the birth of advanced instructional tehnology, on the other, intersected at a point where other pedagogical issues were in the making. These pedagogical issues focused on how to quickly, massively and effectively readdress the problem of distributing educational opportunities to youth in general and to disadvantaged learners in particular. This effort led to development of a philosophy of programmed instruction 
and individualized instruction. Educators and technologists together, by applying information technology to education, produced a computer based instructional approach that has continued to revolutionize the instruction-learning continuum everywhere.

CBI has been advocated for its ability to be an equal oppcrtunity source of instruction, as well as an effective instructional method. Several claims have been made, for CBI; its advocates claim that it provides for individualized instruction, diversity in mode of instruction, flexibility, pacing at the learner's rate, saving or increasing learning time, accomplishing more learning tasks, increasing positive attitude and motivation, and, most of all, increasing leaining achievement at a reasonably low cost.

Other important clains are that computers are effective in needs assessment, diagnosis and prescription of learning tasks on an individual basis. There are also impressive claims regarding advantages of continuous drill and practice, monitoring, feedback, and progress assessment. Although these claims seem "too good to be true," those who were seeking alternative ways to increase achievement, cut costs and modernize instruction decided to give computers a try. This situation ignited controversies between those who support CBI and those who either call for caution or else reject such attempts cutright. These two camps are found everywhere from the local to the national levels, in all 
schools and school districts across the country. Given the broad array of claims, this researcher felt that claims regarding achievement and cost can be reasonably and concretely assessed as they pertain to local urban conditions in portland schools.

In order to understand the scope and implications of claims and counterclaims regarding CBI, a thorough review of literature on this issue was carried out. Findings of other studies on trends in computer application and effectiveness were assessed. Theories of learning and instructional technology were also reviewed in detail to understand the subjects of learning difficulties and their solutions. The approach focused on an effort to address this question: are computers compatable with learning needs of the disadvantaged? Relevent theories of learning on this subject were assessed on six major criteria: learning capacity, motivation, drill and practice, transfer of knowledge, Eorgetting, and remembering.

A summary of the above six criteria indicates that cognitive, stimulus response, and psychodynamic theories help us to understand problems of learning difficulties and their possible solutions. A review of the theory of educational technology confirms that instructional computers are developed on the basis of this understanding. Both cognitive and stimulus response theories view the drill-and-practice mode of instruction as a potentially 
viable method of assisting disadvantaged youngsters. This confirmation led the research to the next step, that of assessing, by way of a casual-comparative inquiry, the achievement and cost-effectiveness of the two computer based programs, CAI and PLL, currently in use in Portland Public Schools, and in contrast with the traditional approach, TMI.

\section{Findings}

1. The two experimental programs, CAI and PLL, were implemented in a relatively similar manner. Youngsters were tested and selected with identical criteria, which were (1) achieving a p-score of 43 or less on the Portland Achievement Test or (2) achieving at or below the 26 th percentile. Both programs provided instructional personnel training, hardware and courseware servicing, and technical consultations as required.

2. The two programs were implemented in schools whose youngsters come from different home backgrounds. This difference is statistically significant. The selected home backgound variables accounted for a slightly significant portion of individual and group differences.

3. The pre-test variable is the most significant correlate and explanatory variable of changes in post-test achievement.

4. Statistically significant differences were found 
between the pre-tests of the three groups, i.e., the two "experimental" and the "control" group. Similarly, a statistically significant difference among the three groups was also found in their post-tests achievement.

5. The post-test differences were adjusted for pre-test achievement differences, to see whether there remain significant differences in post-test achievement after correcting for pre-test differences. It was found that the differences between the adjusted post-test achievements among the three programs were statistically significant in favor of CAI. The same difference, though not statistically significant, was found between PLL and TMI, and in favor of PLL. Educational advantage, as measured by a better achievement score, was demonstrated by (CBI) over the TMI.

6. The three methods were also found to be effective for low achievers in the same rank order as above; however, it is only CAI that appears to help high achievers as much as it does to low achievers.

7. Instructional time and group membership are very significant explanatory variables in regard to the level of achievement. It was found that optimal relationship between time and achievement is quadratic. This research also found that a 
polynominal model accounts for the highest proportion of variation in achievement scores.

8. Effectiveness assessed from growth rate, relative to pre-treatment level and from the treatment expectation point of view, demonstrated a superiority for CAI, but with a mixed result for the other two. The pre-treatment-based growth rate assessment showed a comparative advantage for PLL over TMI; however, the treatment expectation-based growth rate reversed that, and TMI showed a comparative advantage. The difference between PLL and TMI is eight percent and 16 percent, respectively.

9. Resource allocation and use criteria of the total resource "unit" of each method showed that more resources were allocated for CAI, followed by TMI. Nevertheless, distribution of instructional resources point out that conditions were in favor of CBI over the traditional method. Two criteria used to measure resource distribution are cost per student instructional hour and a new student-instructional resource ratio measure that is a form of student-instructor ratio. The latter criterion is also a measure of individualized instruction. The cost criteria showed that TMI is five times and PL.L more than twice as expensive as CAI. This means CBI was indeed more cost effective than TMI. The cost was 
less than one dollar in CAI, close to three dollars in PLI, and close to five and a half dollars in TMI. The resource ratio, or individualizatior criterion, also demcnstrated that fewer youngsters shared the same amount of resource in CAI than in the other methods. CBI, then, serves an equal number of youngsters, while using less resources. It provides a more individualized instruction to an equal number of students with an equivalent amount of resources when compared to TMI.

10. An additional criteria for resource effectiveness was also used, which consisted of an input-output index and benefit-cost index. The input-output is a form of assessment of grade equivalent return per month of instruction. The input-output index on the average showed that computer based methods had a "payback" of more than the expected one month per month of instruction, while the traditional method posted an output of less than one month for each month of instruction. The ratio for the three groups is 2.05 , 1.55 and .92 for CAI, PLL and TMI. Findings of the instructional output index method showed that, for every month of instruction, CAI produced more than two months of grade-equivalent, followed by PLI, which produced about one-and-one-half months. The traditional method, TMI, did not meet even the minimum 
expectation of a one-month return for each month of instruction.

11. As stated above, a benefit-cost ratio technique was used to assess resource effectiveness. This approach was based on the actual cost and expected cost of each method of instruction. The findings spelled out the superiority of CAI over the others. The $B / C$ ratio was $3.14,1.46$ and 1.34 for CAI, PLI and TMI, respectively. In this approach, the difference between PLL and TMI is small.

12. The last criterion of assessment was a survey of teachers and aides involved in the two "experimental" treatments, i.e., CAI and PLL. This exploratory step was taken to compare the two computer based methods using a software evaluation form that contained instruments to assess program content, instructional delivery, technical quality, and performance quality. On a scale of one to four, both were rated above satisfactory. However, on all 40 instruments CAI's courseware and hardware was rated higher than that of PLL. The overall score was 3.41 for CAI and 3.11 for PLL.

\section{CONCLUSION}

1. Unlike several published studies which, after comparing the effectiveness of CAI to TMI reported 
conflicting and inconclusive results (Bozeman and Burns, 1981), this research is one of a very few to render a clear and conclusive result by way of multiple criteria of comparative evaluation. This research concludes that between the two computer based methods compared against the traditional method, CAI is by far superior in its achievement and resource effectiveness.

2. Claims made that computers, as tools of instruction to help accomplish more learning tasks in less time or cover more tasks within the "normal" set time, need to be reassessed. This research has found that instructional time does not have the same effect across the board on achievement levels of various ability groups and different skill areas. This research revealed that "allocated time" is associated with high and low achievement. In other words, there are groups that do well in increasing their achievements with a lesser amount of time and those who only increase their achievement levels as they spend more time. Therefore, the requirement of 1500 minute/year per subject for each student tends to be too little for some youngsters and too much for others.

3. Literature on local and national issues indicates a fear that computers may become substitutes for 
teachers and aides. Though this concern is beyond the scope of this research, three points should be made in regards to the effectiveness of computer based instruction. First, it was noted that youngsters quite often suffer from problems in understanding the task of interaction with the computer. They : ve to raise their hand and wait until they get help from a teacher or an aide. An increase in the amount of assistance can increase the actual time spent on new tasks leading to more learning. Secondly, an increase in the number of instruction personnel would not help achieve maximum effectivenes unless the instructors have sufficient training and skills to render the necessary assistanc?.

4. The number of instructors and even the amount of training they have may not improve the computers' potential, unless they also show interest, motivation, confidence and effort. Third, while the ratio of computers to students is set at one-to-one, the optimal number of students with computers that a teacher and an aide can effectively assist is not defined. Nor is the issue concern of substitution. A computer laboratory run by teachers and aides who have low levels of interest and inadequate training in computers may not enhance the computer effectiveness nor the youngsters' achievement. One of the PLL 
schools has demonstrated this. The achievement of a school that had a dedicated and motivated teacher and an aide was comparable to the best of CAI schools. So this research concludes that the issue should not be one of substitution, but instead one of making the "right" match between computers and teachers, and the compatability of such a match to the subject matter.

5. The cost of CBI is reasonably low compared to the traditional method. This should not be misunderstood as implying computers do a better job than teachers. This researcher is convinced that teachers supported by computers can make a positive educational difference.

6. The cost of CBI i-om the cost-per-student or the cost-per-instructional-hour point of view, could be reduced further if legal restrictions stipulated in the Title I program were less stringent regarding who can use the computer and what it can be used for. Frequent use of computers and their application to various courses, plus a variety of student groups can drastically reduce costs.

7. The treatment period between testing norm dates (for tests such as the California Achievement Test) was found to be seven and one-half months. The official school year is thirty to thirty-two weeks in all. The CAI corporation requires a treatment period of 1500 
minutes/year that is based on 30 weeks, or 150 instruction days. The company claims instruction totaling less than 1500 minutes in a year may not achieve a one-month gain for every month of instruction. This research concludes that unless test results are adjusted for their actual treatment period, the 1500 minutes/year instruction is in conflict with the net instruction time available, which does not allow 1500 minutes of treatment, and hence the recommended amount of instruction is unrealistic. In addition, when CAI is performed at full impact, a youngster is expected to achieve a .7-yr. progress, or grade equivalent, which is .3-yr. behind grade level.

8. The CAI treatment is expected to achieve more than a one-month grade equivalent for every month of instruction. The grounds for effectiveness should be based on a disadvantaged youngster's gains as a result of computer assistance. A standard of expectation of one month for every month of instruction is not good enough to make a difference for age-grade deficiency. Therefore, given that the two kinds of computer based instruction evaluated here have shown results well above the expectation, the treatment expectation should be set at more than one-month grade equivalent return for every month of instruction, if any 
youngster is to make some difference in his/her grade achievement gap.

9. According to the findings of this research, the effectiveness of a multi-audiovisual augmented computer instruction program needs to be reassessed. In most PLL classes this researcher witnessed the disappointment of those scheduled for off-computer activities in contrast to the excitement of those who were scheduled to use computers. The six-strategies-of-instruction approach, including computers as used in PLI classes, seems to affect the computer's optimal impact. This research demonstrates that, even though PLI user achievement was better than for those using only TMI, it was not as high as for those in CAI, who used computers alone. The explanation for this difference could be in a drawback created by one or more of the other strategies used in conjunction with the computer. of course, this explanation is based on an assumption that the teachers and courseware are compatable, as discussed below.

10. Software (courseware) for both CAI and PLL was evaluated by teachers and aides involved in the two programs. Four areas of quality evaluation show that differences exist between the two methods. While instructional personnel using CAI valued their 
courseware's quality highly, those using PLL were not as satisfied with the "instructional" and "performance" qualities of the courseware. On a scale of one to four, both quality indices were below the average score of 2.5 for PLL, whereas the scores for CAI were above average. Accordingly, the instructional and performance aspect of the method may have affected its competitive edge.

\section{RECOMMENDATIONS}

In accordance with the findings of this research, it is the recommendation of this author that plans for increased access to computers or other technology based instruction give priority to CAI or another compatible system.

In our postindustrial society there is a growing trend toward introducing computers into almost all aspects of life. The expanding service sector of the economy is leading in this trend. Computers are here and now. Their integration with the telephone, television and satelites is further revolutionizing the information industry. Unless today's youngsters are given an opportunity to learn how to use computers, they will become both educationally and technologically disadvantaged. The gap has already begun to widen, and there is a clear advantage for those who are affluent or who go to schools in affluent communities. It 
is important that local, state and national educational agencies seek to redress inequities inherent in this new opportunity. To reverse this trend, school districts such as Portland Public Schools should take some or most of the following steps:

1. Assist in the aquisition and distribution of computers to poor neighborhood schools.

2. Require and provide sufficient computer training to all instructional personnel. It is important that principals and other school officials be computer "literate". A district-wide forum for computer teachers should be established and convene periodically to discuss problems and projects. The teachers should also be part of the decision making process.

3. Promote the effort to connect schools, homes and communities with computer networks in several ways. Computer companies and local businesses, as well as community experts, can be brought together in a cooperative effort to train teachers, students and parents in computer usage. Such voluntary programs can be conducted on weekends or evenings. Bright students can assist as computer tutors to those who are slower. Phone-tutor and live-tutor options should also be considered. Teachers should be encouraged to be creative in programming and in the use of local software developments. Through a liaison or committee, contacts with courseware publishers should also be made.

4. Computer networks can be established through the use of courseware libraries, mobil computer classrooms, or computer bases that take the facility to teachers and students, providing equal opportunity of access and maximizing the utility of the hardware-courseware system. Uniformity of hardware and courseware should be encouraged district wide. Technology "magnet schools" can be created and located in areas that maximize equal access. 
Computer based instruction for disadvantaged youngsters should utilize dialog, simulation, gaming, and problem-solving programs as much as they currently use drill-and-practice programs. Choices in available programs should be diverse. The opportunity to learn computer programming and computer science should also be available to disadvantaged youngsters.

The role of instructional time, or time spent on learning tasks, is not clearly understood. This research has discovered that providing an equal amount of instructional time for all students is misguided. Different ability groups need different amounts or doses of instructional time. Therefore, instructional time requirements should reflect the variance in need and abilility level.

The CBI treatment goal of an equal amount of input-output value is not a satisfactory expectation of treatment. Such an expectation is common in the absence of a treatment. For a treatment to be considered viable and effective, its expectation of output should be greater than the input value. The district should plan for a criterion of effectiveness which sets a learning gain higher than a one month grade equivalent for every month of learning treatment.

Multimedia-supported computer instruction, as in PLL, needs to be further examined before it is allowed to expand. 
It appears to create confusion among youngsters at the beginning of every class, and it could be worse in the absence of a well-qualified teacher.

\section{IMPLICATIONS}

This research examined the effectiveness of computer based instruction in its first year of implementation. It was beyond the scope of this research to examine whether the observed difference would continue over time. It will add to the general knowledge of comparative $\mathrm{CBI}$ if a longitudinal study is carried out.

The resource effectiveness part of the research was difficult, especially in identifying the expenditures related to, and direct or indirect costs involved in, the operation of the treatment programs. However, due to the nature of each schools' cost accounting system, this approach did not account for the support staff costs, or for the cost of other professionals that had roles in one way or another. The cost data is an underestimate of resources and not an accurate accounting. Otherwise, a comprehensive cost study for each school would be necessary. Even though some portion of the cost is not accounted for, the finding of this research is a conservative estimate. Those youngsters who received assistance, but did not have either pre-test or post-test scores available, were also excluded from the sample in the study. Therefore, both the cost and the number of youngsters 
who received services were scaled down.

Among the computer corporations operating nationwide, Computer Curriculum Corporation (CCC) has gained national acceptance. It has become a trail blazer for others. Now there is a cottage industry of courseware on the rise with individual, private firm and university efforts. Competition in this new market should be encouraged to avoid a monopolistic control of the courseware market. Such a policy will help the courseware market to be competitive with the textbooks and book market. The level of competition in the area innovation and effectiveness of instructional computers should be examined.

It is essential to recognize that there are tasks the computer can accomplish efficiently and other tasks that it may be neither able nor expected to perform effectively. This research has concluded that both quality computers and well-trained teachers can cooperatively accomplish more than either one alone. The growing use of computers in education should lead to the perfection of this technology, along with awareness of both its strengths and limitations. Future research should focus on the optimal mix of teachers, computers and students. This will help avoid the danger of overreliance on computers in classroom instruction. 
REFERENCES

Abt Associates. Design for An Elementary and Secondary Cost-Effectiveness Model, Volume I Model Description. Washington D.C. U.S. Office of Education; Cambridge, MA: Abt Associates, June 1967.

Abt, Clark C., ed. "Performing urban Education with Cost-Effectiveness Analysis," Education Technology 10 $(1970): 36-38$.

Alessi, Stephen M., and Stanley R. Trollip. Computer-based Instructions, Methods and Development. NJ: Prentice-Hall, Inc., 1985.

American Council on Education. 1981 Fact Book on Higher Education. MacMillan Publishing Company, New York: MacMillan Publishing Co., 1981.

American Council on Education. 1984-85 Fact Book on Higher Education, Demographic and Economic Data. MacMillan Publishing Company, New York: MacMillan Publishing Co. , 1984 .

American Council on Education. The American Freshman, National Norm, Fall Enrollment in Colleges and Universities, 1982, U.S. Department of Education, Cooperative Institutional Research Program, Los Angeles, CA, 1982 .

ACYF-American Council on Youth and Family. Annual Report. United States Congress, Washington D.C., 1980 .

Anderson, Lorin $w$. A measure of student involvement in learning: Time on task. Columbia, S.C. University of South Carolina, n.d.

Anderson, Lorin $W$. Learning Time and Educational Effectiveness. NASSP Curriculum Report, 1980 .

Anderson, Lorin W., and C.C. Scott. "The Relationship Among Teaching Method, student Characteristics, and student Involvement in Learning." Journal of Teacher Education 29 (1978): 52-57. 
Anelli, C.M. "Computer-assisted Instruction and Reading Achievement of Urban Third and Fourth Graders." Ph. D. diss., Rutgers University, Dissertation Abstracts International, $38 \quad(1978): \frac{\text { (University }}{662-\mathrm{A}}$ Microfilms No. 7804582$)$.

Ascher, Carol. Microcomputers: Equity and Equality in Education for Urban Disadvantaged Students, Jan. 1984 (ERDS \#ED 242-801).

Ashby, E. "Machines, Understanding and Learning: Reflections on Technology in Education. The Graduate Journal, $72(1967): 352-73$.

Atkinson, R.C. and H.A. Wilson. Comouter Assisted Instruction, A Book of Readings. New York: Academic Press, Inc., 1969.

Atkinson, R.C. "Where Will Computer-Assisted Instruction Be in 1990?" Education Technology, (1978): 60 .

Auerch, Harvey A. How Effective Is Schooling? A Critical Review of Research, A Rand Education Policy Study. Englewood Cliffs, NJ: Educational Technology Publications, 1974.

Auerch, Harvey, and Herbert Kiesling. The Relationship of School and Environment to Student Performance: Some Simultaneous Models for Project TALENT High Schools. Santa Monica, CA: The Rand Corporation, 1970.

Barnow, Burt S., and Glen Cain. "A Reanalysis of the Effect of Head Start on Cognitive Development: Methodology and Empirical Findings." Journal of Human Resources 12 (1977): 177-187.

Beck, J.J., Jr. "An Analysis of Student Attitude Toward Computer-assisted Instruction in Nebraska Public High Schools." Ph. D. diss., University of Nebraska. Dissertation Abstracts International, 40 (1979) 3006-A. (University Microfilms No. 7926337).

Beck, J.J., Jr. "The Effects on Attitudes of Anticipated Computer Assisted Instruction in Selected High School Courses of Study." AEDS Journal 12 (1979): 138-45.

Berk, Arnold A., ed. Educational Evaluation Methodology, The State of the Art, Baltimore: The John Hopkins University Press, 1981 . 
Bish, Robert L. The Public Economy of Metropolitan Areas. Markham Series in Public Policy Analysis. Chicago: Rand McNally College Publishing Company, 1971.

Blalock, Hubert M., Jr. Social Statistics, New York: MCGraw-Hill, 1960 .

Blalock, Hubert M., Jr. Applied Multi-variate Analysis and Experimental Designs, New York: McGraw-Hill Inc., 1975.

Blancharä, J.S. "Computer-Assisted i struction in Today's Reading Classrooms." Journal of Reading, 5 (1980): $430-4$.

Blanning, Robert $W$. Opportunity Cost and EIfectiveness Analysis by Simulation. Philadelphia: Management Science center, wharton school of Finance and Commerce, University of Pennsylvania, New York: April 1967.

Block, James H., ed. Mastery Learning, Theory and Practice, New York: Holt, Rinehart and Winston, Inc., 1971.

Bloom, B.S. Handbook on Formative and Summative Evaluation of Student Learning. New York: McGraw-Hil1, 1971 .

Blum, Alan F. "Social Structure, Social Class, and Participation in Primary Relationships." In Blue Collar World, edited by Arthur B. Shostak and William Gomberg, Englewood Cliffs, NJ: Prentice-Hall, 1964.

Blushan, V. An Exploratory Study of the Effects of Socioeconomic Status on Learning. Paper presented at the meeting of the American Educational Research Association, New York, February, 1971.

Booth, A.B., S. Welch, and D.R. Johnson. "Crowding and the Urban Crime Rates" Urban Affairs Quarterly, II (1976): 291-322.

Borich, Gary D., ed. Evaluating Educational Programs and Products, Englewood Cliffs, NJ: Educational Technology Publications, 1974.

Bosco, James. "White Flight from Court Ordered Bussing?" Urban Education, 9 (1973) 87-97.

Bowles, Samuel, and Henry M. Levin. "The Determinants of Scholastic Achievement--An Appraisal of Some Recent Evidence," Journal of Human Resources 3 (1968) 2-24. 
Bowles, Samuel, and Herbert Grantis. Schooling in Capitalist America. New York: Basic Books, 1976.

Bozeman, W.C. "Computer-Managed Instruction: State of the Art." AEDS Journal 12 (1979): 117-137.

Bozeman, W.C., and Patricia K. Burns. "Computer-Assisted Instruction and Mathematics Achievement: Is there a Relationship?" Educational Technology. 11 (1981): 32-39.

Brimer, A. Sources of Difference in School Achievement, Slough, England: NFER Publishing Co., 1978.

Brown, Byron w. "Achievement costs and the Demand for Public Education." Western Economic Journal, 10 $(1972): 198-219$.

Bruno, James E. Educational Policy Analysis, A Quantitative Approach, New York: Russak and Company Inc., 1976.

Burkhead, Jessie, Input and output in Large City High Schools, Syracuse, New York: Syracuse University Press, 1967.

Burr, Irving $w$. Applied Statistical Methods, New York: Academic Press, 1974.

Business Week, May 7, 1971, p.72.

Bylinsky, Gene. "A New Industrial Revolution Is on the way." Fortune, 1981.

Campbell Donald T., and Julian C. Stanly. Experimental and Quasi-Experimental Designs For Research. Chicago: Rand McNally \& Company, 1963.

Carpenter, Margaret B., and Sue A. Haggart. "Cost Effectiveness Analysis for Educational Planning." Educational Technology $10(1970): 26-30$.

Casner, J.I. "A Study of Attitudes Toward Mathematics of Eighth Grade Students Receiving Computer-assisted Instruction and Students Receiving Coventional Classroom Instruction." Ph.D. diss., University of Kansas, 1977. Dissertation Abstracts International, 1978, 38, 7106-A. (University Microfilms No. 7800432).

Chin, Robert, Kenneth D. Benne, and Warren G. Bennis. The Planning of Change. New York: Holt, Rinehart and Winston, Inc., 1969. 
Chu, Kong. Principles of Econometrics, Scranton, Pennsylvania: International Textbook Company, 1968.

Churchman, A., C. Shuman, and L. Kogan. Community Factors Associated with School Achievement in New York City. New York: City University of New York Center for Social Research, 1975.

Clark, Harold F. Cost and Quality in Public Education. The Economics and Politics of Public Education, syracuse, $\mathrm{NY}$ : Syracuse Unniversity Press, 1963.

Clark, Philip. "Compensatory Education, the Underlying Stances and Teichers" Attitude." Urban Education 9 $(1975): 340354$.

Cohen, Jacob, and Patricia Cohen. Applied Regression/Correlation Analysis for the Behavioral Sciences. Hillsdale, NJ: Lawrence Erlbaum Associates, Publishers, 1975.

Cohen, Wilbur. Educational Achievement--Its Causes and Effects, Monograph \#23, Ann Arbor, MI: Survey Research Center, 1961.

Coleman, James. The Evaluation of Equality of Educational Opportunity. Santa Monica, CA: The Rand Corp., 1968.

Coleman, James. "Public Schools, Private Schools, and the Public Interest." The Public Interest, 64 (1981): $19-30$.

Coleman, James. Equality of Educational Opportunity. washington DC: U.S. Dept. of Health, Education and Welfare, 1966.

Coleman, James, Thomas Hoffer, and Sally kilgore. High School Achievement Public, Catholic and Private Schools Compared, New York: Basic Books Inc., 1982.

Colinsk, John. "Determinants of School Enrollment and School Performance." The Journal of Human Resources 6 (1975): 140-157.

Computers in Education: Their Use and Cost. Educational Automation Monograph. Detroit, MI: American Data Processing, Inc., n.d.

Conant, Eaton H. Teacher and Paraprofessional Work Productivity, A Public School Cost Effectiveness Study. D.C. Heath and Canoaun Lexington, MA: 1973. 
Cook, Desmond I. Program Evaluation and Review Technique, Applications in Education. Washington D.C.: U.S. Department of Health, Education, and Welfare, office of Education, 1966.

Corley, Georgia B., and Charles w. Lewis. "The Impact of Indiviłualized Instruction on Low Achieving Youth," Urban Education 10 (1975): 321-326.

Cost-Benefit Analysis of Social Projects, Report of a meeting held in Rennes, France, September 27, October 2, United Nations Research Institute for Social Development, Report No. 7, 1965.

Cronbach, I. J., and R. E. Snow. Final Report: Individual Differences in Learning Ability as a Function of Instructional Variables, Stanford, $\mathrm{CA}$ : Stanford University, 1969

Curtis, William $\mathrm{H}$. Educational Resources Management Systems, Research Corporation of the Association of School Business officials, 1971.

Davis, Allison. Social Class Influences Upon Learning. Cambridge, Massachesetts: Harvard University Press, 1952 .

Dearman, Nancy B., and Valena W. Plisko. The Condition of Education. Statistical Report National Center for Education Statistics. Washington D.C.: U.S. Department of Education, 1980.

Deblassio, J. "Student Characteristics Associated with Attitudes Toward Using a Computer in Selected High School Mathematics Courses." Ph.D. diss., Universty of Pittsburgh, 1978 . Dissertation Abstracts International, $1979, \quad 40$, (University Microfilms No. 7917417 ).

Decacco, John P. Educational Technology: Readings in Programmed Instruction. New York: Holt, Rinehart and Winston, 1964 .

Deutsch, M., and Bert Brown. "Social Influence in NegroWhite Intelligence Differences." Social Issues. 20 $(1964): 24-35$.

Dexter, Fletcher. Opportunities and Issues in Commputer Based Instructional Equity. Eugene OR: Oregon Schools Study Council, 1984, (ERIC Document Reproduction Service No. ED 242-063). 
Dot, B. A. "Teaching Method Effectiveness in Relation to Certain Student Characteristics," Journal of Education Research, $60(1967): 363-355$.

Eagle, N., and A. S. Harris. "Interaction of Race and Reading Tests on Performance Scores." Journal of Education Measurement, 6 (1969): 131-135.

Edwards, Judith. "How effective is CAI? A Review of the Research." Educational Leadership, 33 (1975): 147-153.

Edwards, Judith, et al. The Effectiveness of CAI. Iowa City: University of Iowa, 1974

Eisman, Donald. Schools and Neighborhoods Research Study: Phase Two--School District/City Relationships, Seattle, Washington: Seattle public Schools, 1976.

Elementary and Secondary Education Act (ESEA). 20 USC 241 , PL-89-10, 1965 .

Elementary and Secondary Education Act (ESEA) Title I. $\quad 34$ CRF, 201.2, 1982 .

Ellena, william J., ed. Chrisopher Jencks in Perspective. Arlington, VA: American Association of School Administrators, 1973.

Ellul, Jacques. The Technological Society. translated from the French by John Wilkinson. New York: Vintage Books, Random House, 1964.

Enell, Nancy $C .$, and Stanley W. Barrick. An Examination of the Relative Efficiency and Usefulness of Computer Assisted Individualized Education Programs, Sacramento CA: California State Department of Education, 1983, (ERIC Document Reproduction Service No. ED 236 861).

Euchner, Charlie. "Equal Access to Computers in Education Could Become a Major Issue Experts Warn." Education Week, March 2, 1983.

Evans, Gary W. "Crowding and the Development Process," In Human Response to Crowding, edited by A. Baum and T. M. Epstein, 117-140. Hillsdale NH: Lawrence Erlbaum Associates. 1978.

Feldman, David H., and Pauline S. Sears. "The Effect of Computer Assisted Instruction on Childrens' Behavior," Educational Technology. 10 (1970): 11-l4. 
Fenwick, James. Memorandum to the School District Board, dated December 31, 1981 .

Filling, Constance M. "Prospects For an Ethno-graphic Approach to Urban Education," Urban Education, 15 (1980): 259-277.

Fisher, Sethare. "Race, Class, Anomie, and Academic Achievement, A High School Level," Urban Ecication, 16 (1981): 149-173

Fitz-Gibbon, Carol T., and Lynn L. Morris. How to Design A Program Evaluation, Beverly Hills, CA: Sage Publications Inc., 1978.

Fletcher, J.D., and P. Suppes. "Computer Assisted Instruction in Reading Grades 4-6," Educational Technology, 12 (1972): 45-49.

Fogel, Walter. "The Effects of Low Educational Attainment on Income: A Comarative Study of Selected Etinnic Groups," Journal of Human Resources, 1 (1962): $139-150$.

Freire, Paulo. Pedagogy of the Oppressed, Translated by Myra Bergman Ramos. New York: Herder and Herder, 1972 .

Gagne, R.M., ed. Learning and Individual Differences, Columbus OH: Charles E. Merrill, 1967.

Gagne, R.M. The Conditions of Learning. New York: Holt, Rinehart, and winston, 1970 .

Gans, Herbert L. "The Balanced Community: Homogeneity or Heterogeneity in Residential Areas." Journal of American Institute of Planrers, 27 (1961): 175-184.

Gay, L.R. Educational Evaluation and Measurement: Competencies for Analysis and Application, Columbus $\mathrm{OH}$ : Charles E. Merrill Publishing Company, 1976.

Glazer, Nathan and William Gorham. The Urban Predicament, washington, DC: The Urban Institute, 1976.

Goel, S.C. Education and Economic Growth in India, Delhi: The Macmillan Company of India Limited, 1975.

Gottlied, Jay, and Stephen S. Strichart. Developmertal Theory and Research in Learning Disabilities, Eniversity Park Press, 1981. 
Grant, W. Vance and Thomas D. Snyder. Digest of Education Statistics, 1983-1984, washington, DC: National Center for Education Statistics, U.S. Department of Education, 1984 .

Griffith, A. R., and C.B.G. London. "Inner-city Teachers and School Community Relations," Urban Education 15 (1981): 435-449.

Griffith, W., and R. Veitch. "Hot and Crowded: Influence of Population Density and Temperature on Interpersonal Affective Behavior," Journal of Personality and Social Psychology 17 (1971) 92-98.

Hanley, Tom $V$. Microcomputers in Special Education: Organizational Issues, Washington D. C., 1983, (ERIC Document Reproduction Service No. ED 238-221).

Hansen, Kenneth H. Instructional Technology: Policy Issues for State Education Agencies, An Issue Analysis. (ERIC Document Reproduction Service No. ED 235-552).

Harvey, Mary R. "Public School Treatment of Low-Income Children, Education for Passivity", Urban Education, $15(1980)$ : $279-323$.

Hauser, Robert Mason. Socioeconomic Backgrounds and Educational Performance, Monograph Series, American Sociological Association, 1971.

Haven, Robert $H$. and Julis Margolis. Public Expenditures and Policy Analysis. Chicago: Markham Publishing Company, 1970 .

Herriott, Robert E. "Some Social Determinants of Educational Aspiration," Harvard Educational Review, $33(1963)$ : 157-175.

Hickey, Albert E. Computer Asisted Instruction: A Survey of the Literature, Third Edition, Newburgport, MA: ENTELEK Incorporated, 1968.

Hinckley, G. Student Economic and Educational Status and Receipt of Educational Services, Technical Report \#3, Santa Ana, CA: Decima Research, 1978.

Hilgard, Ernest R. and Gordon H. Bower. Theories of Learning. New York: Appleton-Century-Crofts; Meredith Publishing Company, 1966 and 1975. 
Hill, Richard E. and John P. Van Gigch. Using Systems Analysis to Implement Cost-Effectiveness and Program Budgeting in Education, Englewood Cliffs, $\mathrm{NJ}$ : Educational Technology Publications, 1971.

Hills, Philip and John Gilbert. Aspects of Educational Technology: The Spread of Educational Technology, London: Kogan Page Limited, 1977.

Hirsch, Werner. Urban Economic Analysis, New York: McGraw-Hil I Book Company, 1973.

Hollmark, Steven. Education USA. 24 (1982): 143.

Horst, Donald P., Kristine T. Wood, and G. Kasten Tallmadge A Practical Guide To Measuring Project Impact on Student Achievement, Mountain View CA: RMC Research Corporation, 1975.

Howe, J.A. "Computers Can Teach Where others Fail," T.H.E. Journal (Technical Horizons in Education) 8 (1981): 44-5.

Hunt, J. "Has Compensatory Education Failed?", Has It Been Attempted? Harvard Educational Review 39 (1969): $130-152$.

Huntington, John F. Computer-Assisted Instruction Using Basic, Englewood Cliffs NJ: Educational Technology Publications, 1979

Isaac, Stephen, and William B. Michael. Handbook in Research and Evaluation, Robert R. Knapp, 1971.

Informational Technology and Its Impact of American Education, Washington DC: office of Technology Assessment Congress of the United States, 1982.

Jamison, D., P. Suppes, and S. Wells. "The effectiveness of alternative instructional media: a survey," Review of Educational Research 44 (1974): 1-67.

Jamison, Dean T. Evaluation of Instructional Technology, Special Issue, Instructional Science 4 (1975).

Jencks, Christpher S. "The Quality of Data Collected by the Equality of Educational Opportunity Survey," in on Equality of Educational Opportunity, edited by $\bar{E}$. Mosteller and D.P. Moynihan, 69-114. New York: Random House, 1972. 
Jencks, Christpher S. Inequality: A Reassessment of the Effects of Family and Schooling in America, New York: Basic Books, 1972 .

Jenson, A. "How Much Can we Boost IQ and Scholastic Achievement?", Harvard Educational Review 39 (1969): $1-123$.

Jetter, Jan. Approaches to Individualized Education, Alexandria, VA: The Association for Supervision and Curriculum Development, 1982.

Johnson, James P. "Can Computers Close the Equity Gap?", Perspectives, The Civil Rights Quarterly, 14 (1982).

Joiner, L.M. "Microcomputers: An Available Technology for Special Education." Journal of Special Education Technology, 3 (1980).

Kahn, Alfred J. Social Policy and Social Services, 2nd ed. New York: Random House, 1979.

Karr-Morse, Collin. Memorandum to Thomas clint, dated December 10, 1981 .

Katzman, Martin. Distribution and Production in a Big City Elementary School System, Ph.D. diss., Yale University, 1967.

Kaugman, Roger and Fenwick English. Needs Assessment, Concept and Application, Englewood Cliffs, NJ: Educational Technology Publications, 1981.

Keeves, John P. Educational Environment and Achievement. Stochholm: Almquist and Wiksell, 1972 .

Kellaghan, Thomas. School Effectiveness, A Reassessment of the Evidence, New York: McGraw-Hill Book Company, 1980 .

Kepner Jr., Henery S. Computers in the Classroom, Washington DC: National Education Association, 1982.

Keppel, Geoffrey. Design and Analysis: A Reacher's Handbook, Prentice Hall series in Experimental Psychology, Englewood Cliffs NJ: Prentice Hall, Inc., 1973

Kerlinger, Fred N. Foundations of Behavioral Research, Second Edition, New York: Holt, Rinehart and Winston Inc., 1973. 
Kerlinger, F. and Elizar J. Pedhazure. Multiple Regression in the Behavioral Research, New York: Holt, Rinchart and Winston, Inc., 1982 .

Kiesling, H. A Study of Successful Compensatory Education Programs in California, Internal Rand Corporation Document, March, 1970 (unpublished).

Kiesling, Herbert J. Some Estimates for the Cost Effectiveness of Educational Inputs for Reading Performance of Disadvantaged Children in California Title I Projects, Santa Monica, CA: Rand Corporation, 1972 .

Knapper, Christopher Kay. Evaluating Instructional Technology, London: Croom Helm; New York, John Wiley \& Sons, 1980.

Kolich, Eileen M. "Microcomputers Technology with the Learning Disabled: A review of the Literature," Journal of Learning Disabilities, 18 (1970): 428-431.

Kriesberg, Louis. "The Relationship Between Socio-Economic Rank and Behavior," Social Problems, 10 (1963): 334-353.

Kuhn, Thomas S. The Structure of Scientific Revolutions, International Encyclopedia of Unified Science, Vol. II No. 2, Chicago: University of Chicago Press, 1970.

Laplante, Josephine $M$. and Taylor $R$. Durham. An Introduction to Benefit-Cost Analysis for Evaluating Public Expenditure Alternatives Learning Packages in the Policy science. New York: Croton-on-Hudson, (ERIC Document Reproduction Service No. ED 238-312).

LeRoy, M. Craig. "Youth Employment in the Labor Market of the 1980's," Urban Education, 15 (1983).

Leven, Henry M., and Louis Woo. "An Evaluation of the Costs of Computer-Assisted Instruction," Economics of Education Review, 1981

Leven, Roger E. The Emerging Technology Instructional Uses of the Computer in Higher Education, A Carnegie Commission on Higher Education and Rand Corporation Study. New York: McGraw-Hill Book, n.d.

Lipton, Joseph I. "Promising Future Directions Eor Computer Based-Instruction in Science." Journal of Educational Technology System $12(1983-84): 171-180$. 
Litman, G.H. "Relationship Between Computer-Assisted Instruction and Reading Achievement Among Fourth, Fifth, and Sixth Grade Students," Ph.D. diss., Northern Illinois University, 1977. Dissertation Abstracts International, 1977, 38, 2003-A. (University Microfilms No. 77-20, 883).

Lohnes, Paul R. and William W. Cooly. Multi-variate Data Analysis, New York: John Wiley and Sons, Inc., 1971.

Lord, Frederic M. "Further Problems in the Measurement of Growth," Educational and Psychological Measurement 18

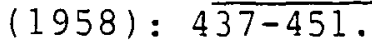

Lucas, J.A. "Learning Efficiency of students in Varying Environments," Journal of Experimental Education 39 $(1970): 63-68$.

Lysiak, F., S. Wallace and C.L. Evans. Computter-Assisted Instruction: 1975-76 Evaluation Report, A Title I Program, Ft. Worth, TX. 1976, (ERIC Document Reproduction Service No. ED 140495 ).

Maddox, Cleborne D. "Using Microcomputers with the Learning Disabled: Will the Potential be Realized?" Educational Computers, 1984 .

Macleod,I. and D. Overheu. "Computer Aided Assessment and Development of Basic Skills," The Exceptional Child 24 (1977): 18-35. (ERIC Document Reproduction Service No. ED 102613 ).

Malone, Thomas $W$. "Projecting student Trajectories in a Computer-Assisted Instruction Curriculum," Journel of Educational Psychology 71 (1979): 74-84.

Mandel, Allen S. Resource Distribution Inside School Districts, Lexington, MA: Lexington Books, D.C. Heatin and Company, 1975.

Market Data Retrieval 1982 (unpublished study).

Martin, E.G. "Microcomputer Applications to Special Education Administration," AEDS Monitor, 19, 10, 11, 12, (1981).

Maser, A.L., V. Johnson and J. Davis. Highline Public Schools Computer-assisted Instruction Project: A Program to meet Disadvantaged Students Individual Needs for Basic Skills Development: Final Report. Seattle, WA: Highline Public Schools: 1977 (ERIC Document Reproduction Service No. ED 167 114). 
Mason; George E. Micro Can Connect Home, School and Community--But It Must Be Read, Columbia, SC: 1984 (ERIC Document Reproduction Service No. ED 245-194).

Masters, Stanley and Thomas Rebich. "Schooling and Learning of Low Achievers: Comments," American Economic Review 62 (1972): 755-759.

Mayeske, George. A study of the Achievement of Our Nation's Students. Washington DC: U. S. Department of Health, Education, and Welfare, 1973.

McAdoo, Harriette P. "Youth, School and the Family in Transition," Urban Education, 16 (1981) 261-277.

Mendenhall, William, O. H. Lyman, and Richard L. Schaffer. Elementary Survey Sampling, Belmont CA: Duxbury Press, A Division of Wardsworth Publishing Company, Inc., 1971 .

Menis, Y., M. Snyder and E. Ben Kahan. "Improving Achievement in Algebra by means of Computer." Educational Technology $20(1980): 19-22$.

Microcomputers in Education 2 (1982): 8-9.

Mishan, E.J. Economics For Social Decision, Elements of Cost-Benefit Analysis, New York: Praeger Publishers, 1972 .

Modisett, D.M. "Effects of Computer-Assisted Instruction on Achievement in Remedial Secondary Mathematical Computation,". Ph.D. diss., Fordan University Dissertation Abstracts International, 1980,40 , 5770-A.

Morris, L.L., and C.T. Fitz-Gibbon. How to measure Achievements, Beverly Hills, CA: Sage Publications Inc., 1978 .

Moursund, D. "Introduction to computers in Education for Elementry and Middle School Teachers." The Computing Teacher, $8(1980-81): 26-34$.

Moynihan, Danial P., and Frederick Mosteller. On the Equality of Educational Opportunity, Papers Deriving from the Harvard University Faculty seminar on the Coleman Report, New York: Random House, 1972. 
Mravetz, P.J. "The Effects of Computer-Assisted Instruction on Student Self-concept, Locus of Control, Level of Aspiration, and Reading Achievement," Ph.D. diss., the University of Akron, 1980. Dissertation Abstracts International, $1980, \quad 41, \quad \frac{494-a . \quad \text { (University }}{\text { Microfilna }}$ Microfilms No. 8019116$)$.

Murnane, Richard. The Impact of School Resources on the Learning of Inner City Children, Cambridge, Mass: Ballinger, 1975 .

Nagel, Stuart S. (ed.). Improving Policy Analysis, Beverly Hills, CA: Sage Publication, 1980.

NACEDC-National Association of Compensatory Education for Disadvantaged Children. Annual Report to the U.S. Congress, Washington DC: 1978.

NCES-National Center for Education Statistics. Conditions of Education Washington DC: U.S. Department of Education, 1982 .

NCES-National Center for Education Statistics. Digest of Education Statistics 1981 washington DC: U. S. Department of Education, 1982 .

NCES-National Center for Education Statistics. Digest of Education Statistics, 1983-8ם washington DC: U. S. Department of Education, 1984 .

National Institute of Education. Title I Funds Allocation: The Current Formula. Compensatory Education Study. Washington DC, 1977 .

National Institute of Mental Health. Reading Achievement and Its Relationship to Academic Performance. Part III. Rockville, MD: U.S. Department of Education, 1972 .

National School Public Relations Association. "Compensatory Education: What Works to Help Disadvantaged Pupils," In Education USA, Special Report, n.d.

Nie, Norman H., C. H. Hull, G. Jenkins, K. Steinbrenner, and Dale H. Bent. Statistical Package for the Social Sciences, New York: McGraw-Hill, 1975.

NWREL-Northwest Regional Educational Laboratory, "Microcomputers in Today's Schools: A Conference." In An Administrator's Handbook. Portland, OR, 1981. 
o'Neil, Harold F., Jr., ed. Computer-Based-Instruction, The State of the Art Assessment. Orlando FL: Academic Press: 1981 .

Okun, Authur M. Equality and Efficiency: The Big Tradeoff. washington DC: The Brookings Institution, 1975.

Oosternoff, Albert $C$. Cost-Effective Computer Management of Instruction. Paper presented at the Annual Meeting of the American Educational Research Association, San Francisco, CA, April 1979 (ERIC Document Reproduction Service No. ED 172762$)$.

Pappert, Seymore. Mindstorms, Children, Computers and Powerful Ideas. New York: Basic Book Inc., Publisher, 1980 .

Parkus, Lawrence. Computer Assisted Instruction in Elementary/Secondary Education: The state of The Art. Washington DC: Academy for Educational Development, Inc., 1970

Payne, David A. The Assessment of Learning, Cognitive and Affective. L. C. Heath and Company, 1974.

Payre, David A. The Specification and Measurement of Learaing Outcomes. Blaisdell Publising Company, 1968.

Phi Delta Kappa, Feb. 1971, p.386.

Phillips, Bernard S. Social Research, Strategy and Tactics. New York: The Macmillian Company, 1966.

Plisko, Valena White, ed. The Conditions of Education. 1983 Edition. Washington DC: National center for Education Statistics, U.S. Department of Education. 1983.

Pollard, J. "Testimony to a Micro-Peter Can Now Read," Recreational Computing 7 (1979): 8-12.

Popham, w. James ed. Criterion-Referenced Measurement, An Introduction. Englewood Cliffs NJ: Educational Technology Publications, 1973.

Poulsen, G. and E. Macken. A Study of CAI Effectiveness. Computer Curriculum Corporation, Los Angeles, CA. 1978 . 
Ragosta, M., Computer-Assisted Instruction: A Iongitudinal Study. Paper presented at the meeting of the American Educational Research Association, Boston, MA, April 1980 .

Ranis, Gustao, and William Beranek, Jr. Science, Technology and Economic Development, New York: Praeger Special Studies n.d.

Ravindrakumar, Dave H. The Identification and Measurment of Evidence of Environmental Process Variables that are Related to Educational Achievement, Ph.D. diss., Department of Education, University of Chicago, 1963

Rich, R. C. "Neglected Issues in the Study of Urban Services Distributions: A Research Agenda." Urban Studies 16 (1979): 143-156.

Richmond, Kenneth. The Education Industry, Methuen and Co., 1968 .

Ritzen, Josef, and Donald Winker. "The Production of Human Capital Over Time." Review of Economics and Resources. (1977): 427-437.

Roman, R.A., and N.C. Laudato. Computer-Assisted Instruction in Word Problems: Rationale and Design. Washington DC: National Institute of Education, 1974. (ERIC Document Reproduction Service No. ED 101 688).

Romero, S.R. "The effectiveness of Computer-assisted Instruction in Mathematics at the Middle School." Ph.D. diss., University of the Pacific, 1979. Dissertation Abstracts International, 1980, 41, 577-A. (University Microfilms No. 016797).

Rosenbaum, Peter S., and Francis A.J. Ianni. "Technology in the Urban Education Marketplace." Educational Technology $10(1970): 39-44$.

Rushby, Nicholas John. Computers in the Teaching Process, New York: Halsted Press Book, John Wiley \& Sons, 1979.

Sandals, L.H. Computer-Assisted Applications for Learning With Special Needs Children. Paper presented at the meeting of the American Educational Research Association, San Francisco, California, April, 1979. (ERIC Document Reproduction Service No. ED 173 983).

Sax, Gilbert. Empirical Foundations of Educational Research. Englewood Cliffs NJ: Prentice-Hall, Inc., Englewood Cliffs, 1968 . 
Schneider, Edward. Memorandum to James Fenwick, dated December 29, 1981.

Schultz, Theodore $w$. The Economic Value of Education, New York: Columbia University Press, 1963.

Sewell, William H. "Social Class, Parental Encouragement, and Educational Aspirations." The American Journal of Sociology $73(1975)$ : 559-572.

Sexton, Patricia C. "Education and Income." In School Children in the Urban Slum, edited by Joan I. Roberts. New York: The Free Press, 1967.

Sharpe, William F. The Economics of Computers, New York: Columbia University Press, 1969.

Simmons, Rosa M., and Susan G. Broyles. Fall Enrollment in Colleges and Universities, 1980. Washington DC, U.S. Department of Education, 1982 .

Skinner, B.F. The Technology of Teaching. New York: Appleton-Century Crofts, Educational Division, Meredith Corporation, 1968.

Smith, Elsie J., and Clement B.G. London. "Overview: A Union of School Community and Family." Urban Education 16 (1981): 247-260.

Smith, I.D., and R.D. Hess. The Effects of Computer-Assisted Instruction on student Self-Concept, Locus of Control, and Level of Aspiration. Research and Development Memorandum No. 89. Stanford, CA: Stanford Center for Research and Development in Teaching, 1970 .

Sorensen, A. and Maineen T. Hilliman. A Conceptualization of School Effects. Madison, WI: University of Wisconsin, 1976 .

Statistical Abstract of the United States. U.S. Bureau of Census, 1981 .

Steele, Sara M. Contemporary Approaches to Program Evaluation: Implications for Evaluating Programs for Disadvantaged Adults. Washington, DC: Capitol Publications Inc., 1973.

Stolurow, Lawrence M. Education Automation Monograph Series: Computer Assisted Instruction. Detroit, MI: American Data Processing Inc., 1968. 
Studivant, Patricia. "Access to Technology: The Equity Paradox." The Computing Teacher 11 (1984): 65-67.

Stufflebeam, Daniel. Educational Evaluation and Decision Making. Bloomington, IN: Phi Delta Kappa, Inc., 1974.

Sumner, Gerald C. Analysis of the Cost And Effectiveness of Compensatory Education, Technical Report \#7, RMC Research Corporation, 1979

Suppes, Patrick, and J.D. Fletcher. "Performance Models of American Indian Instructions on Computer-Assisted Instruction in Elementary Mathematics, Instructional Science. Amsterdam, Netherland, 4 (1975).

Suppes, Patrick, J.D. Fletcher, and M. Zanotti. "Models of Individual Trajectories in Computer-Assisted Instruction for Deaf Students." Journal of Educational Psychology 68 (1976): 117-127.

Suppes, Patrick, D.T. Jamison, and C. Butler. "Estimated Costs of Computer-assissted Instruction for Compensatory Education in Urban Areas." Educational Technology $10(1970): 49-57$.

Suppes, Patrick, J. Jerman, and D. Brian. Computer-assisted instruction: Stanford's 1965-66 Arithmetic Program. New York: Academic Press, 1968.

Suppes, Patrick, C. Butler, G.C. Sumner, "Projecting Student Trajectories in a Computer-Assisted Instruction Curriculum." Journal of Educational Psychology 71 (1979): 74-84.

Tallmadge, G.K. "The Relationship Between Training Method and Learner Characteristics." Journal of Education Psychology $59(1968): 32-36$.

Tallmage, G.K., Procedure Guide for Validating Achievement Gains in Educational Projects No. 2 in a Series of Monographs on Evaluation in Education, Washington, DC. 1976 .

Tauckman, Howard P. "High School Inputs and Their Contribution to School Performance." The Journal of Human Resources 6 (1975): 500-507.

Theil, Henri. Introduction to Econometrics. Englewood Cliffs, NJ: Prentice-Hall Inc., 1978. 
Thomas, D.B. "The Effectiveness of Computer-assisted Instruction in Secondary Schools." AEDS Journal 12 (1979): 103-116.

Tuckman, Bruce W. Evaluating Instructional Programs. Boston, MA: Allym and Bacon Inc., 1979.

UNESCO, The Economics of New Educational Media. New York: Unesco, 1977 .

UNESCO, Year Book, 1984, New York: UNESCO, 1984.

Vincent, A.T. "The Effects of Supplementary Computer-Assisted Instruction on the Mathematics Achievement Attitude Toward Mathematics of EMR High School Students." Ph.D. diss., University of Cininnati, 1977. Dissertation Abstracts International, 1978, 39, 736-A. (University Microfilms No. 7812963).

Vinsonhaler, John F., and Ronald K. Bass. "A Summary of Ten Major Studies on Drill and Practice." Educational Technology, (1972).

Walberg, Herbert J., and A. Ahlgren. "Predictors of the Social Environment of Learning." American Educational Review Journal 7 (1970): 153-167.

Walberg, Herbert J., and Wayne C. Frederick. "Learning as a Function of Time." Journal of Educational Research 73 $(1980)$.

Weiner, Cheryl. Practice Guide to Computers in Education. Addison-Wesley Publishing Company, 1982 .

Welch, Finis. "Measurement of the Quality of Schooling." American Economic Review 56 (1966): 379-392.

Wells, S., B. Whelchel, and D. Jamison. The Impact of Varying Levels of Computer-Assisted Instruction on the Academic Performance of Disadvantaged Students. Princeton, NJ: 1974. (ERIC Document Reproduction Service No. ED 157 899).

Wieck, C. "Computer Resources: Will Educators Accept, Reject or Neglect the Future?" Education Unlimited 2 (1980) 24-7. (ERIC Document Reproduction Service No. ED 124657$)$.

Wilkinson, Gene L. "Needed: Information for Cost Analysis," Educational Technology 12 (1972): 33-38. 
wilkinson, J.H. "The Effectiveness of an Individualized Computer-assisted Instructional Program (PLAN) with Students from a Low Socio-Economic Community." Ph.D. diss., St. John's University. Dissertation Abstracts International 1979, 40, 1889-A.

Williams, J.G, R. Thorkildson, W.K. Bickel. "A Microcomputer Videodisc CAI System for the Moderatley Mentally Retarded", Journal of Special Education Technology, V.II 3 (Spring 1979) 45-51, ERIC: EC 130622.

Wilson, H.A., and N.H. Fitzgibbon. "Practice and Perfection: A preliminary Analysis of Achievement Data from the CAI Elementary English Program." Elementary English 47 (1970): 576-579.

Wilson, $R$. The Effectiveness of Computer-Assisted Instruction. A Survey of the Research. Portland, OR: Northwest Regional Educational Laboratory, Computer Technology Program, 1980.

Wise, Arthur E., and Linda D. Hammond. "Educational Vouchers: Regulating Their Efficiency and Effectivness." Educational Research 12 (1983) 9-12.

Year Book of Higher Education. Marquis Professional Publications. 1982-1983.

Zender, Bryce F. Computers and Education in the Soviet Union. Englewood Cliffs, NJ: Educational Technology Publications, 1975.

Zinn, Karl L. "Analysis of the Technology Education Act of 1982." In Microcomputers in Education 2 (1982). 
Bummary o: Insories and soncepts 
TABLE XVIII

VIEISS AID THCUGHTS OF

THORNDIKE AND PAVLOV

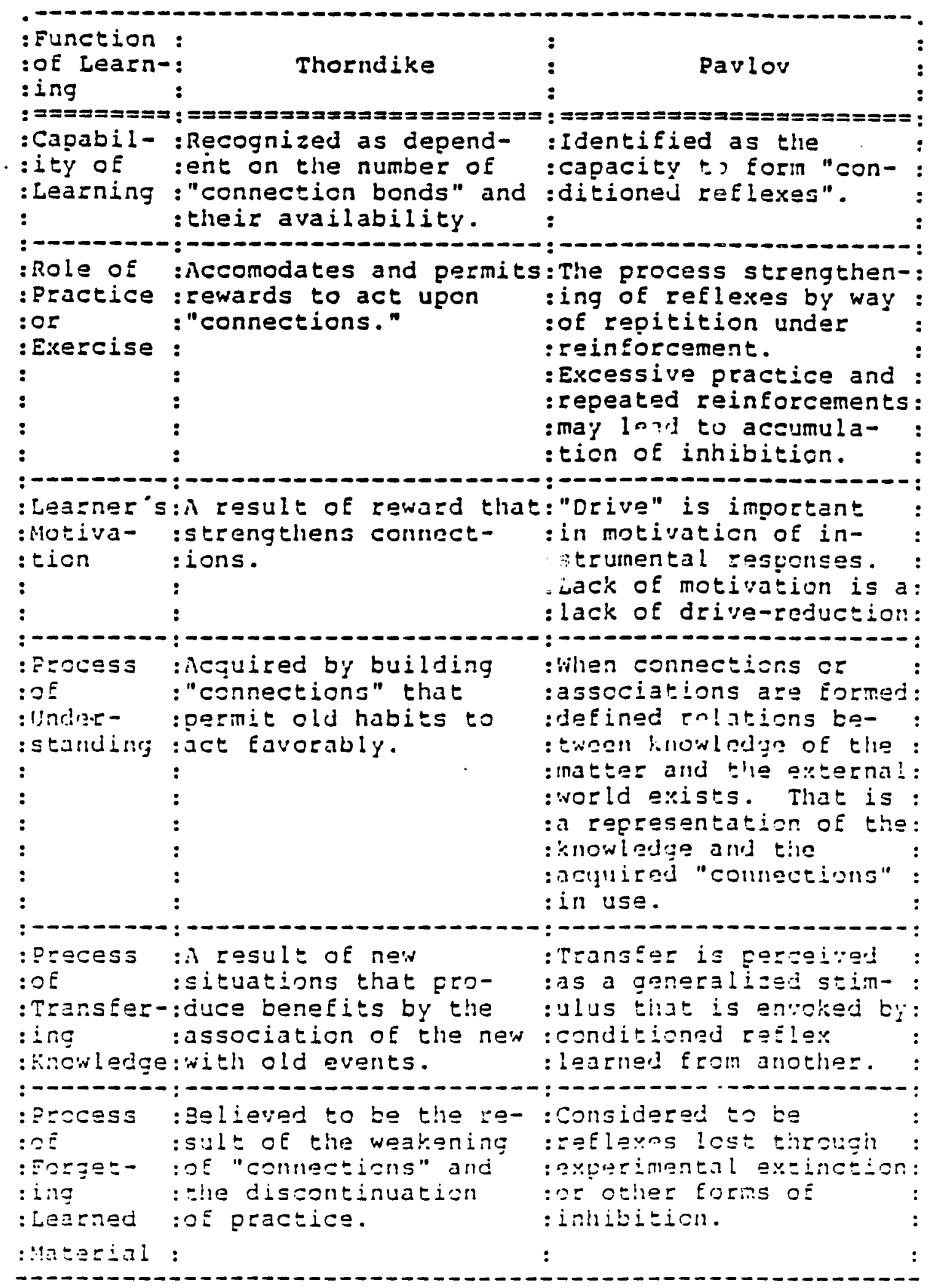


TABLE XIX

VIEWS AID THOUGIITS OE GUTHRIE AHO SKIMINER

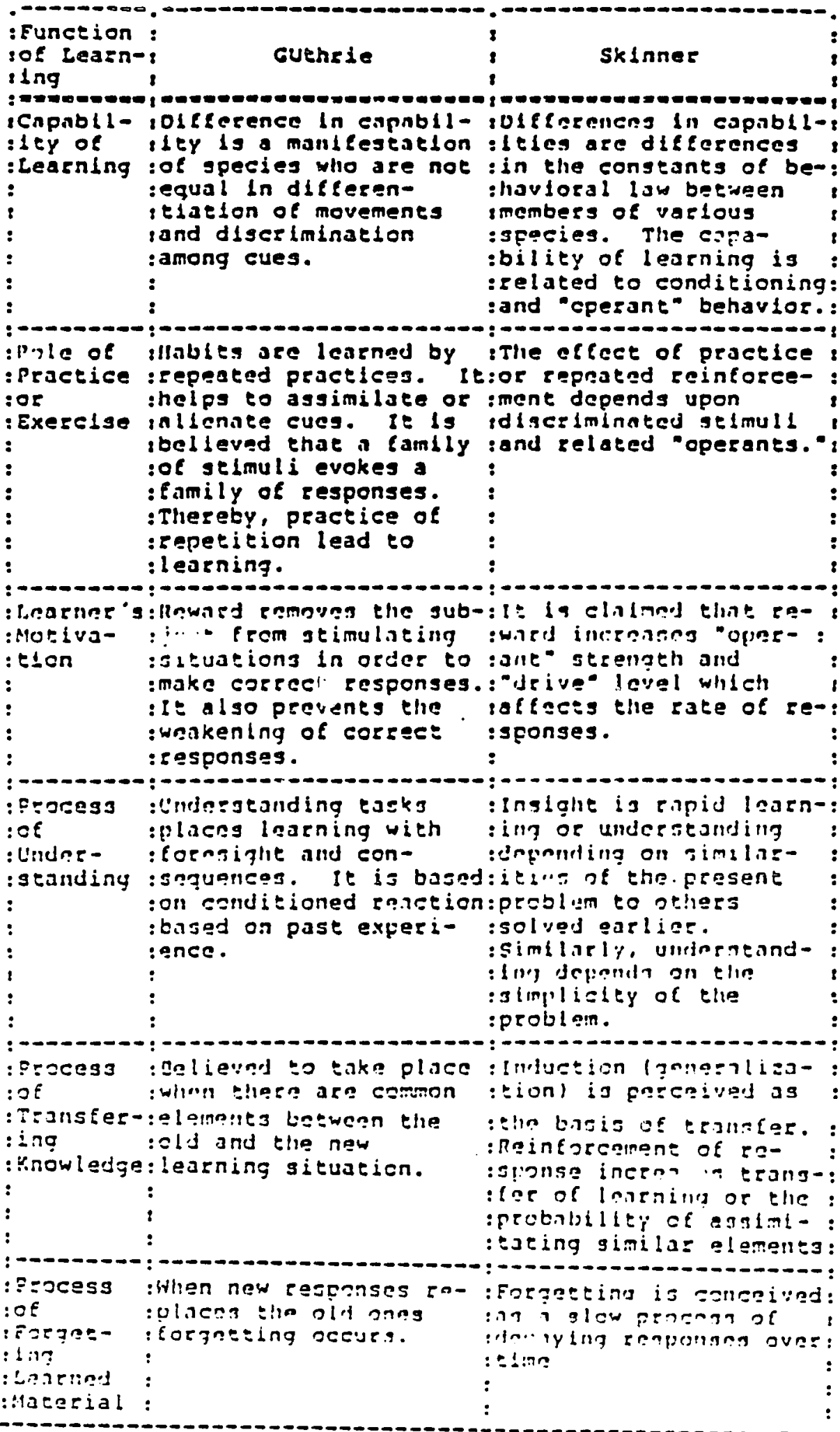


TABLE XX

VIEHS AND THOUGHTS OF HULL AHD IULAMH

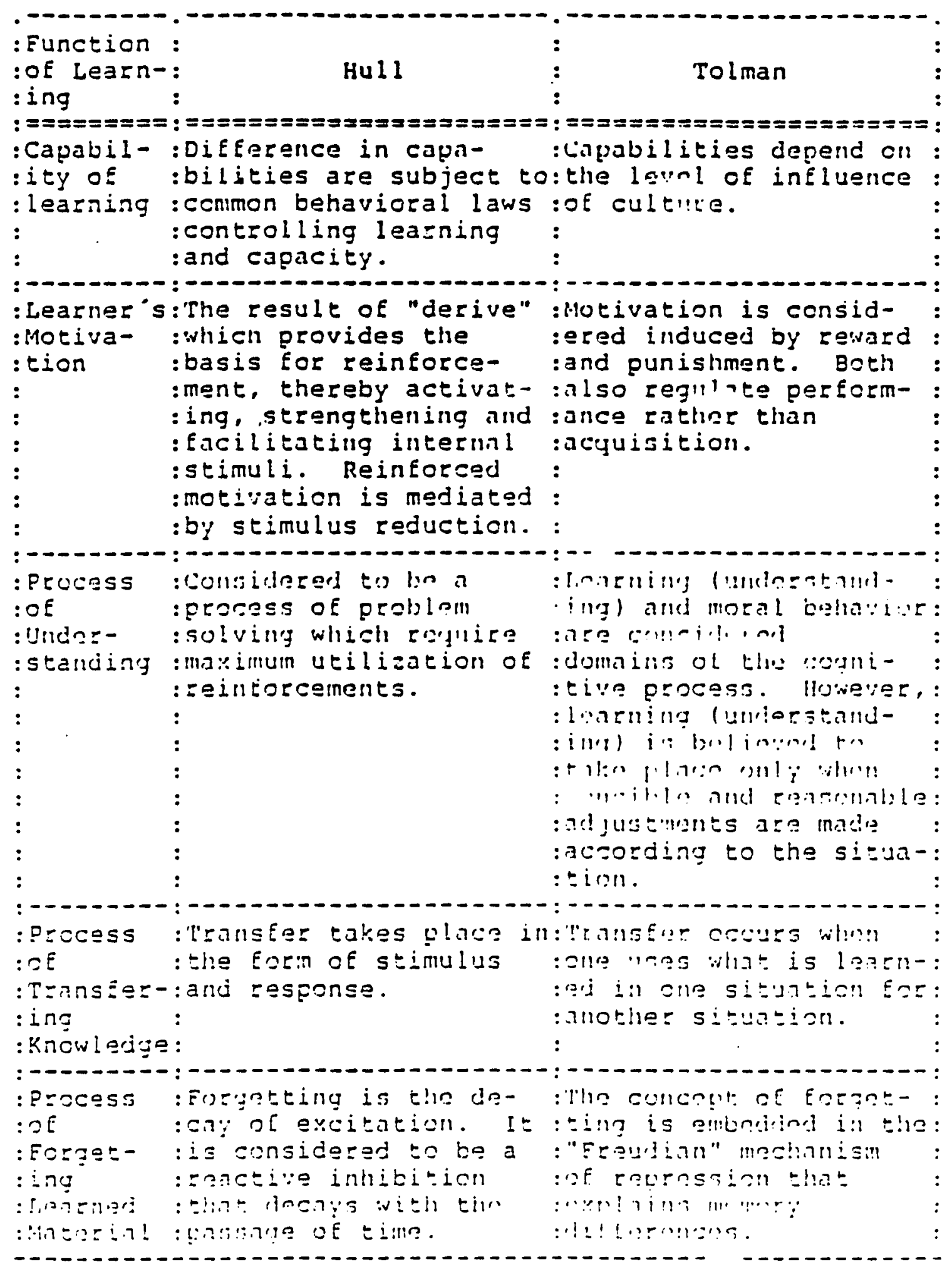


ฐ

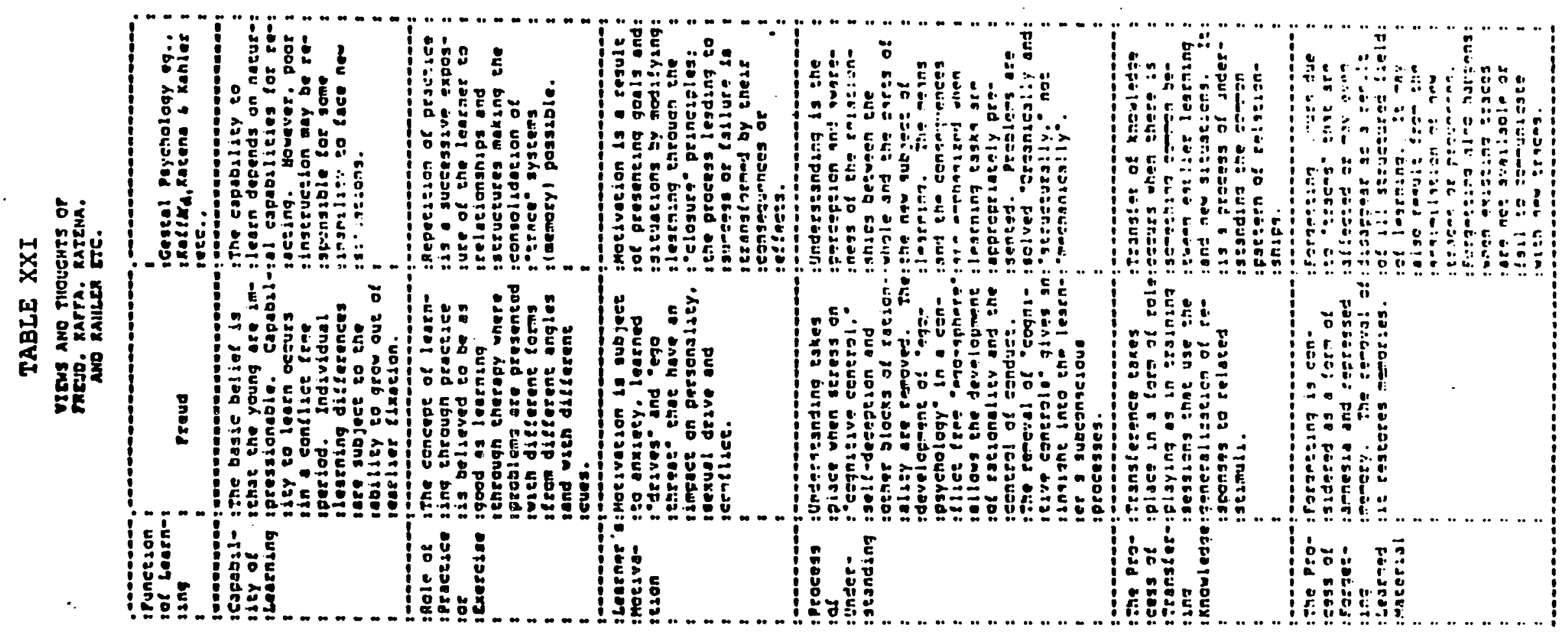


TABLE XXII

VIEISS NHD THOUGHTS OF ROBINSON

ANU THE FUHCTIONALISIS

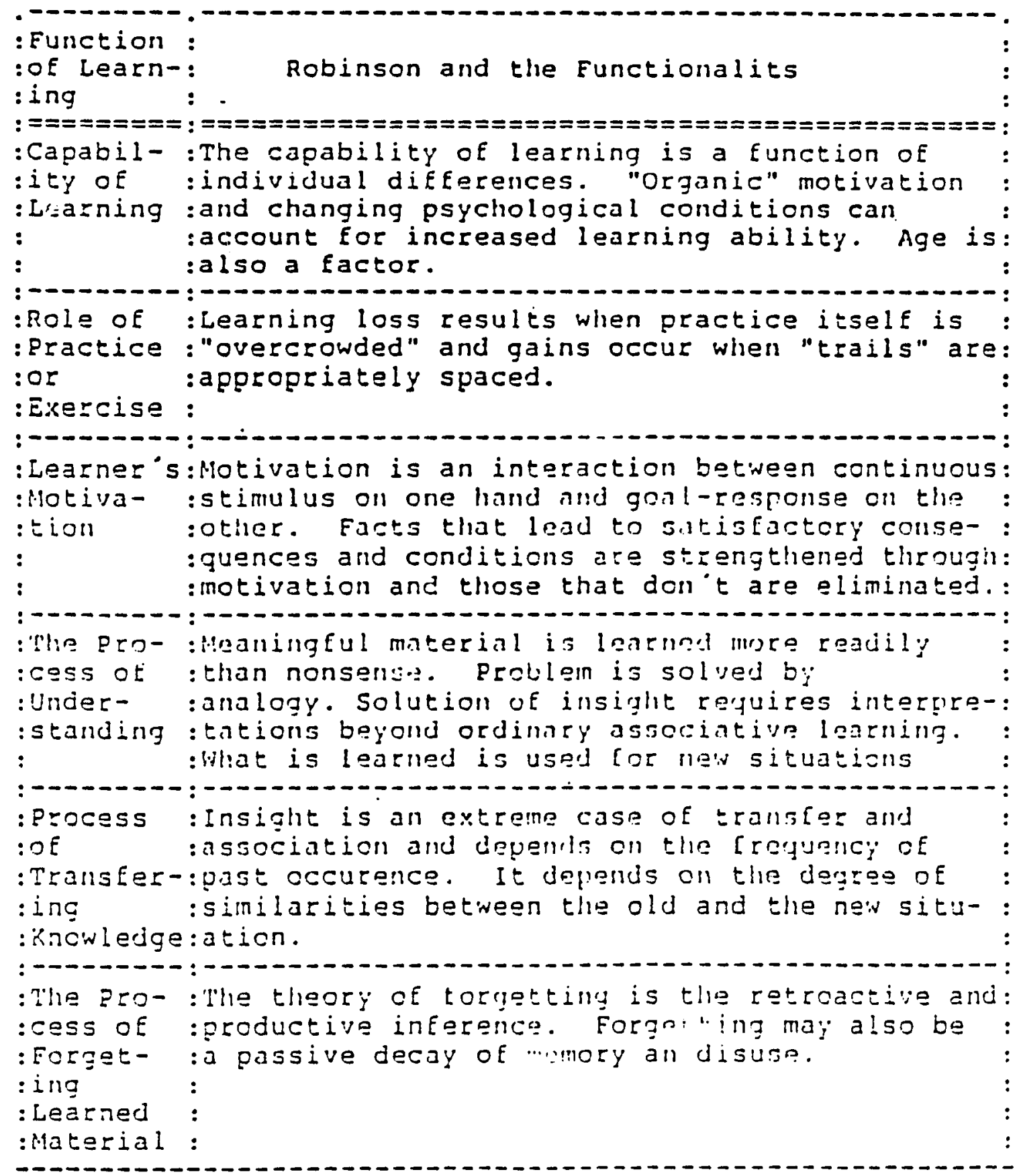


TABLE XXIII

PEDAGOGIC INNCVATION

IN INSTRUCTIONAL TECHNOLOGY (CFAPT)

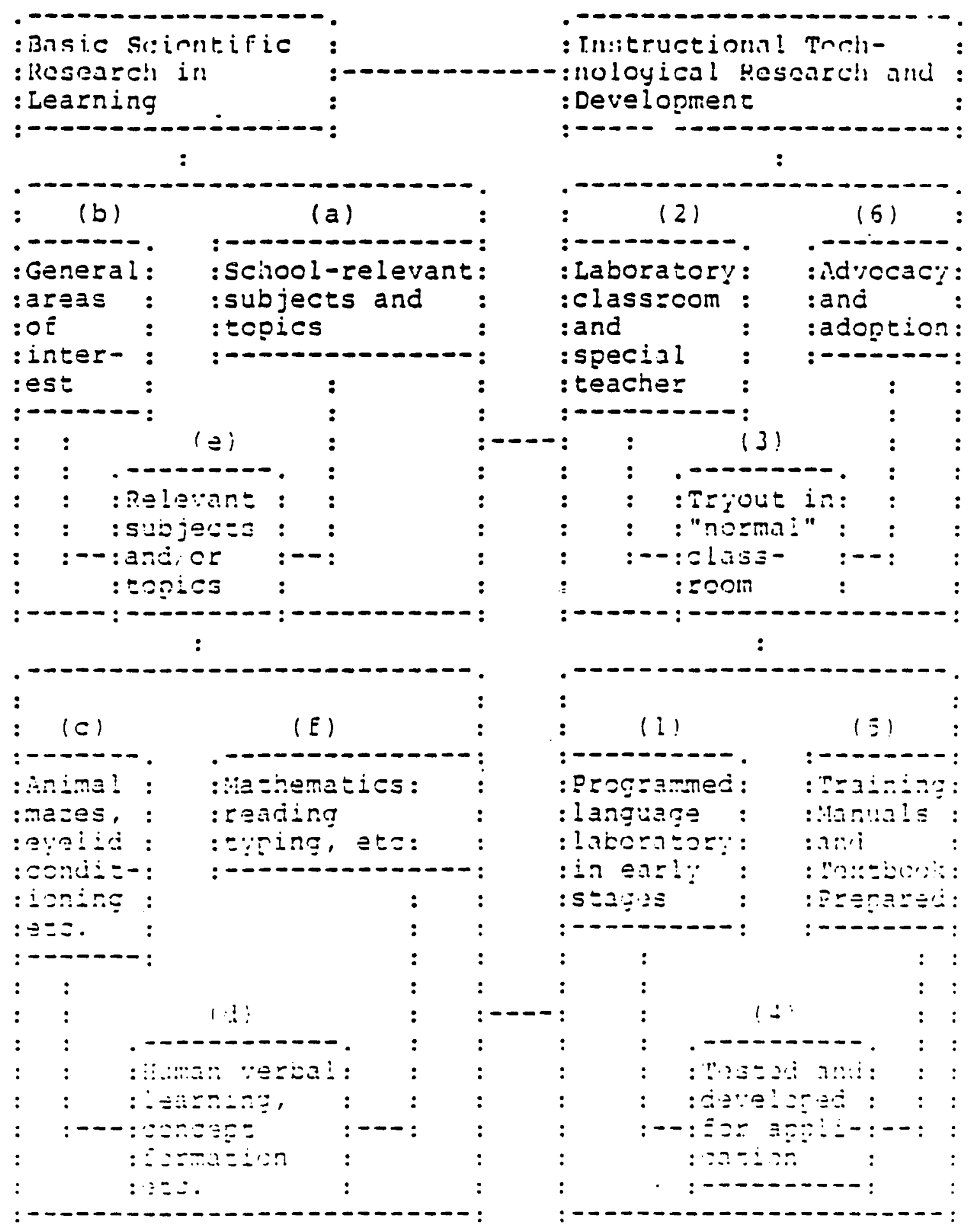


TABLE XXIV

TITEE I CRITSRIA AND FROCESSES OF

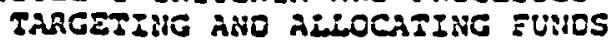

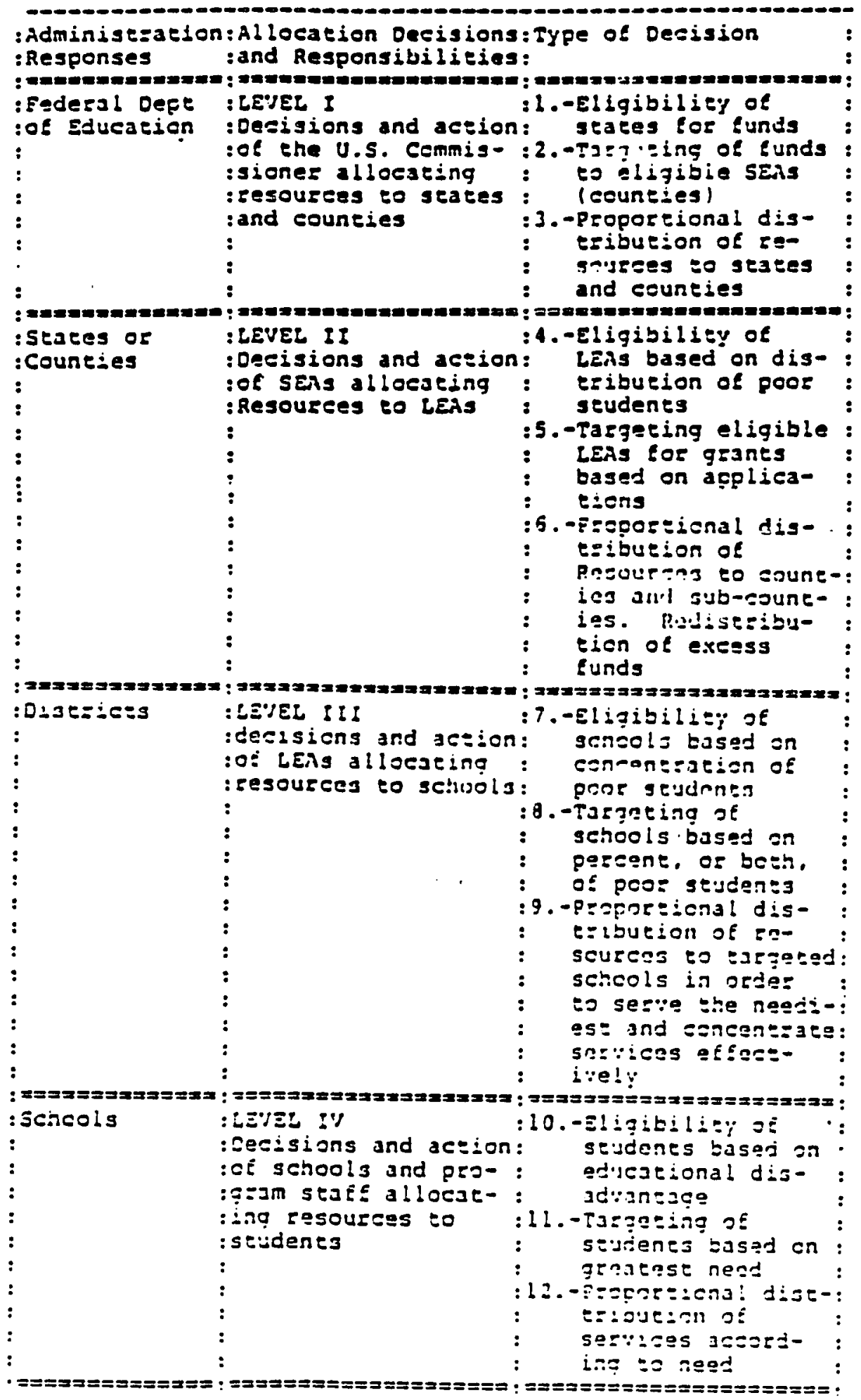


Regression Model 
TABLE XXV

Predicted pest-test Values of CiI,PLI and TMI The apolisa:ton of the folloming thase equations frdccue a fredictad values of post-tests based ca a gives pre-test.

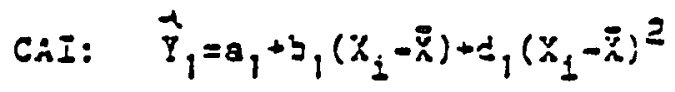

PLL: $\quad \hat{I}_{2}=a_{2}+z_{2}\left(x_{j}-\bar{X}\right)+c_{z}\left(x_{j}-\bar{x}\right)^{2}$

TYI $=\vec{I}_{j}=a_{3}+b_{3}\left(x_{k}-\overline{\bar{X}}\right)+\dot{c}_{j}\left(y_{x_{x}}-\overline{\bar{x}}\right)^{2}$

\begin{tabular}{|c|c|c|c|c|c|c|}
\hline p:q-:s::s & & \multicolumn{2}{|c|}{ ?っs:-*es: } & \multicolumn{3}{|c|}{ Ga:s: } \\
\hline$(x)$ & 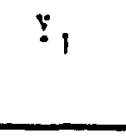 & $r_{2}$ & $i_{3}$ & $\begin{array}{l}E_{1} \\
\left(\ddot{z}_{1}-! !\right)\end{array}$ & $\begin{array}{l}S_{\varepsilon} \\
(\ddot{z},-x)\end{array}$ & $\begin{array}{l}G= \\
(\Sigma:-X)\end{array}$ \\
\hline $1: 0$ & $1 \Xi .2$ & iji. & $15 \overline{.2}$ & $\Xi 三 .2$ & $7 . \subseteq$ & $\Xi Z . z$ \\
\hline ! :-: & 1.5 .3 & 155.5 & $1,1.2$ & ż. 5 & $\Xi .5$ & $2 i . \Sigma$ \\
\hline 175 & IES.S & 173.3 & $1 \hat{z}: .1$ & $1 \leq .5$ & $\Xi . \xi$ & $1=.1$ \\
\hline 150 & $19 \Xi .9$ & 195.5 & $15 . .1$ & T.C & $\Xi .5$ & $\therefore 1$ \\
\hline$E: 0$ & Z!ล. & $2 i c . \dot{s}$ & EIC. & $\Xi .5$ & c. 5 & $6 . \vdots$ \\
\hline$E: Z$ & 213.5 & 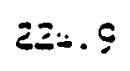 & $z=-. \leqslant$ & $1 \equiv .3$ & $-\equiv .1$ & $-\therefore$. \\
\hline$z=:$ & $=-4$. & 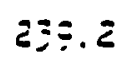 & $\Xi j \Xi . \leqslant$ & $E^{\prime}-L$ & $-! . \Xi$ & $-: i .1$ \\
\hline
\end{tabular}


Sample Iata 
TABLE XXVI

SAMPIE BREUNDCWNI PY GRACE MID SCFCOI.

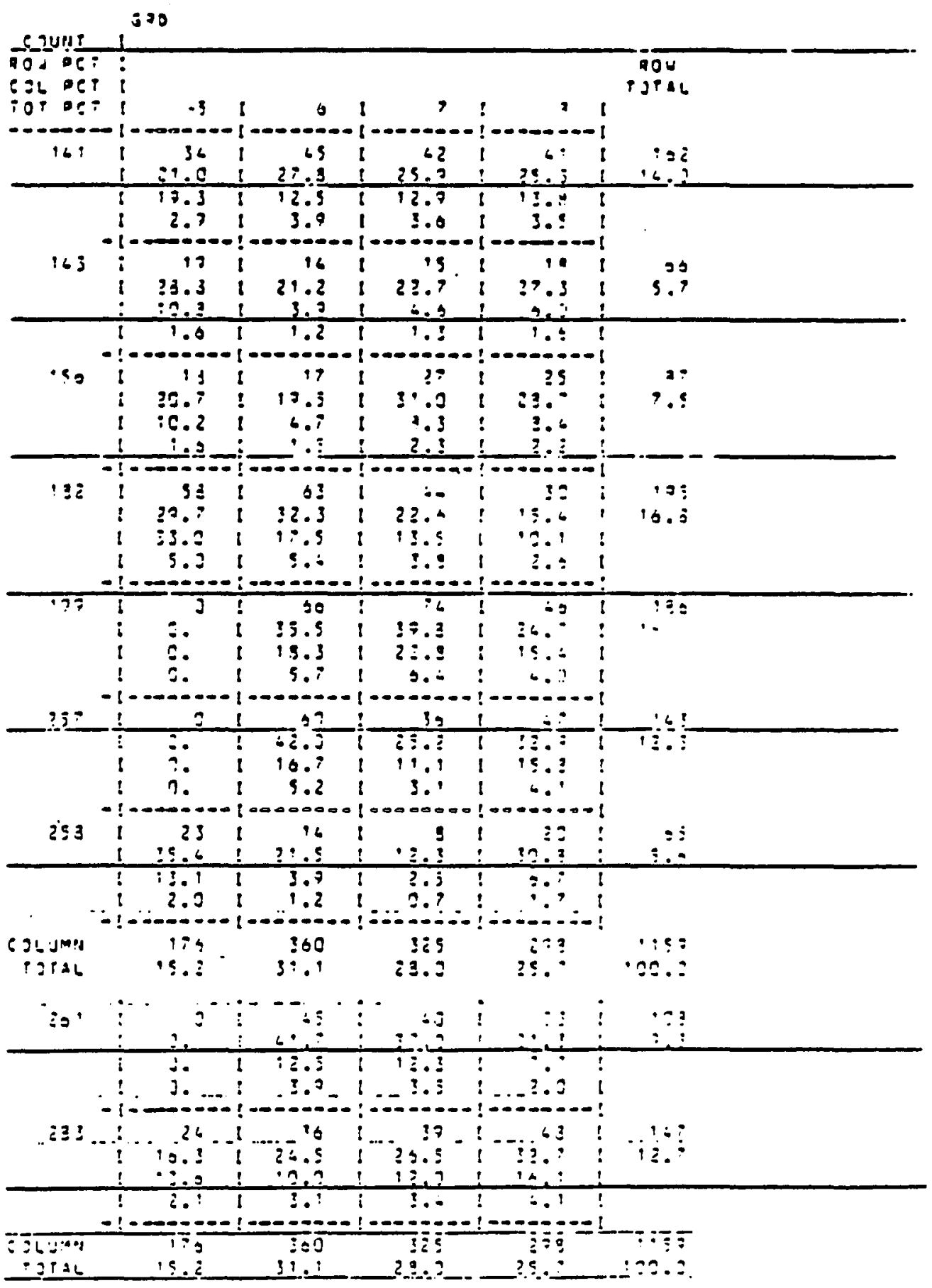


TABLE XXVII

SAMTLE BREAOCIN BY SCEOOL PND EIENIC GROLP

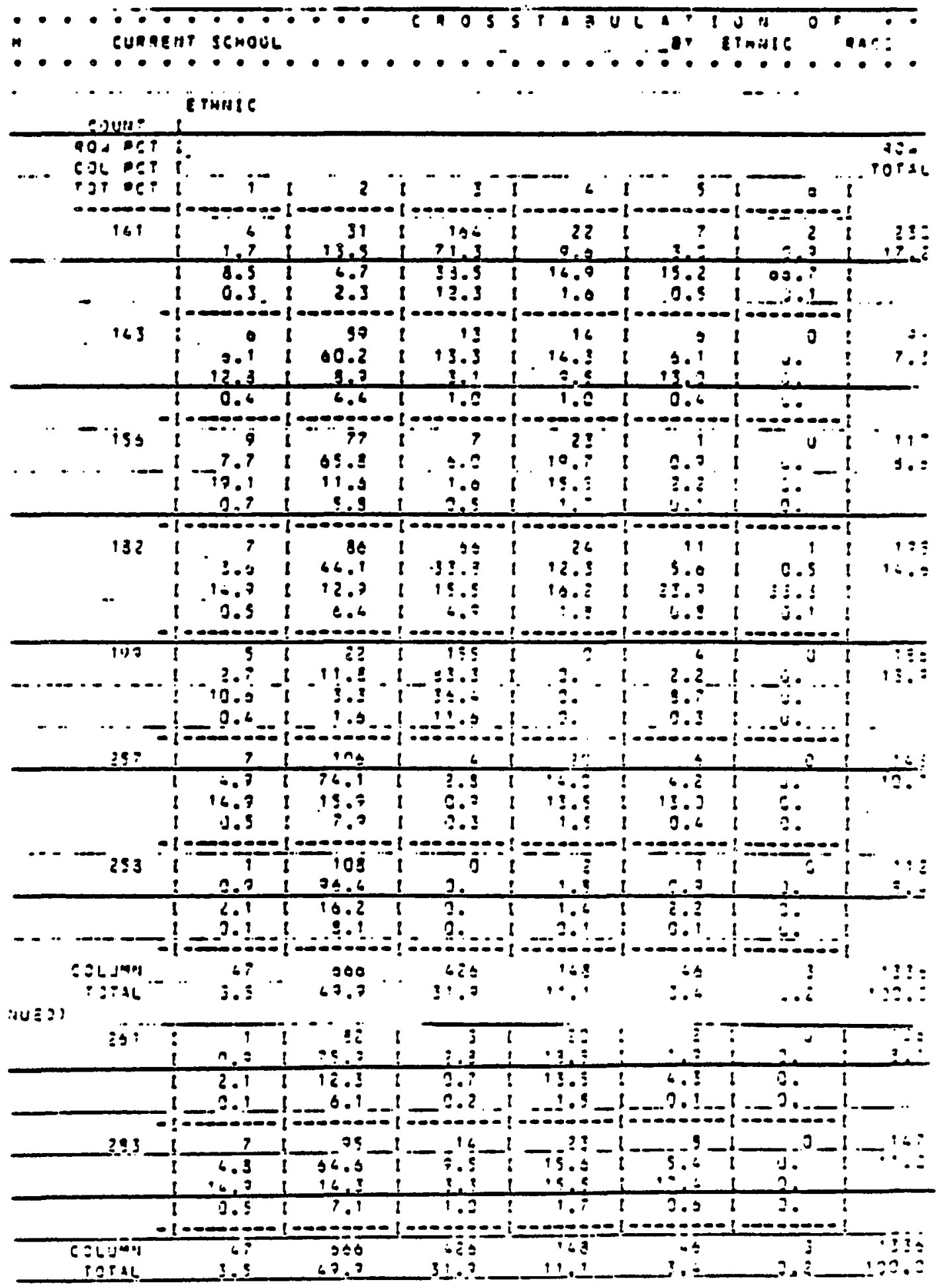


TABLE XXVIII

SMPLE BRENDOFAN BY EIINIC AND GEDER

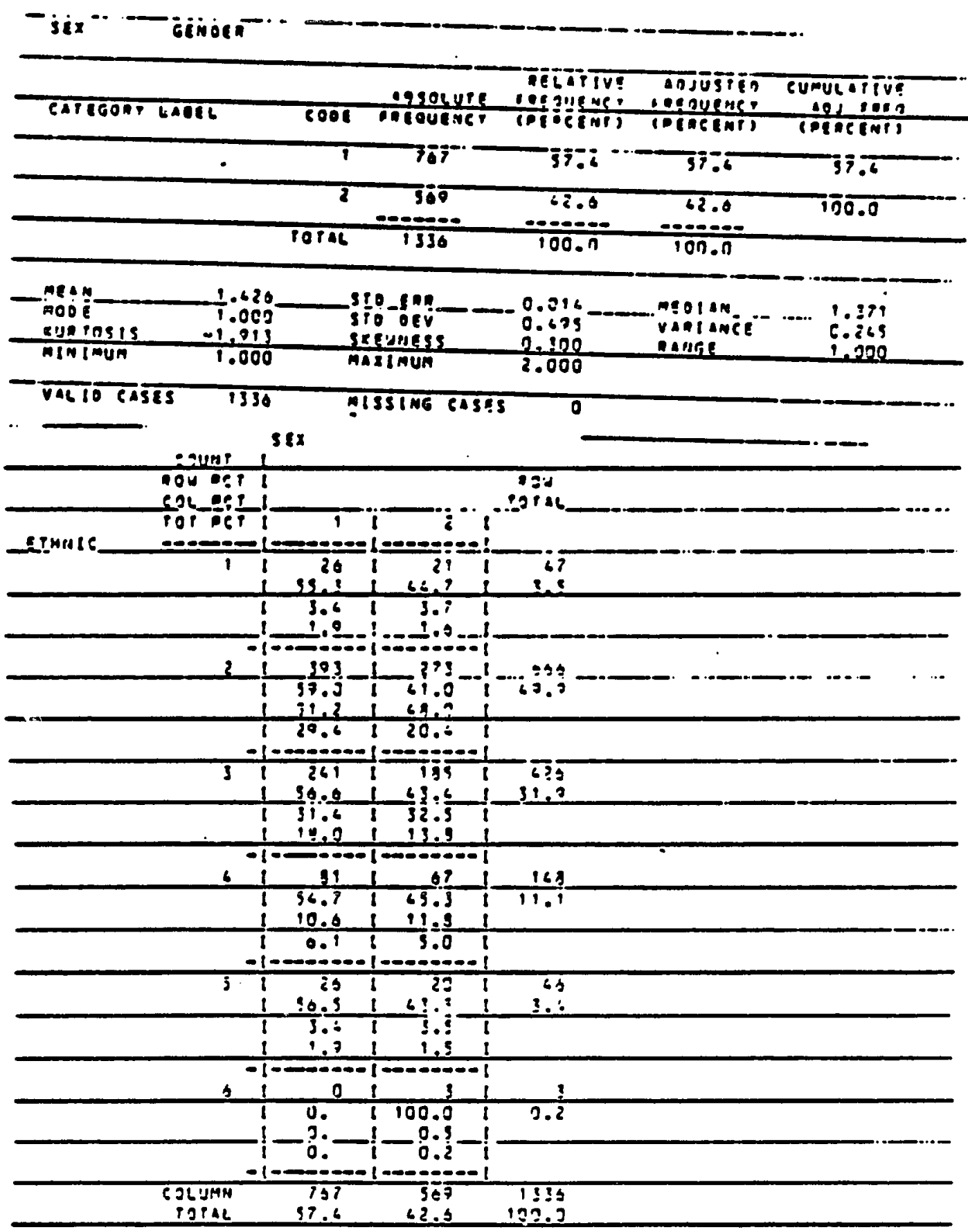

where male $=1$ and femele $=2$, ethric $1=1,2=(\cdot 4,3=8,4=5,5 \Rightarrow)$

and $6=0$ ther 
TABLF XXIX

SAMPLE BREANDOWN BY GRIDE NN GENDER

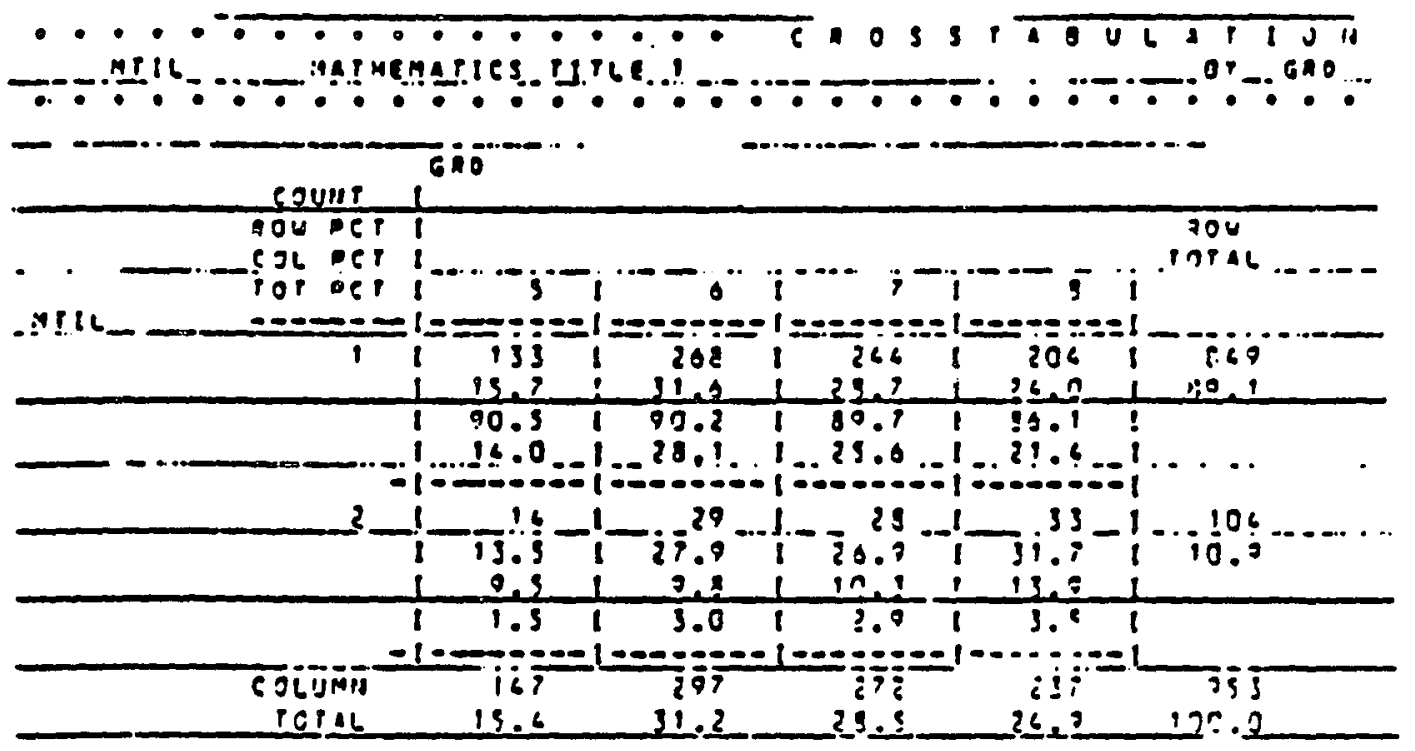

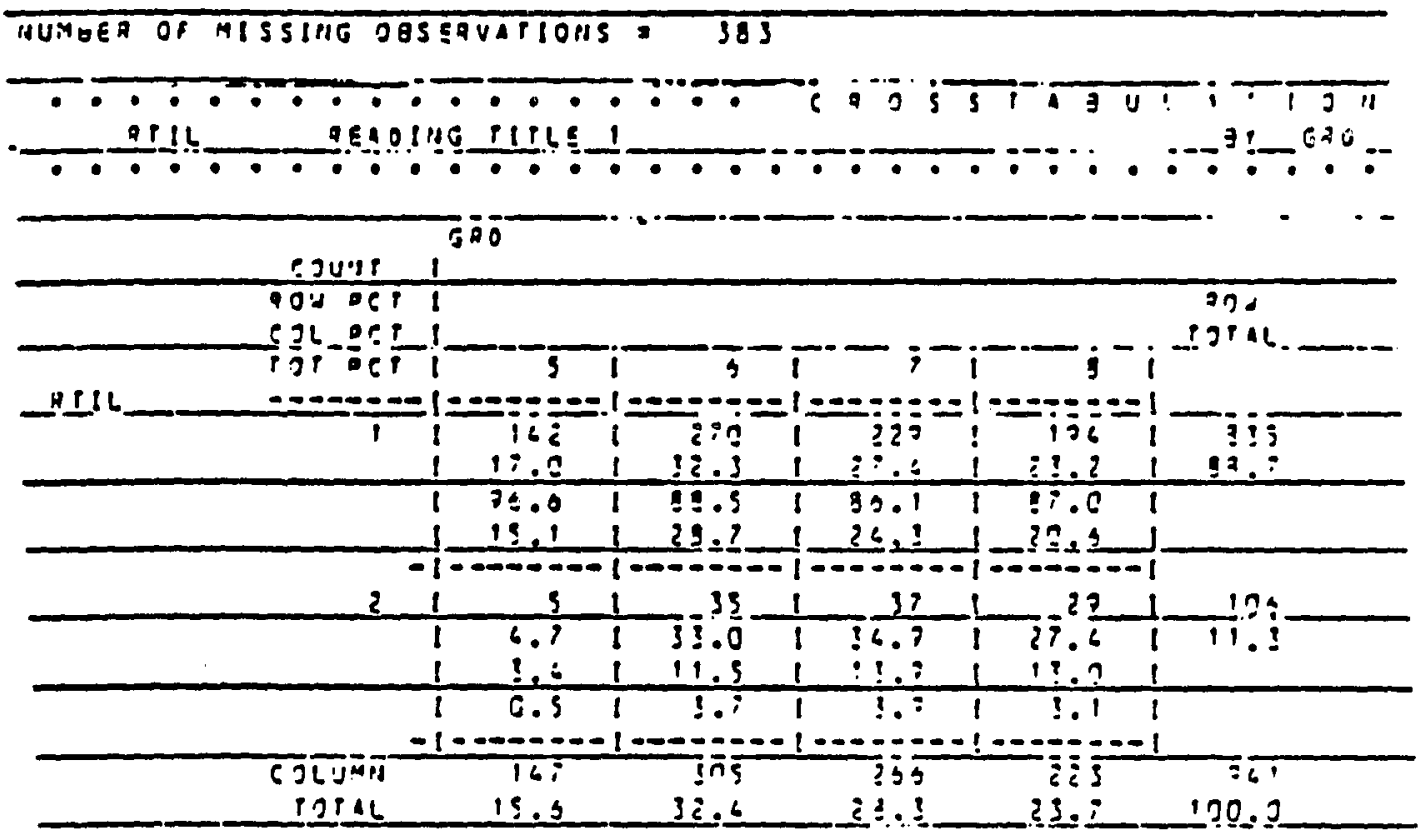




\section{Rezression output Tables}




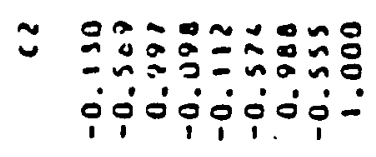

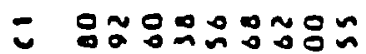
ํํำํํํํำ -0ं0000ं-0ं

密

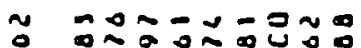

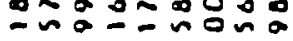
iिं $\dot{0} \dot{0} \dot{0} \dot{0}$

- $\sim 000 \div 0$

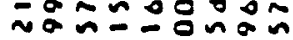
வ0ं0ं-0்

是

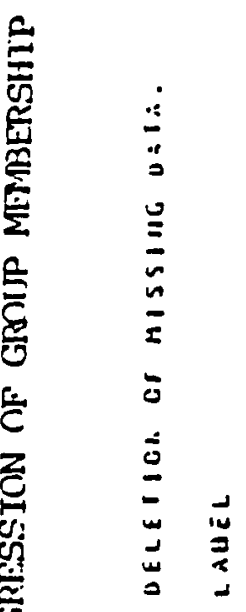

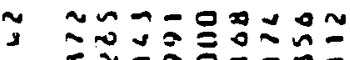

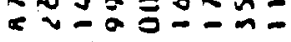
ته

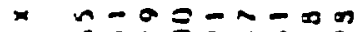

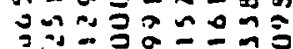
$\therefore \dot{\square}=\dot{0} 0 \dot{0} 0$ $i-\infty 0_{i}=q_{1}$

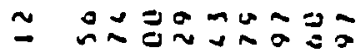

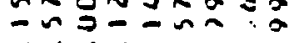

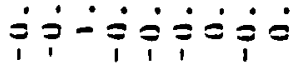

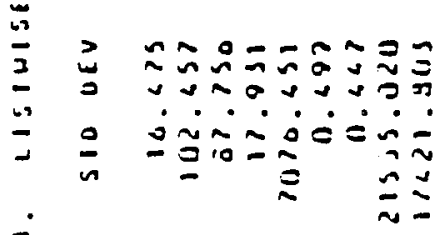

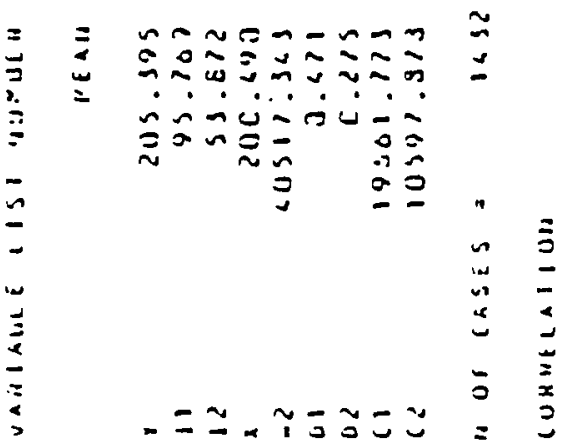

-

$\therefore \dot{0} \dot{=} \dot{=}=\dot{=}$

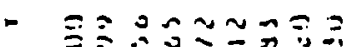

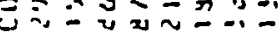

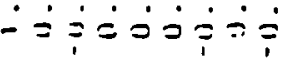


TABLE XXXI

DEPEHOEII VARIAGLE.. I

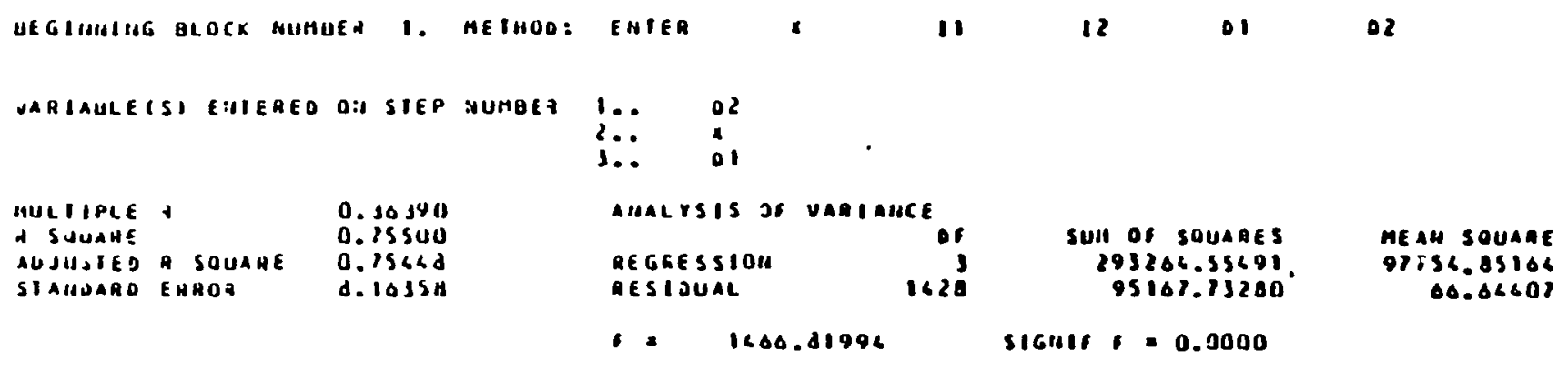

\begin{tabular}{|c|c|c|c|c|c|c|}
\hline VARIABLE & B & SE & SS2 COHFONCE & InIAve & $\operatorname{ag} I A$ & 5161 \\
\hline $\begin{array}{l}02 \\
0 \\
01 \\
\text { (c UIASIAUI) }\end{array}$ & $\begin{array}{r}-0.02981 \\
11.39525 \\
2.53650 \\
61.02019\end{array}$ & $\begin{array}{l}0.59510 \\
0.01223 \\
0.53200 \\
2.58621\end{array}$ & $\begin{array}{r}-1.19863 \\
0.15090 \\
1.50991 \\
62.15314\end{array}$ & $\begin{array}{r}1.13880 \\
0.20795 \\
1.54916 \\
51.89860\end{array}$ & $\begin{array}{r}-0.0086-03 \\
0.25321 \\
0.07743\end{array}$ & 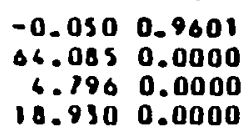 \\
\hline
\end{tabular}

\begin{tabular}{|c|c|c|c|c|}
\hline VAHIAULE & DEIA IU & PAHIIAL & MIII IOLES & S1G \\
\hline $\begin{array}{l}11 \\
12\end{array}$ & $\begin{array}{r}1.01280 \\
-0.12005\end{array}$ & $\begin{array}{r}0.14620 \\
-3.31260\end{array}$ & $\begin{array}{l}0.013720 \\
1.00351\end{array}$ & 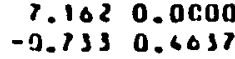 \\
\hline
\end{tabular}

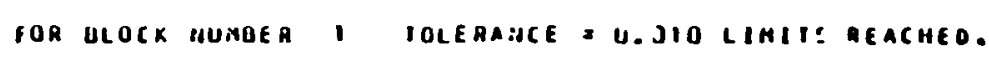

\begin{tabular}{|c|c|c|c|c|c|c|c|c|c|c|c|c|}
\hline SIEP & nuL IR & ค SO & $\cos 050$ & $f(E O U)$ & 5165 & n socu & ICH & $316 C H$ & & VARIABLE & OE JAIN & CORAEL \\
\hline $\begin{array}{l}1 \\
2 \\
3\end{array}$ & $0.5 \angle 84$ & 0.7550 & 0.7565 & 1600.920 & 0.000 & $0 .: 530$ & 1666.820 & 0.000 & $\begin{array}{l}\text { III: } \\
\text { III: } \\
\text { III: }\end{array}$ & $\begin{array}{l}02 \\
01 \\
01\end{array}$ & $\begin{array}{r}-0.1836 \\
0.0542 \\
0.0776\end{array}$ & $\begin{array}{r}-0.1836 \\
0.8655 \\
0.2118\end{array}$ \\
\hline
\end{tabular}


TABLE XXXII

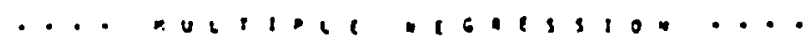

Lualiull bunoe: :

otechatit velavel..

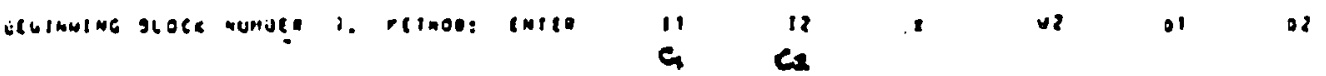

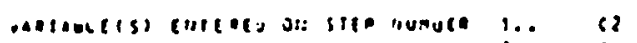

i.: is

3...

1.. 02

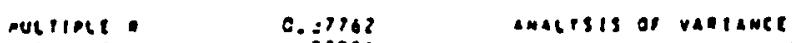

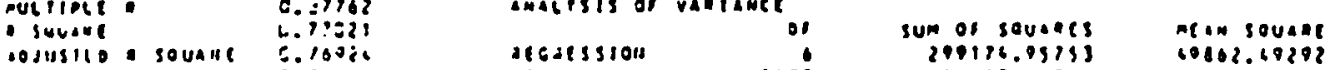

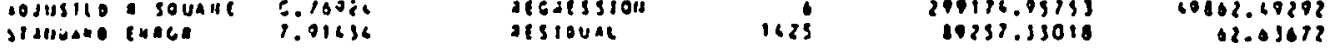

- 200.09160 SIENII. 0.0000

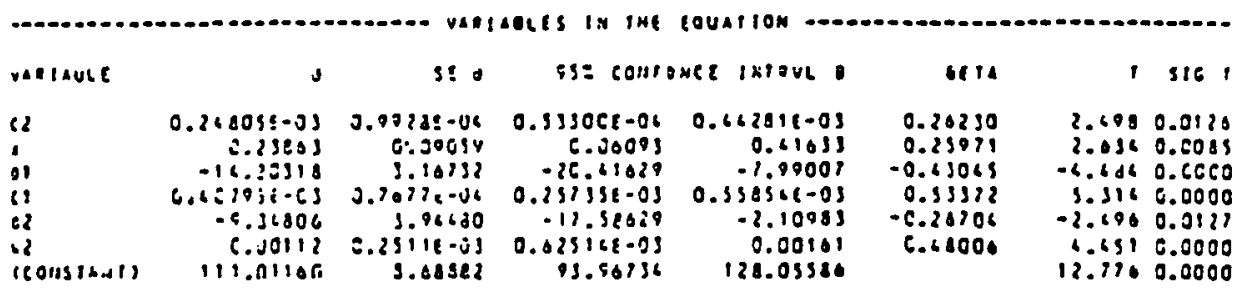

............. valisules idot in int toustion.............

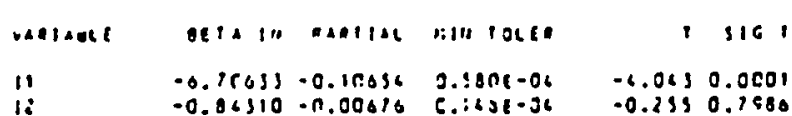

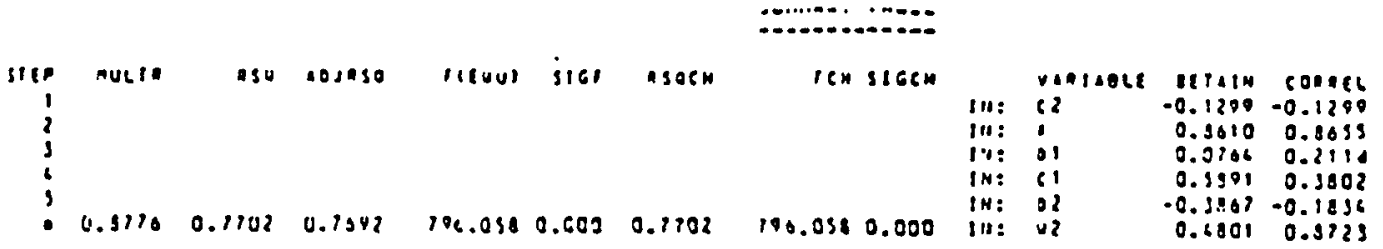




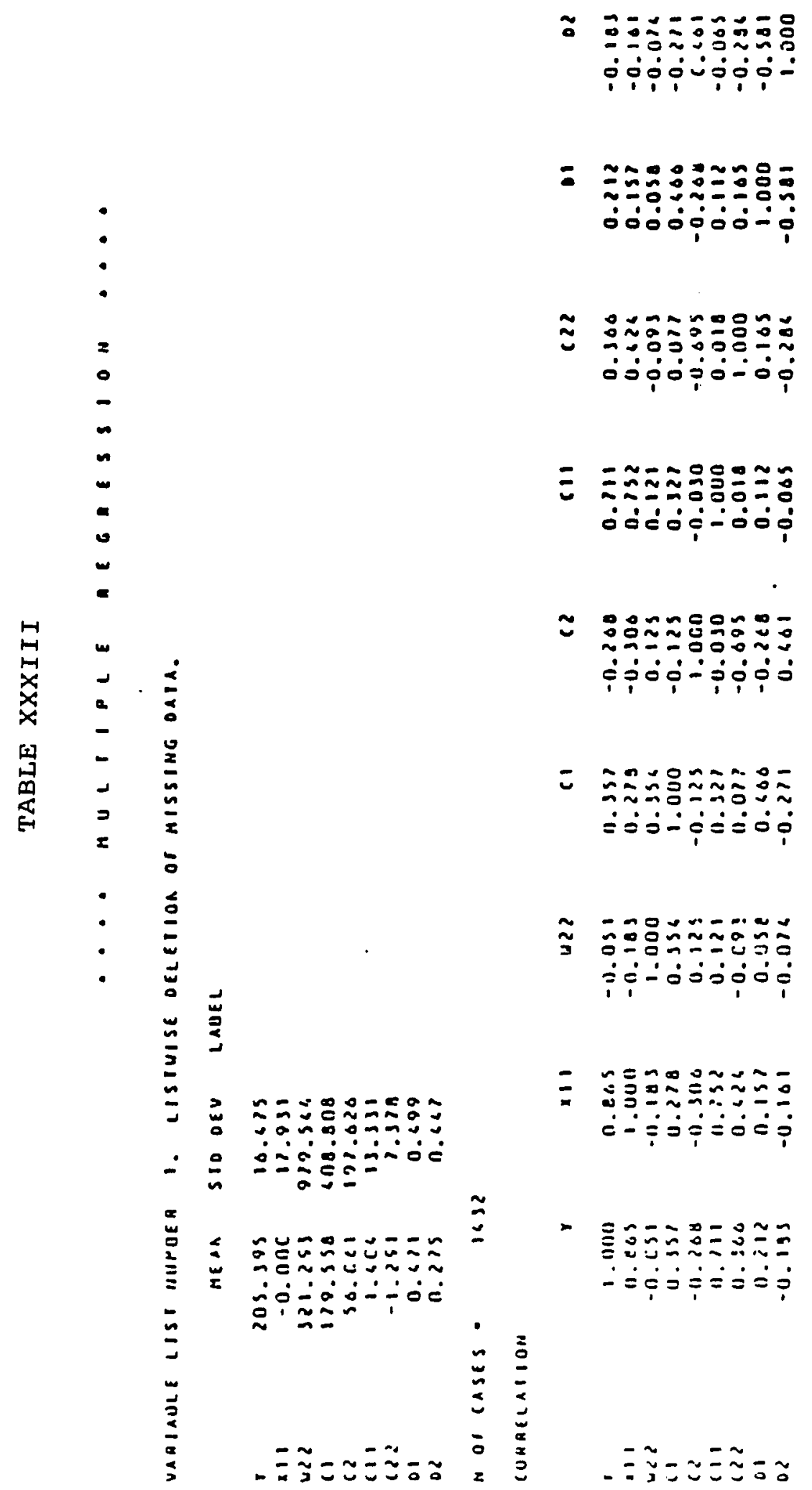




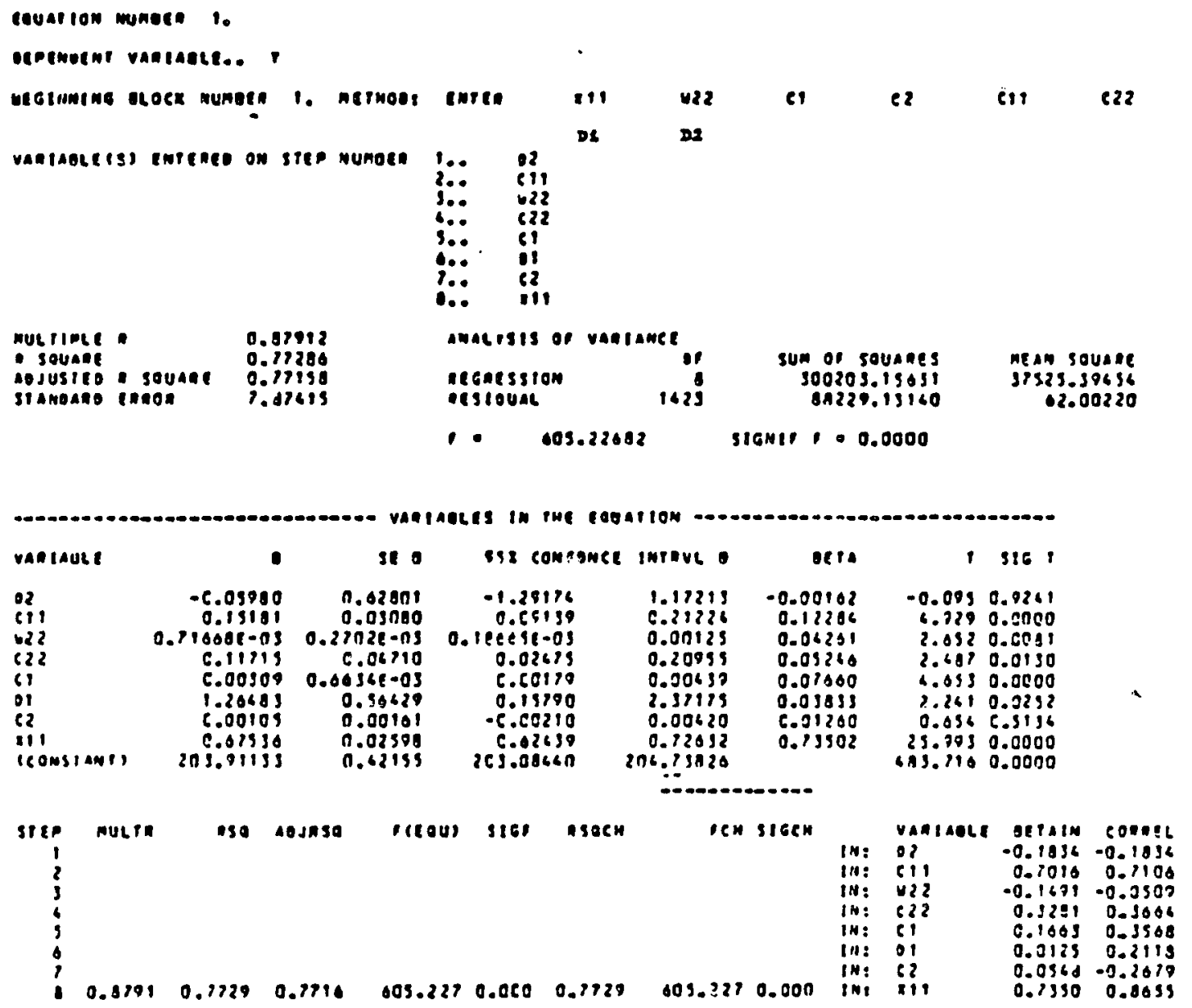




\section{IABLE XXXV}

STAIIAAROIZED SCATTERPLOT (a:

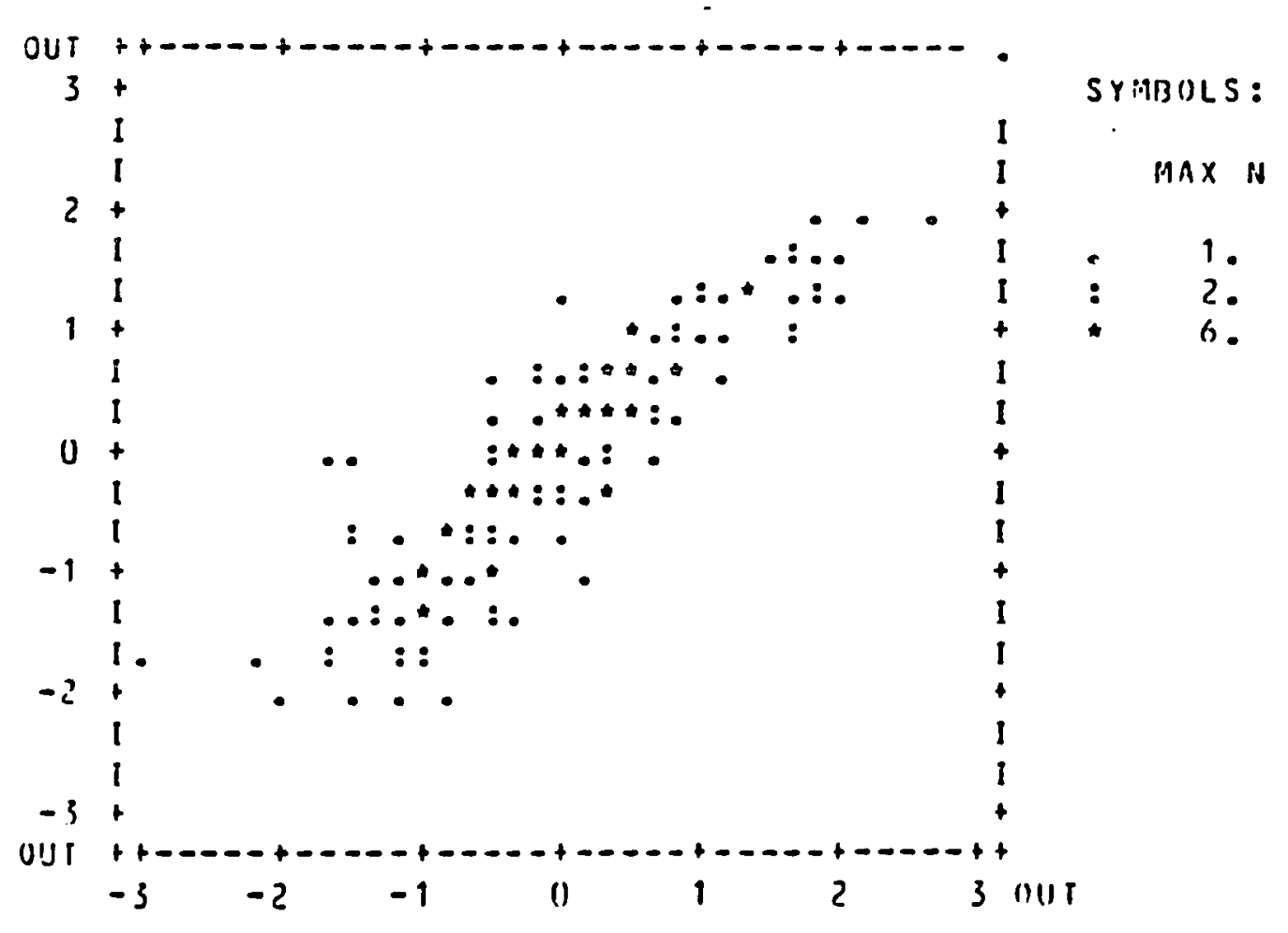

STA.RUAKOILEO SCATTEKINLUT ( bj

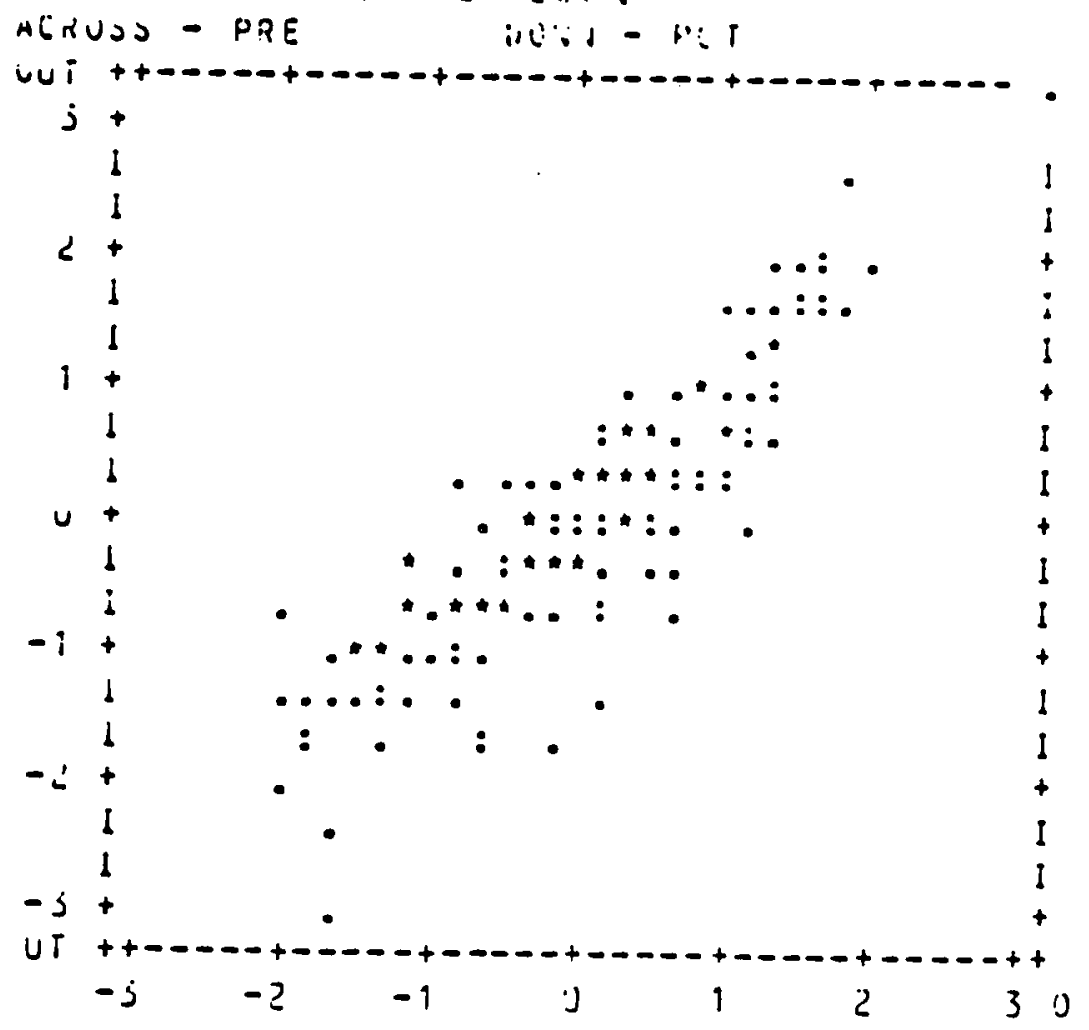


Test of Group Differences 
TABLE XXXVI

PERCENIIIP RAHK BY SKILL, NREA

NIJU GRAUE LEVEL

\section{Math: Rank Standings}

\begin{tabular}{|c|c|c|c|c|c|c|c|c|}
\hline \multirow{2}{*}{$\begin{array}{l}\text { 'l'reatiment } \\
\text { l'est }\end{array}$} & \multirow{2}{*}{$\begin{array}{l}\text { Methous/ } \\
\text { (iroups }\end{array}$} & \multicolumn{7}{|c|}{ ztile placement lovel } \\
\hline & & 5 & : & 6 & : & 7 & : & $\boldsymbol{\theta}$ \\
\hline \multirow{4}{*}{ PRE- } & CAI & 1.1 & $:$ & 9.3 & : & 5.5 & : & 14.4 \\
\hline & I'LL & 12.3 & : & 11.2 & $:$ & 4.3 & $:$ & 8.2 \\
\hline & IHII & 24.1 & $\begin{array}{l}: \\
:\end{array}$ & & $:$ & 12.7 & : & 41.7 \\
\hline & & & $\therefore$ & & $:$ & & : & \\
\hline \multirow{3}{*}{ losj'l'- } & $C \wedge 1$ & 16.3 & $\begin{array}{l}: \\
:\end{array}$ & 23.7 & $\begin{array}{l}: \\
:\end{array}$ & 18.8 & : & 27.5 \\
\hline & l'l, & 24.1 & $:$ & 16.0 & $\begin{array}{l}: \\
:\end{array}$ & 13.11 & : & 18.8 \\
\hline & & 23.8 & $:$ & 11.2 & : & 2.4 .7 & : & \\
\hline
\end{tabular}

Rcadiug: Rank:

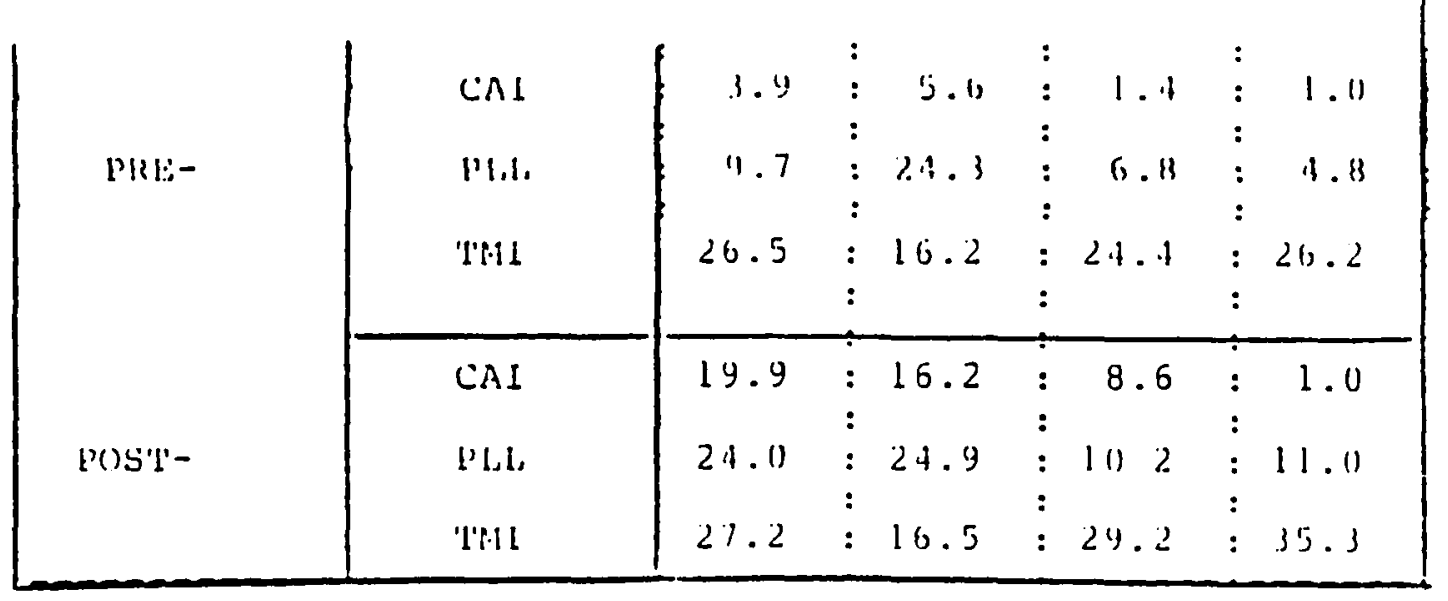


TABLE XXXVII

FEMALE ACHTFMEMENT DIFFERENCES BY METHOD OF INSTRUCTION

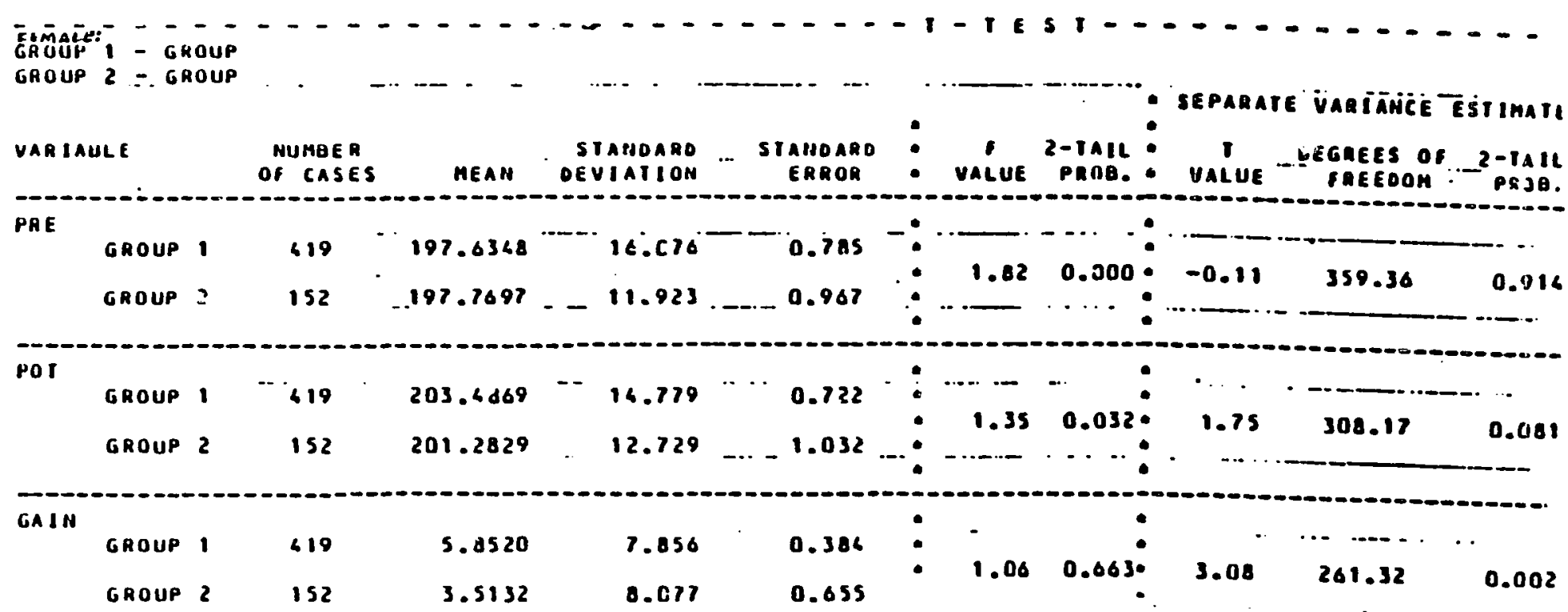

where GROUP $1=$ CAI, $2=$ PLI 
TABLE XXXVIII

MALE ACHIEVEMENT DTFFEREICES

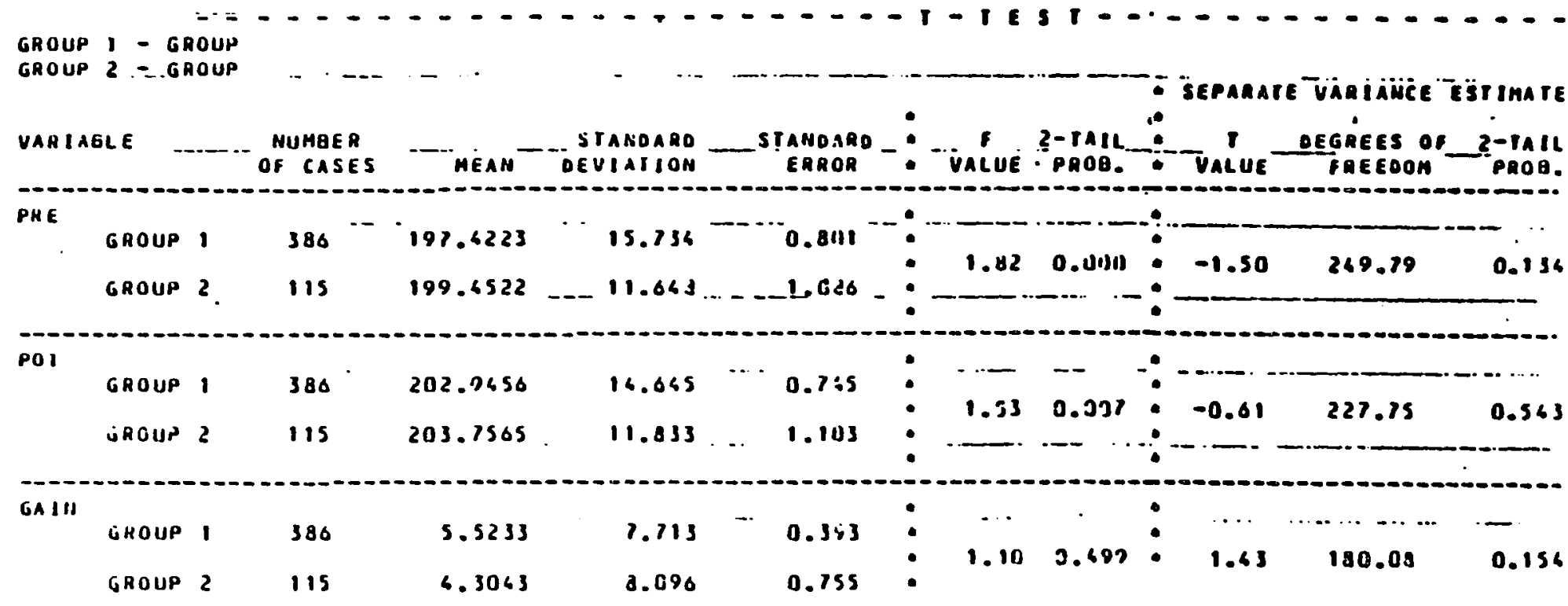

wiure GROUP $1=$ CAI, $2=$ PLI 
TABLE XXXVIX

WUITE ETINTC GROUP ACHIEVEMENT DIFFERENCES BY METHOD OF TREATMENT

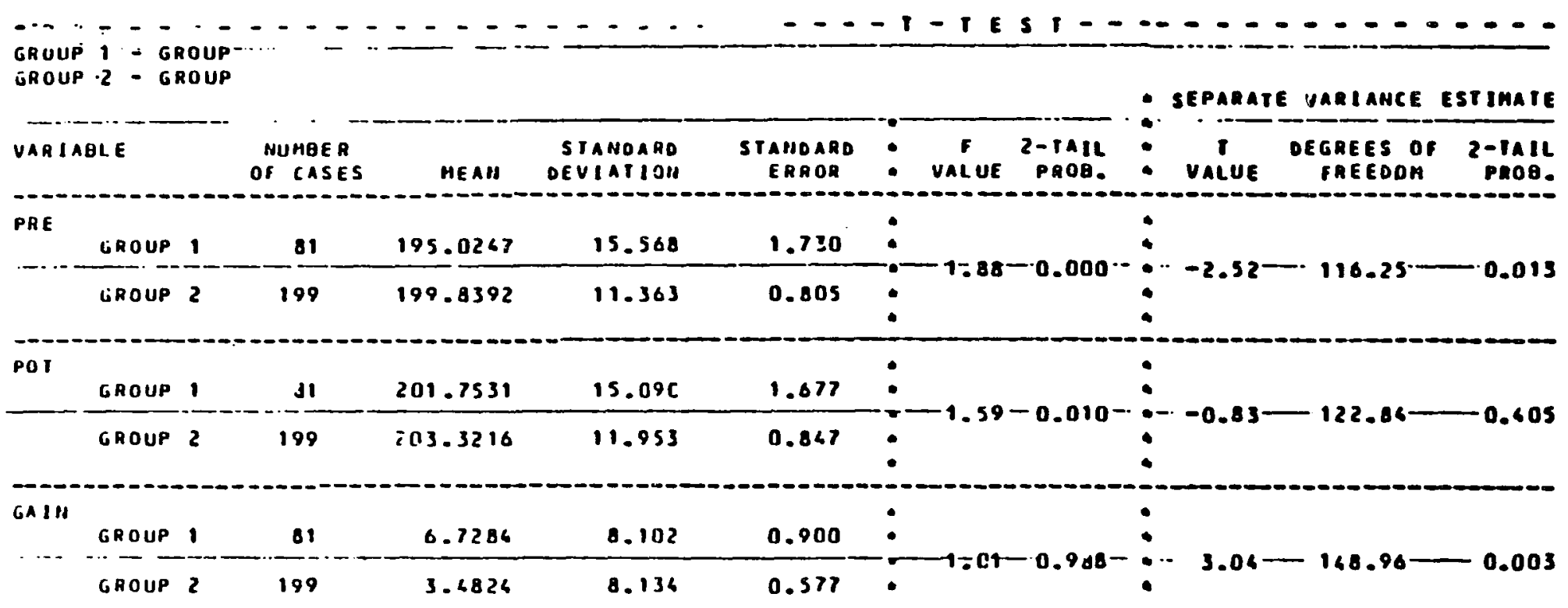


TABLE XL

ETINIC MTHRTTY ACHIEVEMENT DTFFERENCES

GHUUP $1-$ GROUP
GROUF. 2 GROUP -
VARIAGLE


COMPARISON OF NEICHBORHOOD VARIABLES

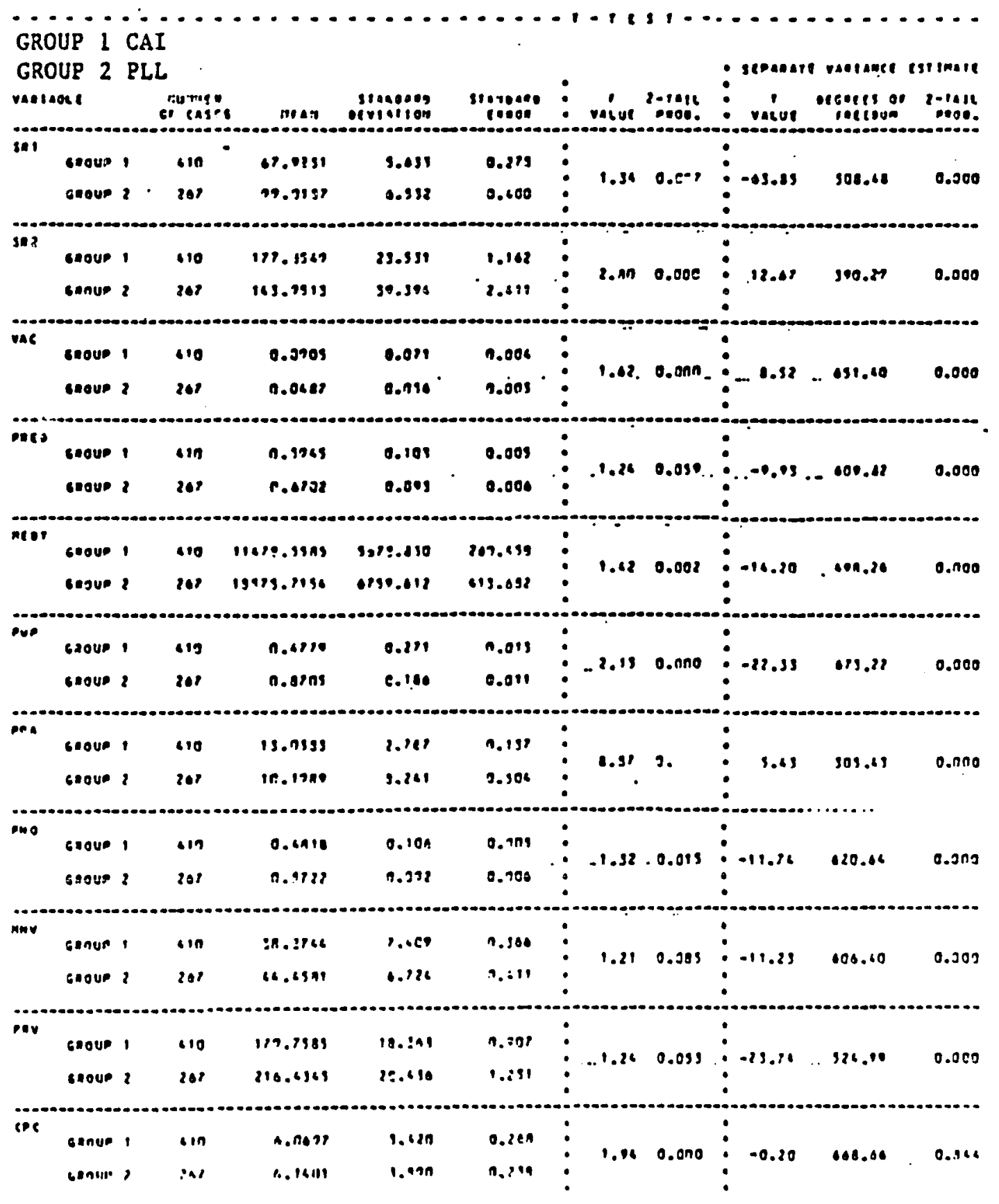


Treatment Impact Analysis 
TABLE ẌLII

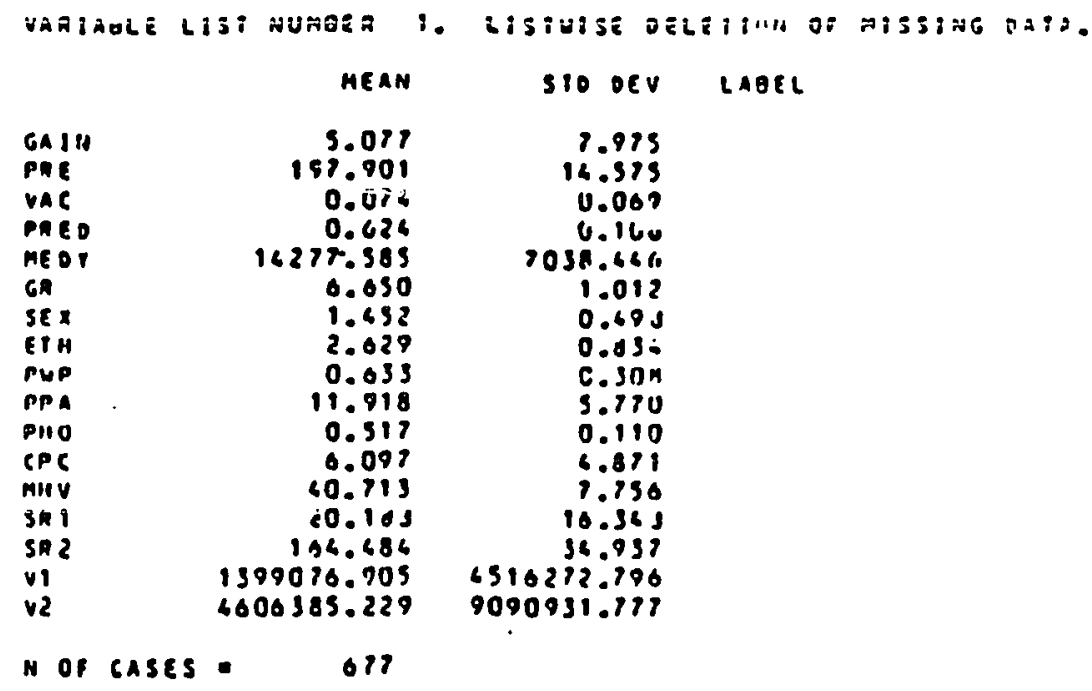

CORHELATION

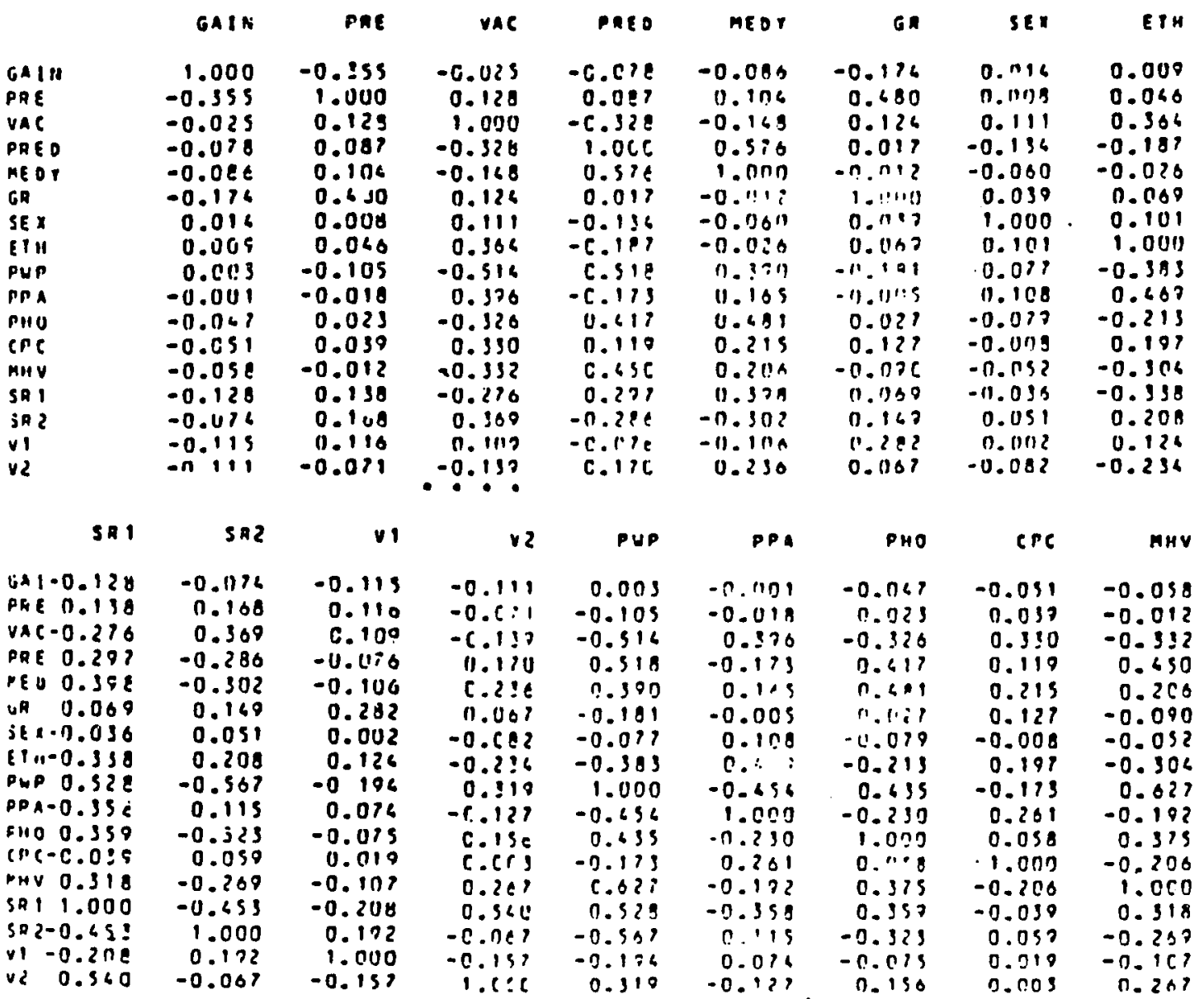


TABLE XLIII

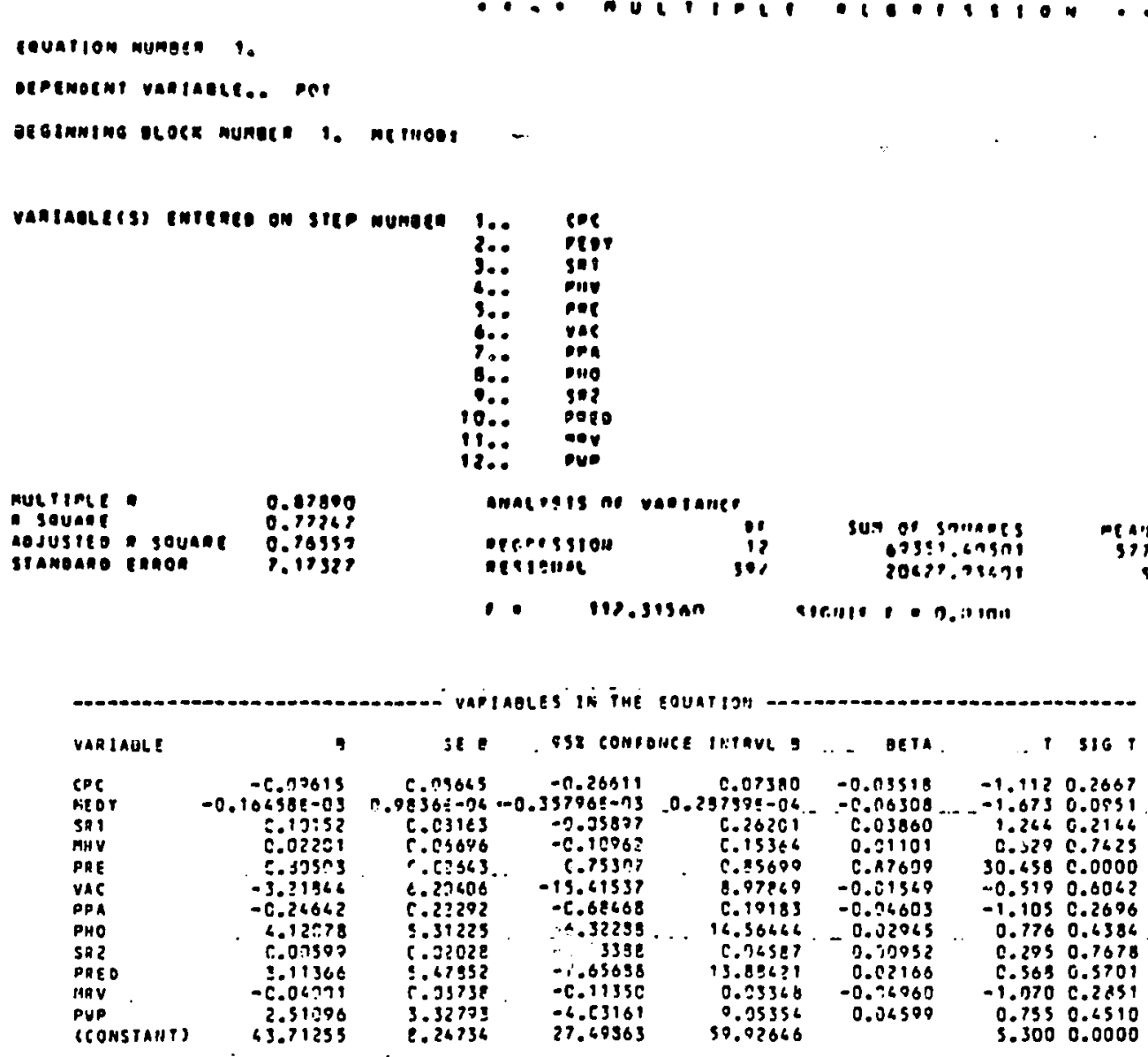


TARIE XIIV

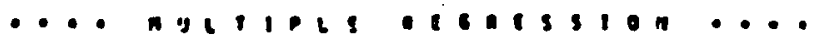

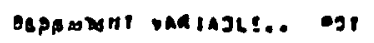

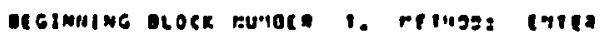

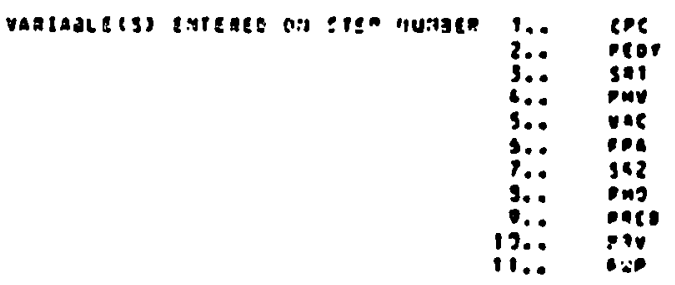

\begin{tabular}{|c|c|c|c|c|c|c|}
\hline 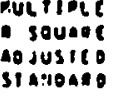 & $\begin{array}{l}\text { a sunce } \\
\text { ingog }\end{array}$ & 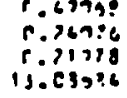 & $\begin{array}{l}\text { andersis or } \\
\text { icsession } \\
\text { resicuil }\end{array}$ & $\begin{aligned} \text { vapiaset } \\
11 \\
j 08\end{aligned}$ & 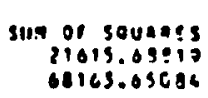 & $\begin{array}{l}\text { men suUane } \\
1903.00256 \\
171.20563\end{array}$ \\
\hline
\end{tabular}

\begin{tabular}{|c|c|c|c|c|c|c|c|}
\hline valaule & $\mathbf{t}$ & $: 10$ & 65: $(311 \cdot 01: 6 t$ & titive & atia & 1 & $\$ 16:$ \\
\hline 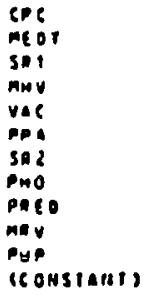 & 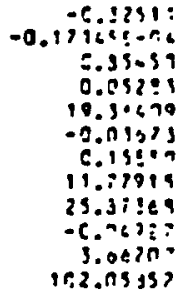 & 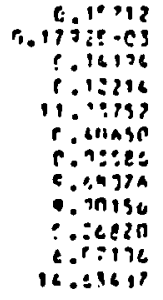 & 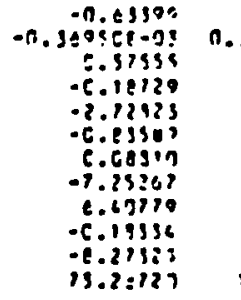 & 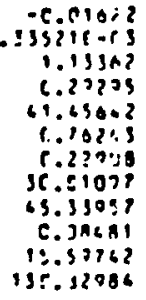 & $\begin{array}{r}-0.11006 \\
-3.01657 \\
0.38670 \\
0.02662 \\
0.09321 \\
-0.00686 \\
0.25189 \\
0.08619 \\
0.17009 \\
-0.06109 \\
0.116707\end{array}$ & $\begin{array}{r}-2.080 \\
-0.070 \\
0.021 \\
0.613 \\
1.123 \\
-0.090 \\
6.623 \\
1.219 \\
2.013 \\
-6.122 \\
0.603 \\
0.274\end{array}$ & $\begin{array}{l}0.0322 \\
0.7235 \\
6.2031, \\
0.0030 \\
0.0930 \\
0.923 n \\
0.0030 \\
0.2266 \\
0.0009 \\
0.6705 \\
0.3607 \\
0.0000\end{array}$ \\
\hline
\end{tabular}


TABLE XLV

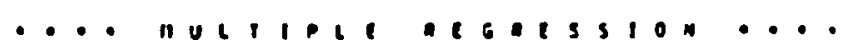

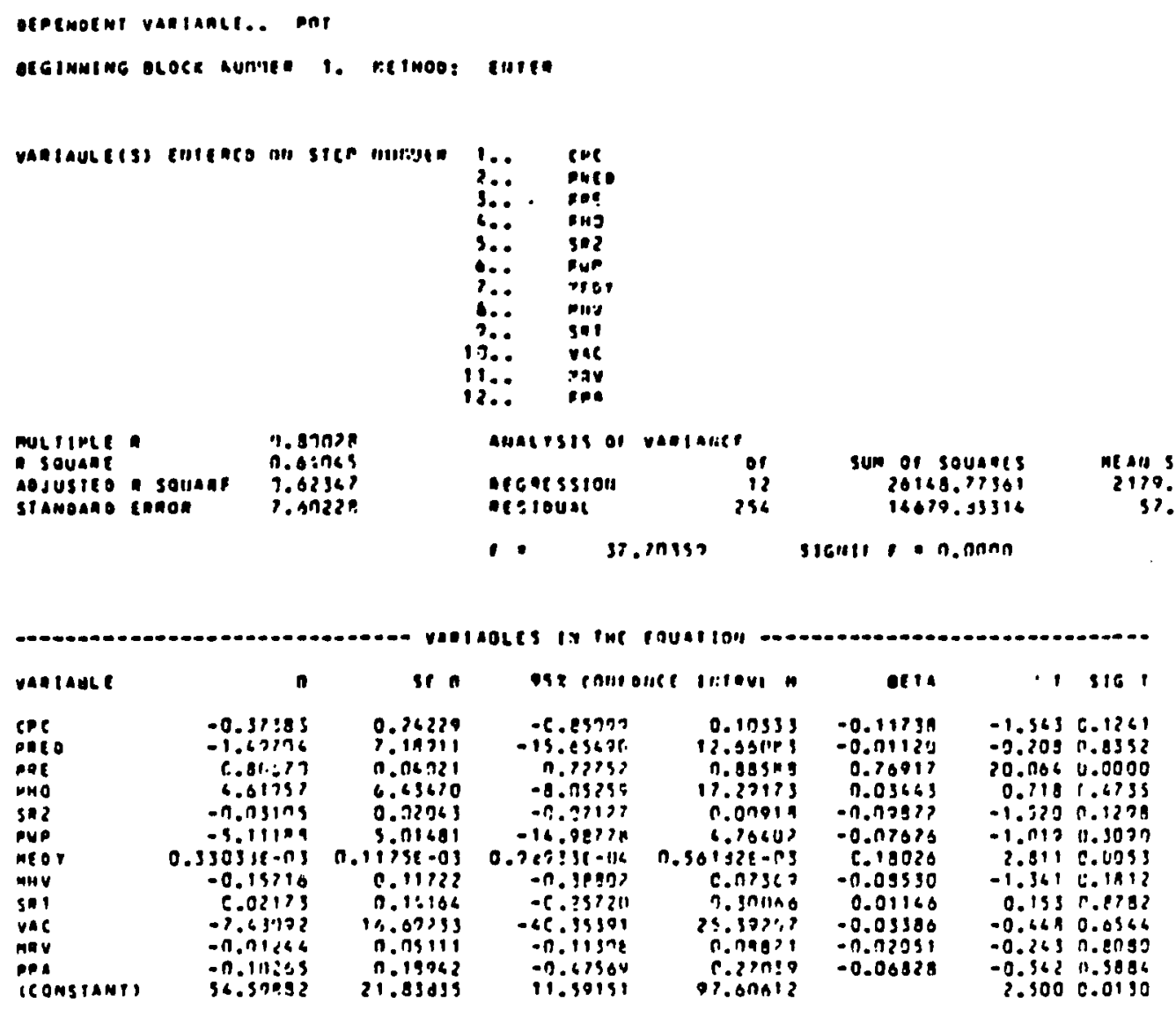


oterhotile vahiagle.. agt

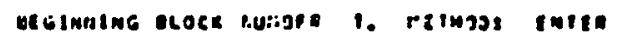

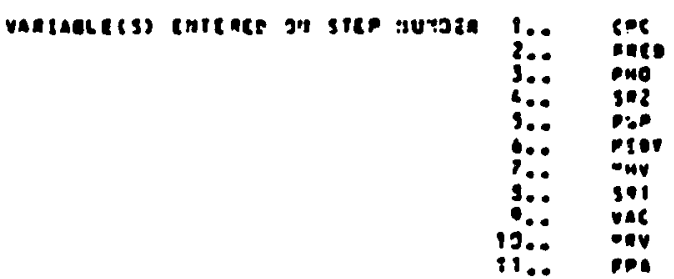

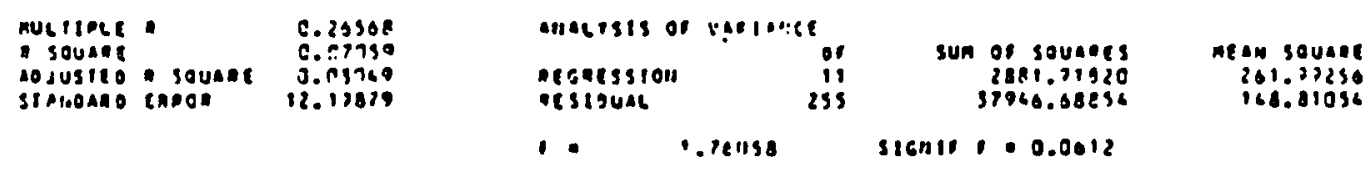

\begin{tabular}{|c|c|c|c|c|c|c|c|}
\hline VAAIAdL: & 3 & :E 9 & 95: : gnconec & Jetsve a & oets & $t$ & 3168 \\
\hline 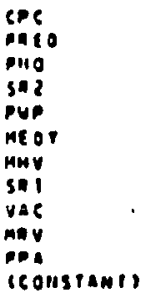 & 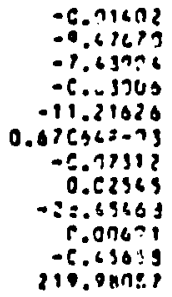 & 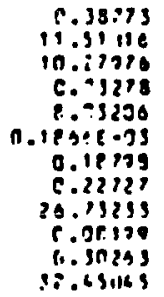 & 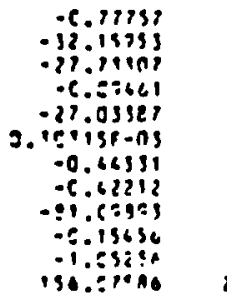 & 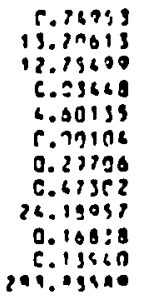 & $\begin{array}{r}-0.05640 \\
-0.07089 \\
-0.09392 \\
-0.09539 \\
-0.10867 \\
0.36591 \\
-1.03969 \\
0.01362 \\
-0.12990 \\
0.011167 \\
-0.10372\end{array}$ & 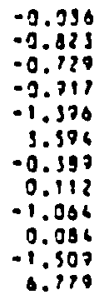 & $\begin{array}{l}0.9718 \\
0.6114 \\
0.6010 \\
0.3970 \\
0.1610 \\
0.0096 \\
0.0770 \\
0.9159 \\
0.2591 \\
0.9329 \\
0.1328 \\
0.0000\end{array}$ \\
\hline
\end{tabular}


EGUAIION NUMGER 3.

DEPEINUENT UAR'ABLE.. POT

UES LHAING OLOCK AUHOES 1. HETHOD: ENTER

WRRIAGLE (S) EHIEHED ON STEP NUMBEA 1 .. G GA

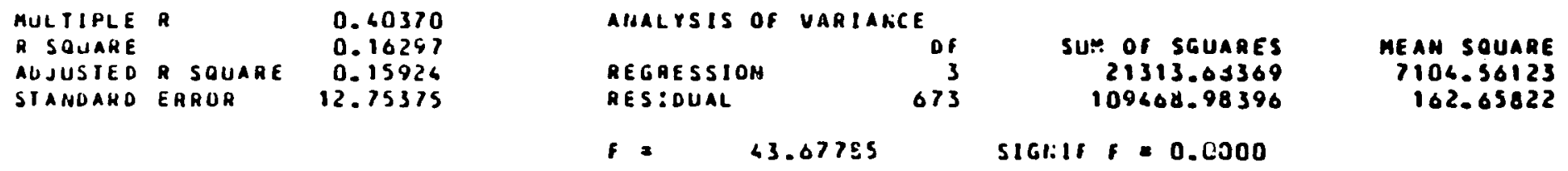

\begin{tabular}{|c|c|c|c|c|c|c|c|}
\hline VARIABLE & $\mathbf{8}$ & SE $B$ & $95:$ CONFONCE & INIRUE $\theta$ & Geta & $\mathbf{I}$ & 516 \\
\hline $\begin{array}{l}\text { GR } \\
\text { SEX } \\
\text { ETH } \\
\text { (C UNSTANT) }\end{array}$ & $\begin{array}{r}5.51677 \\
-6.06096 \\
C .53155 \\
165.22784\end{array}$ & $\begin{array}{l}0.68020 \\
0.99048 \\
0.59203 \\
3.71613\end{array}$ & $\begin{array}{r}4.56011 \\
-1.52575 \\
-6.73207 \\
157.93716\end{array}$ & $\begin{array}{r}0.66943 \\
1.90386 \\
1.59517 \\
172.52252\end{array}$ & $\begin{array}{r}\text { C.60113 } \\
-\quad .00167 \\
=.02567\end{array}$ & $\begin{array}{r}18.362 \\
-0.068 \\
0.728 \\
66.687\end{array}$ & $\begin{array}{l}0.0000 \\
0.9670 \\
0.4667 \\
0.0000\end{array}$ \\
\hline
\end{tabular}

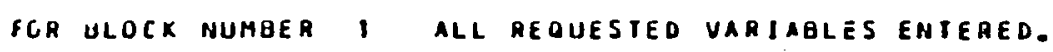


TABLE XLVIII

AULIIPLE EEG KESSION

DEPEHDENT VARIABLE. .POT

$\begin{array}{lr}\text { MULTIPLE R } & 0.35899 \\ \text { R SOUARE } & 0.12387 \\ \text { ADJUSIER R SOUARE } & 0.12369 \\ \text { STAHUARC ERAOR } & 13.02562\end{array}$

ANALYSIS OF VASIANCE

RE GRES 51011

RESIDUAL

of
672

SUM OF SQUARES

16054.09507

11392 R. 57258

MEAN SOUARE

4213.52377

$F=2: .85319 \quad$ stanif $F=0.0000$

VARIABLES IN THE EOUATION

VARIAULE

12

SA 2

II

SR 1

(CONSTANT)
SF. 0

$-0.0 n 35 n$

0.111152

$-0.31495[-0]$

0.44466

155.13171
n. $4366 E-03$ O. 01630

ก. $5630 \mathrm{E}-\mathrm{n3}$

ก. 05127

5.67253
75X CONFDNCE INTAVL

$-n .0 n 445$

0.06953

$-0.0138$

0.34399

164.356 .39

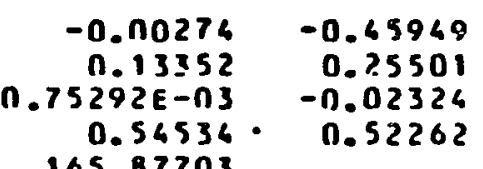

$0.54536 \cdot 0.52262$
Beta

ISIG

$-8.2690 .000 n$ $6.23 n 0.0000$ $-0.5790 .5627$ 8.6720 .0000 28.3470 .0000 
TABLE XLIX

- nulT1ple

DEPEHDEHI UARIAGLE.. Y

$\begin{array}{ll}\text { MULIIPLE } & 0.06 \text { DOZ } \\ \text { RSOUARE } & 0.75346 \\ \text { ADJUSIED R SQUARE } & 0.75294 \\ \text { STAHDARD ERROR } & 8.18918\end{array}$

AHALYSIS Of VARIANCE

STABOARD ERROR B.18918

$\begin{array}{lrr} & \text { OS } & \text { SUA OF SOLARES } \\ \text { REGRESSION } & 3 & 292066.71159 \\ \text { RESIOUAL } & 1428 & 95765.57612\end{array}$

MEAN SOUARE

97555.57053

47.06273

$$
\text { F } 1656.69136 \text { S16n1F }=0.0000
$$

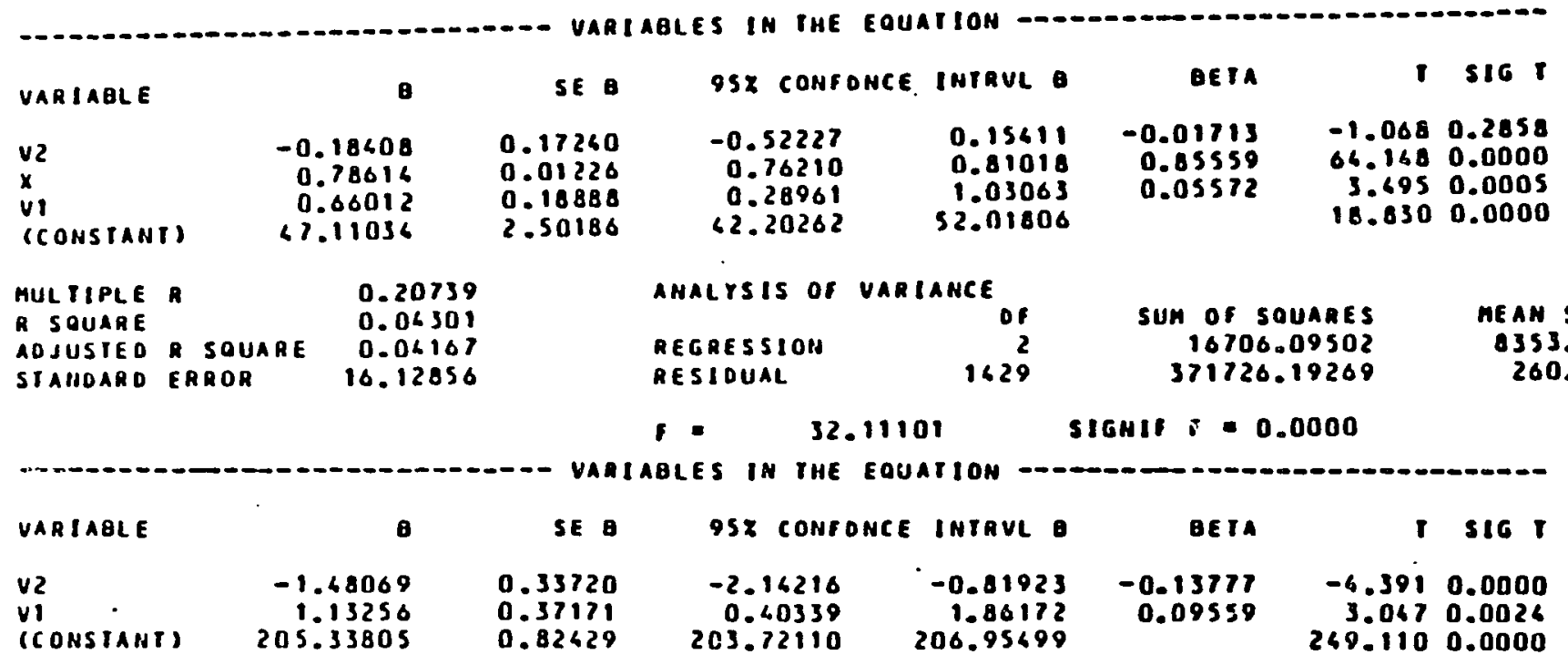


TABLE L

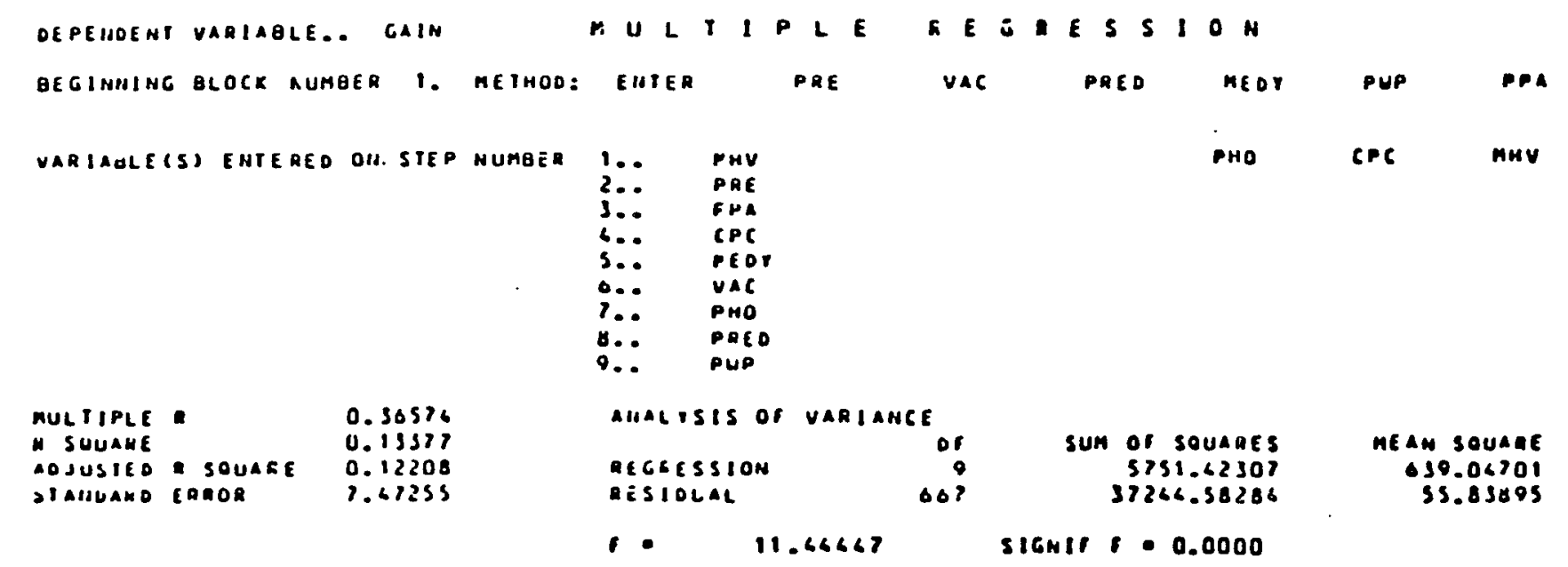

\begin{tabular}{|c|c|c|c|c|c|c|c|}
\hline VAUIAULE & $\boldsymbol{\theta}$ & SE d & 552 CONOONCE & INIRUL $B$ & QE IA & I & sic \\
\hline MHV & -0.08139 & 0.05239 & $-c .: 8576$ & 0.02197 & -0.07903 & -1.568 & 0.1220 \\
\hline $\begin{array}{l}\text { FNE } \\
\text { PDA }\end{array}$ & $-c .19126$ & 0.02008 & $-c .3266$ & $-c .15126$ & -0.15060 & -9.277 & 0.0000 \\
\hline CPC & $-6.0=1.6$ & 0.4003 & $\begin{array}{l}-0,12902 \\
-0,21000\end{array}$ & $\begin{array}{l}0.13392 \\
0.03312\end{array}$ & $\begin{array}{r}0.00325 \\
-0.06075\end{array}$ & $\begin{array}{r}0.066 \\
-1.128\end{array}$ & 0.2351 \\
\hline plur & $-0.626876-06$ & $0.0607 \varepsilon-U 6$ & -0.107 CE-OS & $0.837268-06$ & -0.03716 & -0.057 & 0.5113 \\
\hline $\begin{array}{l}\text { IAC } \\
\text { rac }\end{array}$ & $\begin{array}{l}2.63208 \\
0.27972\end{array}$ & $\begin{array}{r}5.36750 \\
3.16966\end{array}$ & $\begin{array}{r}-8.00000 \\
-6.03027\end{array}$ & $\begin{array}{r}12.93276 \\
6.80572\end{array}$ & $\begin{array}{l}0.02098 \\
0.00386\end{array}$ & $\begin{array}{l}0.455 \\
0.083\end{array}$ & $\begin{array}{l}0.0696 \\
0.9339\end{array}$ \\
\hline PHED & C.casis & 3.92029 & -7.21265 & 8.18276 & 0.00061 & 0.126 & 0.9015 \\
\hline $\begin{array}{l}\text { PAP } \\
\text { (( OUSIAUIt) }\end{array}$ & $\begin{array}{r}0.16393 \\
60.32185\end{array}$ & $\begin{array}{l}1.02901 \\
2.79363\end{array}$ & $\begin{array}{l}-2.63457 \\
36.56952\end{array}$ & $\begin{array}{r}3.92062 \\
55.733 d 7\end{array}$ & 0.02870 & $\begin{array}{l}0.659 \\
9.066\end{array}$ & $\begin{array}{l}0.0606 \\
0 . \operatorname{coc} 0\end{array}$ \\
\hline
\end{tabular}


TABLE LI

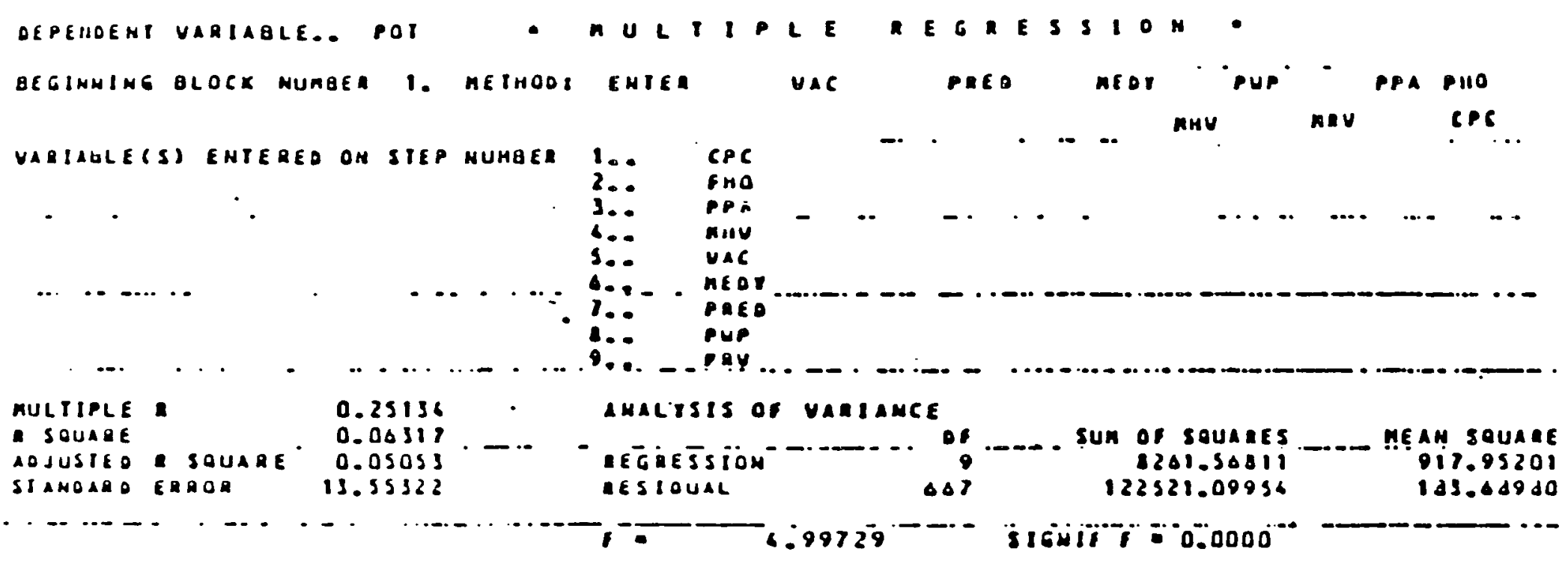

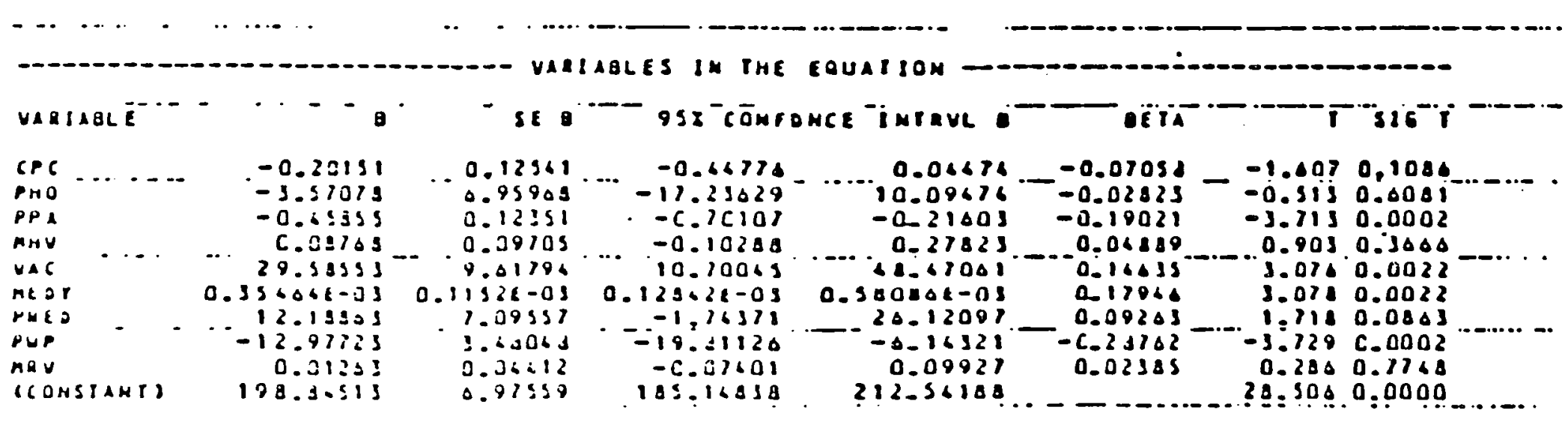


TABLE LII

aeg IHAIHG alock number 1.

MULIIPLE REGRESSION

\begin{tabular}{|c|c|c|}
\hline $\begin{array}{l}\text { MUL TIPLE } \\
\text { R SQUAAEE }\end{array}$ & R & $\begin{array}{l}0.86757 \\
0.75267\end{array}$ \\
\hline ADJUSIED & A SQUARE & 0.75215 \\
\hline STAHOAAD & ERROR & 8.20219 \\
\hline
\end{tabular}

$$
\begin{array}{ll}
1 \\
2 \cdots & 12 \\
3 & x
\end{array}
$$

ANALYSIS OF VARIANCE

REGRESSIOH DF
RESIOUAL

SUM OF SOURRES 292362.19152

96070.09619

HEAH SOUARE

AESIOUAL

$97656.063 d 6$

- 1648.57150 signil: $0.0000^{\circ}$

\begin{tabular}{|c|c|c|c|c|c|c|}
\hline VARIABLE & $\mathbf{a}$ & SE $B$ & $95 \times$ CONFL & DNCE INTRVL & BETA & 516 \\
\hline $\begin{array}{l}\text { I2 } \\
x \\
\text { I } \\
\text { (CONSTANT) }\end{array}$ & $\begin{array}{r}-0.66286 E-03 \\
0.78597 \\
-0.16319 E-03 \\
68.41732\end{array}$ & $\begin{array}{r}0.1637 E-03 \\
0.01231 \\
0.2339 E-03 \\
2.49566\end{array}$ & $\begin{array}{r}-0.92087 E-03 \\
0.76182 \\
-0.60191 E-03 \\
43.52176\end{array}$ & $\begin{array}{r}-0.36486 E-03 \\
0.81013 \\
0.31556 E-03 \\
53.31288\end{array}$ & $\begin{array}{r}-0.06226 \\
0.85561 \\
-0.00832\end{array}$ & 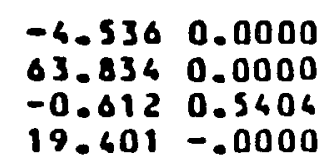 \\
\hline
\end{tabular}


TABLE LIII

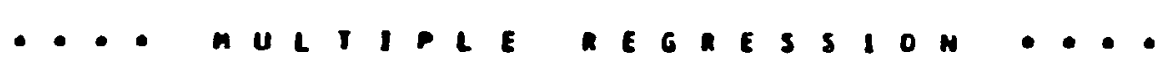

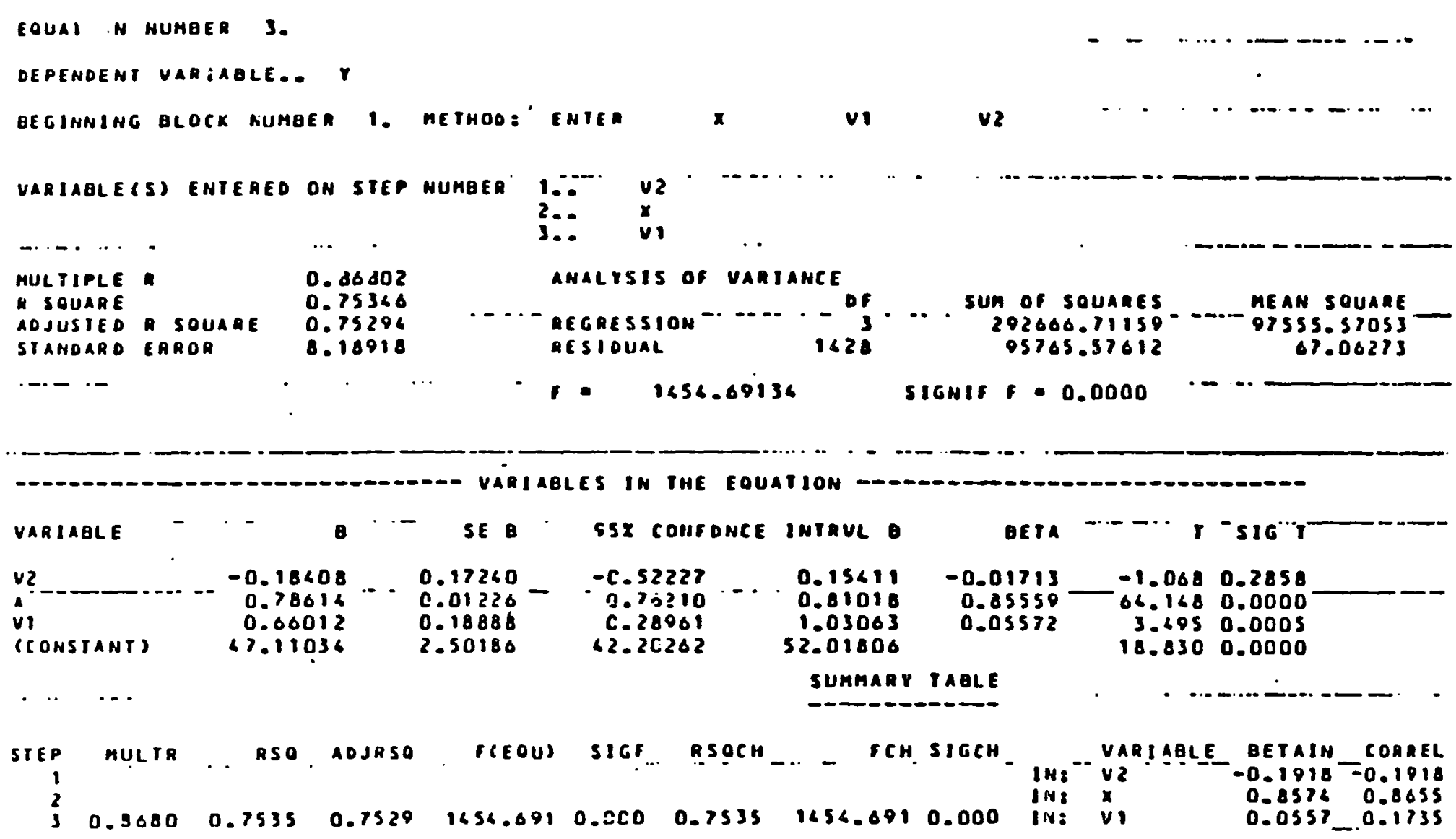


Instructional Time Analysis 


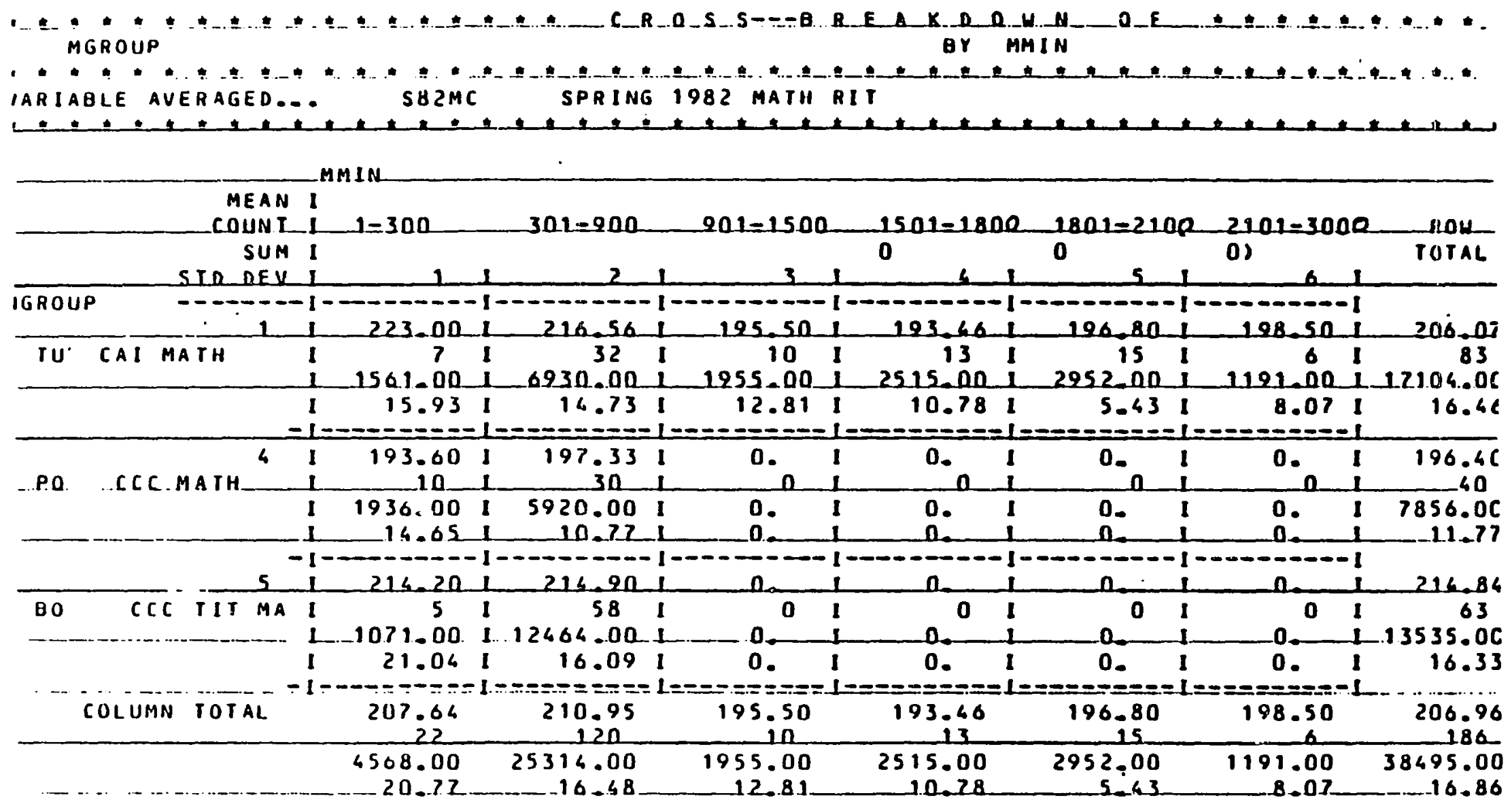


TABLE LV

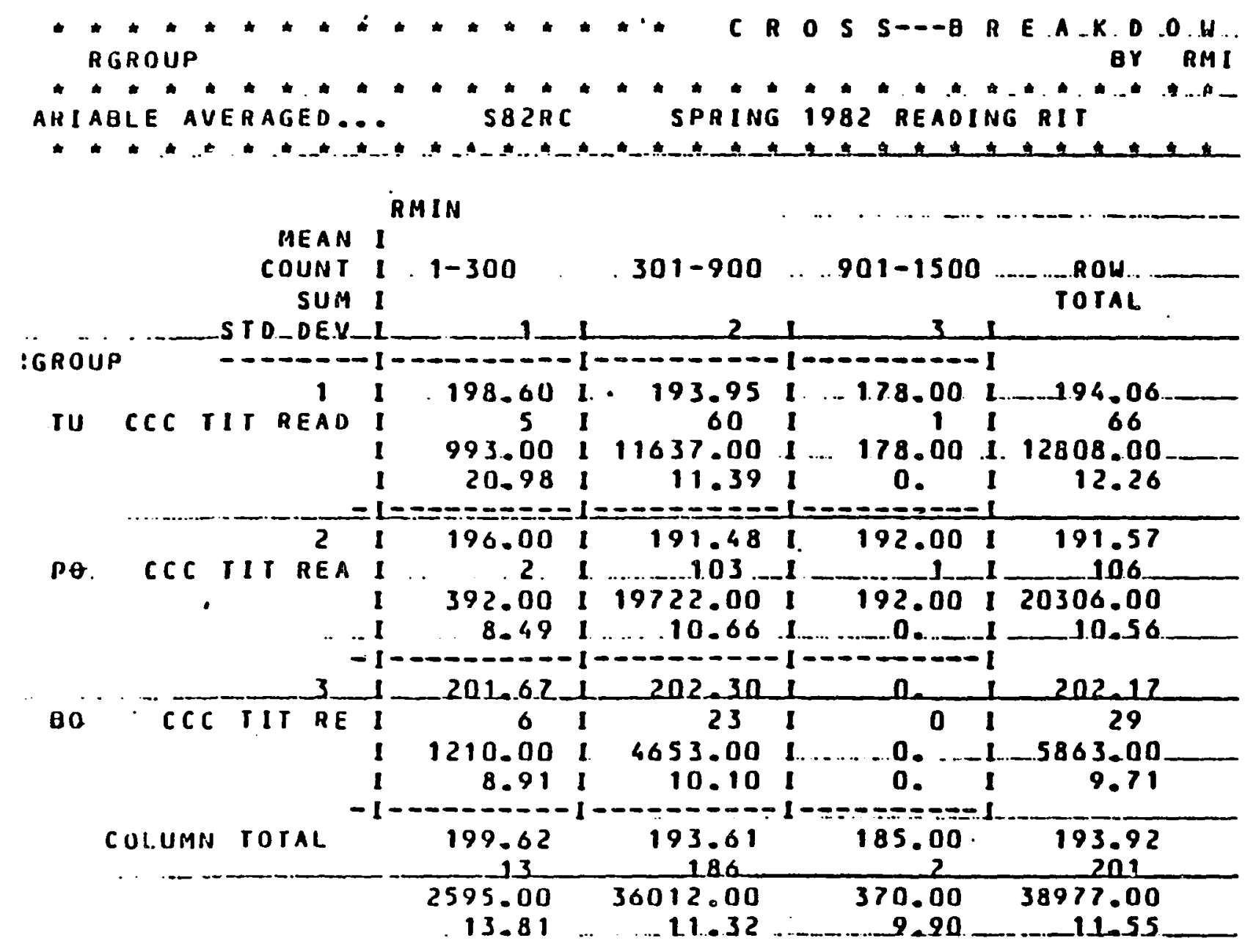




\section{TABLE LVI}

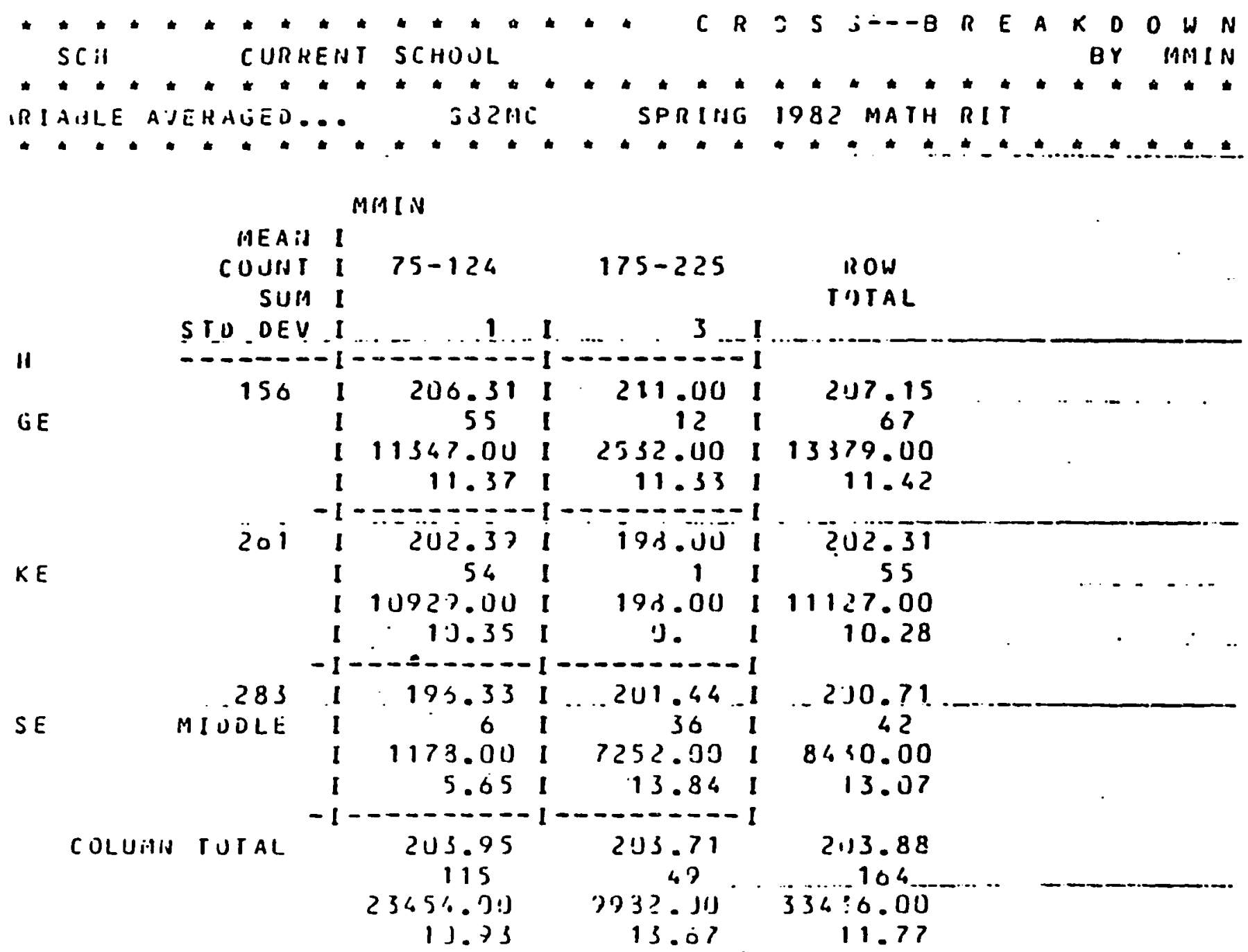


TABLE LVII

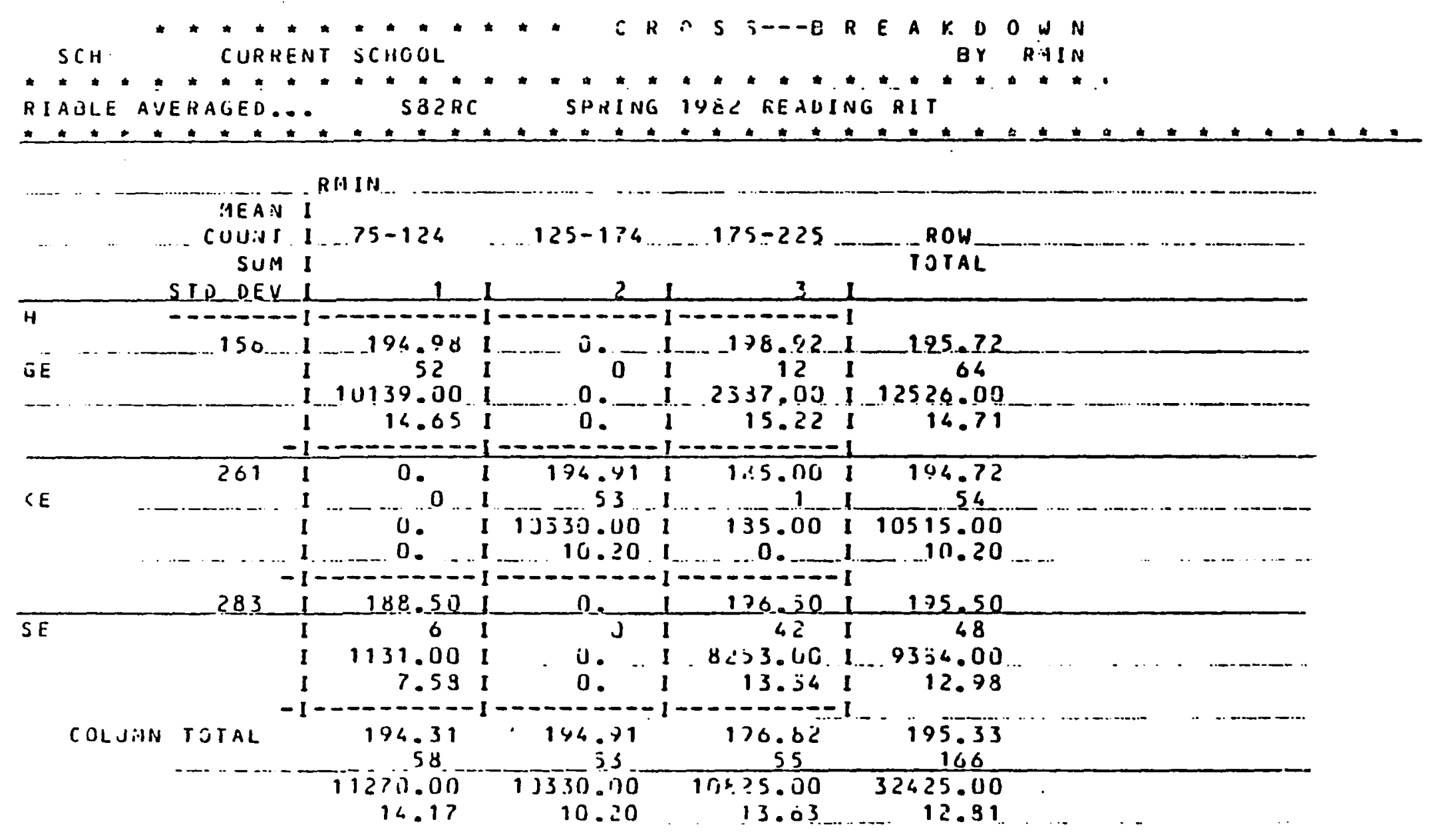


Survey of CBI Staff 
TABLE LVIII

COURSEWARE QUALITY EVALUATION

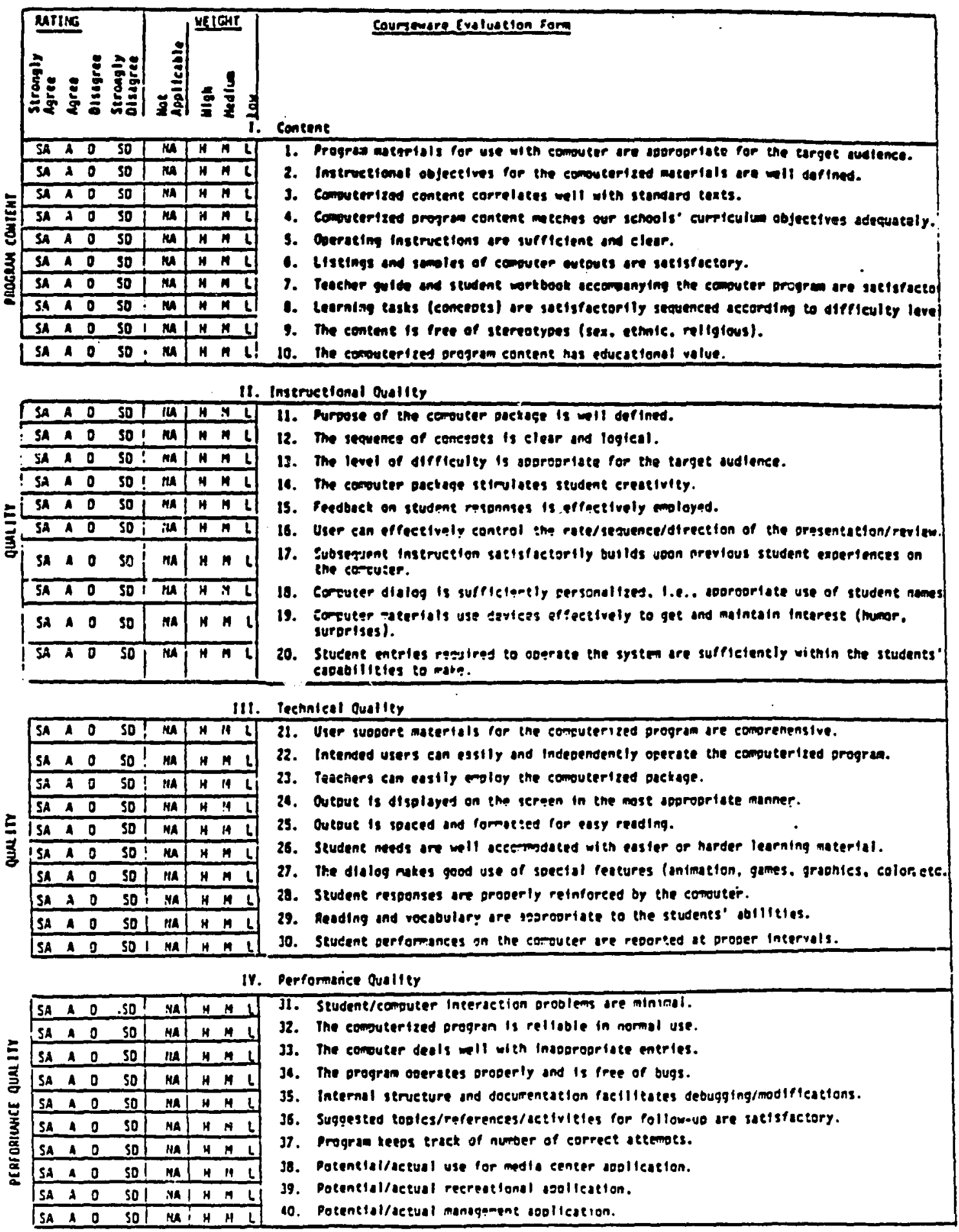


TABLE LIX

\section{COURSEWARE QUALITY EVALUATION OF THE \\ COMPUTER ASSISTED INSTRUCTION \\ MICRO-COMPUTER (CAI)}

* SCALE

SA A D SD AVG

I CONTENT QUALITY:

1. Program materials to use with 84 - 3.67 computer are appropriate for the target audience.

2. Instructional objectives for the $84-3.67$ computerized materials are well defined.

3. Computerized content correlates well with standard text.

4. Computerized program content matches our schools" curriculum objectively adequately.

5. Operating instructions are suf- $66-3.50$ ficient and clear.

6. Listings and samples of computer $65-3.5 \div$ outputs are satisfactory.

7. Teacher guide and student work- $13-3.2 \equiv$ bcok accompanying the computer program are sazisfactory.

8. Learning tasks (concepts) are $66-3.50$ satisfactorily sequenced according to difficulty level.

a. The content is free of stereo- $66-3.50$ tọes (sax, race, relicion).

10. The computerized program content 84 - 4 3.6? has ecucational value. 
TABLE LX

SCALE

SA A S SD AVG

II INSTRUCTIONAL DELIVERY QUALITY:

11. Pufpose of the computer package 84 - 3.67 is well defined.

12. The sequence of concepts is clear and logical.

13. The level of difficulty is appro- 75 - 3.58 priate for the target audience.

14. The computer package stimulates $\quad 6 \quad 1 \quad 1 \quad 1 \quad 3.09$ student creativity.

15. Feedback on student responses is $75-3.50$ effectively employed.

16. User can effectively control the $65-3.54$ rate/sequence/direction of the presentation/review.

17. Subsequent instruction satisfactorily builds upon previous student experiences on the computer.

18. Computer dialog is sufficiently $84-\quad-3.67$ personalized, i.e.. appropriate use of student names.

19. Computer materials use devices effectively to get and maintain interest (humor, surprises).

20. Student entries required to operate the system are sufficiently within the students ' capabilities to make.

$741-3.50$

$722-3.42$

$93--3.75$

INDEX :

3.54 
TABLE LXI

SCALE

SA A D SD AVG

III TECHNICAL CONTROL QUALITY: 21. User support materials for the
computerized program are comprehensive.

22. Intended users can easily and independently operate the computerized program.

23. Teachers can easily employ the $75-3.58$ computerized package.

24. Output is displayed on the screen $75-3.58$ in the most appropriate manner.

25. Output is spaced and formatted 6 - -3.50 for easy reading.

26. Student needs are well accomo- $74-3-3.63$ dated with easier or harder learning material.

27. The dialog makes good use of 1 - 1 - 3.00 special features (animation, games, grapicics, color, etc.).

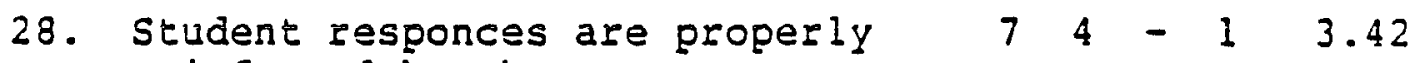
reinforced by the computer.

29. Reading and vocabulary are appro- 66 - 3.50 priate to the students ${ }^{\circ}$ abilities.

30. Student performances on the com- 6 6 - -3.50 puter are reported at proper intervals. 
TABLE LXII

SCALE

SA A D SD AVG

IV OPERATIONAL QUALITY

31. Student/computer interaction $651-3.41$ problems are minimal.

32. The computerized program is re- $66-3.50$ liable in normal use.

33. The computer deals well with 651 - 3.41 inappropriate entries.

34. The program operates properly $\quad \begin{array}{llllll}6 & 2 & 2 & 2 & 3.00\end{array}$ and is free of bugs.

35. Internal structure and documen- - $6-3.00$ tation facilitates debugging/ modification.

36. Suggested topics/references/act- - - 1 - 2.00 ivities for follow-up are satisfactory.

37. Program keeps track of number $84-3.67$ of correct attempts.

38. Potential/actual use for media 15 - 3.17 center applications.

39. Potential/actual recreational - 1212.00 application.

40. Potential/actual management app- 74 - 3.42 Iication.

$\begin{array}{rr}\text { INDEX } & 3.0= \\ \text { ÄERAGE INDEX } & 3.33\end{array}$

* Scale Rating: SA=Strongly Agree (4), A=Agree (3), D=Disagree (2), SD=Strongly Disagree (1), AVG=Average Score 
COURSEWARE QUALITY EVALUATION OF THE PRESCRIPTIVE LEARNING LAB'S MINI-COMPUTER (PLL)

* SCALE

SA A D SD AVG

I CONTENT QUALITY:

1. Program materials to use with computer are appropriate for the target audience.

2. Instructional objectives for the computerized materials are well defined.

3. Computerized content correlates 18 - $\quad 3.11$ well with standard text.

4. Computerized program content matches our schools' curriculum $86--3.57$ objectively adequately.

5. Operating instructions are suf- $77-3.50$ ficient and clear.

6. Listings and samples of computer - 8 - 3.00 outputs are satisfactory.

7. Teacher guide and student work- 112 - 3.08 book accompanying the computer program are satisfactory.

8. Learning tasks (concepts) are 68 - 3.43 satisfactorily sequenced according to difficulty level.

9. The content is free of stereo- $59-\quad-3.36$ types (sex, race religions).

10. The computerized program content 122 - 3.86 has educational value. 
TABLE LXIV

$$
\begin{aligned}
& \text { SCALE } \\
& \text { SA A S SD AVG. }
\end{aligned}
$$

II INSTRUCTIONAL DELIVERY QUALITY:

11. Purpose of the computer package $311-3.21$ is well defined.

12. The sequence of concepts is $311-3.21$ clear and logical.

13. The level of difficulty is appro- $311-3.21$ priate for the target audience.

14. The computer package stimulates - $\begin{array}{llll}3 & 3 & 2.29\end{array}$ student creativity.

15. Feedback on student responses is $311-3.21$ effectively employed.

16. User can effectively control the $-\begin{array}{llll}8 & 1 & 5 & 2.21\end{array}$ rate/sequence/direction of the presentation/review.

17. Subsequent instruction satisfactorily builds upon previous student experiences on the computer.

18. Computer dialog is sufficiently $2102-3.00$ personalized, i.e., appropriate use of student names.

19. Computer materials use devices effectively to get and maintain interest (humor, surprises).

20. Student entries required to operate the system are sufficiently within the students capabilities to make.

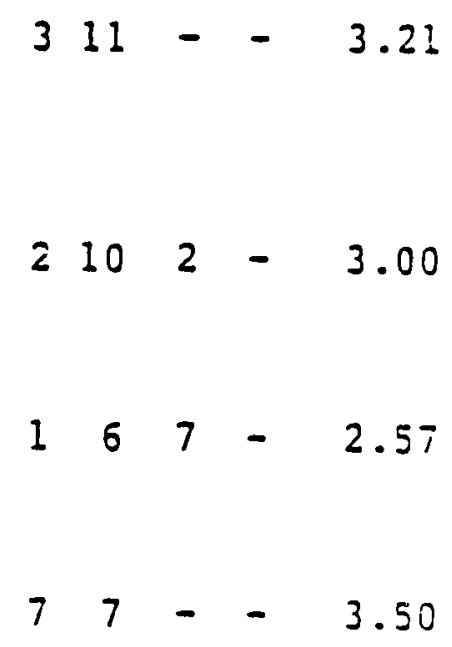

INDEX :

2.96 
TABLE LXV

SCALE

SA A D SD AVG

II TECHNICAL CONTROL QUALITY:

21. User support materials for the

$210--2.83$

computerized program are comprehensive.

22. Intended users can easily and independently operate the conputerized program.

23. Teachers can easily employ the computerized package.

24. Output is displayed on the screen $310--3.14$ in the most appropriate manner.

25. Output is spaced and formatted 2111 - 3.07 for easy reading.

26. Student needs are well accomodated with easiez or harder learing material.

27. The dialog makes good use of games, graphics, color, etc.).

28. Student responces are properly 68 - $\quad 3.43$ reinforced by the computer.

29. Reading and vocabulary are appro- 113 - -3.07 priate to the students" abilities.

30. Student performances on the com- $311-3.21$ puter are reported at proper intervals.

INDEX : 